\title{
Um método robusto de volumes finitos de alta ordem para advecção em malhas esféricas geodésicas
}

\author{
Jeferson Brambatti Granjeiro
}

TESE APRESENTADA

$\mathrm{AO}$

Instituto DE MATEMÁticA E EstatísticA

DA

UNIVERSIDADE DE SÃO PAULO

PARA

OBTENÇÃO DO TÍTULO

$\mathrm{DE}$

DOUTOR EM CIÊNCIAS

\author{
Programa: Matemática Aplicada \\ Orientador: Prof. Dr. Pedro da Silva Peixoto \\ Coorientador: Prof. Dr. Luis Carlos de Castro Santos
}

Durante o desenvolvimento deste trabalho o autor recebeu auxílio financeiro da CAPES

São Paulo

Junho de 2019 


\section{Um método robusto de volumes finitos de alta ordem para advecção em malhas esféricas geodésicas}

Esta versão da tese contém as correções e alterações sugeridas pela Comissão Julgadora durante a defesa da versão original do trabalho, realizada em 28/06/2019. Uma cópia da versão original está disponível no Instituto de Matemática e Estatística da Universidade de São Paulo.

Comissão Julgadora:

- Prof. Dr. Pedro da Silva Peixoto (orientador) - IME-USP

- Prof. Dr. Saulo Rabello Maciel de Barros - IME-USP

- Prof. Pedro Leite da Silva Dias - IAG-USP

- Prof. Wellington Carlos de Jesus - UFMS

- Prof. Ernani Vitillo Volpe - POLI-USP 


\section{Agradecimentos}

Ao longo deste trabalho, muitas coisas aconteceram em minha vida. Não é fácil prosseguir diante de situações inesperadas, mas com muita fé e esforço consegui terminar esta tese.

Assim, primeiramente agradeço a Deus pelo dom da vida, pela graça concedida, por sua infinita misericórdia e pelo privilégio em estudar Matemática.

Agradeço ao meu filho Jeferson Isaac Morais Brambatti, um menino muito inteligente e questionador, que sempre me recebeu com um lindo sorriso, um abraço apertado e um beijo.

Aos meus pais Francisco Deshuite Granjeiro e Izabel Brambatti Granjeiro pelo apoio, amor e incentivo. Pela paciência nos momentos difíceis, pela sabedoria nos conselhos, os quais foram importantes para o término desta etapa em minha vida.

Também agradeço aos meus avós paternos Gregório Alves Granjeiro (in memoriam) e Maria de Lourdes Granjeiro, e aos avós maternos Aparecido Brambatti (in memoriam) e Vitória Magri (in memoriam) pelo exemplo de integridade, pelos ensinamentos e orações.

Às minhas irmãs Heloiza e Izabel Cristina que sempre estiveram presentes na minha vida. Aos meus cunhados e sobrinhos pelos momentos de descontração. Ao meu tio Ildo e minha tia Ivone pela ajuda em São Paulo, que foi fundamental para o término desse trabalho.

Ao meu orientador, Prof. Dr. Pedro da Silva Peixoto, e coorientador, Prof. Dr. Luis Carlos de Castro Santos, pela paciência, compreensão e contínua supervisão para a elaboração desta tese. Aos membros da Comissão Julgadora, pela leitura e sugestões para o trabalho. Aos amigos do LabMap da USP pela ajuda e pelos momentos divertidos. Aos professores da UNESP, ITA e USP que foram responsáveis pela minha formação acadêmica.

À professora Suely Zambon pelo incentivo em dar continuidade nos estudos. Aos colegas Juan Eduardo Casavilca Silva e Fábio Dall Cortivo pelas sugestões e ajuda durante este projeto. Aos demais familiares e amigos que contribuíram de forma direta ou indireta para o término deste trabalho, o meu sincero agradecimento.

O doutorado é apenas o início de um trabalho encantador e infinito.

São Paulo, Junho de 2019

Jeferson Brambatti Granjeiro 
"Embora ninguém possa voltar atrás e fazer um novo começo, qualquer um pode começar agora e fazer um novo fim." Chico Xavier 


\section{Resumo}

Granjeiro, Jeferson. B. Um método robusto de volumes finitos de alta ordem para advecção em malhas esféricas geodésicas. 2019. 123 f. Tese (Doutorado) - Instituto de Matemática e Estatística, Universidade de São Paulo, São Paulo, 2019.

A esfera é comumente usada como domínio computacional para representar o planeta Terra. Dessa forma, é possível modelar diversos fenômenos físicos, como a previsão numérica do tempo. A discretização pode ser feita de formas distintas, mas devido a uma crescente necessidade de eficiência computacional, as malhas geodésicas têm ganhado a atenção da comunidade científica. Dentre as quais, por serem mais isotrópicas em relação às malhas latitude/longitude, destacam-se as malhas icosaédricas. A qualidade dos modelos de previsão do tempo é fortemente influenciada pela precisão da solução da equação de advecção (ou transporte), pois, é necessário avaliar o transporte de diversas substâncias presentes na atmosfera. Nesse contexto, pesquisadores têm se interessado em desenvolver métodos de alta ordem na esfera para melhorar a qualidade da solução do transporte escalar. Apesar de existirem alguns modelos numéricos de alta ordem que usam malhas icosaédricas, não há consenso sobre as metodologias e os tipos de malhas a serem utilizadas. O objetivo deste trabalho foi estudar os métodos disponíveis na literatura e propor um novo método de alta ordem na esfera, baseado nos trabalhos de Ollivier-Gooch e colaboradores. O método de volumes finitos de alta ordem foi validado com testes de interpolação, integração e discretização do divergente. Por fim, foram utilizadas várias funções testes para a advecção. Os resultados foram comparados com os da literatura para malhas icosaédricas com distintas otimizações. Os testes incluem funções suaves, com descontinuidades e testes de deformações na distribuição do campo transportado, que são fundamentais no desenvolvimento de modelos atmosféricos globais. Os resultados numéricos mostram que o método proposto, que será denominado por FV-OLG, foi capaz de obter alta ordem de precisão e verificou-se que as taxas de erro são pouco influenciadas por distorções de malha. Foi feito um teste adicional para avaliar o transporte de uma colina de gaussiana na malha icosaédrica com refinamento local. Os resultados obtidos demonstram que as taxas de convergências são as mesmas obtidas em malhas com distintas otimizações, demonstrando ser um método robusto a ser explorado em modelos atmosféricos globais.

Palavras-chave: Malhas geodésicas, malha icosaédrica, volumes finitos, alta ordem, transporte, advecção. 


\section{Abstract}

Granjeiro, Jeferson. B. A robust high-order finite volume method for advection on geodesic spherical grids. 2019. 123 f. Thesis (Doctorate) - Institute of Mathematics and Statistics, University of São Paulo, São Paulo, 2019.

The sphere is commonly used as a computational domain to represent the planet Earth. In this way, it is possible to model several physical phenomena, such as the numerical weather forecast. Discretization can be done in different ways, but due to an increasing need for computational efficiency, geodesic meshes have gained the attention of the scientific community. These are more isotropic in relation to the latitude / longitude meshes, among which, the icosahedral meshes stand out. The quality of weather forecast models is strongly influenced by the accuracy of the solution of the advection (or transport) equation, since it is necessary to evaluate the transport of various substances present in the atmosphere. In this context, researchers have been interested in developing high-order methods on the sphere to improve the quality of the scalar transport solution. Although there are some high order numerical models that use icosahedral meshes, there is no consensus on the methodologies and types of meshes to be used. The objective of this work was to study the methods available in the literature and to propose a new high order method in the sphere, based on the works of Ollivier-Gooch et al. The finite-order finite-volume method was validated with interpolation, integration and discretization tests of the divergent. For this purpose, several tests were used for the advection and the results were compared with those from the literature for icosahedral meshes with different optimizations. The tests include smooth functions, with discontinuities and tests of deformations in the distribution of the transported field, which are fundamental in the development of global atmospheric models. The numerical results show that the proposed method, which will be called FV-OLG, was able to obtain a high order of accuracy and verified that the error rates are little influenced by mesh distortion. An additional test was carried out to evaluate the transport of a Gaussian hill in the icosahedral grid with local refinement. The results show that the convergence rates are the same as those obtained in meshes with different optimizations, demonstrating that it is a robust method to be used in global atmospheric models.

Keywords: Geodesic grids, icosahedral mesh, finite volumes, high order, transport, advection. 


\section{Sumário}

1 Introdução $\quad \mathbf{1}$

1.1 Motivação . . . . . . . . . . . . . . . . . . . . . . . . 1

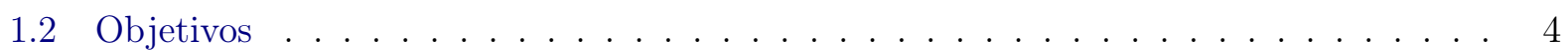

1.3 Organização do trabalho . . . . . . . . . . . . . . . . . . . . . 4

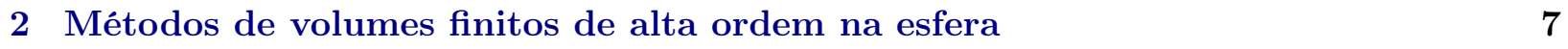

2.1 Equação de adveç̧ão na esfera . . . . . . . . . . . . . . . . . . . . . . . . . .

2.2 Método de volumes finitos . . . . . . . . . . . . . . . . . 8

2.2 .1 Discretização do domínio da equação diferencial . . . . . . . . . . . . . . . . . . . . . . . . .

2.2 .2 Definição dos volumes de controle . . . . . . . . . . . . . . . . 9

2.2 .3 Formulação integral . . . . . . . . . . . . . . . . . . . . . . . . . . . .

2.3 Formulação básica de fluxo na esfera . . . . . . . . . . . . . . . . . . . . . 10

2.3 .1 Malha esférica geodésica icosaédrica . . . . . . . . . . . . . . . . . . . . . . . . . . . . . .

2.3.2 Malha icosaédrica otimizada . . . . . . . . . . . . . . . . . . . . 11

2.3 .3 Aproximação polinomial . . . . . . . . . . . . . . . . . . . . . . . . . . . . . . 12

2.3.4 Limitadores e avanço temporal . . . . . . . . . . . . . . . . . . . . 14

2.4 Comentários . . . . . . . . . . . . . . . . . . . . . . . . . . . . . 14

2.5 Método de Skamarock e Menchaca, 2010 (FV-MEN) . . . . . . . . . . . . . . 15

2.6 Método de Skamarock e Gassmann, 2011 (FV-GAS) . . . . . . . . . . . . . . 17

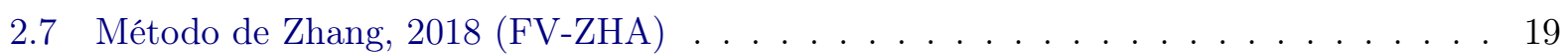

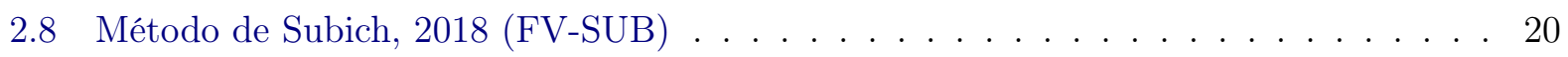

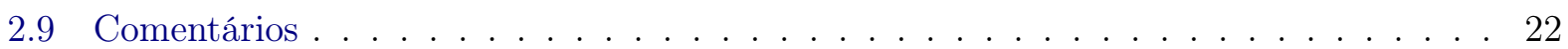

3 Método de alta ordem de Ollivier-Gooch transposto para esfera 23

3.1 Condição inicial . . . . . . . . . . . . . . . . . . . . . . 25

3.2 Reconstrução da solução . . . . . . . . . . . . . . . . . . . . . . . . 28

3.3 Integração do fluxo . . . . . . . . . . . . . . . . . . . . 31

3.4 Evolução temporal . . . . . . . . . . . . . . . . . . . . . . . 32

3.5 Comentários . . . . . . . . . . . . . . . . . . . . . . . 33

4 Validação do método FV-OLG 35

4.1 Interpolação . . . . . . . . . . . . . . . . . . . 35

4.1 .1 Função duas colinas de gaussianas . . . . . . . . . . . . . . . . 36

4.1 .2 Função dois sinos de cossenos . . . . . . . . . . . . . . . . . . . . . . 39

4.2 Integração . . . . . . . . . . . . . . . . . . . . . . . . . . 43 
4.2.1 Utilizando um ponto de Gauss . . . . . . . . . . . . . . . . . . . . 44

4.2 .2 Utilizando dois pontos de Gauss . . . . . . . . . . . . . . . . . 45

4.3 Interpolação e integração . . . . . . . . . . . . . . . . . . . . . . 45

4.3.1 Utilizando polinômio de $2^{\mathrm{a}}$ ordem . . . . . . . . . . . . . . . 46

4.3.2 Utilizando polinômio de $3^{\mathrm{a}}$ ordem . . . . . . . . . . . . . . . 46

4.3 .3 Utilizando polinômio de $4^{\mathrm{a}}$ ordem . . . . . . . . . . . . . . . . . 47

4.4 Discretização do divergente . . . . . . . . . . . . . . . . . . . . 47

4.4 .1 Procedimento para validar o divergente . . . . . . . . . . . . . 48

4.4.2 Erro do divergente utilizando-se método de $2^{\mathrm{a}}$ ordem . . . . . . . . . . . 48

4.4.3 Erro do divergente utilizando-se método de $3^{\mathrm{a}}$ e $4^{\mathrm{a}}$ ordens $\ldots \ldots \ldots \ldots$. . . . 51

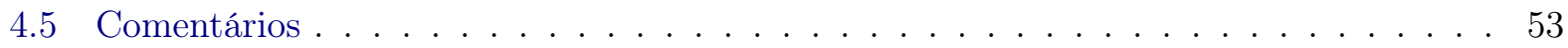

5 Aplicação da equação de advecção $\quad 55$

5.1 Resultados numéricos sem limitador . . . . . . . . . . . . . . . . . 56

5.1 .1 Uma colina de gaussiana . . . . . . . . . . . . . . . . . . . . 56

5.1 .2 Um sino de cosseno . . . . . . . . . . . . . . . . . . 59

5.1 .3 Comparação com o método FV-GAS . . . . . . . . . . . . . . . . . 62

5.1 .4 Um cilindro sólido . . . . . . . . . . . . . . . . . . . 63

5.1 .5 Um cilindro cortado . . . . . . . . . . . . . . . . . . . . 66

5.2 Resultados numéricos com limitador . . . . . . . . . . . . . . . . 69

5.2 .1 Uma colina de gaussiana . . . . . . . . . . . . . . . . . . . . . . . 69

5.2 .2 Um sino de cosseno . . . . . . . . . . . . . . . . . . 71

5.2 .3 Comparação com o método FV-MEN . . . . . . . . . . . . . . . . . . . . 74

5.2 .4 Comparação com o método FV-GAS . . . . . . . . . . . . . . . 75

5.2 .5 Comparação com método FV-ZHA . . . . . . . . . . . . . . . . 77

5.2 .6 Comparação com o método FV-SUB . . . . . . . . . . . . . . 78

5.2 .7 Um cilindro sólido . . . . . . . . . . . . . . . . . . . . . . . 80

5.2 .8 Um cilindro cortado . . . . . . . . . . . . . . . . . . . 82

5.2 .9 Comparação com o método FV-MEN . . . . . . . . . . . . . . . . . . 85

5.2 .10 Comparação com o método FV-GAS . . . . . . . . . . . . . . 86

5.3 Testes de deformação com rotação . . . . . . . . . . . . . . . . . . . . 88

5.3.1 Duas colinas de gaussianas . . . . . . . . . . . . . . . . . . . 88

5.4 Testes desafiadores . . . . . . . . . . . . . . . . . . . . . . . . 92

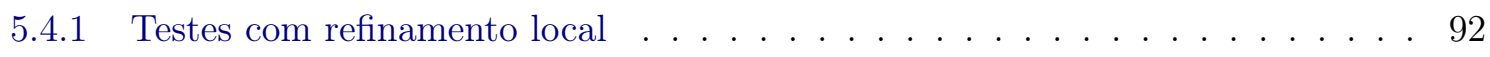

5.4 .2 Testes em malhas NOPT e HR95 . . . . . . . . . . . . . . . . . . . . 96

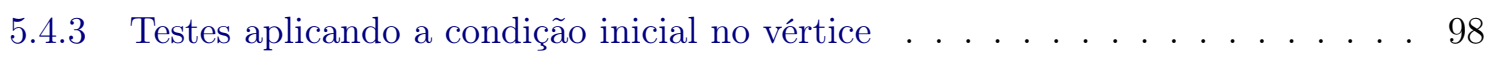

5.5 Comentários . . . . . . . . . . . . . . . . . . . . . . . . . . 99

6 Conclusões $\quad 101$

$\begin{array}{ll}\text { A Geometria esférica } & 103\end{array}$

$\begin{array}{ll}\text { B Considerações técnicas } & 105\end{array}$

$\begin{array}{ll}\text { Referências Bibliográficas } & 107\end{array}$ 


\section{Capítulo 1}

\section{Introdução}

\subsection{Motivação}

Diversos fenômenos ocorrem na superfície terrestre e, para estudar suas características, modelos matemáticos são utilizados a fim de fazer simulações e previsões, como, por exemplo, na modelagem oceânica (Budgell et al., 2007; Ringler et al., 2013); em modelos atmosféricos de previsão do tempo (Giraldo e Rosmond, 2004; Jablonowski e Williamson, 2011) e outros. Na maioria dos modelos aplicados na superfície terrestre, a qual pode ser representada por uma esfera, estruturalmente, tem-se equação de adveç̧ão ou transporte.

Dentre estes modelos, podemos destacar os modelos atmosféricos globais, cujas formulações são complexas, uma vez que estes são formados por vários submodelos relacionando diversos fenômenos físicos. Um exemplo é a dinâmica atmosférica, que consiste em equações diferenciais parciais fundamentadas nas relações físicas entre velocidade, pressão e temperatura para o fluido atmosférico, o ar (Durran, 2010). No estudo da dinâmica atmosférica, há também a presença da equação de advecção em sua formulação, para modelar o transporte de substâncias contidas no fluido. Para resolver numericamente a equação de advecção, é preciso, em primeiro lugar, discretizar a esfera, ou seja, é necessária uma malha computacional para modelar a superfície da Terra.

Várias malhas podem ser utilizadas para discretizar a esfera. Uma delas, denomina-se malha latitude-longitude, conforme ilustrada na Figura 1.1. Essa malha foi aplicada nos primeiros modelos globais de previsão do tempo, utilizando-se métodos de diferenças finitas, por possuir uma estrutura regular e propriedades de ortogonalidade e simetria, importantes para a precisão.
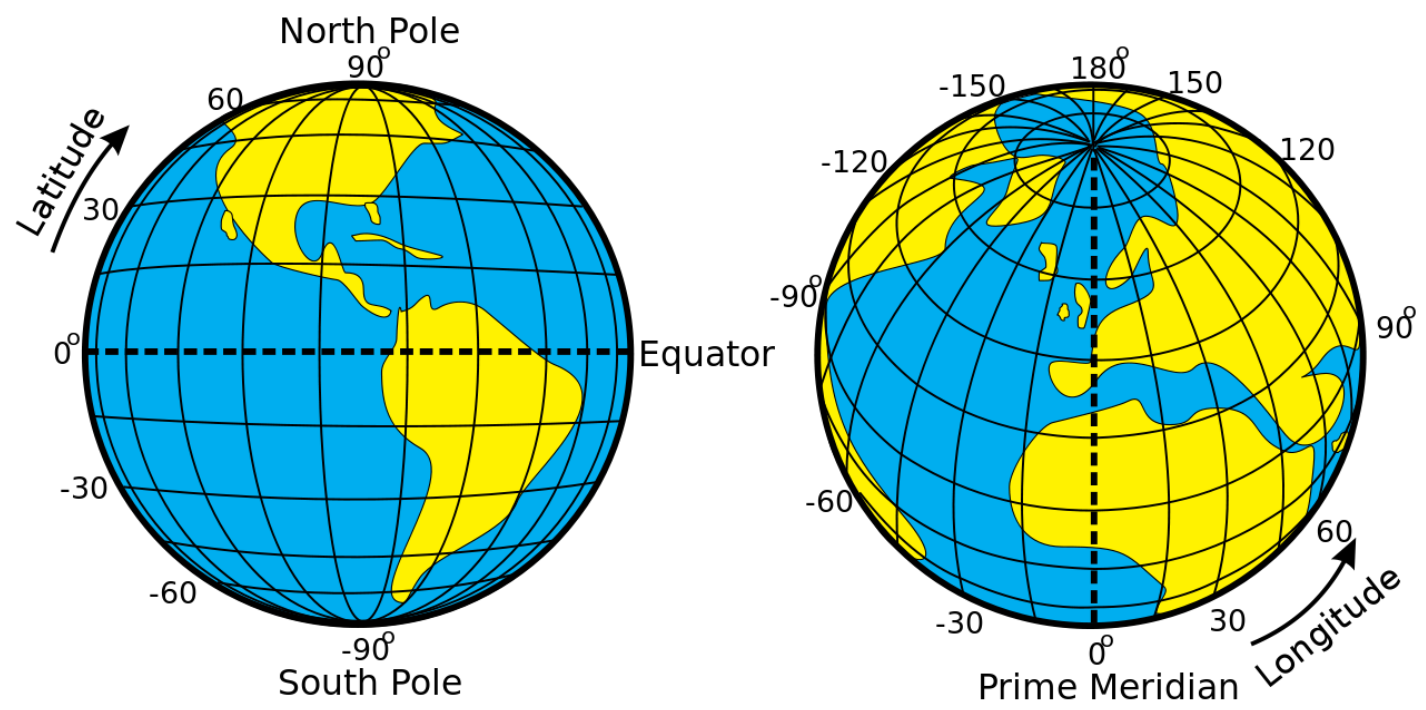

Figura 1.1: Malha em coordenadas geográficas, tipo lon/lat. Fonte: Wikipédia-Imagem de domínio público. 
Nessa malha há uma grande concentração de pontos próximos aos polos, que caracteriza o chamado "problema dos polos" (Li et al., 2013). Essa singularidade aparece ao se utilizar um sistema de coordenadas esféricas e causa problemas computacionais pois, em métodos explícitos de diferenças finitas ou volumes finitos, devido à condição de Courant-Friedrichs-Lewy (CFL), o passo de tempo é muito pequeno. Para contornar esse problema, foram utilizados métodos implícitos de diferenças finitas e espectrais. Porém, estes possuem um acoplamento global, dificultando a obtenção de eficiência computacional em supercomputadores modernos.

Nesse contexto, foram propostas diversas formas alternativas de discretização da esfera. Uma possibilidade é utilizar malhas mais uniformes, denominadas malhas geodésicas, obtidas por meio de sólidos platônicos inscritos na esfera, cujas faces são projetadas na superfície esférica. Por sua vez, os métodos métodos explícitos voltaram a ser explorados pela comunidade científica. Essas malhas são mais isotrópicas e não têm singularidades polares, sendo a malha cubada e a malha icosaédrica as mais utilizadas.
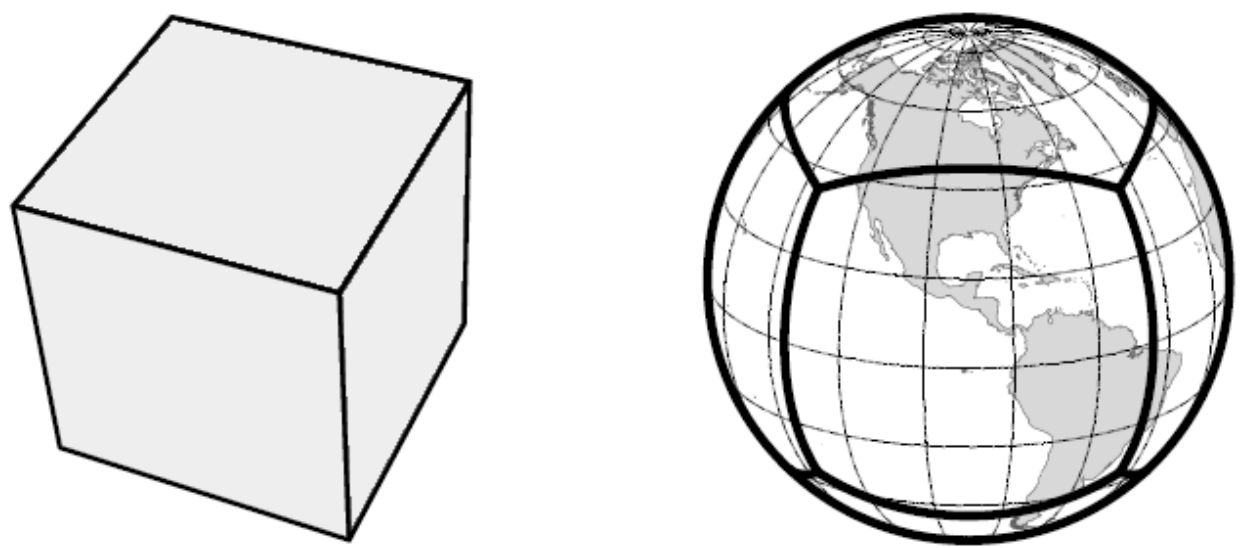

Figura 1.2: Malha em coordenadas cartesianas, tipo cubada. Fonte: (Gregory et al., 2008).

A malha cubada, ilustrada na Figura 1.2, foi introduzida por Sadourny (1972). Essa malha é obtida ao se projetar as arestas do cubo inscrito na esfera sobre a superfície esférica na direção radial, obtendo um total de seis quadrados esféricos. Essa malha é mais homogênea e possui uma distribuição de área mais uniforme quando comparada com a malha latitude-longitude. No trabalho de Ronchi et al. (1996), o pesquisador contribuiu com características adicionais, melhorando o espaçamento e ortogonalidade da malha cubada. Atualmente, essa malha vem sendo usada por grupos de pesquisa na modelagem atmosférica (Chen e Xiao, 2008; Nair et al., 2005; Ullrich e Jablonowski, 2012) e por modelos operacionais, como o FV3 (Finite-Volume Cubed-Sphere) (Lin et al., 2017) e o CAM-SE (Atmosphere Model Spectral Elements) (Lauritzen et al., 2018).
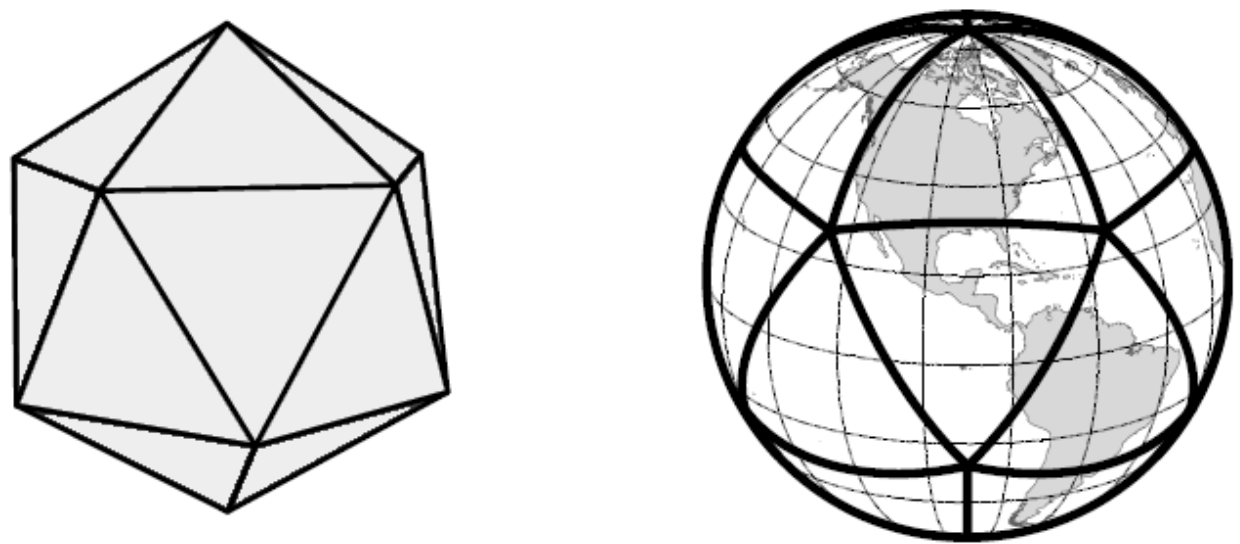

Figura 1.3: Malha em coordenadas cartesianas, tipo icosaédrica. Fonte (Gregory et al., 2008). 
A malha icosaédrica, ilustrada na Figura 1.3, também é obtida utilizando-se sólidos platônicos. Sua construção inicia-se projetando radialmente (gnomonicamente) as arestas do icosaedro inscrito na esfera sobre a superfície esférica, obtendo-se um total de vinte triângulos esféricos. Após essa primeira projeção, cada triângulo esférico é subdividido em quatro novos triângulos e, assim, sucessivamente, gerando vários níveis de resolução de malha. A vantagem é que essa malha é mais uniforme, ou seja, mais isotrópica ao longo de toda a esfera, em comparação com as outras malhas obtidas pelos sólidos de Platão. Além disso, estas características são adequadas para processamento paralelo em supercomputadores. Posto isso, a malha iscosaédrica tem sido utilizada por diversos grupos de pesquisa (Majewski et al., 2002; Tomita et al., 2002), em modelos atmosféricos de águas rasas (Li e Xiao, 2010; Ringler et al., 2000) e em modelos operacionais, como o MPAS (Model for Prediction Across Scales) (Ha et al., 2017) e o ICON (ICOsahedral Non-hydrostatic) (Giorgetta et al., 2018).

A precisão das simulações numéricas depende dos métodos numéricos utilizados e também das propriedades geométricas da malha utilizada. Assim, para aumentar a precisão da solução numérica, os métodos numéricos de baixa ordem, ou seja, os que possuem discretização espacial de até segunda ordem, precisam de um maior refinamento de malha, proporcionando um alto custo por iteração. Por outro lado, os métodos de alta ordem, permitem obter uma maior precisão em malhas mais grosseiras, reduzindo o tempo de processamento (Michalak, 2009) e, por esse motivo, têm sido apresentados como ferramentas alternativas a serem aplicadas na solução numérica de modelos atmosféricos globais, já que são fortemente influenciados pela qualidade da solução da equação de advecção ou do transporte (Williamson, 2007). Há também uma preocupação com o fato de o esquema ser positivamente definido e também com relação às propriedades conservativas que são proporcionadas pelos vínculos físicos nas equações que governam os movimentos dos fluidos. Por esses motivos, métodos de alta ordem têm-se tornado motivo de investigação para desenvolver métodos de transporte para problemas atmosféricos (Li et al., 2013; Skamarock e Gassmann, 2011; Skamarock e Menchaca, 2010; Subich, 2018; Zhang, 2018), obtendo-se taxa de convergência superior à ordem dois.

Em relação aos métodos de diferenças finitas (MDF), elementos finitos (MEF) e volumes finitos (MVF), um método para resolver uma equação diferencial parcial em um domínio com geometria complexa, usando malha não estruturada, por exemplo, é o método dos volumes finitos, o qual trabalha com um princípio importante da física, que é a conservação da média, no volume de controle, da propriedade relativa à função incógnita na equação diferencial. Por isso, este método tem sido muito explorado na literatura.

No contexto de métodos de volumes finitos de alta ordem, os mais populares incluem métodos essencialmente não oscilatórios (ENO) (Fu et al., 2018; Ivan et al., 2015), métodos ENO ponderados (WENO) (Buchmüller et al., 2018; Dumbser e Boscheri, 2013) e métodos k-exatos (Chassaing et al., 2013; Lee et al., 2018).

Os métodos ENO (Essentially Non-Oscillatory) foram desenvolvidos para se obter uma precisão mais uniforme em todos os pontos de uma solução suave (Abgrall, 1994), porém este utiliza polinômios de alta ordem para a reconstrução da solução, sendo necessário utilizar o estêncil "mais suave" para cada volume de controle em estudo. Nesse processo, determinam-se todos os polinômios aproximadores associados ao seu respectivo estêncil ao redor do volume de controle em estudo e, durante a interpolação, escolhe-se o polinômio que gerar o melhor resultado com alta ordem de precisão. Esse procedimento compromete o desempenho computacional do método ENO, devido ao esforço computacional em procurar os estênceis "suaves".

O método WENO (Weighted Essentially Non-Oscillatory) surge como uma proposta de resolver o problema da procura do estêncil mais "suave" (Hu e Shu, 1999). Dessa forma, esse esquema utiliza uma combinação dos polinômios obtidos na busca realizada pelo método ENO, dando pesos dependentes dos dados da função em estudo para se obter a solução numérica, ou seja, faz-se uma ponderação com base em todos os polinômios aproximadores obtidos para obter uma solução com alta ordem de precisão.

Nos métodos k-exatos de alta ordem, desenvolvidos por Barth e Frederickson (1990), a alta 
ordem é obtida pela construção de uma representação polinomial da solução dentro de cada volume de controle do domínio computacional, com base nas soluções médias de um estêncil de células vizinhas do volume de controle em estudo. A integração numérica do fluxo em cada aresta do volume de controle pode ser calculada de maneira precisa, utilizando-se quadratura gaussiana. Após soma do fluxo em todas as arestas, atualizam-se as soluções médias e avalia-se a solução no tempo. Observa-se que, por definição, um esquema k-exato de grau k reconstruirá de maneira exata a solução verdadeira, se ela for um polinômio de grau k.

O método de alta ordem, proposto por Ollivier-Gooch, tem como base o método k-exato de alta-ordem desenvolvido por Barth e Frederickson (1990), e difere dos métodos ENO e WENO pois não exige a necessidade de um estêncil "suave" para a reconstrução da solução por meio dos polinômios de alta ordem, uma vez, que nem sempre o estêncil "suave" existe. Em seu trabalho, Ollivier-Gooch utiliza um estêncil fixo com pesos dependentes da distância dos dados e a solução numérica é obtida pela reconstrução da solução, integração do fluxo e evolução temporal. Esse método tem sido utilizado com sucesso em diversas aplicações em malhas não estruturadas no plano (Hoshyari e Ollivier Gooch, 2018; Jalali et al., 2014; Nejat e Ollivier-Gooch, 2008; Ollivier-Gooch, 1997; Ollivier-Gooch e Van Altena, 2002).

Devido à estrutura flexível e versatilidade desse método de alta ordem, o mesmo foi aplicado em diversos trabalhos de doutorado na USP: Casavilca (2016); Saito (2008); Santana (2007) com excelentes resultados. Com base em todas as aplicações desse método em malhas não estruturadas, bem como os resultados obtidos na literatura, pretende-se transportar essa técnica aplicada no plano para a superfície esférica, utilizando-se malhas icosaédricas, e avaliar suas contribuições.

\subsection{Objetivos}

O objetivo deste trabalho é estender a metodologia baseada no método de volumes finitos de alta ordem desenvolvido por Ollivier-Gooch e colaboradores (Hoshyari e Ollivier Gooch, 2018; Jalali et al., 2014; Nejat e Ollivier-Gooch, 2008; Ollivier-Gooch, 1997; Ollivier-Gooch e Van Altena, 2002; Ollivier-Gooch et al., 2009), que apresenta resultados relevantes em alta ordem, aplicadas em malhas no plano, para a superfície esférica. A transição do método para esse novo contexto será verificada de forma rigorosa, ou seja, serão feitos testes para validar todas as etapas no processo de implementação. Para verificar o desempenho do método, será utilizada a equação de advecção com diversos testes padrão da literatura, que serão comparados com recentes trabalhos de diversos autores representativos da área. Através dos resultados numéricos, pretende-se avaliar as contribuições que o método proposto pode proporcionar nesse campo de pesquisa.

\subsection{Organização do trabalho}

O capítulo 2 aborda uma revisão sobre os principais métodos de alta ordem aplicados na esfera, destacando suas características e os tipos de otimizações utilizadas em malhas icosaédricas. Todos os métodos abordados utilizam a equação de advecção ou do transporte e os que difere é a forma como cada pesquisador avalia o fluxo nas arestas dos volumes de controle na malha icosaédrica. Esse capítulo abrange a revisão da literatura e os progressos dos pesquisadores em obter alta ordem na esfera, com suas respectivas contribuições.

No capítulo 3 são descritos todos os estágios do método proposto, que será obtido com base no método de alta ordem de Ollivier-Gooch e colaboradores. Neste trabalho, a proposta utilizada para discretizar o operador divergente, como os formatos dos volumes de controle, diferem dos métodos disponíveis na literatura.

No capítulo 4 serão validadas todas as etapas necessárias para se obter um método de alta ordem na esfera, o que inclui testes de interpolação e integração, obtendo-se métodos de $2^{\mathrm{a}}, 3^{\mathrm{a}}$ e $4^{\mathrm{a}}$ ordens de precisão e, por fim, a discretização em alta ordem do operador divergente na esfera.

No capítulo 5 são apresentados os resultados de diversas funções de referência, aplicadas para a equação de adveç̧ão e comparados os métodos da literatura, abordados no capítulo 2. Demais 
testes foram propostos e seus resultados permitem afirmar que o método proposto neste trabalho de forma original, possui um desempenho diferenciado em relação aos métodos da literatura.

O capítulo 6 discute globalmente os resultados obtidos no capítulo 5. Em síntese, obtém-se um solver de volumes finitos de alta ordem implementado e validado, sendo uma proposta original na literatura podendo ser uma opção para aplicações atmosféricas.

No apêndice A apresentamos algumas notações e propriedades da geometria esférica utilizadas em malhas icosaédricas. Por fim, o apêndice B aborda as considerações técnicas da plataforma computacional e os softwares usados no desenvolvimento deste trabalho. 


\section{Capítulo 2}

\section{Métodos de volumes finitos de alta ordem na esfera}

Aplicações relativas a fenômenos globais requerem a capacidade de modelar o transporte de escalares na superfície esférica. Para estudar a equação de advecção na esfera, diversos métodos numéricos podem ser aplicados, no entanto, em malhas não estruturadas o método de volumes finitos é mais flexível e tem por construção, o princípio de conservação de uma determinada quantidade física, expressa pelas equações governantes sobre qualquer volume de controle (Ollivier-Gooch, 1997). As simulações envolvendo modelos de previsão do tempo têm sua precisão global diretamente influenciada pela precisão da solução da equação do transporte (Williamson, 2007). Nesse contexto, os métodos de alta ordem permitem obter soluções com alta ordem de precisão e com menor tempo computacional, quando comparados com métodos de baixa ordem (Michalak, 2009), e por esse motivo, têm sido explorados por diversos pesquisadores.

Vamos discutir neste capítulo os métodos de volumes finitos de alta ordem aplicados à esfera e as diferentes técnicas para avaliar o fluxo nas arestas dos volumes de controle. Dessa forma, iniciaremos com a formulação matemática da equação de advecção na esfera, utilizando-se a metodologia de volumes finitos. Na sequência, apresentaremos os conceitos fundamentais do método de volumes finitos e, posteriormente, os métodos de reconstrução de alta ordem da literatura aplicados na esfera.

\subsection{Equação de advecção na esfera}

A equação de adveç̧ão de uma grandeza escalar $\phi(r, t)$, que representa a concentração de uma substância (ou traçador) associada ao escoamento de um fluido, é dada por

$$
\frac{\partial(\rho \phi)}{\partial t}=-\nabla \cdot(\vec{V} \rho \phi)
$$

onde, $\rho(r, t)$ é a densidade do fluido e $\vec{V}(r, t)$ o vetor velocidade do fluido em um ponto $r=(x, y, z)$ da esfera, em um instante $t$ do tempo.

A equação (2.1) representa o balanço da grandeza escalar $\phi$ em um volume de controle infinitesimal na superfície da esfera, conforme Figura 2.1. O lado esquerdo da equação (2.1) representa a variação local de $\phi$ no tempo e o lado direito representa o transporte advectivo através da superfície de controle. Assim, a equação (2.1) na forma integral será

$$
\int_{\Omega_{i}} \frac{\partial(\rho \phi)}{\partial t} d \Omega_{i}=-\int_{\Omega_{i}} \nabla \cdot(\vec{V} \rho \phi) d \Omega_{i}
$$

A equação (2.2) representa o balanço em uma região da esfera compacta, denotada por $\Omega_{i}$, contendo o ponto $\left(x_{i}, y_{i}, z_{i}\right)$ com fronteira $\partial \Omega_{i}$ suave por pedaços, fixa em uma região do espaço pela qual escoa um fluido. 


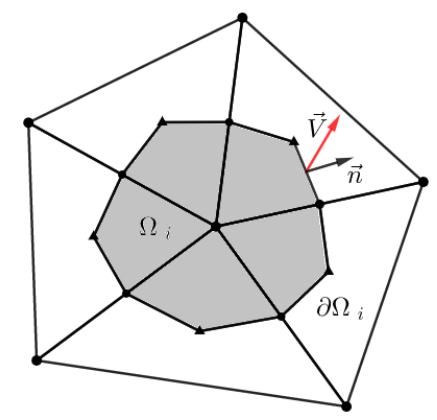

Figura 2.1: Volume de controle esférico infinitesimal $\Omega_{i}$.

Aplicando o Teorema da Divergência na equação (2.2), converte-se a integral de área em uma integral de linha, resultando na expressão

$$
\int_{\Omega_{i}} \frac{\partial(\rho \phi)}{\partial t} d \Omega_{i}=-\int_{\partial \Omega_{i}}(\vec{V} \rho \phi) \cdot \vec{n} d \partial \Omega_{i}
$$

O termo $\vec{V} \rho \phi \cdot \vec{n} d \partial \Omega_{i}$ representa o fluxo por um elemento de linha $d \partial \Omega_{i}$ referente ao volume de controle $\Omega_{i}$, e $\vec{n}$ é o vetor unitário normal exterior à fronteira $\partial \Omega_{i}$. Se $\rho$ for uma constante, sem perda de generalidade, considerando $\rho=1$ e utilizando-se o Teorema da Derivação sob o sinal de integral, pode-se comutar a derivada no tempo com a integral e reescrever a equação (2.3) da seguinte forma

$$
\frac{d}{d t} \int_{\Omega_{i}}(\phi) d \Omega_{i}=-\int_{\partial \Omega_{i}}(\vec{V} \phi) \cdot \vec{n} d \partial \Omega_{i}
$$

Para se obter a média da solução armazenada no volume de controle $\Omega_{i}$, divide-se a equação (2.4) pela área geodésica do volume de controle $\left|\Omega_{i}\right|$, obtendo-se

$$
\frac{1}{\left|\Omega_{i}\right|} \frac{d}{d t} \int_{\Omega_{i}}(\phi) d \Omega_{i}=-\frac{1}{\left|\Omega_{i}\right|} \int_{\partial \Omega_{i}}(\vec{V} \phi) \cdot \vec{n} d \partial \Omega_{i}
$$

Isso resultará na equação integro-diferencial, que será aplicada em cada volume de controle $\Omega_{i}$ sobre a superfície esférica, dada por

$$
\frac{d \bar{\phi}_{i}}{d t}=-\frac{1}{\left|\Omega_{i}\right|} \int_{\partial \Omega_{i}}(\vec{V} \phi) \cdot \vec{n} d \partial \Omega_{i}
$$

onde,

$$
\bar{\phi}_{i}=\frac{1}{\left|\Omega_{i}\right|} \int_{\Omega_{i}}(\phi) d \Omega_{i}
$$

é a média da solução $\phi$ da equação de adveç̧ão no volume de controle $\Omega_{i}$.

A equação de adveç̧ão será resolvida utilizando-se métodos de volumes finitos aplicados na esfera e por isso, faremos uma breve revisão dessa metodologia na proxima seção.

\subsection{Método de volumes finitos}

Dada a equação integro-diferencial (2.6), com suas respectivas condições iniciais, o método de volumes finitos (MVF) consiste nas etapas descritas abaixo.

\subsubsection{Discretização do domínio da equação diferencial}

A geração de uma malha estruturada ou não estruturada é necessária para discretizar o domínio espacial, conforme Figura 2.2. A primeira busca a subdivisão do domínio, preservando alguma 
estrutura de indexação e facilitando o acesso aos elementos através de seus índices. Por outro lado, as malhas não estruturadas não preservam tal característica, fazendo com que o acesso aos elementos seja feito através de relações de vizinhança.
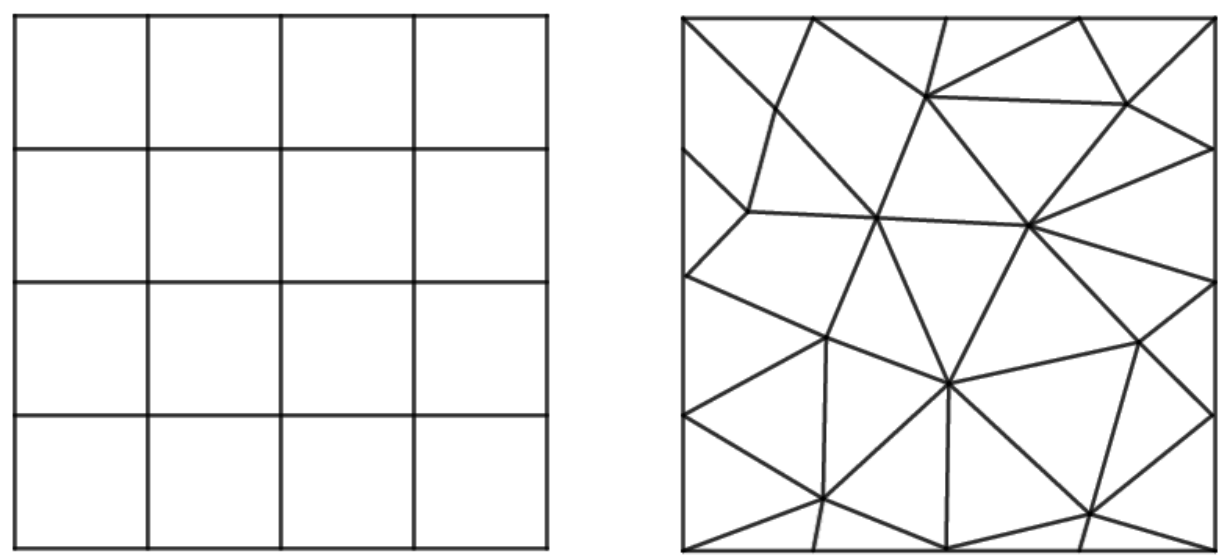

Figura 2.2: Malha estruturada (esquerda) e malha não estruturada (direita).

As malhas não estruturadas têm como vantagem a representação de domínios complexos, normalmente difíceis de serem representados por malhas estruturadas em bloco único, além de facilitar a implementação de técnicas de refinamento local para estudos em regiões específicas do domínio computacional.

\subsubsection{Definição dos volumes de controle}

O domínio computacional discretizado é formado por um número finito de nós, que definem um número finito de volumes de controle. No método de volumes finitos, os volumes de controle são classificados em dois tipos: cell - centered e cell - vertex, conforme ilustrado na Figura 2.3.
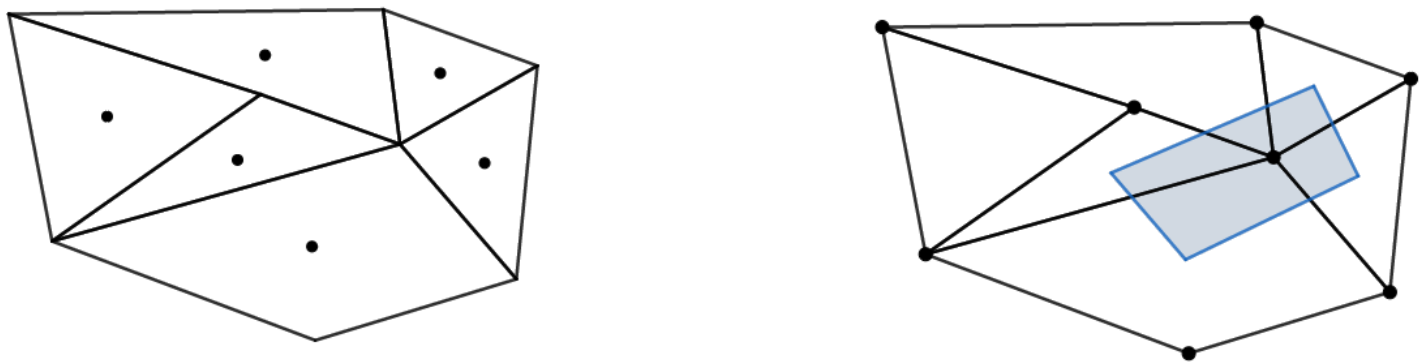

Figura 2.3: Volumes de controle: cell-centered (esquerda) e cell-vertex (direita).

No volume de controle tipo cell - vertex as variáveis a serem determinadas ficam armazenadas nos vértices dos volumes de controle, que coincidem com os próprios nós da malha. No volume de controle tipo cell - centered as informações são armazenadas no centróide das células computacionais. Em ambos, o fluxo será avaliado nas arestas dos volumes de controle.

\subsubsection{Formulação integral}

O método dos volumes finitos é baseado na formulação integral das equações diferenciais. As integrais serão calculadas em cada volume de controle por alguma técnica de integração numérica, 
resultando em equação algébrica, ou seja, em uma equação discretizada. O lado direito da equação (2.6) representa o fluxo advectivo, que será avaliado pela integral em cada aresta $e_{j}$ do volume de controle $\Omega_{i}$, formado por $m$ arestas, dado por

$$
\frac{1}{\left|\Omega_{i}\right|} \int_{\partial \Omega_{i}}(\vec{V} \phi) \cdot \vec{n} d \partial \Omega_{i}=\frac{1}{\left|\Omega_{i}\right|} \sum_{j=1}^{m} \int_{e_{j}}(\vec{V} \phi) \cdot \vec{n}_{e_{j}} d l .
$$

\subsection{Formulação básica de fluxo na esfera}

Nesta seção são abordados alguns tópicos importantes que são comuns no método de volumes finitos de alta ordem na esfera. Inicia-se explicando a construção da malha icosaédrica com suas otimizações e características. Depois, aborda-se alguns tipos de projeções da esfera para o plano tangente, onde serão construídos os polinômios aproximadores para avaliar o fluxo nos volumes de controle da malha icosaédrica.

\subsubsection{Malha esférica geodésica icosaédrica}

A geometria esférica introduz uma série de complicações na solução discreta da equação do transporte. Essas discretizações, por sua vez, exigem alguma decomposição da malha na superfície esférica. Os diversos tipos de malhas foram abordadas no trabalho de Williamson (2007). Uma delas, é a malha icosaédrica, que tem sido explorada por possuir uma discretização mais uniforme em relação à malha latitude/longitude (Li e Xiao, 2010).

A construção da malha icosaédrica inicia-se a partir do icosaedro inscrito na esfera, com suas faces projetadas na superfície da esfera de raio unitário, resultando em uma malha composta por 20 triângulos esféricos conforme ilustrado na Figura 2.4. A partir da malha triangular com 12 vértices, pode-se aumentar a resolução da malha adicionando pontos nas posições médias das arestas dos triângulos e conectando-os por segmentos geodésicos para gerar a próxima malha triangular com 42 vértices. O número de pontos é calculado com base na equação $10.2^{(2 m)}+2$ (Miura e Kimoto, 2005), onde $m=0,1,2, \ldots$, indica o nível de resolução da malha.

0

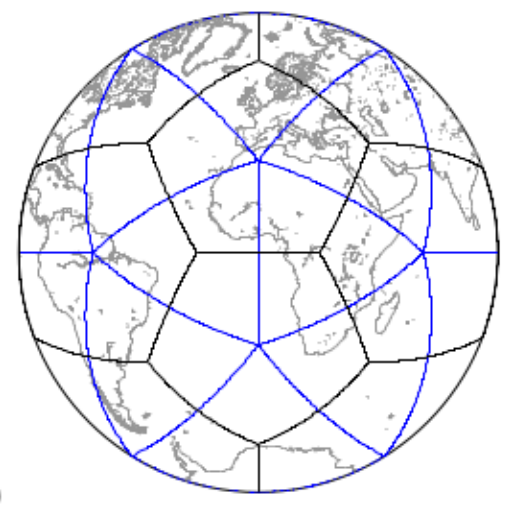

1

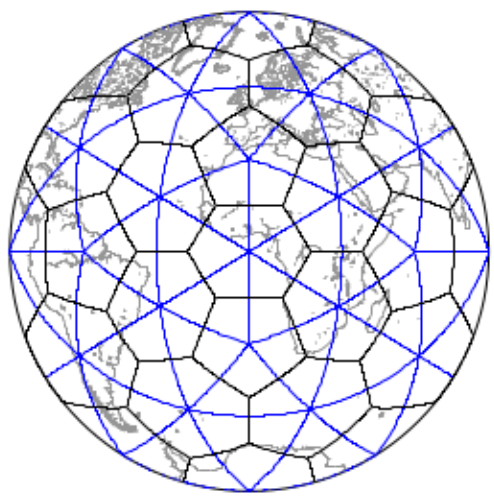

2

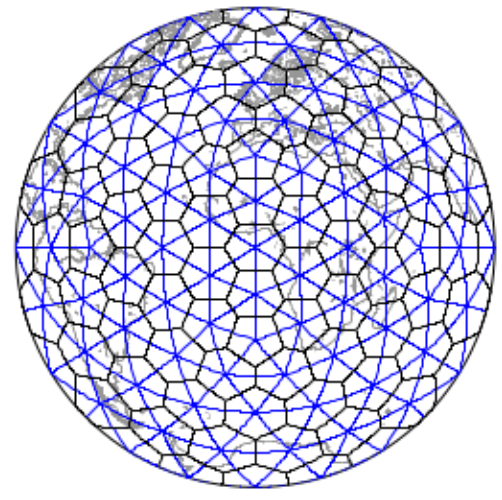

Figura 2.4: Diagrama de Voronoi para malhas icosaédricas de níveis 0, 1 e 2, respectivamente com 12, 42,162 nós geradores.

A Tabela 2.1 aborda vários níveis de malha. A demais colunas são obtidas por meio da fórmula de Euler \#arestas = \#faces+\#vértices-2. Por exemplo, a malha icosaédrica de nível 0 é formada por um icosaedro de 12 vértices e 20 faces triangulares, resultando em 30 arestas. 


\begin{tabular}{|c|c|c|c|}
\hline Nível & Vértices & Triângulos & Arestas \\
\hline 0 & 12 & 20 & 30 \\
\hline 1 & 42 & 80 & 120 \\
\hline 2 & 162 & 320 & 480 \\
\hline 3 & 642 & 1280 & 1920 \\
\hline 4 & 2562 & 5120 & 7680 \\
\hline 5 & 10242 & 20480 & 30720 \\
\hline 6 & 40962 & 81920 & 122880 \\
\hline 7 & 163842 & 327680 & 491520 \\
\hline 8 & 655362 & 1310720 & 1966080 \\
\hline
\end{tabular}

Tabela 2.1: Níveis e características da malha esférica geodésica icosaédrica.
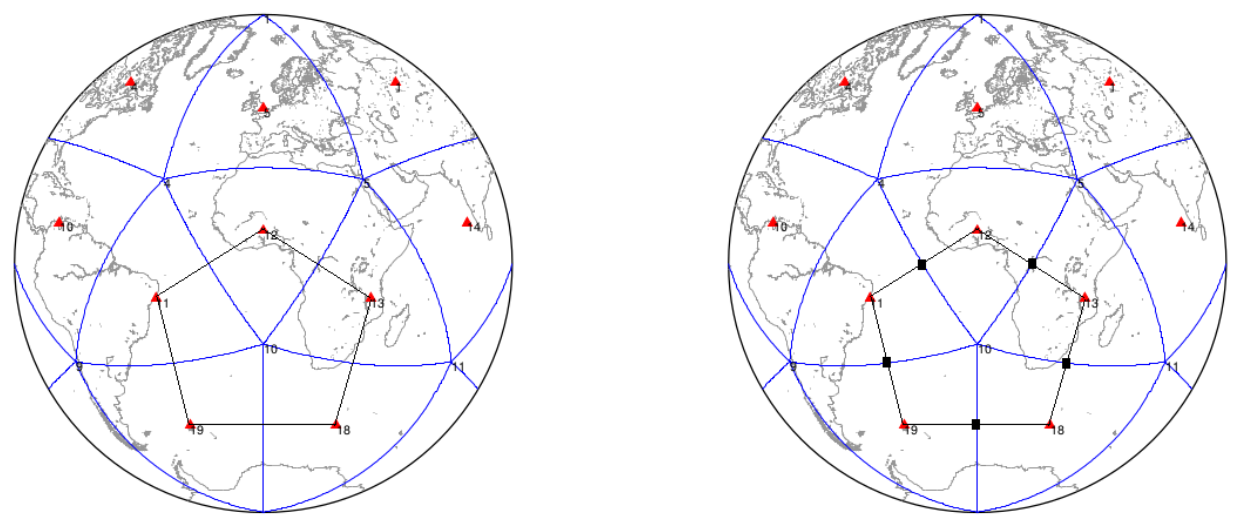

Figura 2.5: Volume de controle de Voronoi (esquerda) e de Donald (direita).

A partir da malha primal (Triangularização de Delaunay), formada pelos triângulos esféricos é determinada a malha dual (Diagrama de Voronoi), formada pela união de todos os volumes de controle de Voronoi ou pela malha dual (Diagrama de Donald) (MacDonald et al., 1968; Su et al., 2018), formada pela união de todos os volumes de controle de Donald, conforme Figura 2.5. Os volumes de controle de Voronoi são obtidos ao se conectar os circuncentros de todos os triângulos esféricos adjacentes aos vértices da malha primal por segmentos geodésicos. Ao final, tem-se uma malha dual formada por 12 volumes de controle pentagonais. Para os próximos níveis de malha, tem-se a presença dos 12 pentágonos e, os demais, serão hexágonos, conforme Figura 2.4.

Os volumes de controle de Donald são formados ao se conectar os baricentros dos triângulos esféricos adjacentes aos vértices da malha primal, com seus respectivos pontos médios das arestas, por segmentos geodésicos, formando uma outra malha dual ou malha de Donald. Ressalta-se que os baricentros e circuncentros dos triângulos esféricos, descritos na Figura 2.5, só coincidem devido ao fato da malha ser de nível 0. Para os próximos níveis, isso não acontece. Maiores detalhes sobre malha icosaédrica primal e dual podem ser vistos em Peixoto (2013).

\subsubsection{Malha icosaédrica otimizada}

A malha icosaédrica formada pelo Diagrama de Voronoi, cujos volumes de controle são de Voronoi, conforme ilustrado na Figura 2.4, denomina-se malha NOPT, ou seja, trata-se de uma malha icosaédrica não otimizada.

Para melhorar os resultados numéricos da solução na superfície esférica, vários tipos de otimizações com características distintas podem ser aplicadas em malhas icosaédricas, obtendo-se malhas otimizadas conforme Figura 2.6. Dentre elas, pode-se destacar as malhas SCVT (Spherical Centroidal Voronoi Tesselation) ou malhas centroidais de Voronoi, cuja otimização tem como objetivo fazer com que os nós geradores dos volumes de controle centrado no vértice, sejam o mais próximo dos baricentros do volume de controle. Uma outra opção, são as malhas HR95, proposta por 
Heikes e Randall (1995), cuja otimização proporciona que os pontos de intersecção da malha primal e do diagrama de Voronoi sejam mais próximos possíveis do ponto médio da aresta que liga os vértices das células da malha icosaédrica. Temos também as malhas SD com otimização spring dynamics, propostas por Tomita et al. (2002) e inicialmente utilizadas em modelos atmosféricos. Essa otimização consiste na solução de um sistema de equações diferenciais ordinárias pelo método de diferenças finitas para um conjunto de molas que conectam os pontos de malha, com o objetivo de minimizar as distorções das células. Uma revisão completa sobre malhas icosaédricas e outros tipos de otimização foi abordada em Peixoto (2013). O uso de cada tipo de otimização de malhas depende das características e da finalidade do modelo numérico a ser implementado.
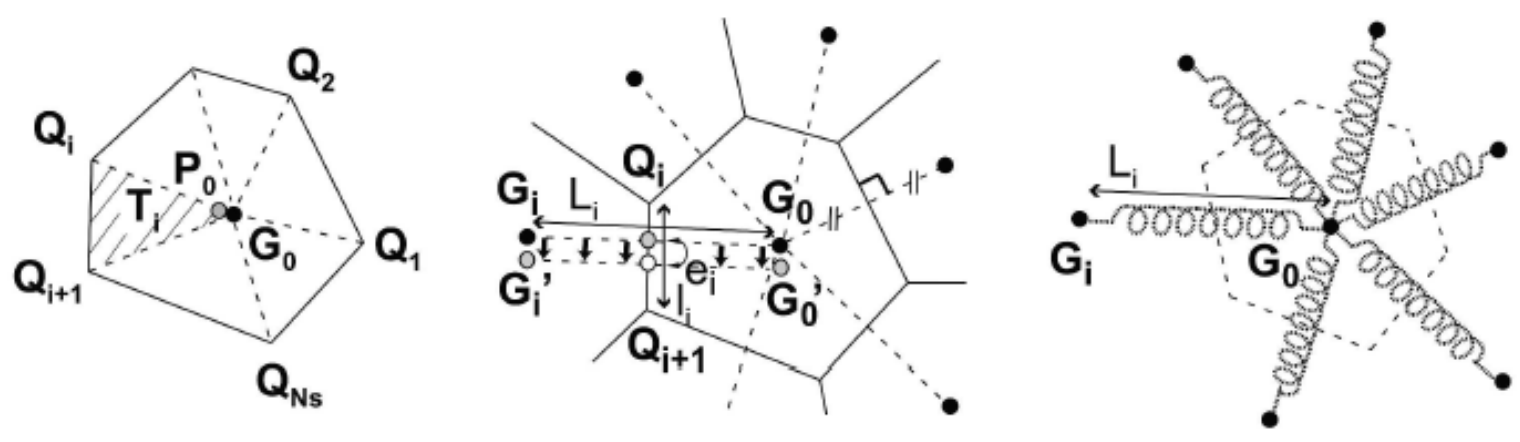

Figura 2.6: Malhas icosaédricas com otimização SCVT, HR95 e SD, respectivamente. Fonte: (Miura e Kimoto, 2005).

\subsubsection{Aproximação polinomial}

No método de volumes finitos precisamos calcular o valor de $\phi$, dada na equação (2.8) em pontos de malha icosaédrica. Como a função $\phi$ não é conhecida em todos os pontos, precisamos fazer uma estimativa com base nos pontos onde ela é conhecida, por meio de um polinômio aproximador $\phi_{i}^{p}$ de grau $p$.

Como é difícil determinar essa aproximação polinomial na esfera, vamos aproximar $\phi$ localmente por um polinômio aproximador que será definido no plano tangente à esfera, passando pelo vértice do volume de controle $\Omega_{i}$. Nesse plano tangente, vamos definir polinômios de graus $1,2,3$ e 4 que possuem 3, 6, 10 e 15 coeficientes, respectivamente, dados por

$$
\begin{gathered}
\phi_{i}^{1}(x, y)=c_{0}+c_{1} x+c_{2} y \\
\phi_{i}^{2}(x, y)=c_{0}+c_{1} x+c_{2} y+c_{3} x^{2}+c_{4} x y+c_{5} y^{2} \\
\phi_{i}^{3}(x, y)=c_{0}+c_{1} x+c_{2} y+c_{3} x^{2}+c_{4} x y+ \\
c_{5} y^{2}+c_{6} x^{3}+c_{7} x^{2} y+c_{8} x y^{2}+c_{9} y^{3}, \\
\phi_{i}^{4}(x, y)=c_{0}+c_{1} x+c_{2} y+c_{3} x^{2}+c_{4} x y+c_{5} y^{2}+c_{6} x^{3}+c_{7} x^{2} y+ \\
c_{8} x y^{2}+c_{9} y^{3}+c_{10} x^{4}+c_{11} x^{3} y+c_{12} x^{2} y^{2}+c_{13} x y^{3}+c_{14} y^{4} .
\end{gathered}
$$

Observa-se que os polinômios aproximadores de grau $p$ levam um erro de aproximação de ordem $p+1$, ou seja, se uma função $\phi$ for suficientemente suave, o erro associado à aproximação será da ordem $p+1$ no plano.

Aqui iremos abordar os dois tipos de projeções utilizados da esfera para o plano, conforme ilustrado na Figura 2.7. A projeção radial ou gnomônica (ver (Lashley, 2002)), consiste em passar 
um plano tangente ao vértice $P_{0}$ do volume de controle em estudo e projetar na direção radial o ponto $P_{1}$ contido na esfera para o plano tangente, obtendo-se o ponto $P_{1}^{* *}$. Na projeção perpendicular, a partir do mesmo plano tangente, projeta-se perpendicularmente o ponto $P_{1}$ contido na esfera para o plano tangente obtendo-se o ponto $P_{1}^{*}$. As projeções determinam diferentes sistemas de coordenadas locais, porém ambos são centrados no ponto tangente à esfera.

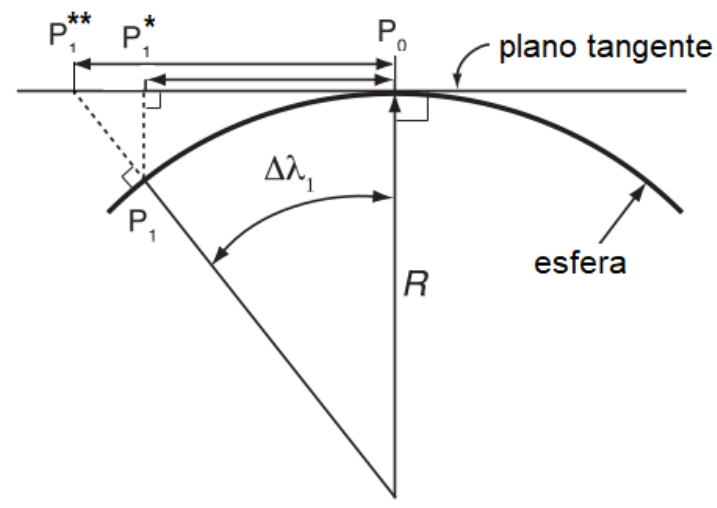

Figura 2.7: Tipos de projeção da esfera para o plano tangente.

No trabalho de Lashley (2002), o pesquisador observou que os resultados numéricos da equação de advecção não sofreram influência das opções exploradas de projeção da esfera para o plano, que possui um erro de ordem 2. Na revisão bibliográfica, os pesquisadores utilizaram a projeção radial e, neste trabalho, foi utilizado a projeção perpendicular devido à facilidade de implementação e por não afetar a ordem do método proposto para a esfera. Independentemente das projeções discutidas, a construção do polinômio aproximador é feita no plano tangente associado ao seu respectivo volume de controle. Para ilustrar o procedimento, considere que queremos construir um polinômio $\phi_{i}^{2}$ de grau 2 no volume de controle $\Omega_{i}$.

Para isso, precisamos utilizar o estêncil da Figura 2.8 e a quantidade de vizinhos a serem utilizados depende do número de coeficientes a serem determinados do polinômio aproximador. Nesse caso, vamos precisar apenas dos primeiros vizinhos do volume de controle $\Omega_{i}$.

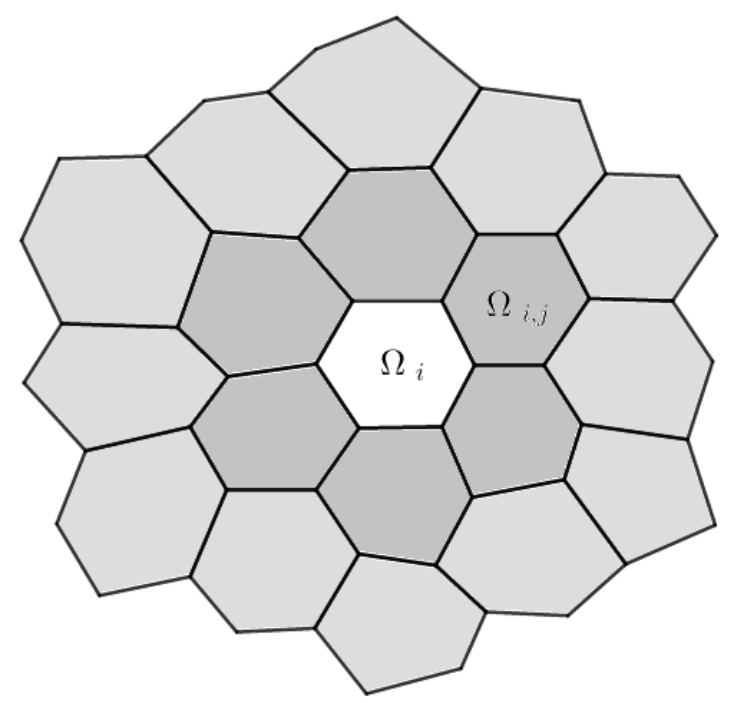

Figura 2.8: Estêncil utilizado para reconstrução de $2^{a}$, $3^{a}$ e $4^{a}$ ordens.

O polinômio aproximador $\phi_{i}^{2}$, relativo ao volume de controle $\Omega_{i}$ é dado por

$$
\phi_{i}^{2}=c_{0}+c_{1} x+c_{2} y+c_{3} x^{2}+c_{4} x y+c_{5} y^{2} .
$$

Estamos forçando que o polinômio aproximador $\phi_{i}^{2}$ de grau 2 , seja interpolador em $\Omega_{i}$, ou seja, 
$\phi_{i}^{2}\left(x_{i}, y_{i}\right)=\phi_{i}$ e também seja interpolador nos volumes de controle vizinhos $\Omega_{i, j}$, dessa forma, $\phi_{i}^{2}\left(x_{j}, y_{j}\right)=\phi_{j}, j=j(i) \in n b(i)$ onde $n b(i)$ representa o número de vizinhos a serem utilizados para a construção do polinômio aproximador do volume de controle $\Omega_{i}$, resultando no sistema matricial $P \cdot c=s$. Assim, temos que $s=\left[\phi_{0}, \phi_{1}, \ldots, \phi_{m}\right]^{T}$ representa os valores conhecidos da função $\phi$ nos vértices $\left(x_{i}, y_{i}\right)$ dos volumes de controle e $m$ representa o total de vizinhos a ser utilizado na construção do polinômio interpolador; $c=\left[c_{0}, c_{1}, \ldots, c_{n}\right]$ representa os $n$ coeficientes da aproximação polinomial e $P=\left[1, x_{i}, y_{i}, \ldots, y_{i}^{2}\right]$ com $i=0, \ldots, m$; representa a matriz polinomial, resultando em sistema com $m$ equações e $n$ incógnitas. Vamos resolver o sistema matricial $P \cdot c=s$ utilizando-se o método de mínimos quadrados (MMQ), por ser um sistema sobredeterminado $(m>n)$. A solução do sistema matricial $P \cdot c=s$ dada por $c=P^{*} \cdot s$, são os coeficientes do polinômio aproximador descrito na equação (2.13). Observe que $P^{*}=\left(P^{T} P\right)^{-1} P^{T}$ é a matriz pseudoinversa de $P$ e como os elementos da matriz não dependem do campo vetorial e do tempo, ela é calculada para cada $\Omega_{i}$ e armazenada. Após determinar os coeficientes dos polinômios aproximadores, calcula-se o fluxo em cada aresta e armazena-se a solução no vértice de $\Omega_{i}$.

\subsubsection{Limitadores e avanço temporal}

Em um modelo atmosférico, a equação de adveç̧ão ou do transporte é frequentemente usada para testar métodos numéricos (Dubey et al., 2014). Um esquema de transporte desejado precisa atender algumas propriedades importantes, incluindo a conservação de massa, evitando oscilações numéricas diante de descontinuidades, sendo computacionalmente eficiente em uma geometria esférica (Skamarock, 2006).

Segundo Thuburn (1996), um esquema é monotônico se não amplificar os extremos nas taxas iniciais da propriedade transportada. Nesse contexto, o uso de limitadores é fundamental para evitar "undershoots" e "overshoots" em regiões com descontinuidades. Um dos limitadores utilizados em métodos de alta ordem na esfera é o limitador FCT (Flux Corrected Transport), desenvolvido por Zalesak (1979). O limitador FCT restringe o fluxo normal usando um procedimento anti-difusivo e difusivo para alcançar o transporte monotônico do método aplicado na equação de advecção. Mais detalhes para implementação desse limitador encontram-se no trabalho de Zhang et al. (2017).

O próximo passo para avaliar a equação do transporte, consiste em utilizar um esquema explícito de avanço temporal, sendo que os mais utilizados são os esquemas Runge-Kutta de $3^{\mathrm{a}}$ ordem (RK3) ou de $4^{\mathrm{a}}$ ordem (RK4) (Durran, 2010).

\subsection{Comentários}

A alta ordem dos métodos de volumes finitos aplicados na esfera está relacionada com a discretização espacial do operador divergente. A partir dessa discretização, cada método calcula o fluxo nas arestas dos volumes de controle de forma diferente, ou seja, o objetivo consiste em aproximar a função $\phi$ por um escalar $\phi_{e_{j}}$ em cada aresta $e_{j}$ do volume de controle em estudo. Por isso, nas próximas seções serão abordadas as propostas disponíveis na literatura para calcular $\phi_{e_{j}}$ e os resultados obtidos. 


\subsection{Método de Skamarock e Menchaca, 2010 (FV-MEN)}

O trabalho de Skamarock e Menchaca (2010), que será denominado de FV-MEN, consiste em estender o método de volumes finitos de $1^{\mathrm{a}}$ ordem de Miura (2007) em malhas icosaédricas, para obter reconstruções de alta ordem e avaliar os resultados por meio de diversos testes padrão da literatura. O cálculo do fluxo da equação (2.8) abordado em FV-MEN utilizando-se o método de Euler explícito, é dado por

$$
\frac{\Delta t}{\left|\Omega_{i}\right|} \sum_{j=1}^{m} \int_{e_{j}}(\vec{V} \phi) \cdot \vec{n}_{e_{j}} d l \approx \frac{1}{\left|\Omega_{i}\right|} \sum_{j=1}^{m}\left(\vec{V}_{e_{j}} \cdot \vec{n}_{e_{j}}\right) \phi_{e_{j}} l_{e_{j}} \Delta t,
$$

onde, $\phi_{e_{j}}$ é a concentração da substância avaliada no ponto médio da aresta $e_{j}, \vec{V}_{e_{j}}$ é o vetor velocidade do fluido avaliado no ponto médio da aresta $e_{j}, \vec{n}_{e_{j}}$ é o vetor unitário normal à aresta $e_{j},\left|\Omega_{i}\right|$ é a área geodésica do volume de controle $\Omega_{i}, m$ é o número de faces do volume de controle $\Omega_{i}$ e $l_{e_{j}}$ é o comprimento geodésico da aresta $e_{j}$ do volume de controle $\Omega_{i}$.

O método FV-MEN utiliza malhas icosaédricas com otimização HR95, cujos volumes de controle são da forma de hexágonos e/ou pentágonos. O segundo termo da equação (2.14) representa a soma dos fluxos nas arestas do volume de controle $\Omega_{i}$. Seguindo a metodologia do trabalho de Miura (2007), considera-se a velocidade constante nas arestas $e_{j}$, assim o fluxo para cada aresta é aproximado por $\left(\vec{V}_{e_{j}} \cdot \vec{n}_{e_{j}}\right) \phi_{e_{j}} l_{e_{j}} \Delta t$.

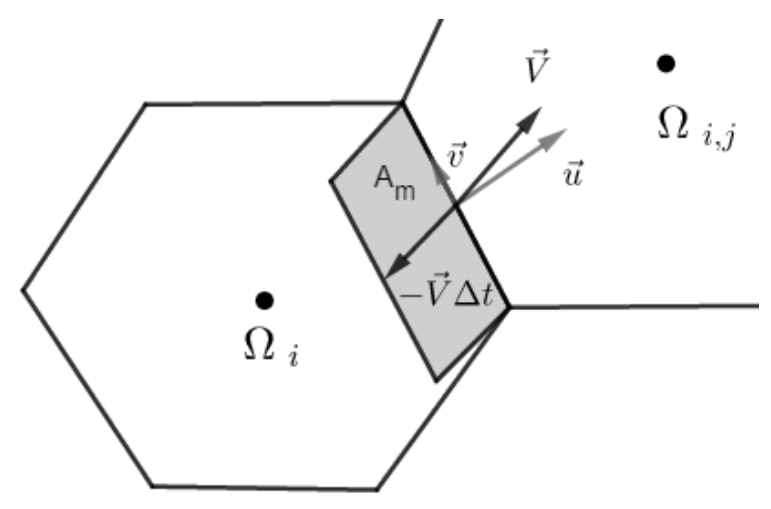

Figura 2.9: Fluxo através da aresta $e_{j}$ do volume de controle $\Omega_{i}$ em um intervalo de tempo $\Delta t$.

O fluxo é calculado dentro da área do paralelogramo $A_{m}$, ilustrado na Figura 2.9. Essa área é obtida pela varredura da aresta $e_{j}$ do volume de controle, movendo-se com velocidade constante $\vec{V}$ durante um período de tempo $\Delta t$, conhecido como método de "área varrida". A área a ser efetuada a integração depende da direção do fluxo, ou seja, esse método é um esquema upwind puro. Se $\vec{V}_{e_{j}} \cdot \vec{n}_{e_{j}}$ for positivo, utiliza-se a área e o polinômio do volume de controle $\Omega_{i}$, se for negativo utiliza-se a área e o polinômio montante da aresta em estudo do volume de controle $\Omega_{i, j}$, conforme Figura 2.9, de forma que o domínio de dependência do esquema numérico contenha o domínio físico, mantendo a estabilidade do método.

A avaliação da integral do fluxo sobre a área $A_{m}$ é realizada pelo uso de um polinômio aproximador para representar a distribuição do traçador em cada volume de controle $\Omega_{i}$. A ordem da discretização espacial depende da ordem da reconstrução da solução, sendo feita por meio dos polinômios aproximadores de graus 2 ou 4, enquanto que Miura (2007) usou somente polinômios de grau 1. O estêncil para $1^{\mathrm{a}}$ ou $2^{\mathrm{a}}$ ordens utiliza os primeiros vizinhos da malha icosaédrica e para $4^{\mathrm{a}}$ ordem são acrescentados os segundos vizinhos da Figura 2.8. A metodologia utilizada foi descrita na seção de formulação básica de fluxo na esfera com o sistema matricial descrita na seção 2.3.3. A construção do polinômio aproximador é obtida no plano tangente por meio da projeção radial e os coeficientes foram determinados por meio do método de mínimos quadrados (ver (Stuhne e Peltier, 1996)).

A solução da equação do transporte para as ordens desejadas envolve determinar o valor escalar 
do traçador $\phi_{e_{j}}$ dentro do paralelogramo com área $A_{m}$ relativo à aresta $e_{j}$, por meio da integração dos polinômios aproximadores sobre a área com base na direção do escoamento.

Segundo Skamarock e Menchaca (2010), o polinômio aproximador precisa satisfazer a restrição de que a integral de área de $\phi_{i}^{2}$, no volume de controle $\Omega_{i}$, seja a mesma quantidade do valor da solução média $\Omega_{i}$. A restrição pode ser escrita como

$$
\int_{\left|\Omega_{i}\right|} \phi_{i}^{2} d A=c_{0} \cdot\left|\Omega_{i}\right|
$$

onde, $c_{0}$ representa o valor da solução média avaliada no vértice de $\Omega_{i}$.

O polinômio aproximador $\phi_{i}^{2}$ de grau 2 precisou ser modificado, para satisfazer a restrição (2.15), sendo reescrito como

$$
\phi_{c}^{2}=c_{0}+c_{1} x+c_{2} y+c_{3} x^{2}+c_{4} x y+c_{5} y^{2}-\Delta q .
$$

Segundo Miura e Skamarock (2013), o termo $\Delta q$ é dado por

$$
\Delta q=\frac{1}{\left|\Omega_{i}\right|} \sum_{j=1}^{m}\left(\int_{T_{j}} \phi_{i}^{2} d A\right)-c_{0},
$$

onde, $m$ representa o total de arestas e $T_{j}$ os triângulos que formam o volumes de controle $\Omega_{i}$. A integral da equação (2.17) é avaliada utilizando-se quadratura gaussiana em triângulos. Importante ressaltar que o termo $\Delta q$ é atualizado em cada passo de tempo para que a integral do polinômio aproximador $\phi_{c}^{2}$, aplicado no paralelogramo com base na direção upwind, seja igual ao valor escalar no volume de controle $\Omega_{i}$.

O novo polinômio aproximador corrigido $\phi_{c}^{2}$ é denotado pelo subíndice "c". Essa modificação reduziu o erro de fase e a precisão foi melhorada, segundo Miura e Skamarock (2013).

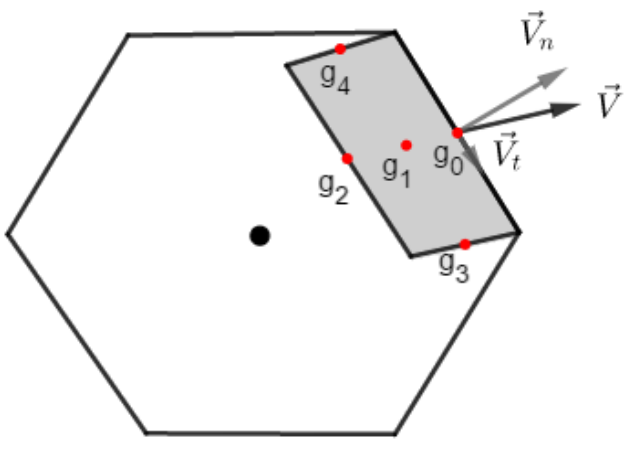

Figura 2.10: Pontos de Gauss utilizados para reconstrução de $2^{a}$ ordem dentro do paralelogramo.

O procedimento para avaliar o fluxo do método de "área varrida", por meio do polinômio aproximador $\phi_{c}^{2}$ de grau 2 sobre a área do paralelogramo $A_{m}$, está ilustrado na Figura 2.10, para a aresta selecionada no volume de controle $\Omega_{0}$, com os respectivos volumes de controle vizinhos. $\mathrm{O}$ ponto $g_{0}$ representa o ponto médio da aresta com extremidades $T_{1}$ e $T_{2}$. Os pontos $g_{1}, g_{2}, g_{3}$ e $g_{4}$ são determinados utilizando-se $g_{0}$ e as componentes $\vec{V}_{n}$ e $\vec{V}_{t}$, representam a componente normal e tangencial do vetor velocidade $\vec{V}$, ao longo da aresta $e$. Os pontos $g_{i}$ com $i=1, . ., 4$ são determinados por $g_{0}=\frac{T_{1}+T_{2}}{\left|T_{1}+T_{2}\right|}, g_{1}=g_{0}-\frac{1}{2} V_{e} \Delta t, g_{2}=g_{0}-V_{e} \Delta t, g_{3}=T_{1}-\frac{1}{2} V_{e} \Delta t$ e $g_{4}=T_{2}-\frac{1}{2} V_{e} \Delta t$. Os termos $g_{i}=\left(x_{i}, y_{i}\right)$ são os pontos de Gauss cujas coordenadas estão no plano tangente, sendo representadas por $\left(x_{g_{0}}, y_{g_{0}}\right),\left(x_{g_{1}}, y_{g_{1}}\right),\left(x_{g_{2}}, y_{g_{2}}\right),\left(x_{g_{3}}, y_{g_{3}}\right),\left(x_{g_{4}}, y_{g_{4}}\right)$, respectivamente. O termo $V_{e}$ representa as velocidades tangenciais e normais em relação à aresta $e$.

$\mathrm{O}$ valor escalar do fluxo atravessando a aresta $e_{j}$, relativo à área do paralelogramo $A_{m}$, será 
estimado por

$$
\phi_{e_{j}}=\frac{1}{A_{m}} \int_{A_{m}} \phi_{c}^{2} d A=\frac{2 \phi_{c}^{2}\left(x_{g_{1}}, y_{g_{1}}\right)+\phi_{c}^{2}\left(x_{g_{2}}, y_{g_{2}}\right)+\phi_{c}^{2}\left(x_{g_{3}}, y_{g_{3}}\right)+\phi_{c}^{2}\left(x_{g_{4}}, y_{g_{4}}\right)+\phi_{c}^{2}\left(x_{g_{0}}, y_{g_{0}}\right)}{6} .
$$

O método FV-MEN utilizou o limitador FCT para garantir a monotonicidade e para o avanço temporal da solução numérica foi utilizado o esquema Euler explícito. Foram feitos testes envolvendo o transporte de um sino de cosseno e um cilindro cortado, utilizando-se campos vetoriais sem e com deformações com os esquemas de $1^{\mathrm{a}}, 2^{\mathrm{a}}$ e $4^{\mathrm{a}}$ ordem. O esquema de $4^{\mathrm{a}}$ ordem é muito caro devido à necessidade de um estêncil maior para a reconstrução do polinômio aproximador e requer mais pontos para aplicar quadratura gaussiana. Nesse contexto, os pesquisadores observaram que os resultados não foram melhores que o esquema de $2^{\text {a }}$ ordem e, por isso, recomendam o uso da reconstrução de $2^{\mathrm{a}}$ ordem. Os resultados serão comparados com os resultados do método proposto neste trabalho.

\subsection{Método de Skamarock e Gassmann, 2011 (FV-GAS)}

No trabalho de Skamarock e Gassmann (2011), foi ampliada a metodologia de alta ordem aplicada em malhas ortogonais retangulares, desenvolvida por Hundsdorfer et al. (1995), para as malhas icosaédricas com otimização SCVT. Esse método será denotado por FV-GAS e o cálculo do fluxo dado na equação (2.8) é aproximado da seguinte forma

$$
\frac{1}{\left|\Omega_{i}\right|} \sum_{j=1}^{m} \int_{e_{j}}(\vec{V} \phi)_{e_{j}} \cdot \vec{n}_{e_{j}} d l \approx \frac{1}{\left|\Omega_{i}\right|} \sum_{j=1}^{m}\left(\vec{V}_{e_{j}} \cdot \vec{n}_{e_{j}}\right) \phi_{e_{j}} l_{e_{j}} .
$$

Denotando $u_{e_{j}}=\vec{V}_{e_{j}} \cdot \vec{n}_{e_{j}}$ a velocidade normal à aresta $e_{j}$, então o termo $\phi_{e_{j}} u_{e_{j}}$ representa o fluxo atravessando a aresta $e_{j}$. O cálculo do fluxo com $2^{\text {a }}$ ordem de precisão é dado por

$$
\phi_{e_{j}}=\frac{1}{2}\left(\phi_{i}^{2}+\phi_{i, j}^{2}\right),
$$

onde, $\phi_{i}^{2}$ e $\phi_{i, j}^{2}$ representam os valores dos polinômios aproximadores de grau 2 avaliados nos vértices dos volumes de controle $\Omega_{i}$ e $\Omega_{i, j}$, respectivamente. O termo $\phi_{i, j}^{2}$ representa o polinômio aproximador vizinho à aresta $e_{j}$ do volume de controle $\Omega_{i}$. O índice $j$ também representa o número de primeiros vizinhos de $\Omega_{i}$.

Por meio da expansão em série de Taylor da equação (2.20), o termo para o cálculo do fluxo em cada aresta com $3^{\mathrm{a}}$ e $4^{\mathrm{a}}$ ordens de precisão será dado por

$$
\phi_{e_{j}}=\frac{1}{2}\left(\phi_{i}^{2}+\phi_{i, j}^{2}\right)-\frac{1}{12}\left(\delta_{x}^{2} \phi_{i}^{2}+\delta_{x}^{2} \phi_{i, j}^{2}\right)+\operatorname{sign}\left(u_{e_{j}}\right) \frac{\beta}{12}\left(\delta_{x}^{2} \phi_{i}^{2}+\delta_{x}^{2} \phi_{i, j}^{2}\right),
$$

onde, o coeficiente $\beta=1$ fornece o fluxo de $3^{\text {a }}$ ordem upwind - biased e em $\beta=0$ tem-se um fluxo de $4^{\mathrm{a}}$ ordem centrado. O termo $\delta_{x}^{2} \phi_{i}^{2}=\phi_{i+1}^{2}-2 \phi_{i}^{2}+\phi_{i-1}^{2}$ e o $\operatorname{sinal} \operatorname{sign}\left(u_{e_{j}}\right)$ é positivo para a velocidade $u_{e_{j}}$, indicando que o fluxo tem a direção do volume de controle $\Omega_{i}$ para o volume de controle $\Omega_{i, j}$, sendo aplicados diretamente em malhas ortogonais retangulares (Hundsdorfer et al., 1995; Wicker e Skamarock, 2002).

O objetivo do trabalho de Skamarock e Gassmann (2011) foi obter o valor escalar $\phi_{e_{j}}$ em alta ordem nas malhas icosaédricas. Por isso foi necessário redefinir $\delta_{x}^{2} \phi_{i}^{2}=\Delta x_{e_{j}}^{2} \frac{\partial^{2} \phi_{i}^{2}}{\partial x^{2}}$ para corrigir a aproximação da segunda derivada na malha esférica. Dado o polinômio aproximador $\phi_{i}^{2}$, então $\frac{\partial^{2} \phi_{i}}{\partial x^{2}}=2 c_{3}$ e será aplicada na direção normal da aresta $e_{j}$, multiplicada por $\Delta x_{e_{j}}$, que representa a distância geodésica entre os centros de massa dos volumes $\Omega_{i}$ e $\Omega_{i, j}$.

Para que o fluxo multidimensional seja aplicado, utiliza-se o conceito unidimensional para as 
malhas icosaédricas, ou seja, para cada aresta é avaliado o fluxo na direção unidimensional que conecta os vértices do volume de controle $\Omega_{i}$ com seu respectivo vizinho $\Omega_{i, j}$, associado à aresta $e_{j}$. Depois, soma-se o fluxo em todas as arestas do volume de controle $\Omega_{i}$ e divide-se pela área geodésica $\left|\Omega_{i}\right|$ para completar a aproximação do operador espacial e obter a média da solução. Porém, os cálculos em alta ordem, utilizados em malhas regulares, são avaliados nos pontos médios das arestas $e_{j}$, o que não ocorre nas malhas com otimização SCVT, conforme ilustrado na Figura (2.11).

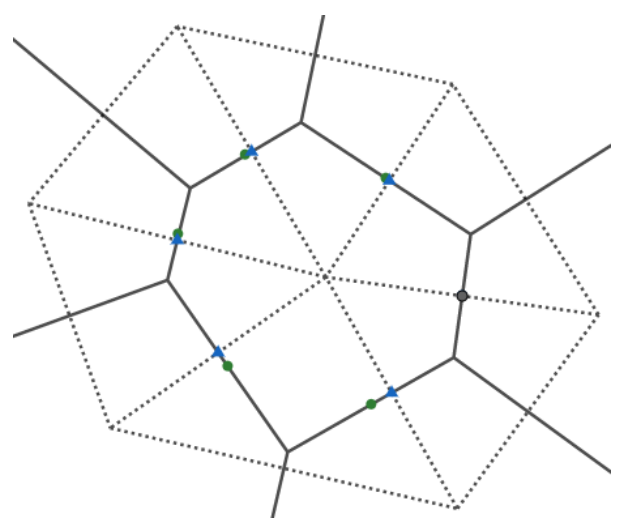

Figura 2.11: Pontos médios de arestas da malha de Delaunay (destacados em triângulos azuis) e pontos médios das arestas das células de Voronoi (destacados com círculos verdes).

Nota-se que existe um erro associado ao se utilizar esses termos, pois, de fato o fluxo não está sendo avaliado nos pontos médios, cujos termos foram estabelecidos e, devido ao espaçamento não uniforme da malha icosaédrica, todos os termos nominalmente de $2^{\mathrm{a}}, 3^{\mathrm{a}}$ e $4^{\mathrm{a}}$ ordens são formalmente apenas de $1^{\mathrm{a}}$ ordem de precisão, conforme demonstrado em Skamarock e Gassmann (2011). Embora a análise teórica sugira que tais termos de alta ordem são formalmente de primeira ordem em malha irregular, eles são mais precisos que os métodos de $2^{\text {a }}$ ordem e, por esse motivo, têm sido estudados na literatura (Zhang, 2018).

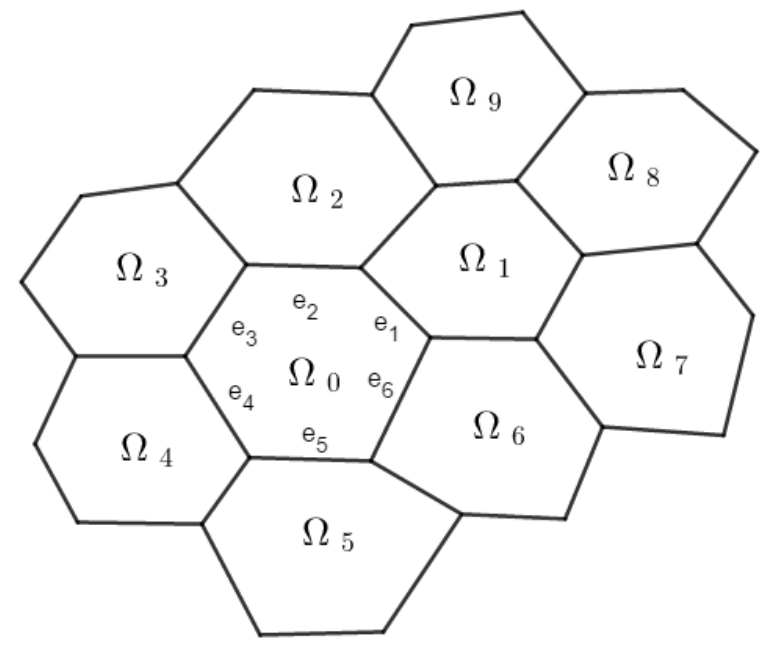

Figura 2.12: Volume de controle $\Omega_{0}$ em uma malha icosaédrica.

Para calcular o fluxo total no volume de controle $\Omega_{0}$ da Figura (2.12) é necessário aplicar a equação (2.21) em cada aresta $e_{j}$. Como exemplo, para calcular o fluxo na aresta $e_{1}$, é necessária a construção dos polinômios aproximadores $\phi_{0}^{2}$ e $\phi_{1}^{2}$ e avaliar suas respectivas segundas derivadas. Dessa forma, os valores dos volumes de controle 0 a 6 serão utilizados para determinar o polinômio aproximador $\phi_{0}^{2}$ de grau 2 do volume de controle $\Omega_{0}$ e os valores 0 a 2 e de 6 a 9 serão utilizados para se obter o polinômio aproximador $\phi_{1}^{2}$ de grau 2 no volume de controle $\Omega_{1}$. Os valores $\phi_{0}$ e $\phi_{1}$ representam o valor escalar da condição inicial aplicada nos vértices dos volumes de controle. 
Assim, são determinados dois sistemas matriciais $P \cdot c=s$ em planos tangentes distintos, por meio da projeção radial para os volumes de controle $\Omega_{0}$ e $\Omega_{1}$, respectivamente. Note que $P$ é do tipo $m \times n$, onde $m$ representa os primeiros vizinhos do volume de controle em estudo e $n$ representa o número de coeficientes do polinômio da equação (2.24). O sistema $P \cdot c=s$ será resolvido pelo método dos mínimos quadrados. No método FV-GAS, utiliza-se o esquema Runge-Kutta de três estágios para cada intervalo de tempo $\Delta t$ e o limitador monotônico descrito em Zalesak (1979) para garantir a monotonicidade. Os esquemas de $2^{\mathrm{a}}, 3^{\mathrm{a}}$ e $4^{\mathrm{a}}$ ordens foram aplicados no transporte de um sino de cosseno e um cilindro cortado com campo vetorial sem e com deformação e no transporte de duas gaussianas em um campo vetorial com deformação. Em todos os testes numéricos, o esquema de $3^{\text {a }}$ ordem obteve os melhores resultados em termos de precisão e taxa de convergência. Os resultados serão comparados e comentados com os resultados deste trabalho.

\subsection{Método de Zhang, 2018 (FV-ZHA)}

Os termos para avaliar o fluxo em $5^{\mathrm{a}}$ e $6^{\mathrm{a}}$ ordens foram abordados no trabalho de Zhang (2018) denominado de FV-ZHA, com aplicações em modelos de águas rasas. Esses termos foram obtidos das extensões de $3^{\mathrm{a}}$ e $4^{\mathrm{a}}$ ordens para malhas icosaédricas do trabalho de Skamarock e Gassmann (2011). O fluxo no método FV-ZHA é discretizado da forma

$$
\frac{1}{\left|\Omega_{i}\right|} \sum_{j=1}^{m} \int_{e_{j}}(\vec{V} \phi)_{e_{j}} \cdot \vec{n}_{e_{j}} d l \approx \frac{1}{\left|\Omega_{i}\right|} \sum_{j=1}^{n}\left(\vec{V}_{e_{j}} \cdot \vec{n}_{e_{j}}\right) \phi_{e_{j}} l_{e_{j}} .
$$

O termo $\phi_{e_{j}}$ para $5^{\mathrm{a}}$ e $6^{\mathrm{a}}$ ordens de precisão é dado por

$$
\phi_{e_{j}}=\frac{1}{2}\left(\phi_{i}^{2}+\phi_{i, j}^{2}\right)-\frac{1}{12}\left(\delta_{x}^{2} \phi_{i}^{2}+\delta_{x}^{2} \phi_{i, j}^{2}\right)+\frac{1}{60}\left(\delta_{x}^{4} \phi_{i}^{4}+\delta_{x}^{4} \phi_{i, j}^{4}\right)-\operatorname{sign}\left(u_{e_{j}}\right) \frac{\beta}{60}\left(\delta_{x}^{4} \phi_{i}^{4}-\delta_{x}^{4} \phi_{i, j}^{4}\right)
$$

onde, $\phi_{i}^{2}$ e $\phi_{i, j}^{2}$ representam os valores dos polinômios aproximadores associados à aresta $e_{j}, \delta_{x}^{2} \phi_{i}^{2}$ e $\delta_{x}^{4} \phi_{i}^{4}$ representam as derivadas parciais dos polinômios aproximadores, em ambos os casos os termos são avaliados nos vértices dos volumes de controle $\Omega_{i}$ e $\Omega_{i, j}$, respectivamente. O índice $j$ representa número de primeiros vizinhos de $\Omega_{i}$.

As aproximações das derivadas parciais de $2^{\mathrm{a}}$ e $4^{\mathrm{a}}$ ordens serão dadas por

$$
\begin{aligned}
\delta_{x}^{2} \phi_{i}^{2} & =\Delta x_{e_{j}}^{2} \frac{\partial^{2} \phi_{i}^{2}}{\partial x^{2}}=2 c_{3} \Delta x_{e_{j}}^{2}, \\
\delta_{x}^{4} \phi_{i}^{4} & =\Delta x_{e_{j}}^{4} \frac{\partial^{4} \phi_{i}^{4}}{\partial x^{4}}=4 c_{10} \Delta x_{e_{j}}^{4},
\end{aligned}
$$

onde, o coeficiente $\beta=1$ representa o termo upwind - biased de $5^{\mathrm{a}}$ ordem de precisão e $\beta=0 \mathrm{o}$ termo centrado de $6^{\mathrm{a}}$ ordem de precisão.

Observe que, além dos polinômios aproximadores de segunda ordem de Skamarock e Gassmann (2011), precisa-se de polinômios de $4^{\mathrm{a}}$ ordem. Dessa forma, os fluxos nas arestas do volume de controle dependem dos polinômios aproximadores $\phi_{i}^{2}, \phi_{i}^{4}, \phi_{i, j}^{2}, \phi_{i, j}^{4}$ e suas respectivas segundas e quartas derivadas, sendo avaliadas no centro dos volumes de controle em estudo. A distância entre os volumes de controle $\Omega_{i}$ e $\Omega_{i, j}$ é dada por $\Delta x_{e_{j}}$, que compartilham a aresta comum $e_{j}$. A construção do polinômio de grau 2 utiliza-se o estêncil com os primeiros vizinhos, e para se obter o polinômio de grau 4, precisa-se dos primeiros e também dos segundos vizinhos do volume de controle em estudo, para a construção do sistema matricial que será resolvido pelo método dos mínimos quadrados. Os estênceis foram obtidos pela projeção radial no plano tangente ao vértice do volume de controle.

O método FV-ZHA utilizou o limitador FCT, para garantir a monotonicidade e o esquema RK3, para a evolução temporal da equação do transporte. Os termos para avaliar o fluxo de $5^{\mathrm{a}}$ e $6^{\mathrm{a}}$ 
ordens para malhas uniformes, são formalmente de primeira ordem em malhas icosaédricas. Porém, sua precisão na prática supera a $2^{\mathrm{a}}$ ordem e, por isso, foi explorado no trabalho de Zhang (2018). Assim, os termos de $2^{\mathrm{a}}$ a $6^{\mathrm{a}}$ ordem foram aplicados no transporte de um sino de cosseno com campo vetorial sem deformação e no transporte de duas gaussianas com deformação.

Os pesquisadores perceberam que, ao aumentar a ordem nominal, obtiveram resultados com erros absolutos menores e convergência inferior à $3^{\mathrm{a}}$ ordem. Sem o limitador, os esquemas de ordem par produziram soluções mais oscilatórias e os esquemas de ordem ímpar soluções mais suaves. Observaram também que os esquemas de ordem par mostraram mais sensibilidade ao utilizar o limitador quando comparados com os esquemas de ordem ímpar. Assim, concluiram que o aumento da ordem nos esquemas avaliados fornece soluções mais precisas, mas não alteram a taxa de convergência e possuem um custo adicional de tempo computacional, devido ao aumento do estêncil dos polinômios aproximadores. Os resultados abordados aqui, serão comparados com o método de alta ordem proposto.

\subsection{Método de Subich, 2018 (FV-SUB)}

No trabalho de Subich (2018), os pesquisadores desenvolveram um método de alta ordem para ser aplicado nos núcleos dinâmicos de modelos atmosféricos globais, utilizando-se o método de volumes finitos, que será denominado de FV-SUB, na malha icosaédrica esférica. O cálculo do fluxo dado na equação (2.8), abordado no trabalho de Subich (2018), na sua versão discretizada será dado por

$$
\frac{1}{\left|\Omega_{i}\right|} \sum_{j=1}^{m} \int_{e_{j}}(\vec{V} \phi)_{e_{j}} \cdot \vec{n}_{e_{j}} d l \approx \frac{1}{\left|\Omega_{i}\right|} \sum_{j=1}^{m} \sum_{k=0}^{n}\left(\vec{V}_{e_{j}} \cdot \vec{n}_{e_{j}}\right) \phi_{e_{j, k}} l_{e_{j}},
$$

onde, $\phi_{e_{j, k}}=w_{k} \phi_{k}^{2}$ é a concentração da substância estimada no ponto médio da aresta $e_{j, k}, \phi_{k}^{2}$ são os polinômios aproximadores do estêncil centrado/upwind-biased aplicados nas arestas $e_{j}, w_{k}$ representa os pesos de acordo com estêncil centrado/upwind-biased utilizado na reconstrução e $n$ representa o número de vizinhos do estêncil centrado/upwind-biased utilizado na reconstrução.

O valor escalar $\phi_{e_{j, k}}$ é dado por $\phi_{k} w_{k}$, onde $w_{k}$ são os pesos relativos aos polinômios $\phi_{k}$ obtidos por $w_{k}=\left[1, x_{k}, y_{k}, x_{k}^{2}, x_{k} y_{k}, y_{k}^{2}\right]^{T} \cdot P^{*}$, que são os monômios avaliados nos vértices do volume de controle $\Omega_{i}$ e multiplicados pela matriz pseudo-inversa, dada por $P^{*}=\left(P^{T} P\right)^{-1} P^{T}$, de acordo com o estêncil desejado conforme ilustrado na Figura 2.13 e os polinômios aproximadores $\phi_{k}$ são avaliados nos dois pontos de Gauss de cada aresta $e_{j}$, conforme Figura 2.14 e 2.15.
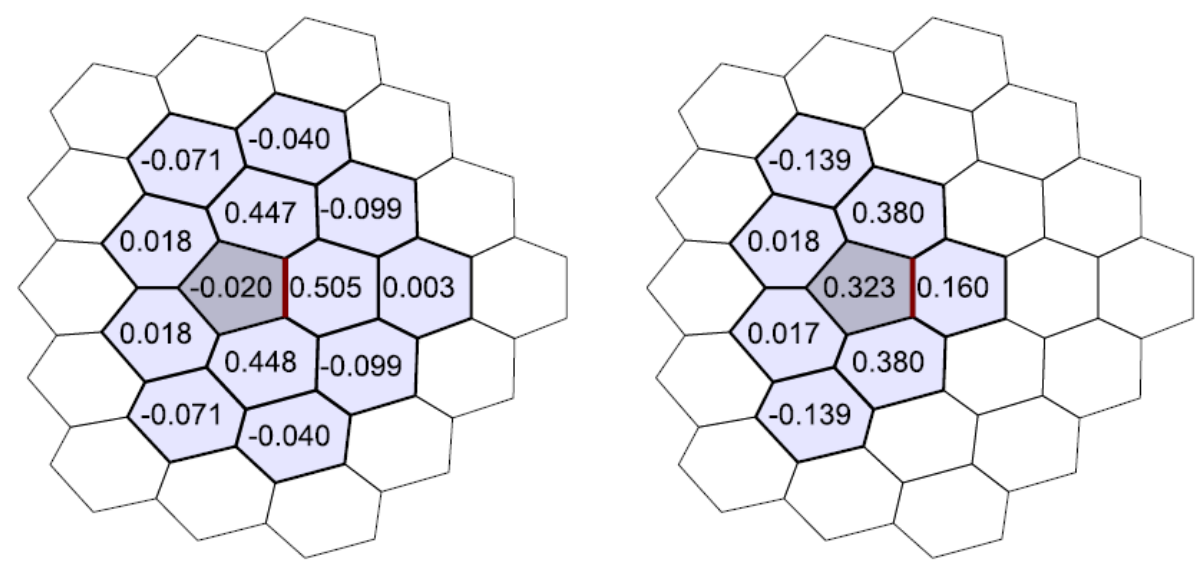

Figura 2.13: Reconstrução na aresta com os respectivos pesos, (Subich, 2018).

A aproximação utilizada nas integrais de contorno no trabalho de Subich (2018) será a quadratura gaussiana, pois fornece uma alta precisão com a utilização de poucos pontos de interpolação. Para conservar a massa, é feita uma expansão local no polinômio aproximador $\phi_{i}$ em termos de 
um conjunto de monômios, para que seja consistente com a média do volume de controle. Para reconstruir a solução média nos volumes de controle $\Omega_{i}$, o fluxo precisa ser avaliado nas arestas dos volumes de controle por meio de duas abordagens: estêncil centrado e estêncil upwind-biased.
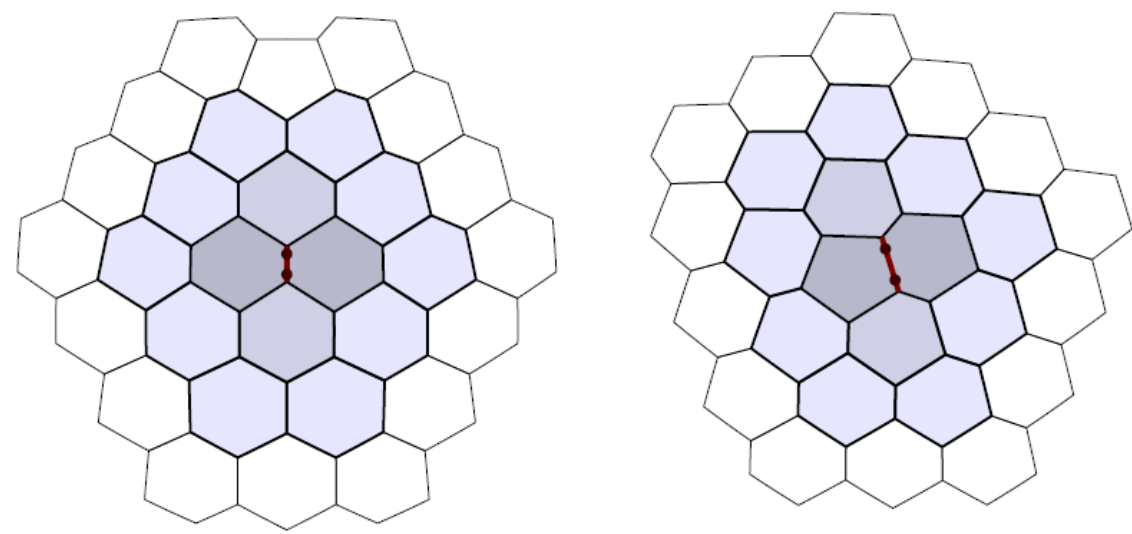

Figura 2.14: Reconstrução na aresta com base central, com pontos dois pontos de Gauss, (Subich, 2018).

O estêncil da Figura 2.14, ilustra o volume de controle hexagonal (à esquerda) e o volume de controle pentagonal (à direita), ambos avaliam o fluxo na aresta do volume de controle. $\mathrm{O}$ valor médio do volume de controle para o gradiente, divergente e rotacional é baseado nos valores médios dos volume de controle alvo e de cada um dos seus vizinhos diretamente adjacentes. Para a reconstrução em $4^{\mathrm{a}}$ ordem, utiliza-se os primeiros e segundos vizinhos, avaliados nos pontos de Gauss, em cada aresta do volume de controle $\Omega_{i}$. A maioria dos volumes de controle têm estêncil de 19 vizinhos. No caso do pentágono, terão 18 vizinhos, quantidade suficiente para determinar a reconstrução de $4^{\mathrm{a}}$ ordem.
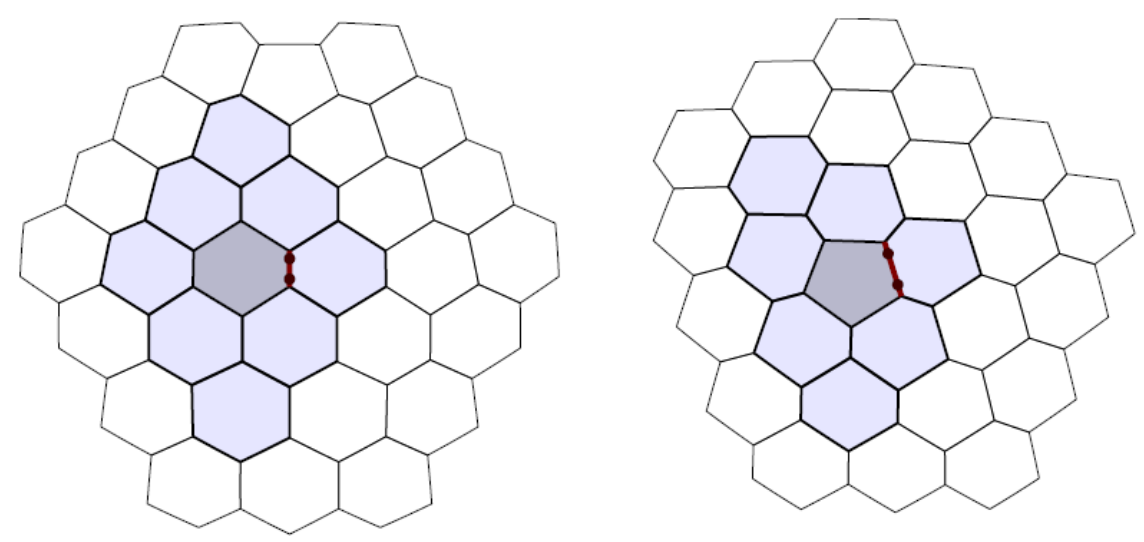

Figura 2.15: Reconstrução na aresta com upwind-biased, com pontos dois pontos de Gauss, (Subich, 2018).

O estêncil da Figura 2.15, ilustra o volume de controle hexagonal (à esquerda) e o volume de controle pentagonal (à direita), ambos avaliam o fluxo upwind-biased na aresta do volume de controle com base nos primeiros e segundos vizinhos para a $4^{\mathrm{a}}$ ordem. Para efetuar a integração, utiliza-se a projeção gnonômica da esfera para o plano tangente para determinar os polinômios aproximadores.

O método desenvolvido conserva a massa por construção para o modelo de águas rasas, mas não necessariamente as outras grandezas são preservadas. A simulação numérica envolve o transporte de um sino de cosseno e uma colina de gaussiana ao redor da Terra. A evolução temporal da solução foi feita pelo método de RK4. Durante os testes, Subich (2018) percebeu que as reconstruções que utilizam o estêncil centrado geram instabilidades na solução numérica, por isso, foi utilizado o estêncil upwind-biased para ter um método estável e quando utilizaram o upwind-biased em algumas 
regiões da malha com base no critério dos pesos que são atribuidos ao polinômios aproximadores, foi possível melhorar a taxa de convergência. Os resultados deste trabalho serão comparados com o método proposto.

\subsection{Comentários}

A revisão bibliográfica abordou as diferentes discretizações que os métodos de alta ordem utilizam para estimar o fluxo nas arestas dos volumes de controle. Além disso, foi possível notar outras características, conforme Tabela 2.2.

\begin{tabular}{|c|c|c|c|c|}
\hline & FV-MEN & FV-GAS & FV-ZHA & FV-SUB \\
\hline Ordem Espacial & $2^{\mathrm{a}}$ e $4^{\mathrm{a}}$ & $2^{\mathrm{a}}, 3^{\mathrm{a}}$ e $4^{\mathrm{a}}$ & $5^{\mathrm{a}}$ e $6^{\mathrm{a}}$ & $3^{\mathrm{a}}$ e $4^{\mathrm{a}}$ \\
\hline Malha Icosaédrica & HR95 & SCVT & SCVT & SCVT \\
\hline Cálculo do Fluxo & Integral de Área & Integral de Linha & Integral de Linha & Integral de Linha \\
\hline Estêncil Utilizado & Centrado & Centrado & Centrado & Centrado e Upwind \\
\hline Avanço Temporal & Upwind & RK3 & RK3 & RK4 \\
\hline
\end{tabular}

Tabela 2.2: Principais propriedades dos métodos de volumes finitos de alta ordem.

Todos os métodos utilizam malhas icosaédricas, mas com otimizações distintas para melhorar a solução e o esquema de avanço temporal com ordens de precisão diferentes. No entanto, percebe-se que todas as propostas de método de alta ordem para a superfície esférica possuem as seguintes etapas em comum:

- Condição inicial: é utilizado o valor de uma função teste avaliada em alguns pontos de malha. Em geral, avalia-se a função no vértice do volume de controle;

- Reconstrução da solução: por meio do método de mínimos quadrados serão determinados os coeficientes dos polinômios aproximadores para reconstruir a solução nos volumes de controle;

- Integração do fluxo: será avaliada pela integração dos polinômios aproximadores em alguns pontos dos volumes de controle;

- Evolução temporal: um esquema explícito de avanço no tempo é utilizado para avaliar a solução numérica até o tempo final ser atingido.

Todos os algoritmos descritos na Tabela 2.2 foram avaliados utilizando-se a equação de advecção com diferentes funções teste. No próximo capítulo, serão abordadas todas as etapas necessárias do método de alta ordem proposto para a esfera e, posteriormente, a etapa de validação e comparação dos resultados das funções teste com os trabalhos da literatura. 


\section{Capítulo 3}

\section{Método de alta ordem de Ollivier-Gooch transposto para esfera}

O objetivo deste trabalho é propor um novo método de alta ordem para esfera, a partir do método de volumes finitos de alta ordem de Ollivier-Gooch et al. (2009). A metodologia apresentada tem como base o trabalho de Barth (1993); Barth e Frederickson (1990) que utiliza a técnica da reconstrução k-exata para aproximar a solução, em cada volume de controle, por um polinômio de reconstrução obtido por meio de um estêncil fixo. Esse polinômio, por sua vez, é utilizado para avaliar os fluxos nas faces dos volumes de controle. O método de reconstrução de alta ordem desenvolvido por Ollivier-Gooch e colaboradores tem diversas aplicações em malhas bidimensionais não estruturadas (Hoshyari e Ollivier Gooch, 2018; Jalali et al., 2014; Nejat e Ollivier-Gooch, 2008; Ollivier-Gooch, 1997; Ollivier-Gooch e Van Altena, 2002).

Na USP, o grupo de pesquisa do Método de Reconstrução de Alta Ordem (MRAO), conduzido por Luis Carlos de Castro Santos, tem explorado aplicações do método proposto por Ollivier-Gooch. Entre os trabalhos, pode-se destacar um estudo na identificação de parâmetros em problemas de adveç̧ão-difusão combinando a técnica do operador adjunto e métodos de volumes finitos de alta ordem, por Santana (2007). A aplicação do MRAO mostrou ser eficaz no cálculo do problema primal e dual, demonstrando que a técnica é versátil na forma como é construída, pois a estrutura se preserva. Um estudo de um esquema numérico com reconstrução de mínimos quadrados de alta ordem em malhas não estruturadas para a formulação euleriana do transporte de partículas foi feito por Saito (2008), onde o MRAO mostrou-se eficaz no cálculo do transporte de gotículas, apresentando bons resultados na resolução de problemas com descontinuidade à medida que se aumentou a ordem do polinômio de reconstrução. O MRAO também foi aplicado no estudo de $p$-multigrid explícito para um método de volumes finitos de alta-ordem não estruturado, estudado por Casavilca (2016). Essa proposta possui uma estrutura mais simples em contraposição com o $p$ - multigrid para esquemas de diferença espectral, porque não precisa de operadores de restrição e prolongação para a comunicação entre diferentes níveis polinomiais. O MRAO foi mais eficiente que o método de volumes finitos de $4^{\mathrm{a}}$ ordem sem $p$-multigrid, isto é, os dois métodos oferecem a mesma precisão, mas o primeiro pode levar menos de $50 \%$ do tempo de CPU do segundo.

Por suas diversas aplicações e os bons resultados obtidos, optou-se por transportar essa técnica do MRAO, que tem diversas aplicações no plano para a superfície esférica, e explorar os benefícios que ela pode oferecer para fenômenos na superfície da Terra.

O método proposto, foi implementado na plataforma computacional desenvolvida na tese de doutorado de Peixoto (2013), denominada iModel. Esse código possui uma estrutura de geração de malhas icosaédricas, interpolações e, reconstruções vetoriais. Na tese foi abordado um estudo detalhado sobre malhas icosaédricas e as interferências da malha na ordem da discretização dos operadores divergente, rotacional e laplaciano. Foi proposto um modelo de transporte semi-lagrangiano em malhas icosaédricas com testes de deformações na distribuição do campo transportado, que mostraram a adequação da metodologia para uso em modelos atmosféricos globais.

Atualmente, a plataforma possui solver Multigrid e modelo de águas rasas. A plataforma foi 
desenvolvida para fins educacionais e de pesquisa, sendo distribuída sob os termos da Licença Pública Geral GNU, conforme publicada pela Free Software Foundation.

No método proposto para a superfície esférica, denominado de FV-OLG, foram utilizadas malhas icosaédricas. A abordagem teórica e as contribuições para se obter o novo método de alta ordem para superfície esférica serão descritas em detalhes neste capítulo.

\section{Método FV-OLG}

A malha utilizada pelo método de alta ordem FV-OLG é obtida a partir da malha primal, formada apenas por triângulos esféricos. A partir dessa malha, determinam-se os baricentros desses triângulos e os pontos médios de suas arestas e, depois, conectam-se esses pontos por segmentos geodésicos, formando uma malha dual (Diagrama de Donald), formada por volumes de controle esféricos diferentes dos volumes de controle apresentados nos trabalhos do capítulo 2. Essa estrutura tem sido utilizada por Ollivier-Gooch em malhas triangulares não estruturadas (Ollivier-Gooch et al., 2009), devido à adaptação em geometrias complexas com possibilidade de refinamento local, conforme ilustrado na Figura 3.1, e utilizado neste trabalho.

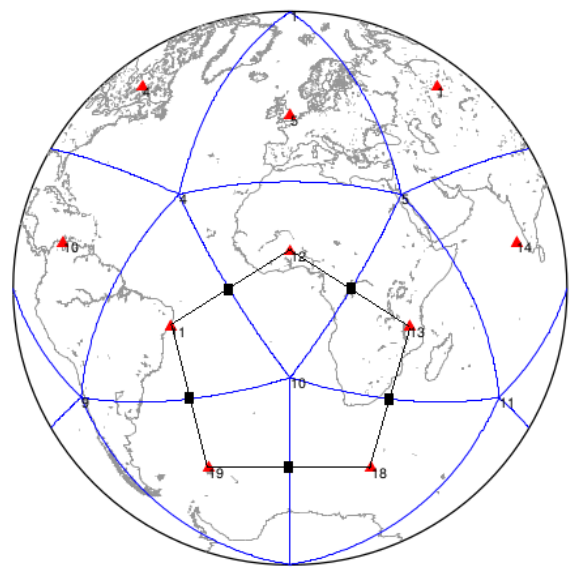

Figura 3.1: Volume de controle $\Omega_{i}$ utilizado no método FV-OLG.

O fluxo no volume de controle da Figura 3.1 será avaliado por meio da integral de linha aplicada ao polinômio de reconstrução (ou aproximador) $\phi_{i}^{p}$ de grau $p$ utilizando-se pontos e pesos de Gauss relativos a cada aresta $e_{j}$ de $\Omega_{i}$, conhecido o campo de velocidade $\vec{V}$. A quantidade de pontos e pesos de Gauss, para aplicar a quadratura gaussiana, depende do grau $p$ ou da ordem $p+1$ do polinômio de reconstrução, enquanto a escolha do polinômio depende da direção do fluxo em cada aresta de $\Omega_{i}$. Após avaliar o fluxo em todas as arestas, determina-se a média da solução e avança-se no tempo. Dessa forma, o fluxo no método FV-OLG é dado por

$$
\frac{1}{\left|\Omega_{i}\right|} \sum_{j=1}^{m} \int_{e_{j}}(\vec{V} \phi)_{e_{j}} \cdot \vec{n}_{e_{j}} d l \approx \frac{1}{\left|\Omega_{i}\right|} \sum_{j=1}^{m} \sum_{k=1}^{n}\left(\vec{V} e_{j, k} \cdot \vec{n}_{e_{j}}\right) \phi_{e_{j, k}} w_{e_{j, k}} l_{e_{j, k}}
$$

onde, $\phi_{e_{j, k}}$ é a concentração da substância avaliada nos pontos de Gauss $r_{j, k}$ na aresta $e_{j}, \vec{V}_{e_{j, k}}$ é o vetor velocidade avaliado nos pontos de Gauss $r_{j, k}$ na aresta $e_{j}, \vec{n}_{e_{j}}$ é o vetor unitário normal à aresta $e_{j}, l_{e_{j, k}}$ é o comprimento da aresta $e_{j}, w_{e_{j, k}}$ são os pesos de Gauss normalizados para aresta $e_{j},\left|\Omega_{i}\right|$ representa a área do volume de controle $\Omega_{i}, m$ número de arestas do volume de controle $\Omega_{i}$ e $n$ representa a quantidade de pontos de Gauss para que a integral de linha seja exata, caso o integrando seja um polinômio de grau $p$.

O fluxo numérico, associado ao polinômio de reconstrução de ordem $p+1$, será dado por

$$
F_{N U M i}^{p}(\bar{\phi})=\sum_{j=1}^{m} \sum_{k=1}^{n}\left(\vec{V}_{e_{j, k}} \cdot \vec{n}_{e_{j}}\right) \phi_{e_{j, k}} w_{e_{j, k}} l_{e_{j, k}},
$$


onde o argumento $\bar{\phi}$, representa o conjunto de todas as soluções médias aproximadas $\bar{\phi}_{i}$ e $\bar{\phi}_{i, j}$, referente ao volume de controle $\Omega_{i}$ e dos respectivos volumes de controle vizinhos $\Omega_{i, j}$, que foram obtidas pelos polinômios de reconstrução $\phi_{e_{j, k}}$ consideradas no estêncil, para definir o fluxo no volume de controle $\Omega_{i}$.

A forma compacta, aplicada em cada volume de controle $\Omega_{i}$, será dada por

$$
\frac{d \bar{\phi}_{i}}{d t}=-\frac{1}{\left|\Omega_{i}\right|} F_{N U M_{i}^{p}}(\bar{\phi})
$$

Será avaliada a ordem final do método FV-OLG, que consiste de diversas ordens dos erros associados à discretização do fluxo numérico, dados por

$$
\left\{\sum_{j=1}^{m}\left[\sum_{k=1}^{n}\left(\phi_{e_{j, k}}+O\left(h^{I}\right)+O\left(h^{P}\right)\right) \vec{V}_{e_{j, k}} \cdot \vec{n}_{j} w_{e_{j, k}}+O\left(h^{Q}\right)\right]\right\}_{i}+O\left(h^{D}\right) .
$$

onde,

$O\left(h^{I}\right)$ é a ordem da discretização do polinômio de reconstrução (Ollivier-Gooch et al., 2009), $O\left(h^{P}\right)$ é a ordem da discretização da esfera para o plano tangente (Lashley, 2002),

$O\left(h^{Q}\right)$ é a ordem da discretização da quadratura gaussiana (Ascher e Greif, 2011),

$O\left(h^{D}\right)$ é a ordem da discretização da solução média (Dunavant, 1985).

O segundo somatório da equação (3.4) avalia fluxo em cada aresta, por meio do valor do polinômio de reconstrução em cada ponto de Gauss, uma vez para $2^{\mathrm{a}}$ ordem e duas vezes para $3^{\mathrm{a}}$ e $4^{\mathrm{a}}$ ordens. De forma geral, calcula-se o somatório para todos os pontos de Gauss necessários para a integração ser exata para um polinômio de grau $p$ ou de ordem $p+1$. Assim, repetindo o processo $n$ vezes, temos

$$
\left\{\sum_{j=1}^{m}\left[\phi_{\text {aproximado }}+O\left(h^{I}\right)+O\left(h^{P}\right)+O\left(h^{Q}\right)\right]\right\}_{i}+O\left(h^{D}\right) .
$$

O somatório da equação (3.5) avalia o fluxo total no volume de controle $\Omega_{i}$, obtido pelo soma de todos os fluxos avaliados nas arestas. Isso corresponde ao número de primeiros vizinhos, ou seja, $m$ vezes, resultando em

$$
\phi_{\text {exato }}=\phi_{\text {aproximado }}+O\left(h^{I}\right)+O\left(h^{P}\right)+O\left(h^{Q}\right)+O\left(h^{D}\right) .
$$

Dessa forma, as fontes de erro apresentadas na equação (3.6) estão associadas à aproximação do fluxo numérico em cada volume de controle $\Omega_{i}$, localizados na malha icosaédrica. As ordens $O\left(h^{I}\right)$, $O\left(h^{P}\right), O\left(h^{Q}\right)$ e $O\left(h^{D}\right)$, relativas aos erros de discretização, serão avaliadas no próximo capítulo, que consiste na validação do método FV-OLG de alta ordem proposto para a esfera. A solução numérica da equação de advecção é obtida por meio das seguintes etapas:

\subsection{Condição inicial}

Seja $f(\lambda, \theta)$ uma função definida na esfera como condição inicial de um problema de transporte, no método FV-OLG a média da solução exata será determinada por meio da condição inicial utilizando-se quadratura gaussiana com precisão de $6^{\mathrm{a}}$ ordem para triângulos, desenvolvida por Dunavant (1985) e armazena-se a solução exata no vértice do volume de controle $\Omega_{i}$. O objetivo é isolar o efeito da ordem referente à média da solução exata, para não interferir na ordem resultante da discretização do fluxo numérico na esfera.

Neste trabalho, escolhemos utilizar volume de controle centrado no vértice (cell-vertex) em relação ao volume de controle centrado na célula (cell-centered), pois o número de vértices é menor que o número de triângulos. Para dar continuidade no desenvolvimento do método FV-OLG 
será necessário abordar em detalhes a construção dos volumes de controle no plano tangente à esfera.

\section{Plano tangente}

No método FV-OLG aplicado na esfera, o cálculo da média da solução exata, que será armazenada nos vértices dos volumes de controle e a estrutura dos polinômios de reconstrução, serão feitas no plano tangente à superfície esférica, passando pelo vértice do volume de controle $\Omega_{i}$. Neste trabalho, utilizou-se a projeção perpendicular, que será descrita em detalhes a seguir.

Para construir localmente o polinômio de reconstrução, associado a cada volume de controle $\Omega_{i}$ em malhas icosaédricas, será utilizado o plano tangente e a técnica de mínimos quadrados (Golub e Van Loan, 2012). Assim, dado um ponto $p$ na malha icosaédrica e seja $S_{n}=\left\{p_{1}, p_{2}, \ldots, p_{n}\right\}$ um conjunto de $n$ pontos de malha contidos no estêncil associado ao volume de controle $\Omega_{i}$. Sejam $f\left(p_{l}\right)=f_{l}, l=1, \ldots, n$ os valores reais associados aos pontos $p_{l}$ e seja $f(p)=f_{p}$ o valor definido em p. O método para construir o polinômio de reconstrução consiste em projetar ortogonalmente os pontos $S_{n}$ do estêncil no plano tangente à esfera, passando pelo ponto $p$.

Seguindo o trabalho de Peixoto (2013), a projeção consiste em rotacionar a esfera para que o ponto $p$ fique na posição do polo norte, ou seja, $(0,0,1)$. A projeção pode ser obtida considerando $z=1$. Para determinar o polinômio de reconstrução de $2^{\text {a }}$ ordem, deve-se utilizar o estêncil contendo os primeiros vizinhos de $\Omega_{i}$, e, para os polinômios de $3^{\mathrm{a}}$ e $4^{\mathrm{a}}$ ordens, o estêncil a ser utilizado é formado pelos primeiros e segundos vizinhos de $\Omega_{i}$.

Nesse processo, impõe-se que o polinômio de reconstrução $\tilde{f}$ seja interpolador em $p$, ou seja, $\tilde{f(p)}=f_{p}$. No sistema matricial, será dado mais peso para os polinômios mais próximos, conforme a sua distância euclidiana do ponto $p_{l}$ no plano em relação ao ponto $p$, ambos projetados no plano tangente, de forma que, os valores mais distantes devem influenciar menos na construção do polinômio desejado. O procedimento para fazer a projeção dos pontos da esfera para o plano tangente é dado pelas seguintes etapas:

\section{Rotação da esfera}

Vamos rotacionar a esfera, para que o ponto $p=(x, y, z)$, que representa o vértice de $\Omega_{i}$ na esfera fique na posição do polo norte, ou seja, $(0,0,1)$. Para isso, utiliza-se a matriz de rotação $U=R_{y} R_{x}$, composta das matrizes de rotação em relação ao eixo $\vec{x}$, representada por $R_{x}$ e em relação ao eixo $\vec{y}$, representada por $R_{y}$. As matrizes de rotação são dadas por

$$
\begin{aligned}
\mathbf{R}_{\mathbf{x}} & =\left[\begin{array}{ccc}
1 & 0 & 0 \\
0 & c_{x} & -s_{x} \\
0 & s_{x} & c_{x}
\end{array}\right], \\
\mathbf{R}_{\mathbf{y}} & =\left[\begin{array}{ccc}
c_{y} & 0 & -s_{y} \\
0 & 1 & 0 \\
s_{y} & 0 & c_{y}
\end{array}\right],
\end{aligned}
$$

onde,

$$
\begin{gathered}
s_{y}=x^{2}, \\
c_{y}=y^{2}+z^{2}, \\
s_{x}= \begin{cases}y / c_{y}, & \text { se } y \neq 0 ; \\
0, & \text { caso contrário. }\end{cases} \\
c_{x}= \begin{cases}z / c_{y}, & \text { se } c_{y} \neq 0 ; \\
1, & \text { caso contrário. }\end{cases}
\end{gathered}
$$




\section{Rotação dos vizinhos}

Por meio da matriz de rotação $U$ pode-se rotacionar os pontos vizinhos ao ponto $p$, representado pelo conjunto $S_{n}$, que ficarão próximo ao polo norte. Dessa forma, tem-se um novo conjunto de pontos $\tilde{S}_{n}=\left\{\tilde{p}_{1}, \tilde{p}_{2}, \ldots, \tilde{p}_{n}\right\} \operatorname{com} \tilde{p}_{l}=\left(x_{l}, y_{l}, z_{l}\right), l=1, \ldots, n$.

\section{Projeção ortogonal}

Posteriormente, o conjunto $\tilde{S}_{n}$ representa os pontos que foram projetados ortogonalmente no plano tangente ao polo norte. Pode-se considerar a coordenada $z=1$ ou não utilizá-la. Neste trabalho, as coordenadas $\left(x_{l}, y_{l}, z_{l}\right)$ serão denotadas no plano, simplesmente por $(x, y)$ e o polinômio de reconstrução por $\phi_{i}=\phi_{i}(x, y)$. No final, tem-se o ponto $p$ e seus respectivos pontos vizinhos definidos no plano para um sistema cartesiano bidimensional, conforme ilustrado na Figura 3.2. Observe que o vértice de $\Omega_{i}$ terá coordenadas $(0,0)$, conforme explicado em 1 .

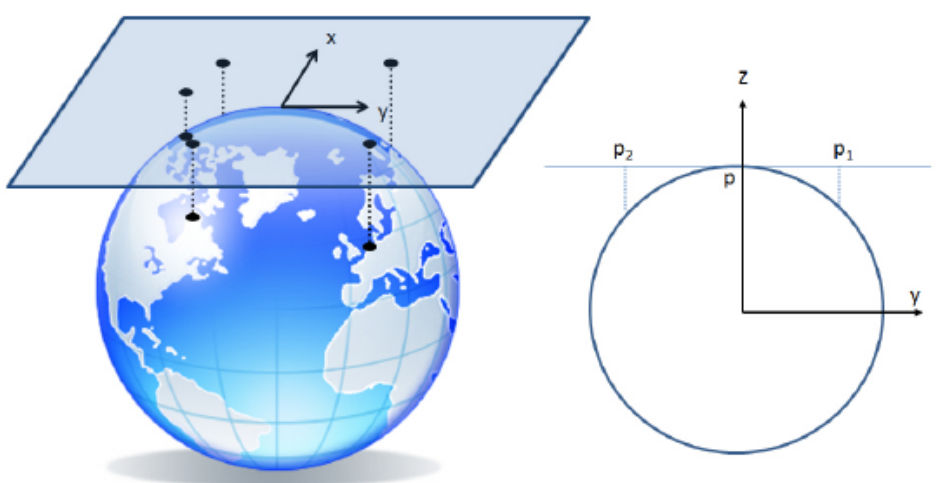

Figura 3.2: Projeção dos pontos vizinhos no plano tangente ao polo norte, (Peixoto, 2013).

A malha esférica utilizada neste trabalho é a dual de Donald, formada por Diagramas de Donald (MacDonald et al., 1968; Su et al., 2018). Para cada volume de controle $\Omega_{i}$, e seus respectivos vizinhos, deve-se fazer a projeção dos vértices no plano tangente e tem-se uma outra malha formada por triângulos planos. Os volumes de controle no plano são determinados pelos pontos médios dos lados dos triângulos planos, com seus respectivos baricentros. Após a construção do volume de controle $\Omega_{i}$, ilustrado na Figura 3.3, será utilizada a condição inicial $f(\lambda, \theta)$ avaliada nos dez triângulos. Para cada triângulo, utilizam-se sete pontos de Gauss, com os respectivos pesos. Posteriormente, divide-se pela área de $\Omega_{i}$, obtendo-se a média da solução exata com $6^{a}$ ordem de precisão (Dunavant, 1985; Ollivier-Gooch et al., 2009).

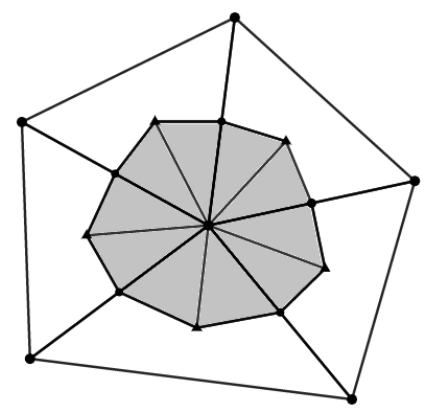

Figura 3.3: Volume de controle $\Omega_{i}$ no plano tangente. 
Assim, a média da solução exata para um volume de controle $\Omega_{i}$ é dada por

$$
\bar{\phi}_{i}=\frac{\sum_{j=1}^{m} A_{T_{j}}\left(\sum_{k=1}^{7} f\left(x_{g}^{k} x_{A}+y_{g}^{k} x_{B}+z_{g}^{k} x_{C}, x_{g}^{k} y_{A}+y_{g}^{k} y_{B}+z_{g}^{k} y_{C}\right) w_{g}^{k}\right)_{i}}{\left|\Omega_{i}\right|},
$$

onde $\left(x_{A}, y_{A}\right),\left(x_{B}, y_{B}\right)$ e $\left(x_{C}, y_{C}\right)$ são as coordenadas dos vértices dos triângulos da Figura 3.3, $x_{g}^{k}, y_{g}^{k}$ e $z_{g}^{k}$ são os parâmetros para determinar os pontos de Gauss a partir das coordenadas dos vértices do triângulos e $w_{g}^{k}$ são os pesos aplicados nos pontos de Gauss. O termo $m$ refere-se ao número de arestas do volume de controle $\Omega_{i}$, com sua respectiva área denotada por $\left|\Omega_{i}\right|$, e o termo $A_{T_{j}}$ refere-se a área de cada triângulo $T_{j}$ do volume de controle $\Omega_{i}$. Dessa forma, a média da solução exata (condição inicial) $\bar{\phi}_{i}$ será armazenada com $6^{\mathrm{a}}$ ordem de precisão no vértice de $\Omega_{i}$.

\subsection{Reconstrução da solução}

Com a média da condição inicial armazenada nos vértices dos volumes de controle na malha icosaédrica, o método de reconstrução de alta ordem, consiste em aproximar a solução $\bar{\phi}_{i}$ em cada volume de controle $\Omega_{i}$ por um polinômio baseado na série de Taylor da forma

$$
\begin{gathered}
\phi_{i}(x, y)=\left.\phi\right|_{i}+\left.\frac{\partial \phi}{\partial x}\right|_{i}\left(x-x_{i}\right)+\left.\frac{\partial \phi}{\partial y}\right|_{i}\left(y-y_{i}\right)+\left.\frac{1}{2} \frac{\partial^{2} \phi}{\partial x^{2}}\right|_{i}\left(x-x_{i}\right)^{2}+ \\
\left.\frac{\partial^{2} \phi}{\partial x \partial y}\right|_{i}\left(x-x_{i}\right)\left(y-y_{i}\right)+\left.\frac{1}{2} \frac{\partial^{2} \phi}{\partial y^{2}}\right|_{i}\left(y-y_{i}\right)^{2}+\left.\frac{1}{6} \frac{\partial^{3} \phi}{\partial x^{3}}\right|_{i}\left(x-x_{i}\right)^{3}+\ldots,
\end{gathered}
$$

onde $\phi_{i}$ é o valor da solução reconstruída em qualquer ponto $(x, y)$ dentro do volume $\Omega_{i},\left.\phi\right|_{i}$ é valor da $\phi_{i}$ aplicada no vértice $\left(x_{i}, y_{i}\right)$ do volume de controle em estudo $\Omega_{i}$ e $\left.\frac{\partial^{l+k} \phi_{i}}{\partial x^{l} \partial x^{k}}\right|_{i}$ são as derivadas aplicadas no vértice $\left(x_{i}, y_{i}\right)$ do volume de controle $\Omega_{i}$.

A precisão da solução depende do número de termos do polinômio de reconstrução obtido na equação (3.12). Por definição, um método $k$-exato reconstruirá de maneira exata a solução verdadeira, se ela for um polinômio de grau $k$. Quanto maior a quantidade de termos da série de Taylor no desenvolvimento do polinômio de reconstrução, maior será a ordem obtida da solução.

As derivadas parciais da equação (3.12), incluindo o termo $\left.\phi\right|_{i}$, representam os coeficientes do polinômio de reconstrução e são ajustados de modo que seja preservada a média da solução dentro do volume de controle $\Omega_{i}$. Após o cálculo dos coeficientes, o polinômio de reconstrução pode ser utilizado para calcular aproximações em qualquer ponto dentro do volume de controle em estudo, assim como suas respectivas derivadas.

Os coeficientes dos polinômios de reconstrução $\phi_{i}(x, y)$ serão obtidos a partir da estimativa da solução $\bar{\phi}_{i}$ do volume de controle $\Omega_{i}$ e das estimativas das médias $\bar{\phi}_{i, j}$ dos volumes de controles vizinhos $\Omega_{i, j}$. Para isso, o polinômio $\phi_{i}(x, y)$ deve satisfazer a propriedade da conservação da média (Barth e Frederickson, 1990), por meio da expressão

$$
\frac{1}{\left|\Omega_{i}\right|} \int_{\Omega_{i}} \phi_{i} d \Omega_{i}=\bar{\phi}_{i}
$$

ou seja, impõe-se que a integral de $\phi_{i}$ no volume de controle $\Omega_{i}$, dividido pela área $\left|\Omega_{i}\right|$ seja igual ao valor da solução média $\bar{\phi}_{i}$.

Substituindo a expansão da série de Taylor representada pela equação (3.12) em (3.13), tem-se

$$
\frac{1}{\left|\Omega_{i}\right|} \int_{\Omega_{i}}\left[\left.\phi\right|_{i}+\left.\frac{\partial \phi}{\partial x}\right|_{i}\left(x-x_{i}\right)+\left.\frac{\partial \phi}{\partial y}\right|_{i}\left(y-y_{i}\right)+\left.\frac{1}{2} \frac{\partial^{2} \phi}{\partial x^{2}}\right|_{i}\left(x-x_{i}\right)^{2}+\cdots\right] d \Omega_{i}=\bar{\phi}_{i} \text {. }
$$

Aplicando a integral em cada um dos termos da equação (3.14) e reescrevendo na forma compacta 


$$
\left.\phi\right|_{i}+\left.\frac{\partial \phi}{\partial x}\right|_{i} \overline{x_{i}}+\left.\frac{\partial \phi}{\partial y}\right|_{i} \overline{y_{i}}+\left.\frac{1}{2} \frac{\partial^{2} \phi}{\partial x^{2}}\right|_{i} \overline{x_{i}^{2}}+\left.\frac{\partial^{2} \phi}{\partial x \partial y}\right|_{i} \overline{x_{i} y_{i}}+\left.\frac{1}{2} \frac{\partial^{2} \phi}{\partial y^{2}}\right|_{i} \overline{y_{i}^{2}}+\cdots=\bar{\phi}_{i},
$$

onde,

$$
\overline{x_{i}^{m} y_{i}^{n}}=\frac{1}{\left|\Omega_{i}\right|} \int_{\Omega_{i}}\left(x-x_{i}\right)^{m}\left(y-y_{i}\right)^{n} d \Omega .
$$

Os termos (3.16) que aparecem na equação (3.15) são os momentos do volume de controle $\Omega_{i}$, ou seja, os coeficientes do polinômio de reconstrução devem satisfazer a propriedade de conservação da média, dada na equação (3.15).

Aplicando o Teorema da Divergência na equação (3.16) converte-se a integral de área na integral de linha, resultando em

$$
\overline{x_{i}^{m} y_{i}^{n}}=\frac{1}{(m+1)\left|\Omega_{i}\right|} \int_{\partial \Omega_{i}}\left(x-x_{i}\right)^{m+1}\left(y-y_{i}\right)^{n} \vec{n} d \partial \Omega,
$$

e, na forma discretizada, é dada por

$$
\overline{x_{i}^{m} y_{i}^{n}}=\frac{1}{(m+1)\left|\Omega_{i}\right|} \sum_{i=1}^{p} \sum_{j=1}^{q}\left[\left(x_{g}-x_{i}\right)^{m+1}\left(y_{g}-y_{i}\right)^{n} \vec{n} w_{g}\right]_{j},
$$

onde, $p$ é o grau do polinômio de reconstrução, ou seja, de ordem $p+1, q$ é o número de pontos de Gauss, $\left(x_{g}, y_{g}\right)$ são os pontos de Gauss com os respectivos pesos $w_{g}$, para que a integral de linha seja exata, caso o integrando seja um polinômio de grau $\mathrm{p},\left(x_{i}, y_{i}\right)$ é o vértice relativo ao volume de controle $\Omega_{i}$ e $\vec{n}$ é o vetor unitário exterior à fronteira de $\Omega_{i}$.

Para determinar os coeficientes do polinômio de reconstrução, Ollivier-Gooch e Van Altena (2002) procuram minimizar o erro na previsão do valor médio da função para volumes de controle no estêncil $\left\{\Omega_{i, j}\right\}_{i}$. O número mínimo de volumes de controle vizinhos no estêncil de reconstrução é igual ao número de termos derivados a serem aproximados, conforme Tabela 3.1.

\begin{tabular}{|c|c|c|}
\hline Ordem & Número de Coeficientes & Número de Vizinhos \\
\hline 2 & 3 & 3 \\
\hline 3 & 6 & 8 \\
\hline 4 & 10 & 14 \\
\hline
\end{tabular}

Tabela 3.1: Número de vizinhos em função da ordem desejada.

Em seu trabalho, Ollivier-Gooch e Van Altena (2002) optaram em exceder esse mínimo para dar alguma liberdade para a reconstrução de mínimos quadrados, melhorando a robustez do método de reconstrução de alta ordem. Os volumes de controle são adicionados ao estêncil de reconstrução com base em sua proximidade topológica com o volume de controle de reconstrução, ou seja, utilizam-se os primeiros vizinhos para o método de $2^{\mathrm{a}}$ ordem e os primeiros e segundos vizinhos para o método de $3^{\mathrm{a}}$ e $4^{\mathrm{a}}$ ordens. Todos os vizinhos de uma determinada vizinhança são adicionados de uma só vez, conforme Figura 2.8.

Além da conservação da média, o polinômio de reconstrução $\phi_{i}(x, y)$ deve-se minimizar o erro na predição do valor médio de $\bar{\phi}_{i, j}$, para o volume de controle $\Omega_{i, j}$, ou seja, considere a seguinte aproximação

$$
\frac{1}{\left|\Omega_{i, j}\right|} \int_{\Omega_{i, j}} \phi_{i} d \Omega_{i, j} \approx \overline{\phi_{i, j}}
$$

Substituindo a equação (3.12) em (3.19), temos

$$
\frac{1}{\left|\Omega_{i, j}\right|} \int_{\Omega_{i, j}}\left[\left.\phi\right|_{i}+\left.\frac{\partial \phi}{\partial x}\right|_{i}\left(x-x_{i}\right)+\left.\frac{\partial \phi}{\partial y}\right|_{i}\left(y-y_{i}\right)+\left.\frac{1}{2} \frac{\partial^{2} \phi}{\partial x^{2}}\right|_{i}\left(x-x_{i}\right)^{2}+\cdots\right] d \Omega_{i}=\overline{\phi_{i, j}} .
$$


Para evitar o cálculo do momento em cada volume de controle $\left\{\Omega_{i, j}\right\}$ sobre $\Omega_{i}$, substitui-se $\left(x-x_{i}\right)$ por $\left(x-x_{j}\right)+\left(x_{j}-x_{i}\right)$ e $\left(y-y_{i}\right)$ por $\left(y-y_{j}\right)+\left(y_{j}-y_{i}\right)$, respectivamente. Aplicando a integral em cada um dos termos da equação (3.20) e reescrevendo na forma compacta

$$
\left.\phi\right|_{i}+\left.\frac{\partial \phi}{\partial x}\right|_{i} \widehat{x_{i, j}}+\left.\frac{\partial \phi}{\partial y}\right|_{i} \widehat{y_{i, j}}+\left.\frac{1}{2} \frac{\partial^{2} \phi}{\partial x^{2}}\right|_{i} \widehat{x_{i, j}^{2}}+\left.\frac{\partial^{2} \phi}{\partial x \partial y}\right|_{i} \widehat{x y_{i, j}}+\left.\frac{1}{2} \frac{\partial^{2} \phi}{\partial y^{2}}\right|_{i} \widehat{y_{i, j}^{2}}+\cdots=\overline{\phi_{i, j}},
$$

onde,

$$
{\widehat{x^{m} y^{n}}}_{i, j}=\frac{1}{\left|\Omega_{i, j}\right|} \int_{\Omega_{i, j}}\left(\left(x-x_{j}\right)+\left(x_{j}-x_{i}\right)\right)^{m}\left(\left(y-y_{j}\right)+\left(y_{j}-y_{i}\right)\right)^{n} d \Omega .
$$

A equação 3.22 na forma discretizada é dada por

$$
{\widehat{x^{m} y^{n}}}_{i, j}=\sum_{k=0}^{n} \sum_{l=0}^{m}\left(\begin{array}{c}
n \\
k
\end{array}\right)\left(\begin{array}{c}
m \\
l
\end{array}\right)\left(x_{j}-x_{i}\right)^{l}\left(y_{j}-y_{i}\right)^{k}\left(\overline{x^{m-l} y^{n-k}}\right)_{j} .
$$

onde,

$$
\left(\overline{x^{m-l} y^{n-k}}\right)_{j}=\frac{1}{(m-l+1)\left|\Omega_{i, j}\right|} \int_{\Omega_{i, j}}\left(x-x_{j}\right)^{m-l}\left(y-y_{j}\right)^{n-k} d \Omega .
$$

Os termos (3.22) que aparecem na equação (3.21) são os termos geométricos (momentos dos volumes de controle vizinhos). Para calcular esses termos, utiliza-se o mesmo procedimento que foi aplicado na equação (3.16) do momento.

Utilizando-se a equação (3.18) dos momentos e a equação (3.23) dos termos geométricos, relativas ao plano tangente à esfera, passando pelo vértice do volume de controle $\Omega_{i}$, constrói-se um sistema linear sobredeterminado $P \cdot c=s$, descrito na equação (3.25). Os coeficientes $c_{i}$ do polinômio de reconstrução, relativo ao volume de controle $\Omega_{i}$, obtidos por meio da série de Taylor serão renomeados por: $c_{0}=\left.\phi\right|_{i}, c_{1}=\left.\frac{\partial \phi}{\partial x}\right|_{i}, c_{2}=\left.\frac{\partial \phi}{\partial y}\right|_{i}$, e assim sucessivamente. Para resolver o sistema matricial da equação (3.25), utiliza-se o método de mínimos quadrados (MMQ), cuja solução será dada pelos coeficientes do polinômio de reconstrução do volume de controle $\Omega_{i}$.

$$
\left[\begin{array}{ccccccc}
1 & \bar{x}_{i} & \bar{y}_{i} & \overline{x_{i}^{2}} & \overline{x y}_{i} & \overline{y_{i}^{2}} & \cdots \\
w_{i 1} & w_{i 1} \widehat{x}_{i 1} & w_{i 1} \widehat{y}_{i 1} & w_{i 1} \widehat{x}_{i 1}^{2} & w_{i 1} \widehat{x y}_{i 1} & w_{i 1} \widehat{y}_{i 1}^{2} & \cdots \\
w_{i 2} & w_{i 2} \widehat{x}_{i 2} & w_{i 2} \widehat{y}_{i 2} & w_{i 2} x_{i 2}^{2} & w_{i 2} \widehat{x y}_{i 2} & w_{i 2} \widehat{y}_{i 2}^{2} & \cdots \\
w_{i 3} & w_{i 3} \widehat{x}_{i 3} & w_{i 3} \widehat{y}_{i 3} & w_{i 3} x_{i 3}^{2} & w_{i 3} \widehat{x y}_{i 3} & w_{i 3} \widehat{y}_{i 3}^{2} & \cdots \\
\vdots & \vdots & \vdots & \vdots & \vdots & \vdots & \ddots \\
w_{i N} & w_{i N} \widehat{x}_{i N} & w_{i N} \widehat{y}_{i N} & w_{i N} \widehat{x_{i N}^{2}} & w_{i N} \widehat{x y}_{i N} & w_{i N} \widehat{y_{i N}^{2}} & \cdots
\end{array}\right]\left[\begin{array}{c}
c_{0} \\
c_{1} \\
c_{2} \\
c_{3} \\
\vdots
\end{array}\right]=\left[\begin{array}{c}
\bar{\phi}_{i} \\
w_{i 1} \bar{\phi}_{1} \\
w_{i 2} \bar{\phi}_{2} \\
w_{i 3} \bar{\phi}_{3} \\
\\
\vdots \\
w_{i N} \bar{\phi}_{i N}
\end{array}\right]
$$

onde $w_{i j}=\frac{1}{\left|\vec{x}_{i}-\vec{x}_{i, j}\right|}$ e $N$ é o número de vizinhos ao volume de controle $\Omega_{i}$. Note-se que $\left|\vec{x}_{i}-\vec{x}_{i, j}\right|$ é a distância euclidiana entre os vértices do volumes de controle $\Omega_{i}$ com seus respectivos vizinhos $\Omega_{i, j}$ no plano tangente. Os pesos $w_{i j}$, definidos no trabalho de Barth (1993), são ponderados, de tal forma que, quanto mais distante um volume de controle $\Omega_{i, j}$ estiver de $\Omega_{i}$, menos ele deve influenciar na reconstrução da solução do volume de controle em estudo.

O número $N$ de volumes de controle vizinhos à $\Omega_{i}$, usados para resolver o (MMQ), depende da ordem de precisão desejada. Vamos descrever o procedimento para resolver o sistema matricial da equação (3.25), que consiste em determinar os coeficientes do polinômio de reconstrução de grau $p$ ou ordem $p+1$ :

- Primeiramente, a restrição para satisfazer a média na equação (3.15), presente na primeira linha do sistema $P \cdot c=s$ é eliminada analiticamente, utilizando-se eliminação gaussiana para 
zerar a primeira coluna da matriz $P$, exceto o primeiro termo (o número 1 );

- Posteriomente, o problema de mínimos quadrados da matriz resultante é resolvido utilizandose a técnica de decomposição em valores singulares (ver (Golub e Van Loan, 2012)) aplicada na matriz $P$ e obtém-se a pseudo-inversa dessa matriz, que será armazenada e utilizada durante o avanço temporal;

- Por fim, a restrição da média é utilizada para encontrar o termo constante $c_{0}$ do polinômio de reconstrução $\phi_{i}(x, y)$ relativo ao volume de controle $\Omega_{i}$.

Deve-se ressaltar que a matriz do problema de mínimos quadrados associada a cada volume de controle $\Omega_{i}$, depende apenas da geometria da malha, sendo invariável no tempo. Dessa forma, a pseudo-inversa da matriz do problema de mínimos quadrados é calculada e armazenada antes do processo iterativo, economizando (em tempo de execução) o uso de processador durante a evolução temporal.

\subsection{Integração do fluxo}

Após obter um polinômio de reconstrução para cada volume de controle do domínio computacional, que conserva a solução média em $\Omega_{i}$, a próxima etapa será calcular a integral do fluxo nas arestas de cada volume de controle. A integração deve ser no mínimo da mesma ordem de precisão da reconstrução da solução, para que possa obter solução em alta ordem. Neste trabalho, será utilizado o método de quadratura gaussiana para a integração numérica, por ter a vantagem de fornecer aproximações precisas com baixo custo computacional.
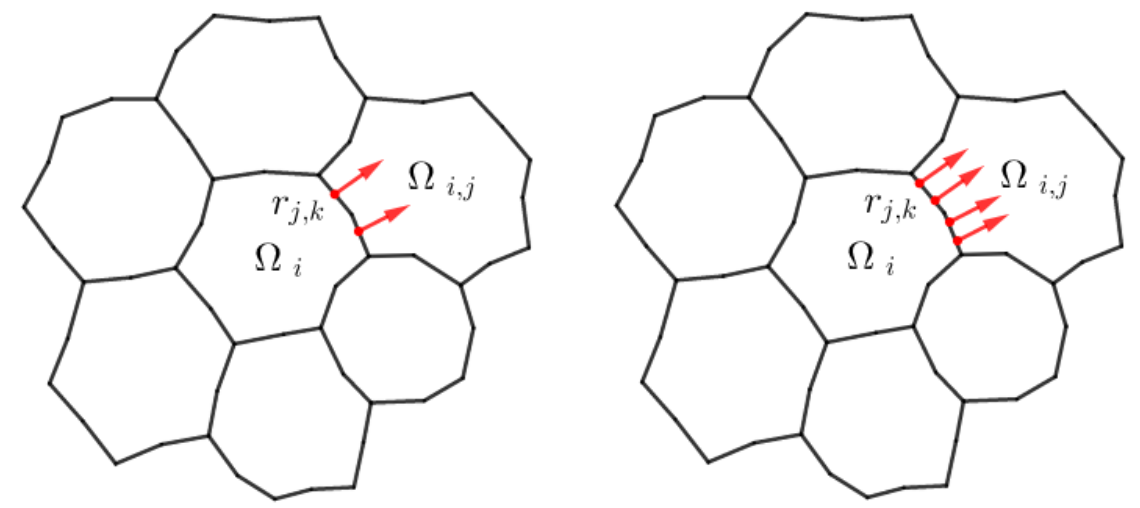

Figura 3.4: Ilustração com os pontos de Gauss para $2^{a}$ ordem (esquerda) e com os pontos de Gauss para $3^{a}$ ordem, que também serve para $4^{a}$ ordem (direita).

Para avaliar o fluxo nas arestas dos volumes de controle $\Omega_{i}$ ilustrado na Figura 3.4, utiliza-se o esquema de interpolação upwind, seguindo Ollivier-Gooch e Van Altena (2002), dado por:

$$
\phi_{e_{j, k}}=\left\{\begin{array}{lll}
\phi_{i} & \text { se } & \overrightarrow{V_{j, k}} \cdot \overrightarrow{n_{j}} \geq 0 \\
\phi_{i, j} & \text { se } & \overrightarrow{V_{j, k}} \cdot \overrightarrow{n_{j}}<0
\end{array}\right.
$$

A escolha do polinômio de reconstrução $\phi_{e_{j, k}}$, na equação (3.26), para avaliar o fluxo nas arestas $e_{j}$ do volume de controle $\Omega_{i}$ depende da direção do fluxo $\left(\vec{V}_{e_{j, k}} \cdot \overrightarrow{n_{j}}\right)$. Se for positivo, o fluxo está saindo da aresta $e_{j}$ e utiliza o polinômio de reconstrução $\phi_{i}$ relativo ao volume de controle $\Omega_{i}$ aplicado na aresta $e_{j}$. Se for negativo, então o fluxo está entrando na aresta $e_{j}$ e utiliza o polinômio de reconstrução vizinho $\phi_{i, j}$, relativo ao volume de controle $\Omega_{i, j}$.

Dessa forma, a soma dos fluxos em cada aresta $e_{j}$ aplicada em cada ponto de Gauss $r_{j, k}$, 
determina o fluxo total no volume de controle $\Omega_{i}$, dado por

$$
F_{N u m}\left(\bar{\phi}_{i}\right)=\sum_{j=1}^{m} \sum_{k=1}^{n} \phi_{e_{j, k}}\left(\vec{V}_{e_{j, k}} \cdot \overrightarrow{n_{j}}\right) w_{e_{j, k}} .
$$

Os termos $\phi_{e_{j, k}}$ e $\vec{V}_{e_{j, k}}$ foram avaliados em cada ponto de Gauss $r_{j, k}$.

\subsection{Evolução temporal}

A equação de adveç̧ão é discretizada para se obter o sistema acoplado de equações diferenciais ordinárias

$$
\frac{d \bar{\phi}_{i}}{d t}=-\frac{1}{\left|\Omega_{i}\right|} F_{N U M_{i}^{p}}(\bar{\phi}),
$$

onde $F_{N U M_{i}^{p}}^{p}$ são os termos da discretização espacial e $\left|\Omega_{i}\right|$ é a área geodésica do volume de controle. A equação (3.28) será resolvida por um método explícito. Após calcular a integral do fluxo nas arestas do volume de controle $\Omega_{i}$ e armazenar no seu respectivo vértice, a solução é avançada no tempo usando um esquema Runge-Kutta de quatro estágios.

Para um tempo n, define-se $\bar{\phi}_{i}^{[0]}=\bar{\phi}_{i}^{[n]}$

$$
\begin{aligned}
& \bar{\phi}_{i}^{[1]}=\bar{\phi}_{i}^{[0]}-\frac{\Delta t}{2} \frac{1}{\left|\Omega_{i}\right|} F_{N U M_{i}^{p}}\left(\bar{\phi}^{[0]}\right), \\
& \bar{\phi}_{i}^{[2]}=\bar{\phi}_{i}^{[0]}-\frac{\Delta t}{2} \frac{1}{\left|\Omega_{i}\right|} F_{N U M_{i}^{p}}\left(\bar{\phi}^{[1]}\right), \\
& \bar{\phi}_{i}^{[3]}=\bar{\phi}_{i}^{[0]}-\Delta t \frac{1}{\left|\Omega_{i}\right|} F_{N U M_{i}^{p}}\left(\bar{\phi}^{[2]}\right), \\
& \bar{\phi}_{i}^{[4]}=\bar{\phi}_{i}^{[0]}-\frac{\Delta t}{6} \frac{1}{\left|\Omega_{i}\right|}\left[F_{N U M_{i}^{p}}\left(\bar{\phi}^{[0]}\right)+2 F_{N U M_{i}^{p}}\left(\bar{\phi}^{[1]}\right)+2 F_{N U M_{i}^{p}}^{p}\left(\bar{\phi}^{[2]}\right)+F_{N U M_{i}^{p}}\left(\bar{\phi}^{[3]}\right)\right] .
\end{aligned}
$$

Para um tempo $\mathrm{n}+1$, define-se $\bar{\phi}_{i}^{[n+1]}=\bar{\phi}_{i}^{[4]}$.

A estabilidade desse esquema depende de uma restrição ao passo de tempo $\Delta t_{i}$ em cada volume de controle $\Omega_{i}$. O valor limite devido à advecção (Saito, 2008) é dado por

$$
\Delta t_{i}=c \frac{\Delta x_{i}}{\left\|\vec{V}_{i}\right\|}
$$

onde $c$ é o número de Courant, $\vec{V}_{i}$ é o vetor velocidade no vértice i relativo ao volume de controle $\Omega_{i}$ e o termo $\Delta x_{i}$ da equação (3.30) será

$$
\Delta x_{i}=\sqrt{\frac{\left|\Omega_{i}\right|}{n b(i)}},
$$

onde $\left|\Omega_{i}\right|$ é a área geodésica do volume de controle $\Omega_{i}$ e $n b(i)$ representa o número de primeiros vizinhos relativo ao volume de controle $\Omega_{i}$.

Nas simulações numéricas envolvendo problemas não estacionários é necessário um passo de tempo global dado por $\Delta t=\min \left\{\Delta t_{i}\right\}$ e o critério de parada é quando o tempo físico desejado $T$ for atingido. Na maioria dos testes para satisfazer a condição de $C F L$ de Courant-Friedrichs-Lewy, foi utilizado o número de Courant $c=0,5785$ e nos demais testes comparativos, utiliza-se o mesmo número de Courant $c$ do trabalho da literatura. 


\subsection{Comentários}

O próximo capítulo tem como objetivo validar o método FV-OLG utilizando-se as funções testes disponíveis na literatura. As etapas de validação consistem em testes numéricos de interpolação, integração, interpolação e integração e por fim, discretização do divergente. Essas etapas são fundamentais para verificar se a ordem resultante do método proposto atinge alta ordem de precisão quando aplicada na superfície esférica. Para isso, foi utilizado o método regressão linear, visando fazer o ajuste da reta e avaliar a ordem efetiva obtida em cada teste deste trabalho. 


\section{Capítulo 4}

\section{Validação do método FV-OLG}

O objetivo deste capítulo é avaliar se as ordens obtidas na implementação do método FV-OLG, na discretização do operador divergente aplicado no transporte de um escalar, descritas na equação (3.6) são respeitadas. Primeiramente, avalia-se a ordem do erro de discretização do polinômio de reconstrução de $2^{\mathrm{a}}, 3^{\mathrm{a}}$ e $4^{\mathrm{a}}$ ordens, posteriormente, a ordem da discretização da integração gaussiana e, por fim, avalia-se a ordem resultante da discretização do divergente.

\subsection{Interpolação}

Nesta seção será validado o processo de interpolação numérica, avaliando-se as ordens descritas na equação (3.6), ou seja, $O\left(h^{I}\right)$ e $O\left(h^{P}\right)$. Para isso, serão utilizadas as métricas de erros entre o campo escalar aproximado $\tilde{f}$ e o valor exato $f$. O erro máximo $E_{\infty}$ e o quadrático médio $E_{L_{2}}$ são definidos como

$$
\begin{gathered}
E_{L_{\infty}}=\|f-\tilde{f}\|_{\infty}=\max _{i=1, \ldots, n}\left|f_{i}-\tilde{f}_{i}\right|, \\
E_{L_{2}}=\|f-\tilde{f}\|_{2}=\sqrt{\frac{\sum_{i=1}^{n}\left(f_{i}-\tilde{f}_{i}\right)^{2}}{n}} .
\end{gathered}
$$

Considere $f_{i} \in \mathbb{R}$, com $i=1, \ldots, n$, definidos em um conjunto de pontos de malha $S=\left\{p_{i}\right\}$, com $i=1, \ldots, n$ na esfera. O objetivo da interpolação escalar consiste em determinar uma função $f$, que satisfaça

$$
f\left(p_{i}\right)=f_{i}, i=1, \ldots, n .
$$

As funções utilizadas neste trabalho estão em coordenadas geográficas $(\lambda, \theta)$, ou seja, temos funções $f(\lambda, \theta)$, onde $-\pi \leqslant \lambda \leqslant \pi$ é a longitude e $-\pi / 2 \leqslant \theta \leqslant \pi / 2$ é a latitude. Para validar a interpolação, será feito um remapeamento da malha icosaédrica para a malha longitude-latitude com 720 x 1440 pontos. Dessa forma, para cada ponto da malha de longitude/latitude será preciso realizar uma interpolação escalar com base em valores dados na malha icosaédrica, utilizando-se as equações (4.1) e (4.2) para avaliar os erros.

O procedimento para validar a interpolação de $n$ pontos, consiste nas seguintes etapas:

- Gera-se uma malha longitude-latitude com 720 x 1440 pontos. Para cada ponto em coordenadas geográficas $(\lambda, \theta)$, determina-se o valor exato $f(\lambda, \theta)$ da função teste neste ponto;

- Para cada ponto da malha $(\lambda, \theta)$, devido ao remapeamento da equação (4.4), tem-se o respectivo ponto em coordenadas cartesianas $(x, y, z)$ e usando métodos de busca, determina-se o 
volume de controle $\Omega_{i}$ ao qual pertence este ponto,

$$
\begin{aligned}
& x=\cos (\theta) \cos (\lambda), \\
& y=\cos (\theta) \sin (\lambda), \\
& z=\sin (\theta)
\end{aligned}
$$

- Conhecido o volume de controle $\Omega_{i}$, utiliza-se o polinômio de reconstrução $\phi_{i}$ no plano tangente e estima-se o de $f(x, y, z)$ na superfície esférica por meio de $\phi\left(x_{p}, y_{p}\right)$. As coordenadas $(x, y, z)$ são projetadas no plano tangente por meio da projeção perpendicular, obtendo-se as novas coordenadas $\left(x_{p}, y_{p}\right)$ no sistema de coordenadas bidimensionais;

- Para cada ponto da malha longitude-latitude com 720 x 1440 pontos, utilizando-se o valor exato $f(\lambda, \theta)$ e o valor estimado $\phi\left(x_{p}, y_{p}\right)$, calcula-se o erro máximo e quadrático médio.

No processo de validação da interpolação numérica, o polinômio de reconstrução $\phi_{\text {aproximado }}$ dado na equação (4.5), será denotado por $\phi_{i}$ e possui duas fontes de erros. O erro da ordem $O\left(h^{I}\right)$, que corresponde ao erro de truncamento da série de Taylor e o erro da ordem $O\left(h^{P}\right)$, referente à projeção dos pontos da esfera para o plano é da ordem $O\left(h^{P}\right)=O\left(h^{2}\right)$, conforme Lashley (2002).

$$
\phi_{\text {exato }}=\phi_{\text {aproximado }}+O\left(h^{I}\right)+O\left(h^{P}\right)
$$

No estudo das ordens de erros cometidos na interpolação, utiliza-se como funções teste duas colinas de gaussianas, por serem suaves, ou seja, diferenciáveis, e dois sinos de cossenos, por possuirem descontinuidade de derivada. Espera-se que o método FV-OLG seja capaz de efetuar a reconstrução dessas soluções exatas sobre a superfície esférica unitária.

\subsubsection{Função duas colinas de gaussianas}

A condição inicial escalar é dada por duas colinas de gaussianas, descritas em Nair e Lauritzen (2010), são definidas por

$$
\phi(\lambda, \theta)=h_{1}(\lambda, \theta)+h_{2}(\lambda, \theta),
$$

onde, cada $h_{i}$ é definido em coordenadas cartesianas como,

$$
h_{i}=\exp \left\{-5\left[\left(x-x_{i}\right)^{2}+\left(y-y_{i}\right)^{2}+\left(z-z_{i}\right)^{2}\right]\right\},
$$

sendo fixadas nos pontos $\left(\lambda_{1}, \theta_{1}\right)=(-\pi / 4,0)$ e $\left(\lambda_{2}, \theta_{2}\right)=(\pi / 4,0)$, respectivamente.

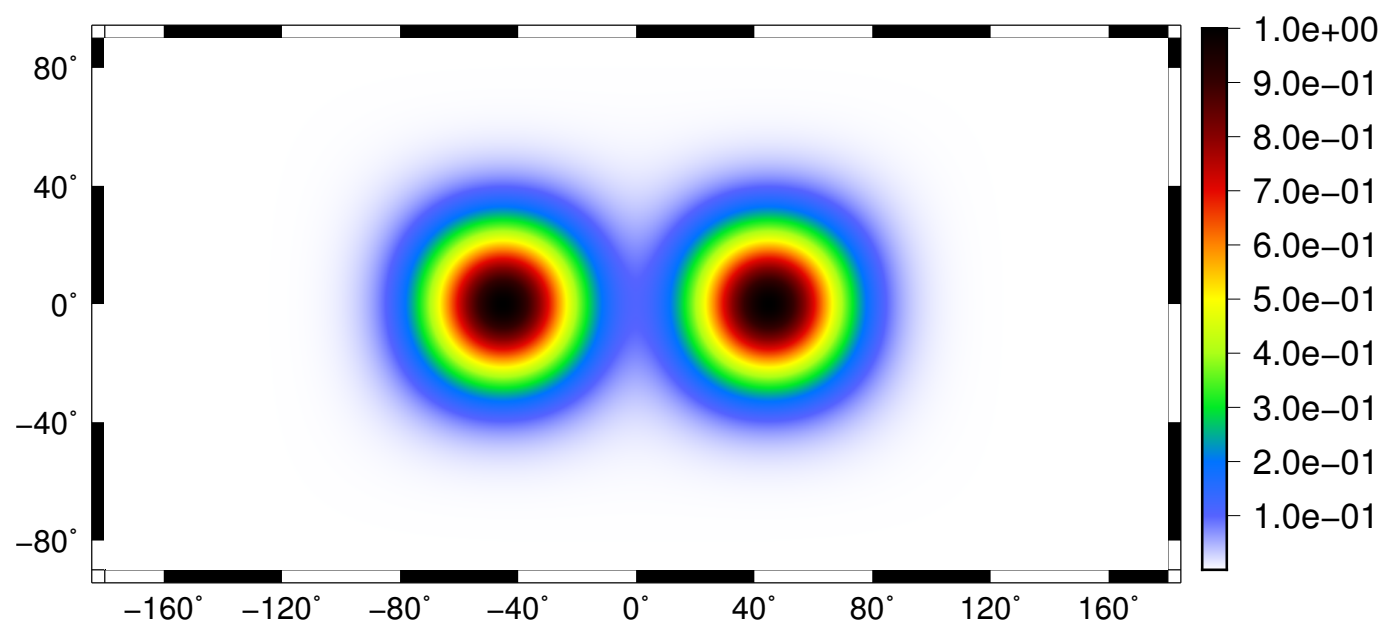

Figura 4.1: Campo escalar da função exata de duas colinas de gaussianas.

O gráfico da solução inicial, ilustrado na Figura 4.1, é o mesmo para os métodos de $2^{\mathrm{a}}, 3^{\mathrm{a}}$ e $4^{\mathrm{a}}$ ordens, pois todas as ordens utilizaram a quadratura de $6^{\text {a }}$ ordem descrita em Dunavant (1985), 
para armazenar a média da solução exata (condição inicial). A seguir, são apresentados os gráficos da reconstrução da solução, com respectivo gráfico do erro máximo para $2^{\mathrm{a}}$, $3^{\mathrm{a}}$ e $4^{\mathrm{a}}$ ordens. A solução final (estimada) da função duas colinas de gaussianas não foi ilustrada, pois visualmente os resultados são semelhantes para os métodos de $2^{\mathrm{a}}, 3^{\mathrm{a}}$ e $4^{\mathrm{a}}$ ordens, por isso foi plotado somente o gráfico dos erros entre a solução aproximada e exata.

\section{Validando a interpolação para $2^{\mathrm{a}}$ ordem}

O polinômio de reconstrução de $2^{\mathrm{a}}$ ordem, obtido por meio da expansão em série de Taylor e apresentado no capítulo anterior é dado por

$$
\phi_{i}^{1}=c_{0}+c_{1} x+c_{2} y+O\left(h^{I}\right) .
$$

Dessa forma, tem-se um polinômio de grau 1 com erro de truncamento da ordem $O\left(h^{I}\right)=O\left(h^{2}\right)$.

\begin{tabular}{|c|c|c|c|c|c|}
\hline Nível & Nós & Erro Máx & Razão Máx & Erro 2 & Razão 2 \\
\hline 2 & 162 & $1,22 \mathrm{E}-01$ & 0,00 & $1,25 \mathrm{E}-02$ & 0,00 \\
\hline 3 & 642 & $2,59 \mathrm{E}-02$ & 4,71 & $2,52 \mathrm{E}-03$ & 4,97 \\
\hline 4 & 2562 & $6,99 \mathrm{E}-03$ & 3,71 & $5,46 \mathrm{E}-04$ & 4,62 \\
\hline 5 & 10242 & $1,55 \mathrm{E}-03$ & 4,50 & $1,29 \mathrm{E}-04$ & 4,23 \\
\hline 6 & 40962 & $3,62 \mathrm{E}-04$ & 4,29 & $3,17 \mathrm{E}-05$ & 4,08 \\
\hline 7 & 163842 & $9,21 \mathrm{E}-05$ & 3,94 & $7,72 \mathrm{E}-06$ & 4,10 \\
\hline 8 & 655362 & $2,24 \mathrm{E}-05$ & 4,12 & $2,00 \mathrm{E}-06$ & 3,87 \\
\hline
\end{tabular}

Tabela 4.1: Erros e razões para as normas do máximo e quadrático médio para a função duas colinas de gaussianas, utilizando-se polinômio de $2^{a}$ ordem para níveis consecutivos de malha.

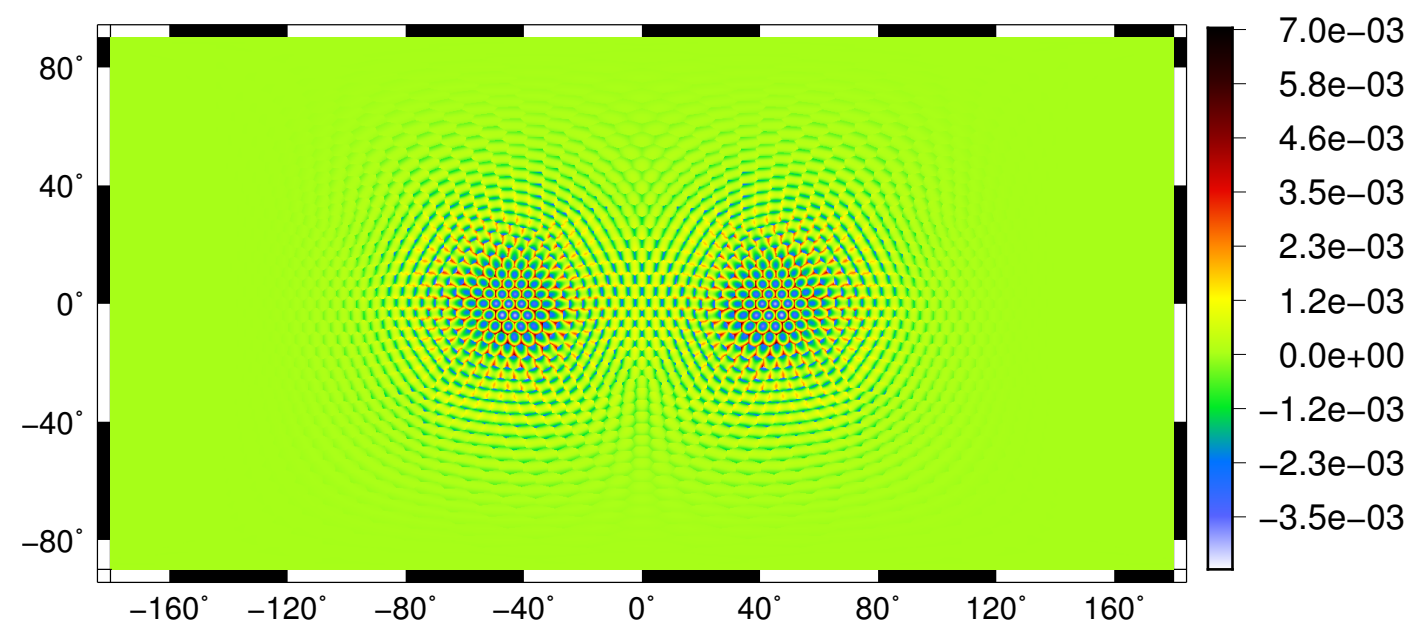

Figura 4.2: Erros associados na interpolação da condição inicial duas colinas de gaussinas, utilizando-se o método de $2^{a}$ ordem em uma malha icosaédrica de nível 5.

\section{Validando a interpolação para $3^{\mathrm{a}}$ ordem}

O polinômio de reconstrução de $3^{\mathrm{a}}$ ordem, obtido por meio da expansão em série de Taylor e apresentado no capítulo anterior, é dado por

$$
\phi_{i}^{2}=c_{0}+c_{1} x+c_{2} y+c_{3} x^{2}+c_{4} x y+c_{5} y^{2}+O\left(h^{I}\right) .
$$

Dessa forma, tem-se um polinômio de grau 2 com erro de truncamento da ordem $O\left(h^{I}\right)=O\left(h^{3}\right)$. 


\begin{tabular}{|c|c|c|c|c|c|}
\hline Nível & Nós & Erro Máx & Razão Máx & Erro 2 & Razão 2 \\
\hline 2 & 162 & $1,72 \mathrm{E}-01$ & 0,00 & $1,98 \mathrm{E}-02$ & 0,00 \\
\hline 3 & 642 & $3,77 \mathrm{E}-02$ & 4,55 & $3,59 \mathrm{E}-03$ & 5,51 \\
\hline 4 & 2562 & $5,41 \mathrm{E}-03$ & 6,97 & $5,06 \mathrm{E}-04$ & 7,10 \\
\hline 5 & 10242 & $7,46 \mathrm{E}-04$ & 7,26 & $6,56 \mathrm{E}-05$ & 7,71 \\
\hline 6 & 40962 & $9,39 \mathrm{E}-05$ & 7,94 & $8,32 \mathrm{E}-06$ & 7,89 \\
\hline 7 & 163842 & $1,15 \mathrm{E}-05$ & 8,19 & $1,05 \mathrm{E}-06$ & 7,90 \\
\hline 8 & 655362 & $1,49 \mathrm{E}-06$ & 7,72 & $1,26 \mathrm{E}-07$ & 8,36 \\
\hline
\end{tabular}

Tabela 4.2: Erros e razões para as normas do máximo e quadrático médio para a função duas colinas de gaussianas, utilizando-se polinômio de $3^{a}$ ordem para níveis consecutivos de malha.

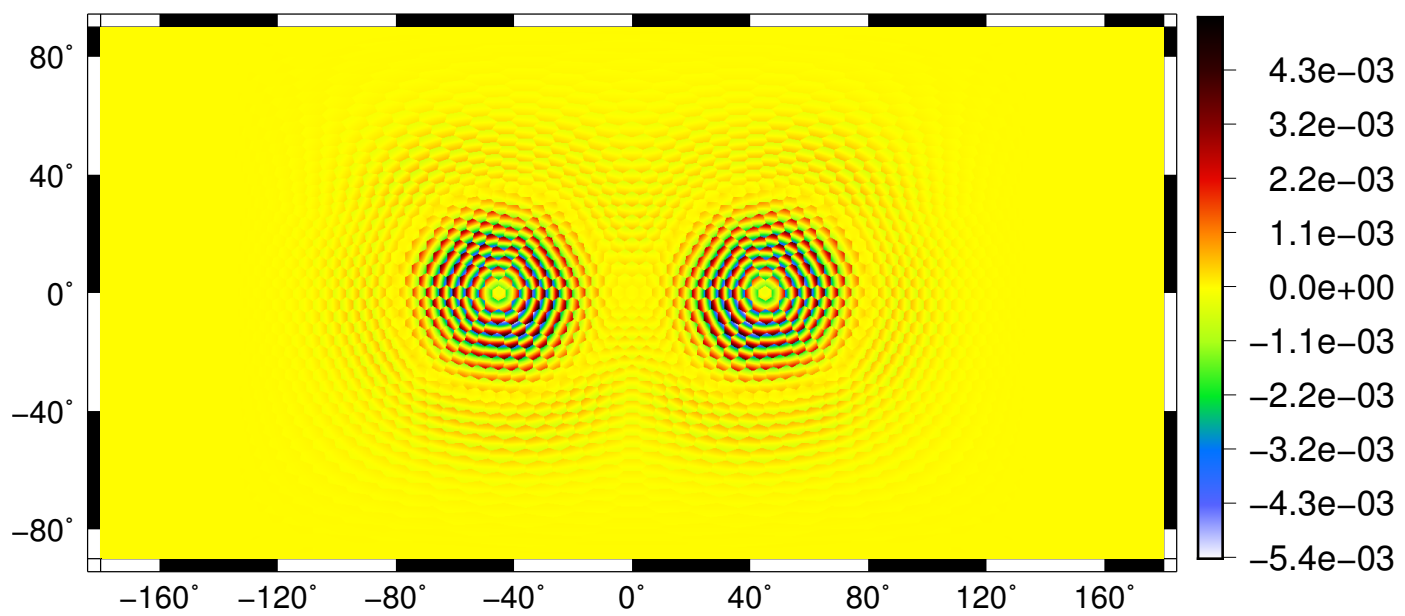

Figura 4.3: Erros associados na interpolação da condição inicial duas colinas de gaussinas, utilizando-se o método de $3^{a}$ ordem em uma malha icosaédrica de nível 5.

\section{Validando interpolação para $4^{\mathrm{a}}$ ordem}

O polinômio de reconstrução de $4^{\mathrm{a}}$ ordem, obtido por meio da expansão em série de Taylor foi apresentado no capítulo anterior e é dado por

$$
\phi_{i}^{3}=c_{0}+c_{1} x+c_{2} y+c_{3} x^{2}+c_{4} x y+c_{5} y^{2}+c_{6} x^{3}+c_{7} x^{2} y+c_{8} x y^{2}+c_{8} y^{3}+O\left(h^{I}\right) .
$$

Dessa forma, tem-se um polinômio de grau 3 com erro de truncamento da ordem $O\left(h^{I}\right)=O\left(h^{4}\right)$.

\begin{tabular}{|c|c|c|c|c|c|}
\hline Nível & Nós & Erro Máx & Razão Máx & Erro 2 & Razão 2 \\
\hline 2 & 162 & $5,05 \mathrm{E}-02$ & 0,00 & $5,22 \mathrm{E}-03$ & 0,00 \\
\hline 3 & 642 & $4,29 \mathrm{E}-03$ & 11,78 & $3,91 \mathrm{E}-04$ & 13,34 \\
\hline 4 & 2562 & $3,34 \mathrm{E}-04$ & 12,83 & $2,51 \mathrm{E}-05$ & 15,61 \\
\hline 5 & 10242 & $2,11 \mathrm{E}-05$ & 15,85 & $1,56 \mathrm{E}-06$ & 16,06 \\
\hline 6 & 40962 & $1,32 \mathrm{E}-06$ & 16,01 & $9,66 \mathrm{E}-08$ & 16,15 \\
\hline 7 & 163842 & $8,10 \mathrm{E}-08$ & 16,28 & $5,90 \mathrm{E}-09$ & 16,35 \\
\hline 8 & 655362 & $4,87 \mathrm{E}-09$ & 16,63 & $3,86 \mathrm{E}-10$ & 15,30 \\
\hline
\end{tabular}

Tabela 4.3: Erros e razões para as normas do máximo e quadrático médio para a função duas colinas de gaussianas, utilizando-se polinômio de $4^{a}$ ordem para niveis consecutivos de malha.

Para os métodos de $2^{\mathrm{a}}, 3^{\mathrm{a}}$ e $4^{\mathrm{a}}$ ordens foi ilustrado somente o gráfico da solução exata, pois o gráfico da solução aproximada, visualmente, não apresenta diferenças. Assim, foi plotado somente o 


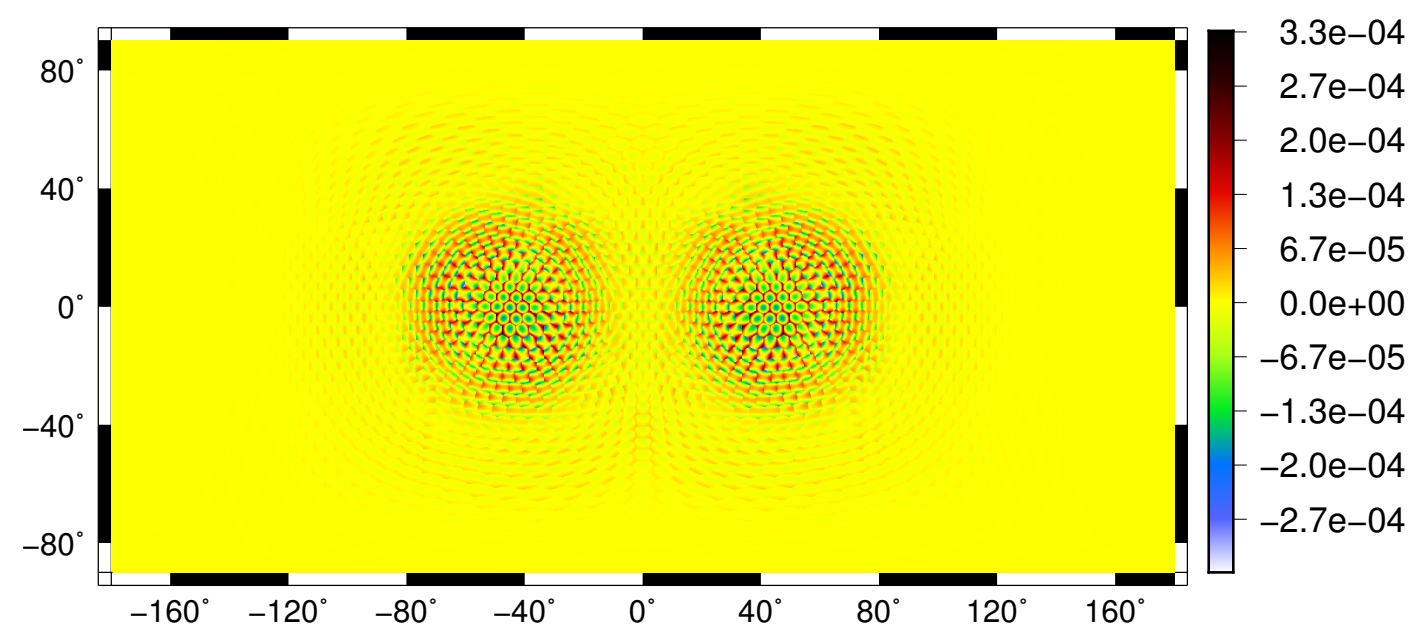

Figura 4.4: Erros associados na interpolação da condição inicial duas colinas de gaussinas, utilizando-se o método de $4^{a}$ ordem em uma malha icosaédrica de nível 5.

gráfico do erro, que permite visualizar as diferenças dos erros cometidos nas aproximações. Em todos os métodos, é possível observar que a distribuição do erro são maiores nas bordas das células, pois o polinômio de reconstrução é sempre construído centrado no vértice, que corresponde a um ponto de malha. Quanto mais próximo o ponto interpolado está do centro do volume de controle, mais precisa será a aproximação e menor será o erro cometido. Assim, se o ponto interpolado estiver na fronteira entre dois ou mais volumes de controle, o erro poderá ser maior, dependendo da descontinuidade da condição inicial, conforme ilustrado na Figura 4.2, para o método de $2^{\mathrm{a}}$ ordem, na Figura 4.3, para o método de $3^{\mathrm{a}}$ ordem e na Figura 4.4, para o método de $4^{\mathrm{a}}$ ordem.

\begin{tabular}{|c|c|c|}
\hline Método & $L_{\infty}$ & $L_{2}$ \\
\hline $2^{\mathrm{a}}$ ordem & 2,06 & 2,10 \\
\hline $3^{\mathrm{a}}$ ordem & 2,84 & 2,90 \\
\hline $4^{\mathrm{a}}$ ordem & 3,91 & 3,97 \\
\hline
\end{tabular}

Tabela 4.4: Ordem de precisão para a interpolação de duas colinas de gaussianas.

Para verificar a ordem da interpolação dos métodos em estudo, foi aplicado um ajuste, por meio da regressão linear nas Tabelas 4.1, 4.2 e 4.3, e estes foram apresentados na Tabela 4.4. É possível observar que, à medida que aumenta a ordem do polinômio de reconstrução, percebemos uma precisão melhor para um dado nível de malha, conforme os gráficos do erro máximo para os métodos de $2^{\mathrm{a}}, 3^{\mathrm{a}}$ e $4^{\mathrm{a}}$ ordens. Todos os polinômios de reconstrução em estudo foram capazes de fazer a reconstrução das duas colinas de gaussianas e a ordem dominante da interpolação foi de $O\left(h^{I}\right)$, relativa ao erro de truncamento de para todos os métodos em estudo, ou seja, o erro de projeção da ordem $O\left(h^{P}\right)$ parece não afetar a aproximação polinomial, assim como discutido em Lashley (2002).

\subsubsection{Função dois sinos de cossenos}

Os testes são repetidos para a função dois sinos de cossenos, descrita em Nair e Lauritzen (2010), para verificar o comportamento do método FV-OLG no caso de descontinuidade de derivada.

A condição inicial escalar será dada por dois sinos cossenoidais, da seguinte forma

$$
\phi(\lambda, \theta)= \begin{cases}b+c h_{1}(\lambda, \theta), & r_{1}<r, \\ b+c h_{2}(\lambda, \theta), & r_{2}<r, \\ b & \text { caso contrário, }\end{cases}
$$


onde, $b=0.1, c=0.9$ e cada $h_{i}$ é dado por

$$
h_{i}(x, y, z)=\frac{1}{2}\left[1+\cos \left(\pi r_{i} / r\right)\right],
$$

sendo $r=1 / 2$ e pontos estão fixados em $\left(\lambda_{1}, \theta_{1}\right)=(-\pi / 4,0)$ e $\left(\lambda_{2}, \theta_{2}\right)=(\pi / 4,0)$. Os termos $r_{1}$ e $r_{2}$ representam as distâncias geodésicas entre $(\lambda, \theta)$ e os centros $\left(\lambda_{1}, \theta_{1}\right)$ e $\left(\lambda_{2}, \theta_{2}\right)$ dos dois sinos de cossenos, respectivamente.

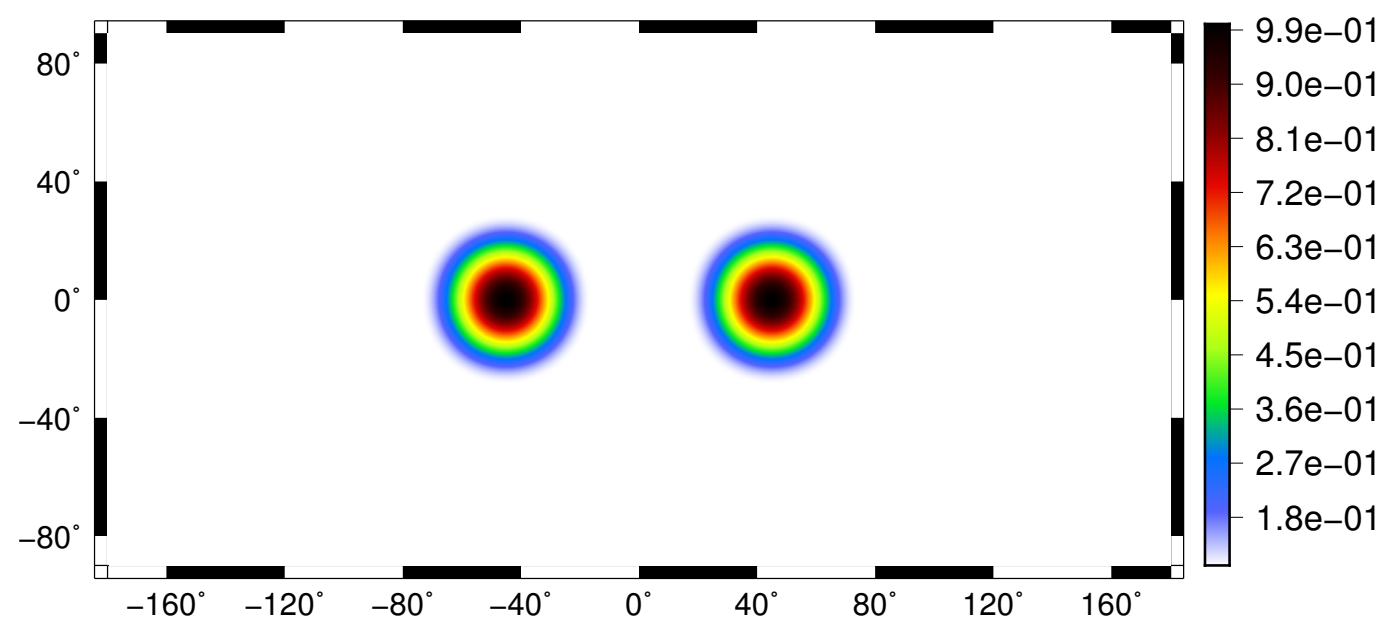

Figura 4.5: Campo escalar da função exata de dois sinos de cossenos, malha icosaédrica de nível 5.

O gráfico da solução inicial, ilustrado na Figura 4.5, é o mesmo para os métodos de $2^{\mathrm{a}}, 3^{\mathrm{a}}$ e $4^{\mathrm{a}}$ ordens, pois todas as ordens utilizam a quadratura de $6^{\mathrm{a}}$ ordem, descrita em Dunavant (1985). A seguir, os gráficos da reconstrução da solução são apresentados com respectivo gráfico na norma do máximo para $2^{\mathrm{a}}, 3^{\mathrm{a}}$ e $4^{\mathrm{a}}$ ordem. A solução final (estimada) da função dois sinos de cossenos não foi ilustrada, pois os resultados visualmente são semelhantes para os métodos de $2^{\mathrm{a}}, 3^{\mathrm{a}}$ e $4^{\mathrm{a}}$ ordens, assim foi plotado somente o gráfico dos erros entre a solução aproximada e exata.

\section{Validando a interpolação para $2^{\mathrm{a}}$ ordem}

Os resultados da interpolação utilizando-se o polinômio de reconstrução $2^{\mathrm{a}}$ ordem, dado por $\phi_{i}^{1}$, com erro de truncamento da ordem $O\left(h^{I}\right)=O\left(h^{2}\right)$, apresentados a seguir.

\begin{tabular}{|c|c|c|c|c|c|}
\hline Nível & Nós & Erro Máx & Razão Máx & Erro 2 & Razão 2 \\
\hline 2 & 162 & $2,43 \mathrm{E}-01$ & 0,00 & $2,28 \mathrm{E}-02$ & 0,00 \\
\hline 3 & 642 & $6,60 \mathrm{E}-02$ & 3,67 & $5,17 \mathrm{E}-03$ & 4,41 \\
\hline 4 & 2562 & $1,62 \mathrm{E}-02$ & 4,08 & $1,10 \mathrm{E}-03$ & 4,72 \\
\hline 5 & 10242 & $3,99 \mathrm{E}-03$ & 4,06 & $2,45 \mathrm{E}-04$ & 4,48 \\
\hline 6 & 40962 & $9,65 \mathrm{E}-04$ & 4,14 & $5,78 \mathrm{E}-05$ & 4,23 \\
\hline 7 & 163842 & $2,34 \mathrm{E}-04$ & 4,12 & $1,39 \mathrm{E}-05$ & 4,16 \\
\hline 8 & 655362 & $5,82 \mathrm{E}-05$ & 4,02 & $3,55 \mathrm{E}-06$ & 3,92 \\
\hline
\end{tabular}

Tabela 4.5: Erros e razões para as normas do máximo e quadrático médio para a função dois sinos de cossenos, utilizando-se polinômio de $2^{a}$ ordem para níveis consecutivos de malha.

\section{Validando a interpolação para $3^{\mathrm{a}}$ ordem}

Os resultados da interpolação, ao utilizar o polinômio de reconstrução $3^{\mathrm{a}}$ ordem, dado por $\phi_{i}^{2}$, com erro de truncamento da ordem $O\left(h^{I}\right)=O\left(h^{3}\right)$, são apresentados a seguir. 


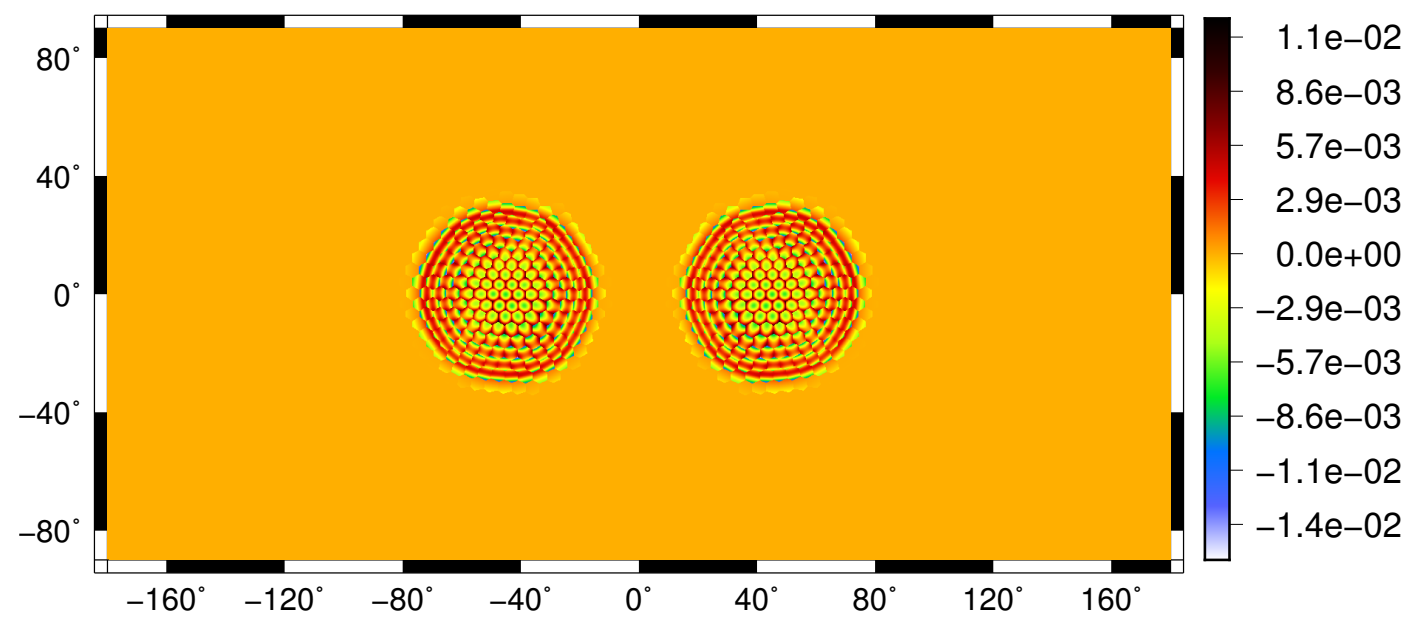

Figura 4.6: Erros associados na interpolação da condição inicial dois sinos de cossenos, utilizando-se o método de $2^{a}$ ordem em uma malha icosaédrica de nível 5.

\begin{tabular}{|c|c|c|c|c|c|}
\hline Nível & Nós & Erro Máx & Razão Máx & Erro 2 & Razão 2 \\
\hline 2 & 162 & $3,59 \mathrm{E}-01$ & 0,00 & $3,11 \mathrm{E}-02$ & 0,00 \\
\hline 3 & 642 & $9,41 \mathrm{E}-02$ & 3,81 & $8,18 \mathrm{E}-03$ & 3,81 \\
\hline 4 & 2562 & $1,40 \mathrm{E}-02$ & 6,73 & $1,45 \mathrm{E}-03$ & 5,62 \\
\hline 5 & 10242 & $3,63 \mathrm{E}-03$ & 3,85 & $2,34 \mathrm{E}-04$ & 6,21 \\
\hline 6 & 40962 & $9,12 \mathrm{E}-04$ & 3,98 & $3,81 \mathrm{E}-05$ & 6,15 \\
\hline 7 & 163842 & $2,19 \mathrm{E}-04$ & 4,17 & $6,36 \mathrm{E}-06$ & 5,98 \\
\hline 8 & 655362 & $5,38 \mathrm{E}-05$ & 4,07 & $1,04 \mathrm{E}-06$ & 6,10 \\
\hline
\end{tabular}

Tabela 4.6: Erros e razões para as normas do máximo e quadrático médio para a função dois sinos de cossenos, utilizando-se polinômio de $3^{a}$ ordem para niveis consecutivos de malha.

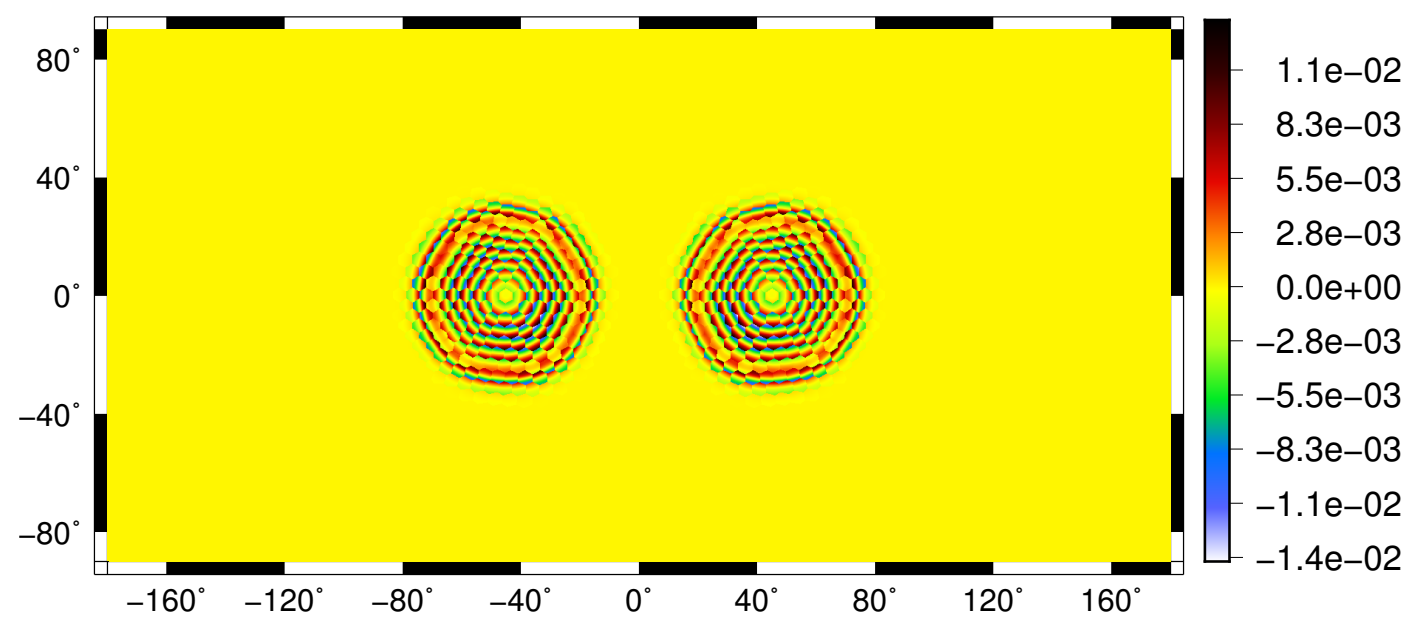

Figura 4.7: Erros associados na interpolação da condição inicial dois sinos de cossenos, utilizando-se o método de $3^{a}$ ordem em uma malha icosaédrica de nível 5.

\section{Validando a interpolação para $4^{\mathrm{a}}$ ordem}

Os resultados da interpolação utilizando-se o polinômio de reconstrução $4^{\mathrm{a}}$ ordem, dado por $\phi_{i}^{3}$, com erro de truncamento da ordem $O\left(h^{I}\right)=O\left(h^{4}\right)$, são apresentados a seguir. 


\begin{tabular}{|c|c|c|c|c|c|}
\hline Nível & Nós & Erro Máx & Razão Máx & Erro 2 & Razão 2 \\
\hline 2 & 162 & $1,83 \mathrm{E}-01$ & 0,00 & $1,65 \mathrm{E}-02$ & 0,00 \\
\hline 3 & 642 & $2,64 \mathrm{E}-02$ & 6,92 & $2,17 \mathrm{E}-03$ & 7,58 \\
\hline 4 & 2562 & $5,44 \mathrm{E}-03$ & 4,85 & $3,29 \mathrm{E}-04$ & 6,60 \\
\hline 5 & 10242 & $1,21 \mathrm{E}-03$ & 4,51 & $5,43 \mathrm{E}-05$ & 6,07 \\
\hline 6 & 40962 & $2,96 \mathrm{E}-04$ & 4,08 & $9,67 \mathrm{E}-06$ & 5,61 \\
\hline 7 & 163842 & $6,61 \mathrm{E}-05$ & 4,48 & $1,69 \mathrm{E}-06$ & 5,71 \\
\hline 8 & 655362 & $1,67 \mathrm{E}-05$ & 3,96 & $2,98 \mathrm{E}-07$ & 5,68 \\
\hline
\end{tabular}

Tabela 4.7: Erros e razões para as normas do máximo e quadrático médio para a função dois sinos de cossenos, utilizando-se polinômio de $4^{a}$ ordem para níveis consecutivos de malha.

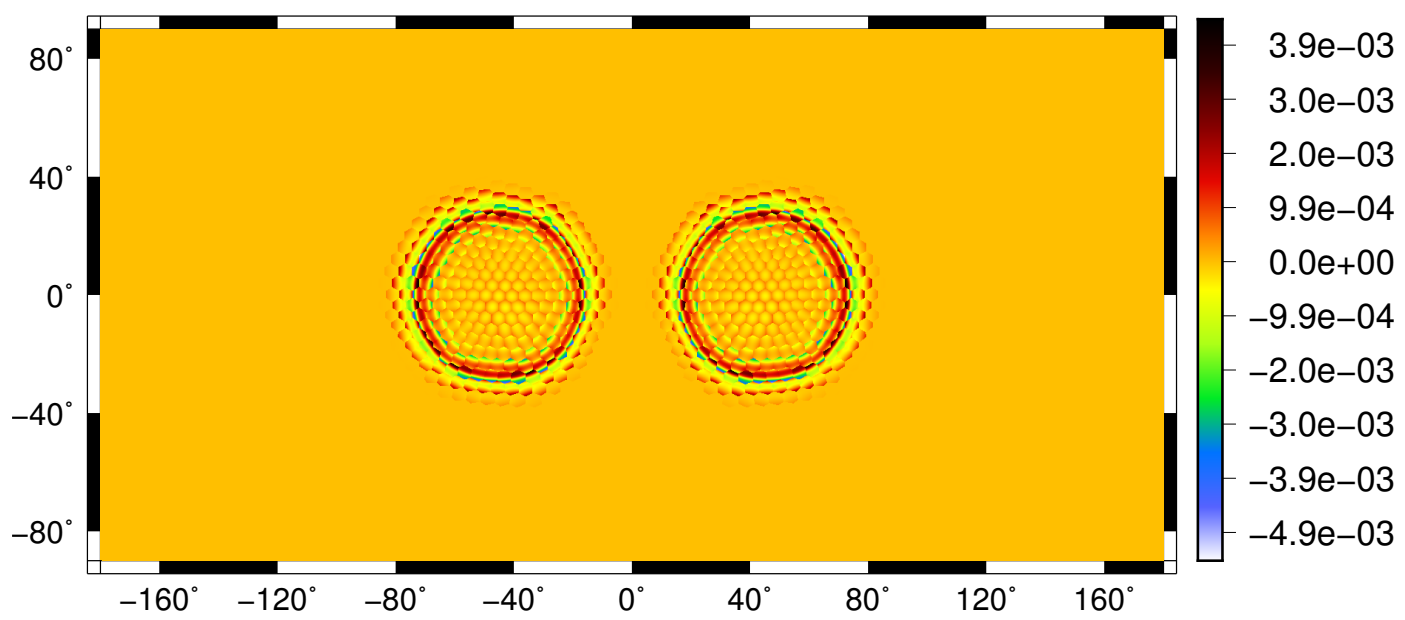

Figura 4.8: Erros associados na interpolação da condição inicial dois sinos de cossenos, utilizando-se o método de $4^{a}$ ordem em uma malha icosaédrica de nível 5.

Para verificar a ordem da interpolação dos métodos em estudo, foi aplicado um ajuste, por meio da regressão linear nas Tabelas 4.5, 4.6 e 4.7 e apresentados na Tabela 4.8. A ordem da interpolação desejada não foi atingida, pois a função dois sinos de cosseno é de classe $C^{0}$, ou seja, possui na borda uma descontinuidade de derivada, que afeta a obtenção da ordem para os polinômios de reconstrução em estudo.

\begin{tabular}{|c|c|c|}
\hline Método & $L_{\infty}$ & $L_{2}$ \\
\hline $2^{\mathrm{a}}$ ordem & 2,02 & 2,12 \\
\hline $3^{\mathrm{a}}$ ordem & 2,13 & 2,52 \\
\hline $4^{\mathrm{a}}$ ordem & 2,21 & 2,61 \\
\hline
\end{tabular}

Tabela 4.8: Ordem de precisão para a interpolação de dois sinos de cossenos.

Do ponto de vista qualitativo, os métodos de $2^{\mathrm{a}}$ e $3^{\mathrm{a}}$ ordens apresentaram resultados semelhantes para a solução aproximada e também para o gráfico do erro máximo, conforme observado na Figura 4.6 e Figura 4.7. Em todos os métodos utilizados, a função de interpolação conseguiu capturar a região de descontinuidade, apresentando os maiores erros nas regiões de transição de volumes de controle. Assim, como mencionado para as duas colinas de gaussianas, quanto mais distante o ponto interpolado está do vértice do volume de controle, maior será o erro cometido, fato observado na Figura 4.6 para o método de $2^{\mathrm{a}}$ ordem, Figura 4.7 para o método de $3^{\mathrm{a}}$ ordem e Figura 4.8 para o método de $4^{\mathrm{a}}$ ordem. Observa-se também que a ordem dominante $O\left(h^{I}\right)$ se verifica devido ao erro de truncamento para todos os métodos em estudo, ou seja, o erro de projeção da ordem $O\left(h^{2}\right)$ não afetou a ordem final do processo de interpolação. 


\subsection{Integração}

O objetivo desta seção é avaliar a ordem de integração numérica descrita na equação (3.6), ou seja, avaliar $O\left(h^{Q}\right)$. O fluxo advectivo será avaliado por meio da integração nas arestas do volume de controle $\Omega_{i}$ e deseja-se precisão de alta ordem. Devido à dificuldade em determinar uma integral exata nas arestas dos volumes de controle sobre a esfera, a regra de Simpson Composta será aplicada em cada aresta para que seja integral exata. A integração por meio da Quadradura Gaussiana foi utilizada para que seja a integral estimada. Por fim, foram avaliadas as ordens obtidas nas normas dos erros máximo e quadrático médio, comparando o resultado da integral exata com o resultado da integral estimada.

A integração com um ponto de Gauss fornece precisão de $3^{\mathrm{a}}$ ordem, ou seja, $O\left(h^{Q}\right)=O\left(h^{3}\right)$, permitindo calcular a integral exata para polinômios até grau 1 e utilizando-se dois pontos de Gauss, tem-se precisão de $5^{\text {a }}$ ordem, ou seja, $O\left(h^{Q}\right)=O\left(h^{5}\right)$, permitindo calcular a integral exata para polinômios até grau 3, conforme Ascher e Greif (2011).

\section{Função Teste}

Para validar a ordem da integração de quadratura gaussiana para um ponto e dois pontos de Gauss, será utilizada a função descrita na equação (4.13) no lugar do polinômio de reconstrução, de tal forma, que o único erro cometido em cada aresta será referente ao método de integração numérica, dada por

$$
f(\lambda, \theta)=(\cos (\theta))^{3}(\sin (\lambda))^{2},
$$

e o campo de velocidade dado por

$$
\begin{aligned}
& u=2 \pi \cos (\theta) \\
& v=0
\end{aligned}
$$

Segue o gráfico da função exata.

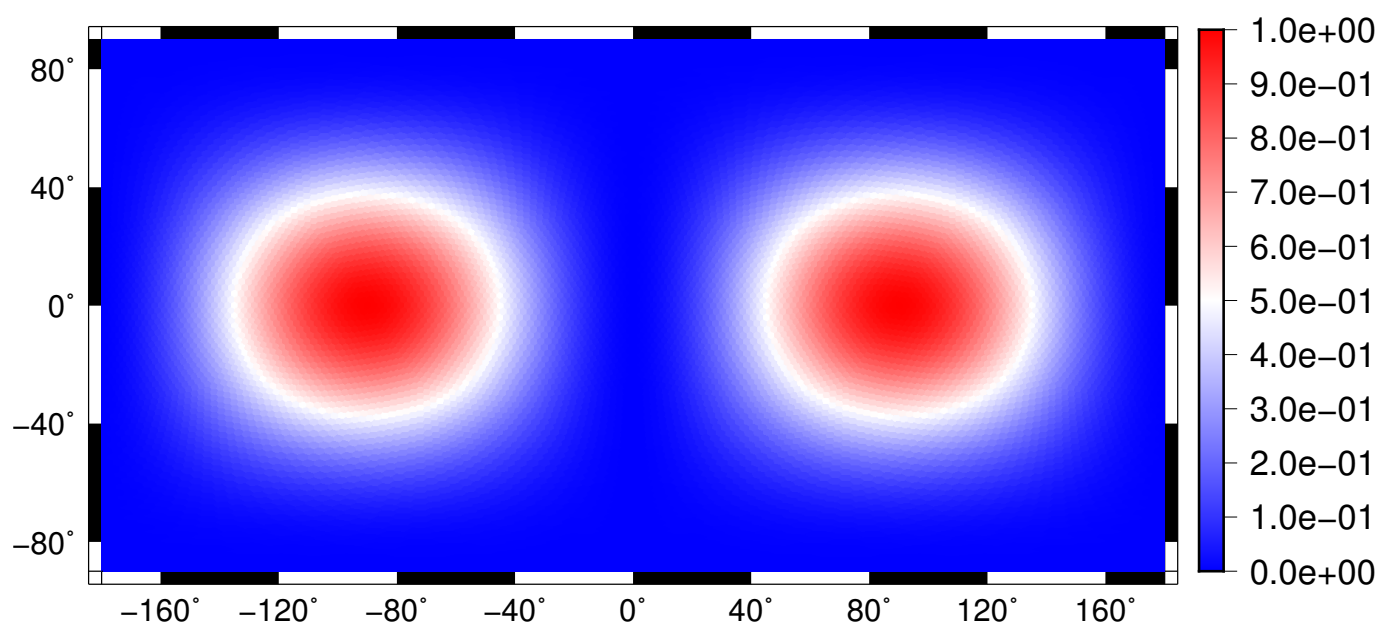

Figura 4.9: Gráfico da função exata para uma malha de nível 5

O procedimento para validar a integração de quadratura gaussiana consiste em

- Para cada aresta do volume de controle $\Omega_{i}$ na malha esférica, o comprimento é dividido em 2000 subintervalos;

- Em cada partição aplica-se a regra de Simpson Composta, obtendo-se o valor da integral do fluxo exato em cada aresta; 
- Em cada aresta do volume de controle $\Omega_{i}$ na malha esférica, determina-se os pontos e pesos de Gauss;

- Aplica-se a Regra de Quadratura Gaussiana nas arestas de $\Omega_{i}$, obtendo-se o valor da integral do fluxo estimado em cada aresta;

- Calcula-se o erro da integral exata e estimada em todas as arestas de todos os volumes de controle nas normas desejadas.

Cabe ressaltar que a implementação da regra de Simpson Composta foi validada utilizando-se uma função suave unidimensional, obtendo nos testes numéricos taxa de convergência de ordem $O\left(h^{4}\right)$. Como tem-se uma quantidade suficiente de partições, o valor da integral estimada pela Regra de Simpson Composta representa o valor da integral exata.

\subsubsection{Utilizando um ponto de Gauss}

Será avaliada a ordem resultante da integração numérica, utilizando um ponto de Gauss em cada aresta do volume de controle $\Omega_{i}$ sobre a esfera unitária.

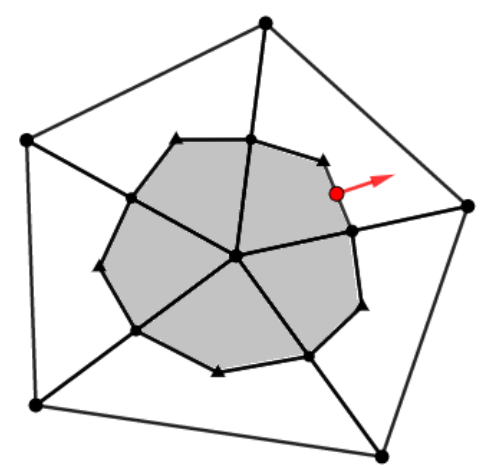

Figura 4.10: Ilustração do volume de controle $\Omega_{i}$ com um ponto de Gauss para $2^{a}$ ordem.

\begin{tabular}{|c|c|c|c|c|c|}
\hline Nível & Nós & Erro Máx & Razão Máx & Erro 2 & Razão 2 \\
\hline 2 & 162 & $2,85 \mathrm{E}-004$ & 0,00 & $3,67 \mathrm{E}-005$ & 0,00 \\
\hline 3 & 642 & $4,22 \mathrm{E}-005$ & 6,75 & $4,73 \mathrm{E}-006$ & 7,76 \\
\hline 4 & 2562 & $5,51 \mathrm{E}-006$ & 7,66 & $5,96 \mathrm{E}-007$ & 7,94 \\
\hline 5 & 10242 & $6,97 \mathrm{E}-007$ & 7,91 & $7,47 \mathrm{E}-008$ & 7,98 \\
\hline 6 & 40962 & $8,73 \mathrm{E}-008$ & 7,98 & $9,34 \mathrm{E}-009$ & 8,00 \\
\hline 7 & 163842 & $1,09 \mathrm{E}-008$ & 7,99 & $1,17 \mathrm{E}-009$ & 8,00 \\
\hline 8 & 655362 & $1,37 \mathrm{E}-009$ & 8,00 & $1,46 \mathrm{E}-010$ & 8,00 \\
\hline
\end{tabular}

Tabela 4.9: Erros e razões para as normas do máximo e quadrático médio avaliados pela regra de Simpson Composta e Quadratura Gaussiana, utilizando-se um ponto de Gauss.

A diferença dos erros estimados pelas regras de integração numérica, na Tabela 4.9 resulta na ordem $O\left(h^{Q}\right)=O\left(h^{3}\right)$, ou seja, apresentando $3^{\text {a }}$ ordem de precisão na integração numérica, como esperado em teoria. Dessa forma, a implementação da Quadratura de Gauss foi validada para um ponto de Gauss. 


\subsubsection{Utilizando dois pontos de Gauss}

Será avaliada a ordem resultante da integração numérica utilizando-se dois pontos de Gauss em cada aresta do volume de controle $\Omega_{i}$ sobre a esfera unitária.

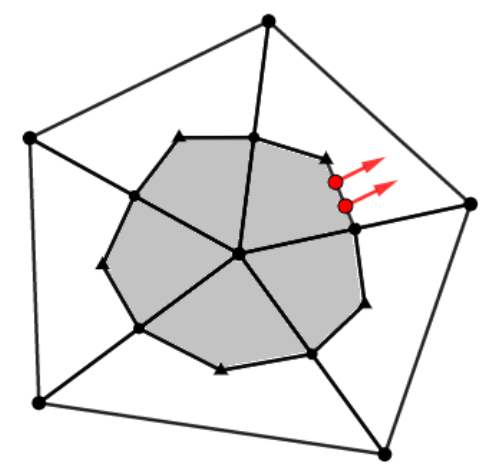

Figura 4.11: Ilustração do volume de controle $\Omega_{i}$ com dois pontos de Gauss para $3^{a}$ e $4^{a}$ ordens.

\begin{tabular}{|c|c|c|c|c|c|}
\hline Nível & Nós & Erro Máx & Razão Máx & Erro 2 & Razão 2 \\
\hline 2 & 162 & $4,14 \mathrm{E}-007$ & 0,00 & $3,36 \mathrm{E}-008$ & 0,00 \\
\hline 3 & 642 & $1,61 \mathrm{E}-008$ & 25,66 & $1,09 \mathrm{E}-009$ & 30,78 \\
\hline 4 & 2562 & $5,31 \mathrm{E}-010$ & 30,37 & $3,44 \mathrm{E}-011$ & 31,72 \\
\hline 5 & 10242 & $1,66 \mathrm{E}-011$ & 31,94 & $1,06 \mathrm{E}-012$ & 32,40 \\
\hline 6 & 40962 & $5,73 \mathrm{E}-013$ & 29,01 & $3,16 \mathrm{E}-014$ & 33,69 \\
\hline 7 & 163842 & $4,61 \mathrm{E}-013$ & 1,24 & $1,32 \mathrm{E}-014$ & 2,40 \\
\hline 8 & 655362 & $9,80 \mathrm{E}-013$ & 0,47 & $2,65 \mathrm{E}-014$ & 0,50 \\
\hline
\end{tabular}

Tabela 4.10: Erros e razões para as normas do máximo e quadrático médio avaliados pela regra de Simpson Composta e Quadratura Gaussiana, utilizando-se dois pontos de Gauss.

A diferença dos erros estimados pelas regras de integração numérica resulta na ordem $O\left(h^{Q}\right)=$ $O\left(h^{5}\right)$, ou seja, obtendo-se $5^{\text {a }}$ ordem de precisão para a integração numérica, conforme Tabela 4.10, a qual demonstra que a implementação da Quadratura de Gauss está validada para dois pontos de Gauss. Observa-se que as razões dos erros nas malhas de nível 7 e 8 não convergem para $5^{\mathrm{a}}$ ordem, pois os resultados estão próximos da precisão de máquina.

Portanto, a implementação da Regra de Quadratura Gaussiana permite precisão de $3^{\mathrm{a}}$ ordem utilizando-se um ponto de Gauss, e $5^{\mathrm{a}}$ ordem, utilizando dois pontos de Gauss, conforme Ascher e Greif (2011), e, apresentado pelos resultados numéricos nas respectivas Tabelas, demonstrando que a implementação da integração está validada para um e dois pontos de Gauss.

\subsection{Interpolação e integração}

O objetivo desta seção é validar a ordem resultante dos erros $O\left(h^{I}\right)+O\left(h^{P}\right)+O\left(h^{Q}\right)+O\left(h^{D}\right)$, descrita na equação (3.6), que será obtida após a interpolação e integração numérica. Dessa forma, deseja-se obter alta ordem de precisão do fluxo avaliado em todas as arestas dos volumes de controle. Conforme discutido anteriormente, a integral exata será dada pela regra de Simpson Composta e a integral estimada pela regra da Quadratura Gaussiana.

\section{Função Teste}

A função teste, descrita na equação (4.13), será utilizada para determinar o valor exato nos pontos de Gauss e o campo de velocidade da equação (4.14). Para validar a ordem da interpolação e integração para um ponto e dois pontos de Gauss, será necessária a construção dos polinômios 
de reconstrução de $2^{\mathrm{a}}, 3^{\mathrm{a}}$ e $4^{\mathrm{a}}$ ordens para estimar o valor aproximado, ao invés de se utilizar o valor exato, conforme descrito na seção 4.2. Por fim, verifica-se a ordem resultante do processo de interpolação e integração em cada aresta, por meio do erro nas normas $L_{\infty}$ e $L_{2}$.

\subsubsection{Utilizando polinômio de $2^{\mathrm{a}}$ ordem}

O polinômio de reconstrução de $2^{\mathrm{a}}$ ordem, ou seja, $\phi_{i}^{1}$ é de grau 1 , na forma compacta é dado por $\phi_{i}^{1}+O\left(h^{I}\right)+O\left(h^{P}\right)+O\left(h^{Q}\right)$. O método de integração numérica, utilizando-se um ponto de Gauss, tem precisão de ordem $O\left(h^{Q}\right)=O\left(h^{3}\right)$.

\begin{tabular}{|c|c|c|c|c|c|}
\hline Nível & Nós & Erro Máx & Razão Máx & Erro 2 & Razão 2 \\
\hline 2 & 162 & $1,19 \mathrm{E}-02$ & 0,00 & $3,18 \mathrm{E}-03$ & 0,00 \\
\hline 3 & 642 & $1,45 \mathrm{E}-03$ & 8,21 & $3,84 \mathrm{E}-04$ & 8,27 \\
\hline 4 & 2562 & $1,91 \mathrm{E}-04$ & 7,61 & $4,75 \mathrm{E}-05$ & 8,08 \\
\hline 5 & 10242 & $2,35 \mathrm{E}-05$ & 8,10 & $5,92 \mathrm{E}-06$ & 8,03 \\
\hline 6 & 40962 & $2,97 \mathrm{E}-06$ & 7,92 & $7,38 \mathrm{E}-07$ & 8,01 \\
\hline 7 & 163842 & $3,72 \mathrm{E}-07$ & 7,98 & $9,22 \mathrm{E}-08$ & 8,01 \\
\hline 8 & 655362 & $4,65 \mathrm{E}-08$ & 8,00 & $1,15 \mathrm{E}-08$ & 8,00 \\
\hline
\end{tabular}

Tabela 4.11: Os erros apresentados são para as normas do máximo e quadrático médio avaliando-se a ordem resultante da interpolação e integração ao se utilizar um ponto de Gauss.

Sabe-se que ao integrar o polinômio de $2^{\text {a }}$ ordem, utilizando-se um ponto de Gauss tem-se

$$
\int_{a}^{b}\left(\phi^{1}+O\left(h^{2}\right)\right) d l+O\left(h^{Q}\right)=\tilde{\phi}^{1}+O\left(h^{3}\right)+O\left(h^{3}\right)=\tilde{\phi}^{1}+O\left(h^{3}\right) .
$$

Nesse caso, utilizando-se um polinômio de grau 1, que possui erro de truncamento de $2^{\mathrm{a}}$ ordem, após ser integrado, resulta no valor escalar $\tilde{\phi}^{1}$ com erro de $3^{\text {a }}$ ordem. O método de integração utilizando-se um ponto de Gauss é de $3^{\mathrm{a}}$ ordem e a menor ordem deve prevalecer. Conforme observado na Tabela 4.11, o erro do fluxo avaliado em todas as arestas de todos os volumes de controle resultante é de $3^{\mathrm{a}}$ ordem de precisão.

\subsubsection{Utilizando polinômio de $3^{\mathrm{a}}$ ordem}

O polinômio de reconstrução de $3^{\text {a }}$ ordem, ou seja, $\phi_{i}^{2}$ é de grau 2, na forma compacta é dado por $\phi_{i}^{2}+O\left(h^{I}\right)+O\left(h^{P}\right)+O\left(h^{Q}\right)$. O método de integração numérica utilizando-se dois pontos de Gauss, tem precisão de ordem $O\left(h^{Q}\right)=O\left(h^{5}\right)$.

\begin{tabular}{|c|c|c|c|c|c|}
\hline Nível & Nós & Erro Máx & Razão Máx & Erro 2 & Razão 2 \\
\hline 2 & 162 & $1,20 \mathrm{E}-02$ & 0,00 & $2,54 \mathrm{E}-03$ & 0,00 \\
\hline 3 & 642 & $9,55 \mathrm{E}-04$ & 12,60 & $1,84 \mathrm{E}-04$ & 13,84 \\
\hline 4 & 2562 & $6,55 \mathrm{E}-05$ & 14,57 & $1,20 \mathrm{E}-05$ & 15,33 \\
\hline 5 & 10242 & $4,28 \mathrm{E}-06$ & 15,31 & $7,60 \mathrm{E}-07$ & 15,75 \\
\hline 6 & 40962 & $2,71 \mathrm{E}-07$ & 15,77 & $4,78 \mathrm{E}-08$ & 15,90 \\
\hline 7 & 163842 & $1,71 \mathrm{E}-08$ & 15,83 & $3,00 \mathrm{E}-09$ & 15,95 \\
\hline 8 & 655362 & $1,08 \mathrm{E}-09$ & 15,88 & $1,88 \mathrm{E}-10$ & 15,98 \\
\hline
\end{tabular}

Tabela 4.12: Os erros apresentados são para as normas do máximo e quadrático médio avaliando-se a ordem resultante da interpolação e integração, ao utilizar dois pontos de Gauss.

Sabe-se que ao integrar o polinômio de $3^{\mathrm{a}}$ ordem utilizando-se dois pontos de Gauss tem-se

$$
\int_{a}^{b}\left(\phi^{2}+O\left(h^{3}\right)\right) d l+O\left(h^{Q}\right)=\tilde{\phi}^{2}+O\left(h^{4}\right)+O\left(h^{5}\right)=\tilde{\phi}^{2}+O\left(h^{4}\right) .
$$


Nesse caso, utilizando-se um polinômio de grau 2, que possui erro de truncamento de $3^{\mathrm{a}}$ ordem, após ser integrado, resulta no valor escalar $\tilde{\phi}^{2}$ com erro de $4^{\mathrm{a}}$ ordem. O método de integração utilizando-se um ponto de Gauss é de $5^{\mathrm{a}}$ ordem e a menor ordem deve prevalecer. Conforme observado na Tabela 4.12, o erro do fluxo avaliado em todas as arestas de todos os volumes de controle resultante é de $4^{\mathrm{a}}$ ordem de precisão.

\subsubsection{Utilizando polinômio de $4^{\mathrm{a}}$ ordem}

O polinômio de reconstrução de $4^{\mathrm{a}}$ ordem, ou seja, $\phi_{i}^{3}$ é de grau 3 , na forma compacta é dado por $\phi_{i}^{3}+O\left(h^{I}\right)+O\left(h^{P}\right)+O\left(h^{Q}\right)$. O método de integração numérica utilizando-se dois pontos de Gauss, tem precisão de ordem $O\left(h^{Q}\right)=O\left(h^{5}\right)$.

\begin{tabular}{|c|c|c|c|c|c|}
\hline Nível & Nós & Erro Máx & Razão Máx & Erro 2 & Razão 2 \\
\hline 2 & 162 & $9,80 \mathrm{E}-04$ & 0,00 & $1,87 \mathrm{E}-04$ & 0,00 \\
\hline 3 & 642 & $3,79 \mathrm{E}-05$ & 25,87 & $6,49 \mathrm{E}-06$ & 28,83 \\
\hline 4 & 2562 & $1,44 \mathrm{E}-06$ & 26,36 & $2,16 \mathrm{E}-07$ & 30,03 \\
\hline 5 & 10242 & $4,65 \mathrm{E}-08$ & 30,93 & $6,89 \mathrm{E}-09$ & 31,38 \\
\hline 6 & 40962 & $1,56 \mathrm{E}-09$ & 29,80 & $2,16 \mathrm{E}-10$ & 31,85 \\
\hline 7 & 163842 & $5,04 \mathrm{E}-11$ & 30,95 & $6,76 \mathrm{E}-12$ & 31,96 \\
\hline 8 & 655362 & $6,92 \mathrm{E}-12$ & 7,28 & $3,61 \mathrm{E}-13$ & 18,75 \\
\hline
\end{tabular}

Tabela 4.13: Os erros apresentados são para as normas do máximo e quadrático médio avaliando-se a ordem resultante da interpolação e integração, ao utilizar dois pontos de Gauss.

Sabe-se que ao integrar o polinômio de $4^{\mathrm{a}}$ ordem utilizando-se dois pontos de Gauss tem-se

$$
\int_{a}^{b}\left(\phi^{3}+O\left(h^{4}\right)\right) d l+O\left(h^{Q}\right)=\tilde{\phi^{3}}+O\left(h^{5}\right)+O\left(h^{5}\right)=\tilde{\phi^{3}}+O\left(h^{5}\right)
$$

Nesse caso, utilizando-se um polinômio de grau 3, que possui erro de truncamento de $4^{\mathrm{a}}$ ordem, após ser integrado, resulta no valor escalar $\phi^{3}$ com erro de $5^{\mathrm{a}}$ ordem. O método de integração utilizando-se um ponto de Gauss é de $5^{\mathrm{a}}$ ordem e a menor ordem deve prevalecer. Conforme observado na Tabela 4.13, o erro do fluxo avaliado em todas as arestas de todos os volumes de controle resultante é de $5^{\mathrm{a}}$ ordem de precisão. Observa-se uma queda da taxa de convergência na malha de nível 8, pois resultados estão próximos da precisão de máquina.

Conclui-se que a ordem final $\left(3^{\mathrm{a}}, 4^{\mathrm{a}}\right.$ e $5^{\mathrm{a}}$ ordens), na integração dos polinômios de reconstrução, está de acordo com a ordem esperada em teoria e que o erro de projeção da ordem $O\left(h^{2}\right)$ não afetou a ordem resultante do processo de interpolação e integração numérica

\subsection{Discretização do divergente}

O objetivo deste tópico será validar a ordem resultante da discretização do operador divergente, dada pelas ordens dos erros $O\left(h^{I}\right)+O\left(h^{P}\right)+O\left(h^{Q}\right)+O\left(h^{D}\right)$. De acordo com Peixoto e Barros (2013), a distribuição do erro de discretização do divergente está ligada à distribuição do índice de alinhamento presente na malha icosaédrica, indicando maiores erros em polígonos não alinhados. Mostrou-se que para quaisquer polígonos esféricos, tem-se pelo menos ordem 1 de aproximação do divergente pelo método dos fluxos nos pontos médios das arestas. Assim, pode-se esperar ordem 2 de discretização do divergente em polígonos alinhados e, pelo menos, ordem 1, caso contrário. Tais resultados valem para qualquer malha geodésica e para quaisquer operadores (divergente, rotacional e laplaciano).

Para avaliar os resultados numéricos da discretização do divergente, com o método de alta ordem proposto para a superfície esférica, serão utilizadas as métricas do erro máximo e do quadrático médio, definidas na seção 4.1, por meio da equação (4.1) e (4.2). 
Como o objetivo deste trabalho é obter um método de alta ordem na esfera, vamos recordar aqui a equação do transporte de um escalar, dada por

$$
\frac{d \bar{\phi}_{i}}{d t}=-\frac{1}{\left|\Omega_{i}\right|} \int_{\partial \Omega_{i}}(\vec{V} \rho \phi) \cdot \vec{n} d \partial \Omega_{i}
$$

onde, $\rho$ é a densidade do fluido e $\vec{V}$ é o vetor velocidade do fluido.

Considerando que a densidade seja igual a um e aplicando o teorema da divergência e quadratura gaussiana, tem-se

$$
\frac{1}{\left|\Omega_{i}\right|} \sum_{j=1}^{m} \int_{e_{j}}(\vec{V} \phi)_{e_{j}} \cdot \vec{n}_{e_{j}} d l \approx \frac{1}{\left|\Omega_{i}\right|} \sum_{j=1}^{m} \sum_{k=1}^{n}\left(\vec{V} e_{j, k} \cdot \vec{n}_{e_{j}}\right) \phi_{e_{j, k}} w_{e_{j, k}} l_{e_{j, k}}
$$

onde, $\phi_{e_{j, k}}$ é a concentração da substância avaliada nos pontos de Gauss $r_{j, k}$ na aresta $e_{j}, \vec{V}_{e_{j, k}}$ é o vetor velocidade avaliado nos pontos de Gauss $r_{j, k}$ na aresta $e_{j}, \vec{n}_{e_{j}}$ é o vetor unitário normal a aresta $e_{j}, l_{e_{j, k}}$ é o comprimento da aresta $e_{j}, w_{e_{j, k}}$ são os pesos de Gauss $k$ normalizados para aresta $e_{j},\left|\Omega_{i}\right|$ representa a área do volume de controle $\Omega_{i}, m$ número de arestas do volume de controle $\Omega_{i}$ e $n$ representa a quantidade de pontos de Gauss para que a integral de linha seja exata, caso o integrando seja um polinômio de grau p.

\subsubsection{Procedimento para validar o divergente}

O objetivo desse teste é avaliar a ordem de discretização do operador divergente, por isso não será utilizado o polinômio de reconstrução, resultando em

$$
(\nabla \cdot \vec{V})_{i}=\frac{1}{\left|\Omega_{i}\right|}\left(\sum_{j=1}^{m} \sum_{k=1}^{n} \vec{V}_{e_{j, k}} \cdot \vec{n}_{j} w_{e_{j, k}}\right)_{i}
$$

Para o processo de validação utiliza-se um campo não divergente, ou seja, divergente nulo definido por

$$
\vec{V}(x, y, z)=(-y, x, 0)
$$

Dessa forma, é possível conhecer o valor exato do divergente, pois será nulo para um campo não divergente. Na sequência, será comparado o valor exato com o valor estimado do divergente, por meio da regra da quadradura gaussiana.

\subsubsection{Erro do divergente utilizando-se método de $2^{\mathrm{a}}$ ordem}

Para o método de $2^{\mathrm{a}}$ ordem, os resultados de FV-OLG serão comparados com o trabalho de Peixoto (2013), cujo volume de controle é obtido a partir da malha primal formada apenas por triângulos esféricos, ilustrado na Figura 4.12. Por meio dessa malha, determina-se os circuncentros desses triângulos e conecta-os por segmentos geodésicos, obtendo-se a malha dual formada por volumes de controle com o formato de pentágonos e hexágonos esféricos. 


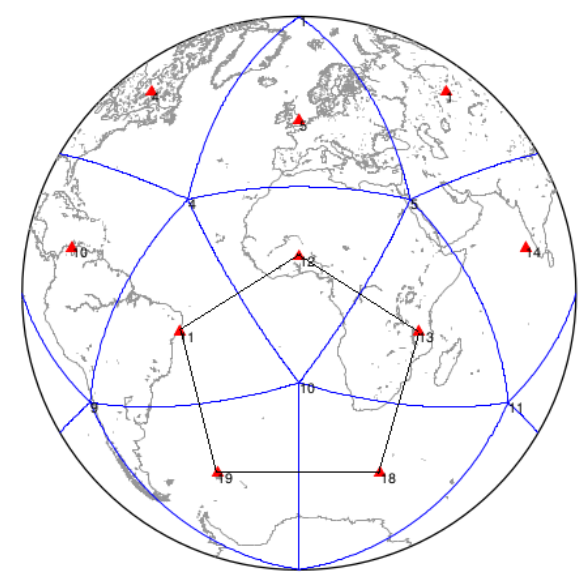

Figura 4.12: Volume de controle utilizado por Peixoto (2013).

A integral do fluxo é obtida utilizando-se a regra do ponto médio, ou seja, utilizando-se quadratura gaussiana em um ponto de Gauss. A ordem resultante na norma do erro máximo é 1 e do quadrático médio é superior à ordem 1, como pode ser observado nas últimas duas colunas da Tabela 4.14. Conforme foi mencionado, isso deve-se a presença dos polígonos não alinhados na malha icosaédrica, que terá sempre um total de 12 pentágonos, devido à projeção das faces do icosaedro para a superfície esférica.

\begin{tabular}{|c|c|c|c|c|c|}
\hline Nível & Nós & Erro Máx & Razão Máx & Erro 2 & Razão 2 \\
\hline 2 & 162 & $1,58 \mathrm{E}-003$ & 0,00 & $5,86 \mathrm{E}-004$ & 0,00 \\
\hline 3 & 642 & $9,79 \mathrm{E}-004$ & 1,61 & $2,75 \mathrm{E}-004$ & 2,13 \\
\hline 4 & 2562 & $5,12 \mathrm{E}-004$ & 1,91 & $1,08 \mathrm{E}-004$ & 2,55 \\
\hline 5 & 10242 & $2,59 \mathrm{E}-004$ & 1,98 & $4,02 \mathrm{E}-005$ & 2,69 \\
\hline 6 & 40962 & $1,30 \mathrm{E}-004$ & 1,99 & $1,45 \mathrm{E}-005$ & 2,77 \\
\hline 7 & 163842 & $6,50 \mathrm{E}-005$ & 2,00 & $5,19 \mathrm{E}-006$ & 2,79 \\
\hline 8 & 655362 & $3,25 \mathrm{E}-005$ & 2,00 & $1,84 \mathrm{E}-006$ & 2,82 \\
\hline
\end{tabular}

Tabela 4.14: Erro na estimativa do divergente de campo de rotação para malha de Voronoi com método de $2^{a}$ ordem. São apresentados os erros máximos e quadráticos médios, além das razões entre erros de malhas, (Peixoto, 2013).

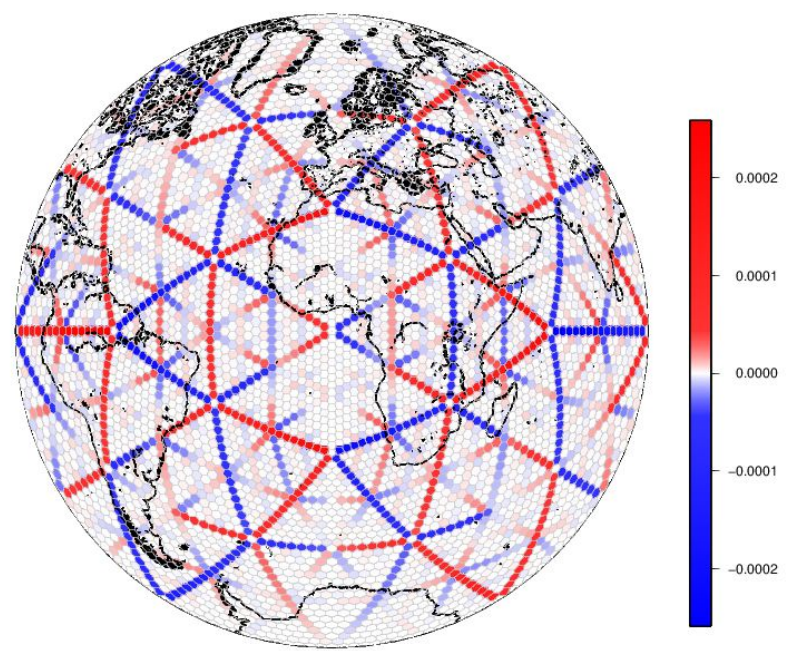

Figura 4.13: Erros associados à discretização do divergente utilizando-se um ponto de Gauss em uma malha icosaédrica de nível 6, (Peixoto, 2013). 
O volume de controle do método de alta ordem proposto FV-OLG é formado a partir da malha primal constituída apenas por triângulos esféricos, conforme ilustrado na Figura 4.14. Por meio dessa malha, determinam-se os baricentros desses triângulos e os pontos médios de suas arestas e conecta-os por segmentos geodésicos, formando uma outra malha dual constituída por volumes de controle esféricos, que difere dos volumes de controle do trabalho de Peixoto (2013).

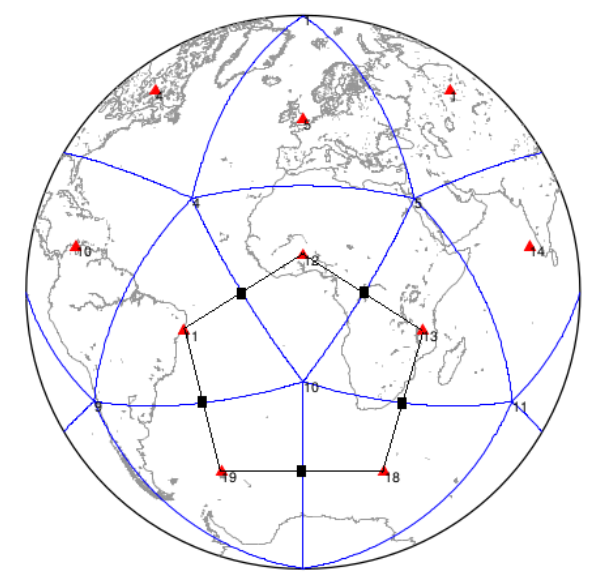

Figura 4.14: Volume de controle utilizado no método $F V$-OLG.

\begin{tabular}{|c|c|c|c|c|c|}
\hline Nível & Nós & Erro Máx & Razão Máx & Erro 2 & Razão 2 \\
\hline 2 & 162 & $1,65 \mathrm{E}-004$ & 0,00 & $6,96 \mathrm{E}-005$ & 0,00 \\
\hline 3 & 642 & $1,03 \mathrm{E}-004$ & 1,60 & $2,70 \mathrm{E}-005$ & 2,58 \\
\hline 4 & 2562 & $5,25 \mathrm{E}-005$ & 1,96 & $8,45 \mathrm{E}-006$ & 3,19 \\
\hline 5 & 10242 & $2,57 \mathrm{E}-005$ & 2,04 & $2,45 \mathrm{E}-006$ & 3,45 \\
\hline 6 & 40962 & $1,25 \mathrm{E}-005$ & 2,06 & $6,83 \mathrm{E}-007$ & 3,59 \\
\hline 7 & 163842 & $6,09 \mathrm{E}-006$ & 2,06 & $1,86 \mathrm{E}-007$ & 3,68 \\
\hline 8 & 655362 & $3,03 \mathrm{E}-006$ & 2,01 & $5,46 \mathrm{E}-008$ & 3,41 \\
\hline
\end{tabular}

Tabela 4.15: Erro na estimativa do divergente de campo de rotação para malha de Voronoi com FV-OLG de $2^{a}$ ordem. São apresentados os erros máximos e quadráticos médios, além das razões entre erros de malhas.

Observando a Tabela 4.15, temos convergência de ordem 1 na norma do máximo, mas um pouco acima de ordem 1 na norma quadrática. Esses resultados estão de acordo com os resultados previstos por Peixoto e Barros (2013), uma vez que para se obter a ordem 2 é necessário que a discretização do divergente seja avaliado no centro de massa das células e que os polígonos estejam alinhados, caso contrário, apenas a primeira ordem é garantida. Note também, que devido ao volume de controle do método FV-OLG ter o dobro de faces, o erro obtido em cada norma geralmente será a metade do erro obtido nos volumes de controle hexagonais/pentagonais. 


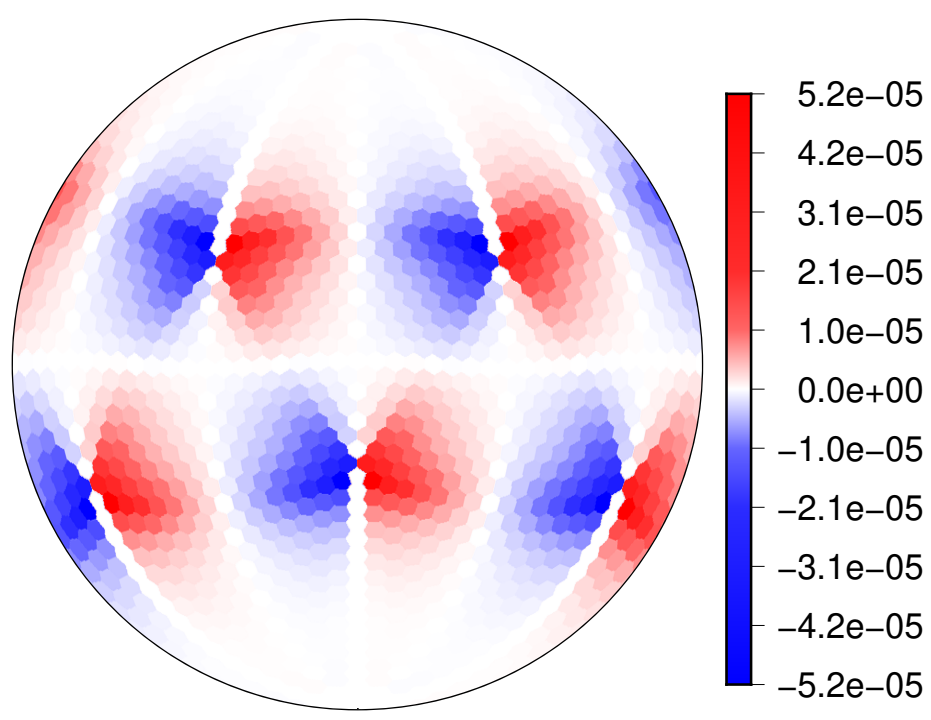

Figura 4.15: Erros associados à discretização do divergente, utilizando-se um ponto de Gauss em uma malha icosaédrica de nível 4, Método FV-OLG.

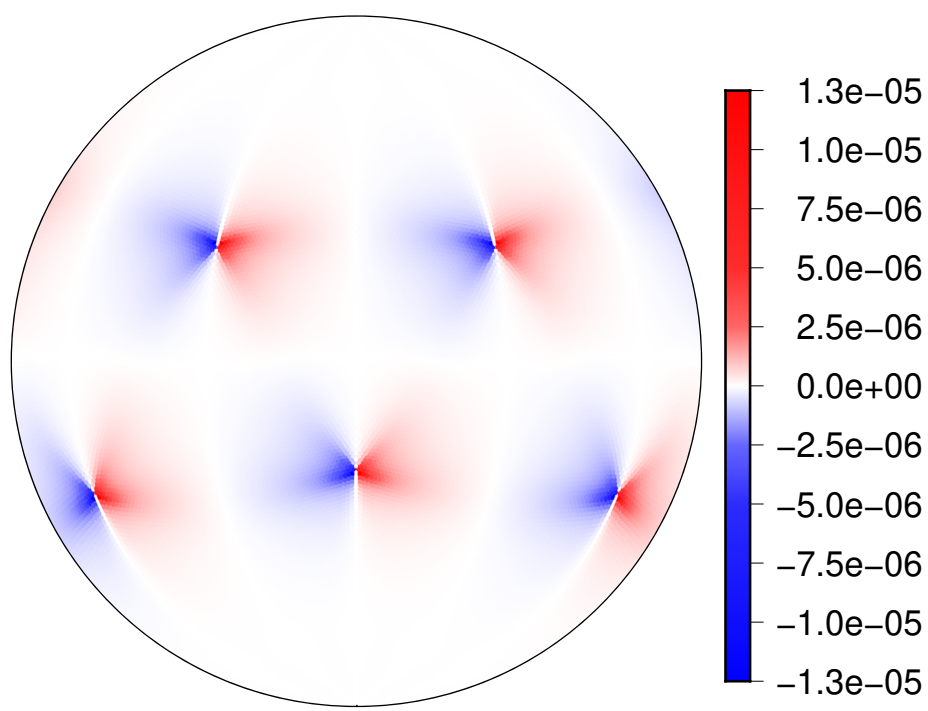

Figura 4.16: Erros associados à discretização do divergente, utilizando-se um ponto de Gauss em uma malha icosaédrica de nível 6, Método FV-OLG.

Dado o campo vetorial em estudo, no trabalho de Peixoto e Barros (2013), percebeu-se que a distribuição de erro parece claramente ligada à distribuição do índice de alinhamento, indicando maiores erros onde os polígonos não são alinhados. Assim, conforme observa-se por meio das Figuras 4.15 e 4.16, os erros estão concentrados nos polígonos pentagonais.

\subsubsection{Erro do divergente utilizando-se método de $3^{\mathrm{a}}$ e $4^{\mathrm{a}}$ ordens}

Serão apresentados os resultados da discretização do divergente utilizando-se os métodos de $3^{\text {a }}$ e $4^{\mathrm{a}}$ ordens, ou seja, a integral será avaliada utilizando-se dois pontos de Gauss em cada aresta do volume de controle $\Omega_{i}$ em estudo, sobre a superfície esférica. Os resultados serão iguais em relação a integração, pois não utilizam polinômio de reconstrução, somente os mesmos pontos de Gauss. 


\begin{tabular}{|c|c|c|c|c|c|}
\hline Nível & Nós & Erro Máx & Razão Máx & Erro 2 & Razão 2 \\
\hline 2 & 162 & $1,31 \mathrm{E}-008$ & 0,00 & $5,53 \mathrm{E}-009$ & 0,00 \\
\hline 3 & 642 & $1,99 \mathrm{E}-009$ & 6,55 & $5,38 \mathrm{E}-010$ & 10,28 \\
\hline 4 & 2562 & $2,62 \mathrm{E}-010$ & 7,62 & $4,20 \mathrm{E}-011$ & 12,80 \\
\hline 5 & 10242 & $2,13 \mathrm{E}-010$ & 1,23 & $4,38 \mathrm{E}-011$ & 0,96 \\
\hline 6 & 40962 & $1,64 \mathrm{E}-009$ & 0,13 & $3,50 \mathrm{E}-010$ & 0,13 \\
\hline 7 & 163842 & $1,87 \mathrm{E}-008$ & 0,09 & $2,78 \mathrm{E}-009$ & 0,13 \\
\hline 8 & 655362 & $1,29 \mathrm{E}-007$ & 0,14 & $2,22 \mathrm{E}-008$ & 0,13 \\
\hline
\end{tabular}

Tabela 4.16: Erro na estimativa do divergente de campo de rotação para malha de Voronoi com o método de $3^{a}$ e $4^{a}$ ordens. São apresentados os erros máximos e quadráticos médios, além das razões entre erros de malhas.

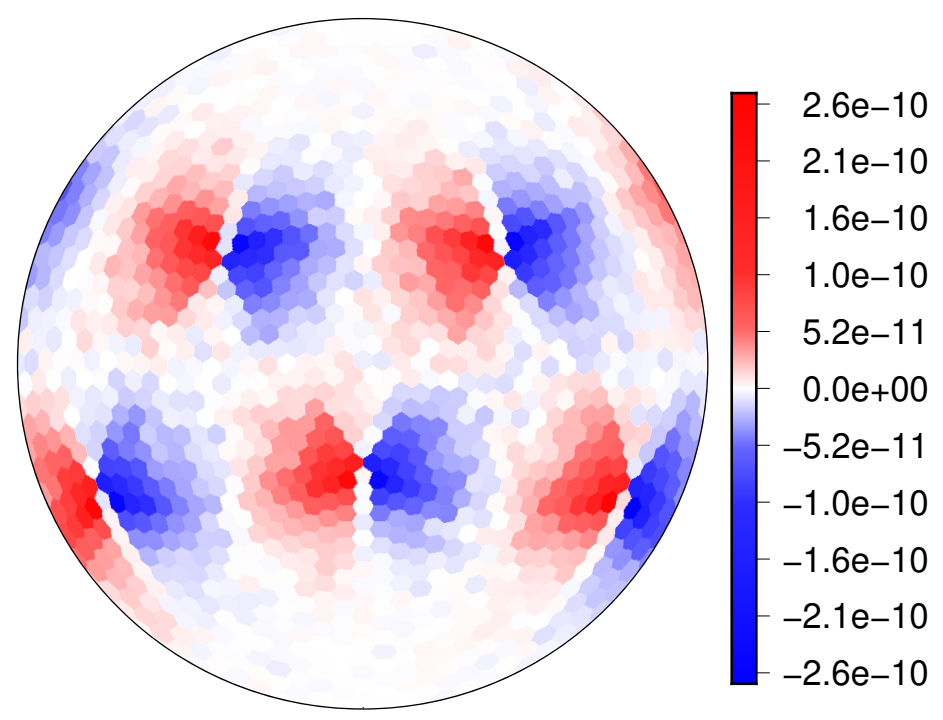

Figura 4.17: Erros associados à discretização do divergente, utilizando-se dois pontos de Gauss em uma malha icosaédrica de nível 4, Método FV-OLG.

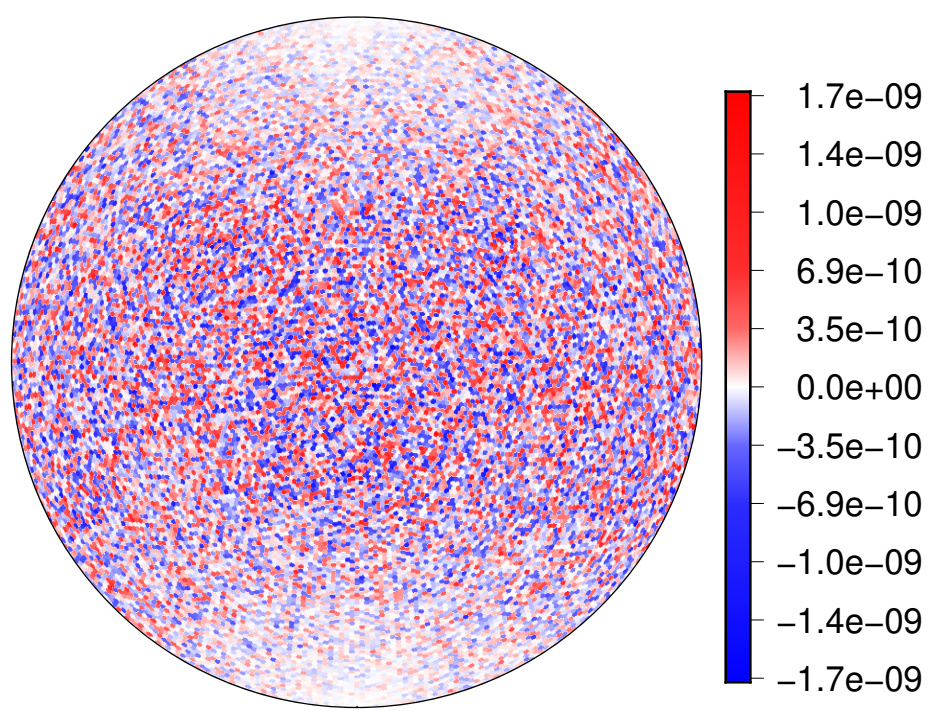

Figura 4.18: Erros associados à discretização do divergente, utilizando-se dois pontos de Gauss em uma malha icosaédrica de nível 6 , Método FV-OLG.

A partir da Tabela 4.16, observa-se que a taxa de convergência da discretização do operador divergente é superior à ordem 3. O que representa um ganho na precisão desse operador em malhas geodésicas, conforme deseja-se em um método de alta ordem para a equação do transporte. A 
diminuição da razão dos erros, está relacionada com os erros de truncamento e arredondamento inerentes aos demais processos numéricos, ou seja, outras rotinas do método de alta ordem devem estar próximas da precisão de máquina, por isso, não consegue-se observar a ordem em todas as malhas em estudo.

\subsection{Comentários}

As etapas necessárias para validar o método de alta ordem proposto para a esfera, incluindo a interpolação, integração, interpolação e integração e a discretização do divergente com suas respectivas ordens, foram avaliadas, permitindo concluir que o método FV-OLG foi transposto para superfície esférica com êxito. No próximo capítulo, o método será avaliado em testes clássicos da literatura, comparando os resultados com os métodos de alta ordem abordados no capítulo 2. 


\section{Capítulo 5}

\section{Aplicação da equação de advecção}

Modelos atmosféricos envolvem a solução da equação de advecção, ou equação do transporte, devido à necessidade de modelar o transporte de várias substâncias na atmosfera. Dessa forma, a solução da equação de advecção é frequentemente usada para testar métodos numéricos (Nair e Lauritzen, 2010). Ao advectar uma substância sobre a superfície esférica pode-se ter concentrações negativas e "overshoots", principalmente em regiões com descontinuidade. Uma forma de reduzir por completo ou atenuar esse efeito é a utilização de um limitador, proporcionando uma diminuição da dispersão numérica durante o transporte da substância.
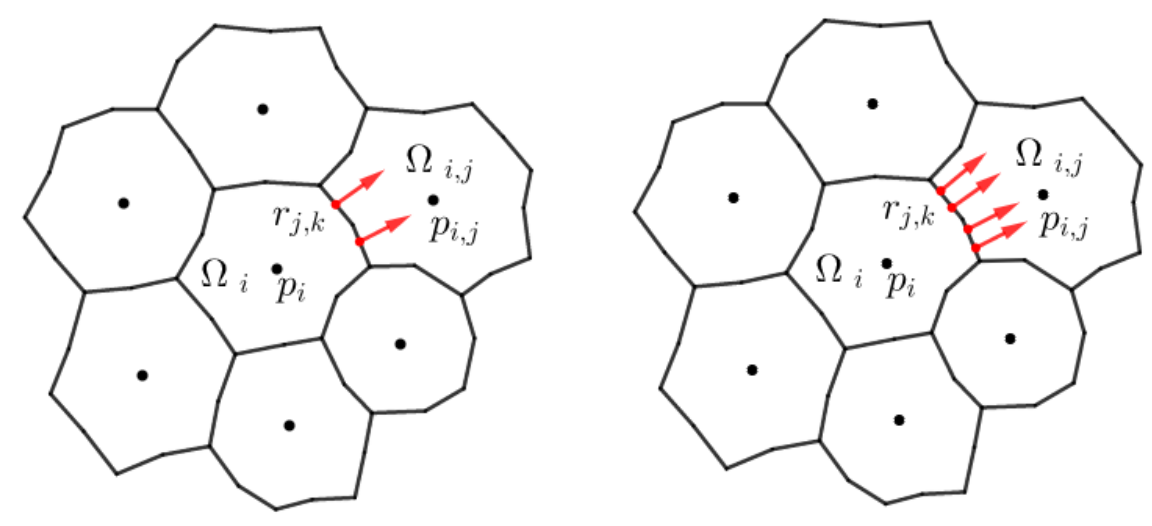

Figura 5.1: Ilustração com os pontos de Gauss para $2^{a}$ ordem (esquerda) e com os pontos de Gauss para $3^{a}$ ordem, que também serve para $4^{a}$ ordem (direita)

O limitador implementado no método FV-OLG avalia o valor do polinômio de reconstrução $\phi_{i}^{p}\left(r_{j, k}\right)$ de grau $p$ nos pontos $r_{j, k}$ de Gauss, localizados nas arestas do volume de controle $\Omega_{i}$, conforme Figura 5.1. O mesmo polinômio de reconstrução também é avaliado nos vértices dos volumes de controle $\Omega_{i}$ e seus primeiros vizinhos $\Omega_{i, j}$, sendo denotados pelos pontos $p_{i}$ e $p_{i, j}$, respectivamente. Nesse contexto, define-se $m=\min \left\{\phi_{i}^{p}\left(p_{i}\right), \phi_{i}^{p}\left(p_{i, j}\right)\right\}$ e $M=\operatorname{máx}\left\{\phi_{i}^{p}\left(p_{i}\right), \phi_{i}^{p}\left(p_{i, j}\right)\right\}$. Assim, o limitador será dado por

$$
\phi_{i}^{p}\left(r_{j, k}\right)=\left\{\begin{array}{l}
m \text { se } \phi_{i}^{p}\left(r_{j, k}\right)<m, \\
M \text { se } \phi_{i}^{p}\left(r_{j, k}\right)>M, \\
\phi_{i}^{p}\left(r_{j, k}\right), \text { caso contrário. }
\end{array}\right.
$$

O objetivo do limitador descrito na equação (5.1), consiste em efetuar uma interpolação durante o cálculo do fluxo nas arestas do volume de controle $\Omega_{i}$, comparar o valor obtido com os valores escalares interpolados nos vértices dos primeiros vizinhos, incluindo o vértice do volume de controle $\Omega_{i}$. Dessa forma, impõe-se que o valor interpolado em cada ponto de Gauss $\phi_{i}^{p}\left(r_{j, k}\right)$ esteja sempre restrito entre o valor mínimo e máximo dos valores considerados na interpolação numérica (Majewski et al., 2002). Esse procedimento pode afetar a ordem do método, mas garante controlar 
as oscilações numéricas, evitando concentrações negativas da substância transportada e "overshoots", características desejáveis para a equação de adveção do método numérico proposto para a superfície esférica.

Para se avaliar o método FV-OLG de alta ordem proposto para a superfície esférica, os resultados obtidos serão comparados com os trabalhos dos pesquidadores abordados no capítulo 2. Os testes abordam a equação de adveç̧ão de complexidade variada sem e com a utilização de limitador. A avaliação qualitativa e quantitativa será feita por meio de gráficos e pelas normas do erro máximo e do quadrático médio, dadas por

$$
\begin{gathered}
L_{\infty}=\max _{\Omega_{i}}\left|\bar{\phi}_{\text {aproximada }}-\bar{\phi}_{\text {exata }}\right| / \max _{\Omega_{i}}\left|\bar{\phi}_{\text {exata }}\right|, \\
L_{2}=\left[\sum_{\Omega_{i}}\left|\Omega_{i}\right|\left(\bar{\phi}_{\text {aproximada }}-\bar{\phi}_{\text {exata }}\right)^{2}\right]^{1 / 2} /\left[\sum_{\Omega_{i}}\left|\Omega_{i}\right|\left(\bar{\phi}_{\text {exata }}\right)^{2}\right]^{1 / 2} .
\end{gathered}
$$

As normas apresentadas nas equações (5.2) e (5.3) são aplicadas para cada volume de controle $\Omega_{i}$ da malha icosaédrica, cuja área geodésica é representada por $\left|\Omega_{i}\right|$. O termo $\bar{\phi}_{\text {exata }}$ representa a média da solução exata (condição inicial) e $\bar{\phi}_{\text {estimada }}$ representa a média da solução estimada, que são armazenadas nos vértices dos volumes de controle.

Será também avaliado o tempo de CPU (em segundos) utilizado pelo método FV-OLG, por meio da subrotina CPU-TIME do Fortran 90, que retorna um valor real, representando o tempo de execução em segundos para cada função teste utilizada na equação de advecção na superfície esférica.

A condição de CFL utilizada foi a mesma descrita nos trabalhos comparados do capítulo 2 . Nos demais testes, o número de Courant foi de 0,5785 e utilizado o esquema RK-4 para avaliar a evolução temporal. Nesta seção, primeiramente serão apresentados os resultados numéricos sem limitador e posteriormente, os resultados com limitador.

\subsection{Resultados numéricos sem limitador}

\subsubsection{Uma colina de gaussiana}

O primeiro teste consiste no transporte de uma colina de gaussiana ao redor da Terra. Por ser uma função diferenciável, é um bom teste para verificar com rigor a ordem do método numérico e sua respectiva taxa de convergência na esfera, pois a descontinuidade limita a taxa de convergência real de qualquer método de volumes finitos.

A condição inicial escalar dada por uma colina de gaussiana (Subich, 2018), em coordenadas geográficas $(\lambda, \theta)$, tem a seguinte forma

$$
\phi(\lambda, \theta)=h(\lambda, \theta)
$$

onde, $h$ é definido em coordenadas cartesianas como

$$
h(x, y, z)=\exp \left\{-3 \pi^{2}\left[\left(x-x_{i}\right)^{2}+\left(y-y_{i}\right)^{2}+\left(z-z_{i}\right)^{2}\right]\right\} .
$$

O centro da colina de gaussiana foi fixado em $\left(\lambda_{c}, \theta_{c}\right)=(0,0)$, ou seja, no cruzamento entre a linha do Equador e o meridiano de Greenwich.

O campo de velocidade é dado por

$$
\begin{aligned}
& u=\frac{2 \pi a \cdot \cos (\lambda)}{12 \text { dias }}, \\
& v=0,
\end{aligned}
$$

onde, $a=6.37122 \times 10^{6} \mathrm{~m}$ é o raio da Terra e 12 dias é o tempo necessário para uma volta completa 
ao redor da Terra, período de revolução.

\section{Resultados numéricos utilizando-se os métodos de $2^{\mathrm{a}}, 3^{\mathrm{a}}$ e $4^{\mathrm{a}}$ ordens}

Foram avaliados o transporte de uma colina de gaussiana sem limitador para vários níveis de malha. Após uma volta completa ao redor da Terra, a solução final coincide com a solução inicial. Dessa forma, os resultados nas normas do erro do máximo e do quadrático médio foram calculados e serão apresentados a seguir para as ordens em estudo.

\begin{tabular}{|c|c|c|c|c|c|c|}
\hline Nível & Nós & Erro Máx & Razão Máx & Erro 2 & Razão 2 & Tempo (s) \\
\hline 4 & 2562 & $1,32 \mathrm{E}-001$ & 0,00 & $1,11 \mathrm{E}-001$ & 0,00 & 13,4 \\
\hline 5 & 10242 & $3,69 \mathrm{E}-002$ & 3,56 & $3,03 \mathrm{E}-002$ & 3,65 & 118,3 \\
\hline 6 & 40962 & $9,25 \mathrm{E}-003$ & 3,99 & $7,63 \mathrm{E}-003$ & 3,98 & 1057,2 \\
\hline 7 & 163842 & $2,28 \mathrm{E}-003$ & 4,06 & $1,91 \mathrm{E}-003$ & 4,01 & 8936,1 \\
\hline
\end{tabular}

Tabela 5.1: Erros e tempo de CPU associados à reconstrução de uma colina de gaussiana em uma malha icosaédrica com otimização SCVT, utilizando-se o método de $2^{a}$ ordem sem limitador.

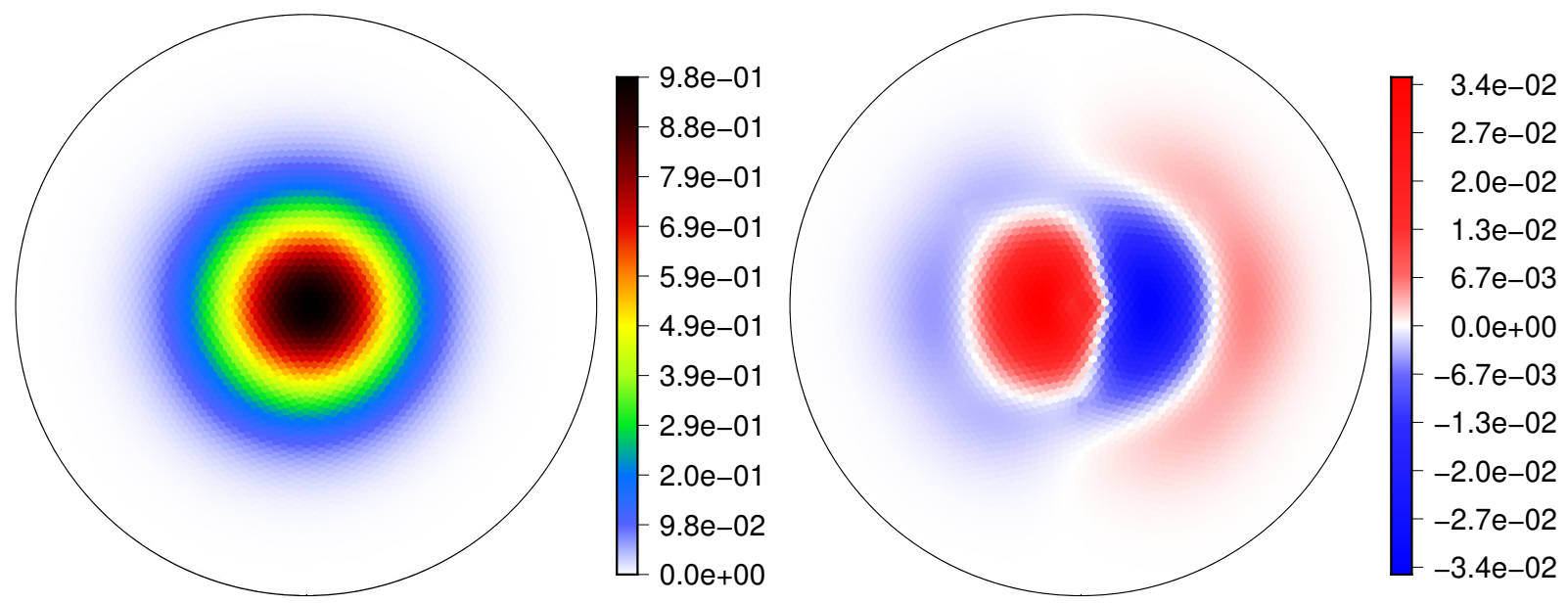

Figura 5.2: Solução final e erro no transporte de uma colina de gaussiana ao redor da Terra em uma malha icosaédrica de nível 5 com otimização SCVT, utilizando-se o método de $2^{a}$ ordem sem limitador.

\begin{tabular}{|c|c|c|c|c|c|c|}
\hline Nível & Nós & Erro Máx & Razão Máx & Erro 2 & Razão 2 & Tempo (s) \\
\hline 4 & 2562 & $1,41 \mathrm{E}-001$ & 0,00 & $9,70 \mathrm{E}-002$ & 0,00 & 30,6 \\
\hline 5 & 10242 & $2,71 \mathrm{E}-002$ & 5,21 & $1,67 \mathrm{E}-002$ & 5,79 & 234,7 \\
\hline 6 & 40962 & $3,74 \mathrm{E}-003$ & 7,23 & $2,24 \mathrm{E}-003$ & 7,48 & 2711,8 \\
\hline 7 & 163842 & $4,75 \mathrm{E}-004$ & 7,88 & $2,83 \mathrm{E}-004$ & 7,91 & 19426,4 \\
\hline
\end{tabular}

Tabela 5.2: Erros e tempo de CPU associados à reconstrução de uma colina de gaussiana em uma malha icosaédrica com otimização SCVT, utilizando-se o método de $3^{a}$ ordem sem limitador. 

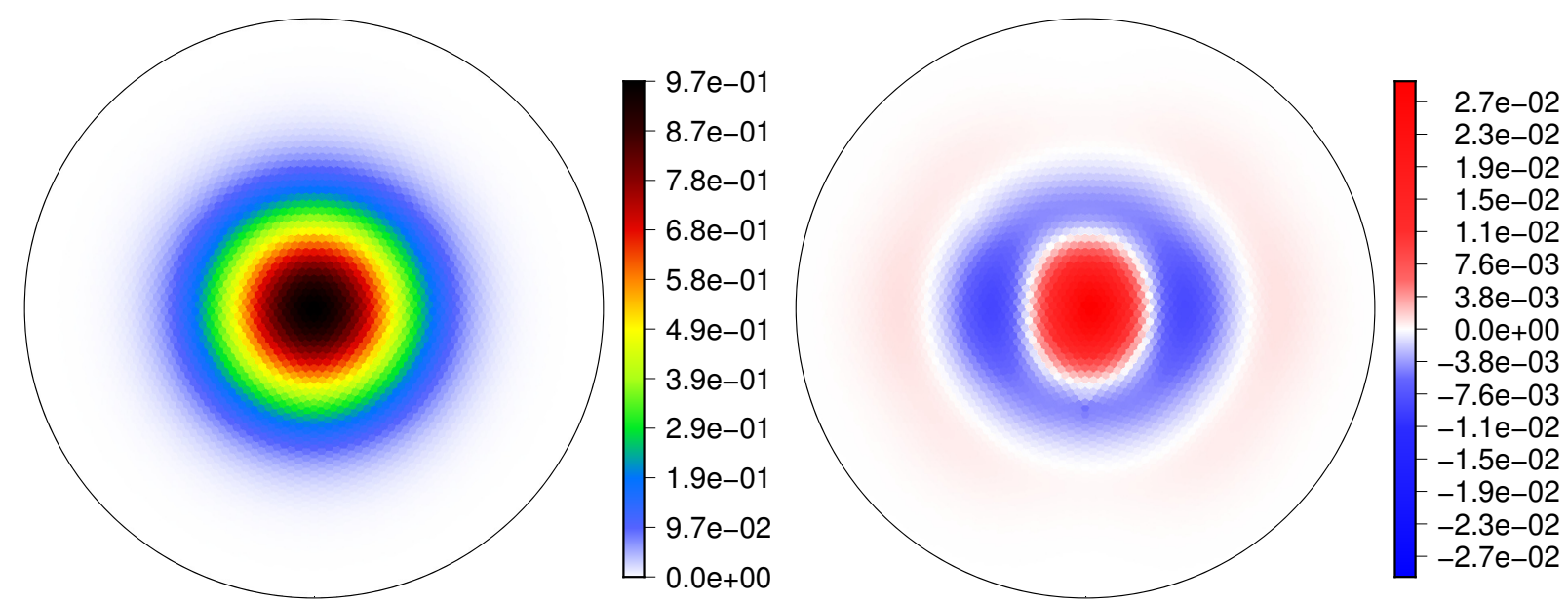

Figura 5.3: Solução final e erro no transporte de uma colina de gaussiana ao redor da Terra em uma malha icosaédrica de nível 5 com otimização SCVT, utilizando-se o método de $3^{a}$ ordem sem limitador.

\begin{tabular}{|c|c|c|c|c|c|c|}
\hline Nível & Nós & Erro Máx & Razão Máx & Erro 2 & Razão 2 & Tempo (s) \\
\hline 4 & 2562 & $9,27 \mathrm{E}-003$ & 0,00 & $7,00 \mathrm{E}-003$ & 0,00 & 31,8 \\
\hline 5 & 10242 & $6,93 \mathrm{E}-004$ & 13,39 & $4,62 \mathrm{E}-004$ & 15,14 & 247,8 \\
\hline 6 & 40962 & $5,23 \mathrm{E}-005$ & 13,23 & $3,20 \mathrm{E}-005$ & 14,45 & 1952,0 \\
\hline 7 & 163842 & $4,56 \mathrm{E}-006$ & 11,48 & $2,76 \mathrm{E}-006$ & 11,57 & 19185,4 \\
\hline
\end{tabular}

Tabela 5.3: Erros e tempo de CPU associados à reconstrução de uma colina de gaussiana em uma malha icosaédrica com otimização SCVT, utilizando-se o método de $4^{a}$ ordem sem limitador.
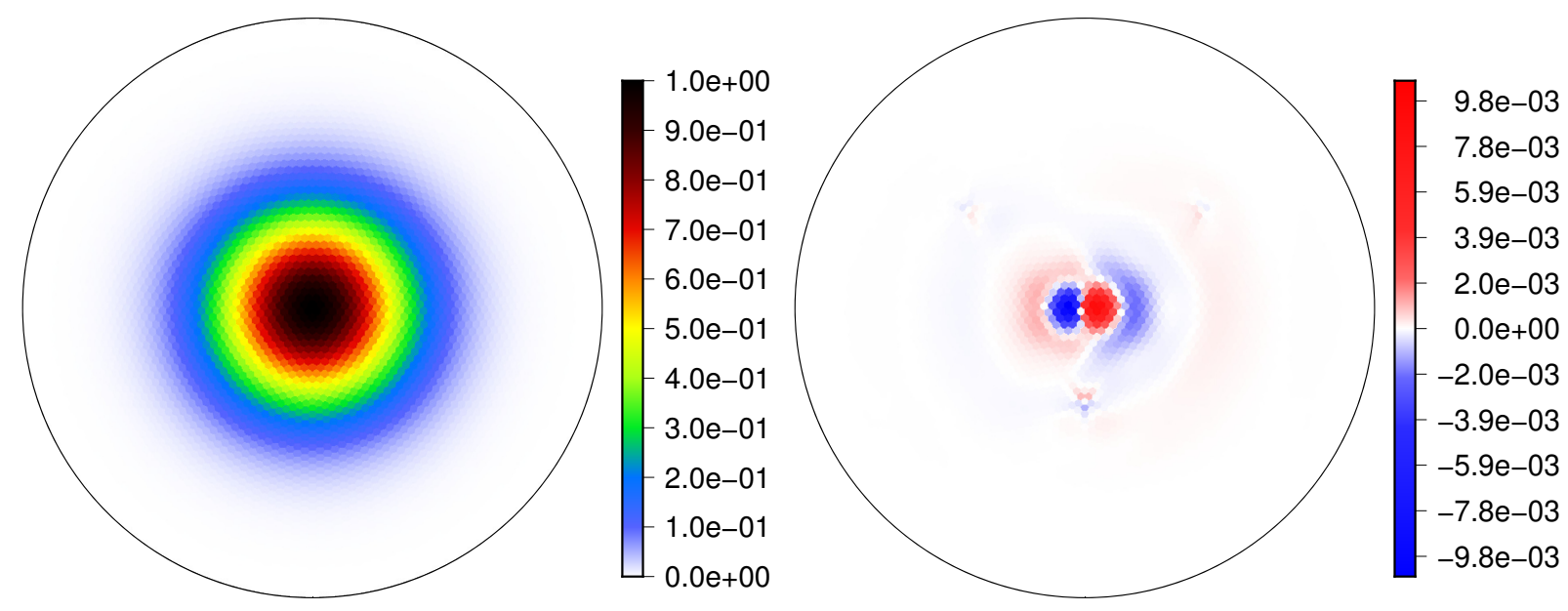

Figura 5.4: Solução final e erro no transporte de uma colina de gaussiana ao redor da Terra em uma malha icosaédrica de nível 5 com otimização SCVT, utilizando-se o método de $4^{a}$ ordem sem limitador.

Observando as Figuras 5.2, 5.3 e 5.4, verifica-se que as reconstruções da solução final de uma colina de gaussiana são semelhantes para os métodos de $2^{\mathrm{a}}, 3^{\mathrm{a}}$ e $4^{\mathrm{a}}$ ordens. Porém, pode-se observar as diferenças por meio do gráfico do erro e das normas dos erros do máximo e quadrático médio. Nota-se que o método de $2^{\mathrm{a}}$ e $4^{\mathrm{a}}$ ordens possui uma maior dispersão numérica, enquanto o método de $3^{\mathrm{a}}$ ordem possui uma maior difusão numérica. Também fica evidente que o aumento da ordem do método permite obter uma solução de alta ordem.

Fizemos um ajuste, por meio da regressão linear nas Tabelas 5.1, 5.2 e 5.3, para determinar as ordens efetivas dos métodos em estudo, que estão ilustrados na Tabela 5.4. Pode-se observar pelos resultados nas normas do erro máximo e do quadrático médio, que ambos os métodos estão próximos das ordens nominais $2^{\mathrm{a}}, 3^{\mathrm{a}}$ e $4^{\mathrm{a}}$ ordens, respectivamente. Devido aos erros associados de arredondamentos durante o processo de cálculo, não é possível obter a ordem nominal dos métodos. 


\begin{tabular}{|c|c|c|}
\hline Método & $L_{\infty}$ & $L_{2}$ \\
\hline $2^{\text {a }}$ ordem & 1,95 & 1,96 \\
\hline $3^{\mathrm{a}}$ ordem & 2,75 & 2,82 \\
\hline $4^{\mathrm{a}}$ ordem & 3,67 & 3,78 \\
\hline
\end{tabular}

Tabela 5.4: Ordem de precisão para o transporte de uma colina de gaussina.

Dentre todas as ordens dos erros associados na discretização do operador divergente, o valor médio da solução exata é dada por: $\bar{\phi}_{\text {exato }}=\bar{\phi}_{\text {aproximado }}+O\left(h^{I}\right)+O\left(h^{P}\right)+O\left(h^{Q}\right)+O\left(h^{D}\right)$, o único erro que não foi verificado é devido à projeção do plano tangente, representado pela ordem $O\left(h^{P}\right)$. Mas pelos resultados obtidos, chegamos à conclusão que não tem afetado a ordem efetiva dos métodos avaliados, conforme o trabalho de Lashley (2002).

A vantagem em se utilizar métodos de alta ordem, reside no fato que, para uma dada precisão, o tempo de CPU será menor, ou seja, para a mesma precisão, o esforço computacional é menor. Considere-se como exemplo o, erro com precisão de $7 \cdot 10^{-3}$, conforme ilustrado na Tabela 5.5.

\begin{tabular}{|c|c|c|c|}
\hline Ordem & Nível & Erro 2 & Tempo (s) \\
\hline 2 & 7 & $1,91 \mathrm{E}-003$ & 8936,1 \\
\hline 3 & 6 & $2,24 \mathrm{E}-003$ & 2711,8 \\
\hline 4 & 5 & $4,62 \mathrm{E}-004$ & 247,8 \\
\hline
\end{tabular}

Tabela 5.5: Comparativo da precisão e tempo de CPU para uma colina de gaussiana, utilizando-se os métodos de $2^{a}$, $3^{a}$ e $4^{a}$ ordens.

Como observado, métodos de alta ordem permitem obter a mesma precisão em malhas mais grosseiras com o menor tempo de CPU. Dada a precisão em estudo, note-se que a razão do tempo de CPU entre $2^{\mathrm{a}}$ e $3^{\mathrm{a}}$ ordens é de 3,2 vezes mais rápido e a razão do tempo de CPU entre $2^{\mathrm{a}}$ e $4^{\mathrm{a}}$ ordens é de 36,1 vezes mais rápido. Por isso, muitos pesquisadores têm explorado essas técnicas para serem aplicadas em modelos globais de previsão do tempo.

\subsubsection{Um sino de cosseno}

O sino de cosseno proposto por Williamson et al. (1991), é advectado sobre a superfície esférica uma vez ao redor da Terra, retornando a sua posição inicial durante o intervalo de tempo de 12 dias. A condição inicial escalar do sino de cosseno é dado por

$$
\phi(\lambda, \theta)= \begin{cases}\frac{1000}{2}[1+\cos (\pi r / R)] & \text { se } r<R \\ 0 & \text { se } r \geqslant R .\end{cases}
$$

O campo de velocidade é dado por

$$
\begin{aligned}
& u=\frac{2 \pi a \cdot \cos (\lambda)}{12 \text { dias }}, \\
& v=0
\end{aligned}
$$

sendo $r$ a distância geodésica entre $(\lambda, \theta)$ e o centro do sino de cosseno, que foi fixado nas coordenadas $\left(\lambda_{c}, \theta_{c}\right)=(3 \pi / 2,0)$ e $R=a / 3$ e $a=6.37122 \times 10^{6} m$ é o raio da Terra.

\section{Resultados numéricos utilizando-se os métodos de $2^{\mathrm{a}}, 3^{\mathrm{a}}$ e $4^{\mathrm{a}}$ ordens}

Foram avaliados o transporte um sino de cosseno sem limitador para vários níveis de malha. Após uma volta completa ao redor da Terra, a solução final coincide com a solução inicial. Dessa forma, os resultados nas normas do erro do máximo e do quadrático médio foram calculados e serão apresentados a seguir para as ordens em estudo. 


\begin{tabular}{|c|c|c|c|c|c|c|}
\hline Nível & Nós & Erro Máx & Razão Máx & Erro 2 & Razão 2 & Tempo (s) \\
\hline 4 & 2562 & $5,88 \mathrm{E}-001$ & 0,00 & $6,00 \mathrm{E}-001$ & 0,00 & 13,4 \\
\hline 5 & 10242 & $3,01 \mathrm{E}-001$ & 1,95 & $3,24 \mathrm{E}-001$ & 1,85 & 120,7 \\
\hline 6 & 40962 & $1,01 \mathrm{E}-001$ & 2,98 & $1,12 \mathrm{E}-001$ & 2,90 & 1053,0 \\
\hline 7 & 163842 & $2,63 \mathrm{E}-002$ & 3,84 & $3,28 \mathrm{E}-002$ & 3,41 & 8640,3 \\
\hline
\end{tabular}

Tabela 5.6: Erros e tempo de CPU associados à reconstrução de um sino de cosseno em uma malha icosaédrica com otimização SCVT, utilizando-se o método de $2^{a}$ ordem sem limitador.
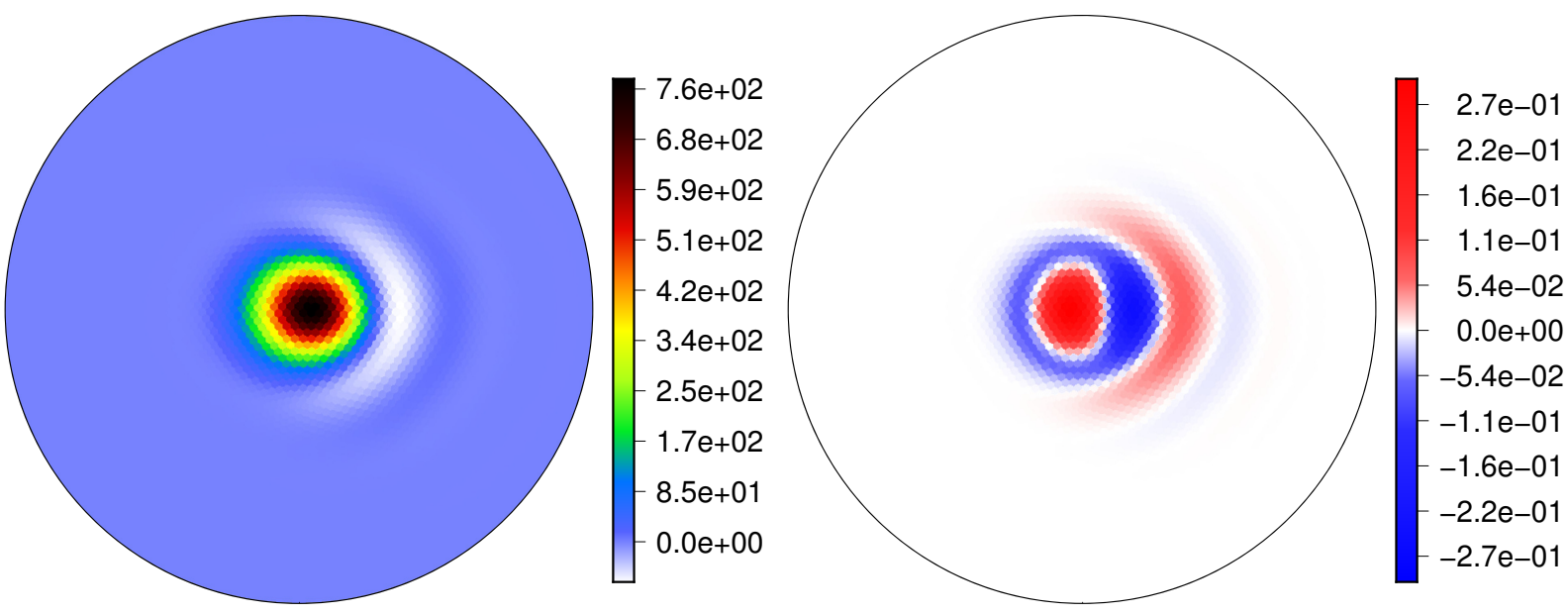

Figura 5.5: Solução final e erro no transporte de um sino de cosseno ao redor da Terra em uma malha icosaédrica de nível 5 com otimização SCVT, utilizando-se o método de $2^{a}$ ordem sem limitador.

\begin{tabular}{|c|c|c|c|c|c|c|}
\hline Nível & Nós & Erro Máx & Razão Máx & Erro 2 & Razão 2 & Tempo (s) \\
\hline 4 & 2562 & $6,31 \mathrm{E}-001$ & 0,00 & $6,07 \mathrm{E}-001$ & 0,00 & 34,2 \\
\hline 5 & 10242 & $2,93 \mathrm{E}-001$ & 2,15 & $2,85 \mathrm{E}-001$ & 2,13 & 235,1 \\
\hline 6 & 40962 & $4,92 \mathrm{E}-002$ & 5,95 & $6,99 \mathrm{E}-002$ & 4,08 & 1931,7 \\
\hline 7 & 163842 & $1,15 \mathrm{E}-002$ & 4,27 & $1,47 \mathrm{E}-002$ & 4,76 & 15698,6 \\
\hline
\end{tabular}

Tabela 5.7: Erros e tempo de CPU associados à reconstrução de um sino de cosseno em uma malha icosaédrica com otimização SCVT, utilizando-se o método de $3^{a}$ ordem sem limitador.
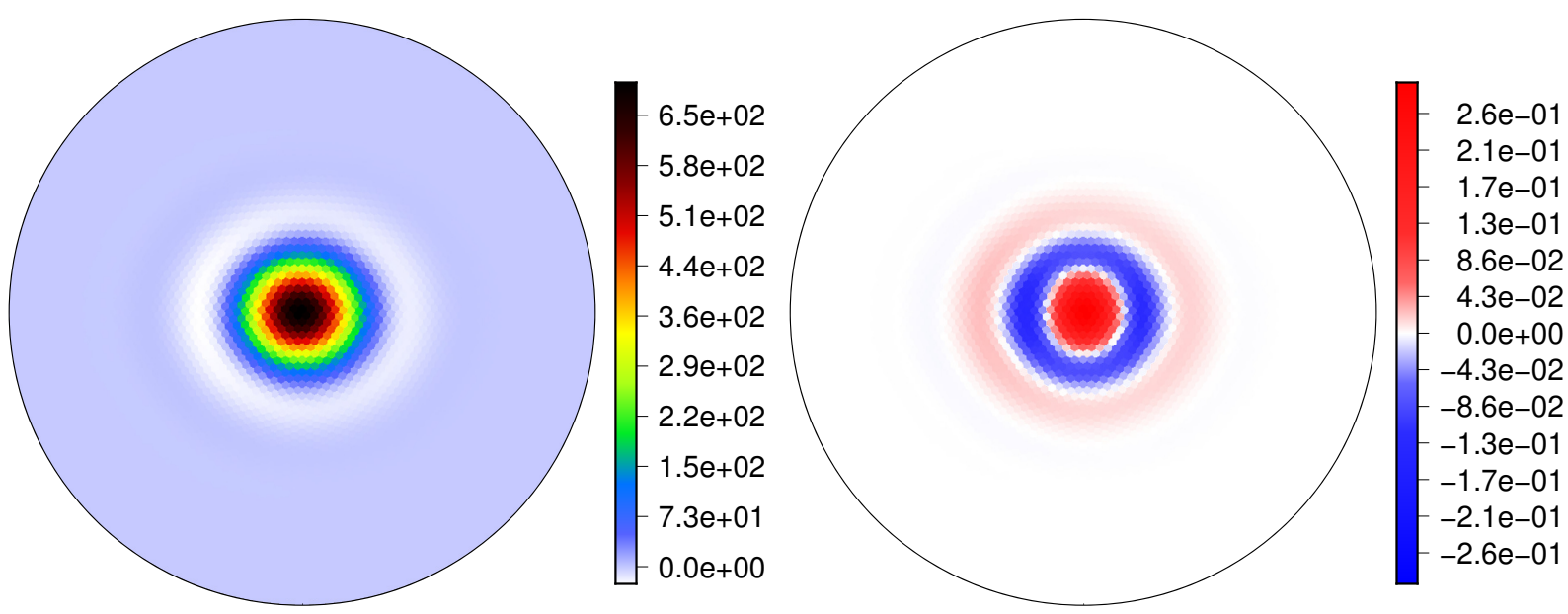

Figura 5.6: Solução final e erro no transporte de um sino de cosseno ao redor da Terra em uma malha icosaédrica de nível 5 com otimização SCVT, utilizando-se o método de $3^{a}$ ordem sem limitador. 


\begin{tabular}{|c|c|c|c|c|c|c|}
\hline Nível & Nós & Erro Máx & Razão Máx & Erro 2 & Razão 2 & Tempo (s) \\
\hline 4 & 2562 & $2,18 \mathrm{E}-001$ & 0,00 & $2,48 \mathrm{E}-001$ & 0,00 & 31,7 \\
\hline 5 & 10242 & $2,90 \mathrm{E}-002$ & 7,53 & $4,25 \mathrm{E}-002$ & 5,84 & 249,5 \\
\hline 6 & 40962 & $7,63 \mathrm{E}-003$ & 3,80 & $8,51 \mathrm{E}-003$ & 4,99 & 2006,1 \\
\hline 7 & 163842 & $2,44 \mathrm{E}-003$ & 3,13 & $2,02 \mathrm{E}-003$ & 4,21 & 20438,6 \\
\hline
\end{tabular}

Tabela 5.8: Erros e tempo de CPU associados à reconstrução de um sino de cosseno em uma malha icosaédrica com otimização SCVT, utilizando-se o método de $4^{a}$ ordem sem limitador.
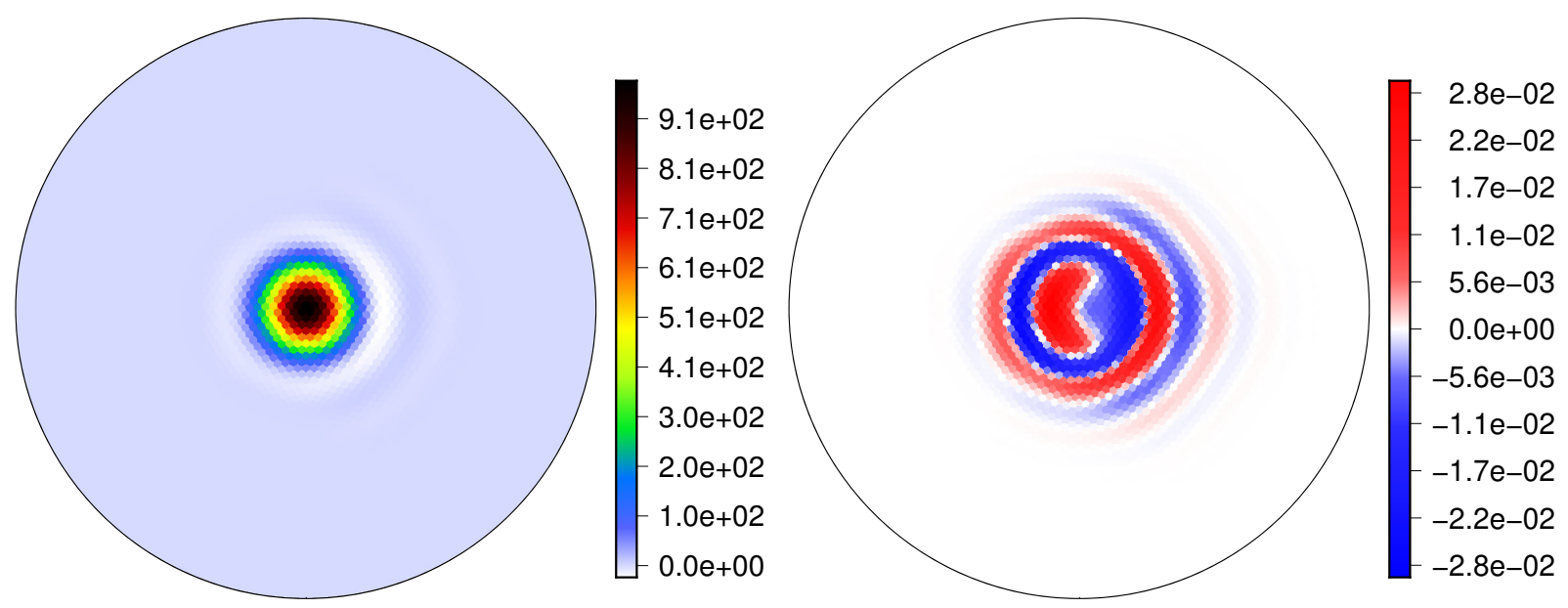

Figura 5.7: Solução final e erro no transporte de um sino de cosseno ao redor da Terra em uma malha icosaédrica de nível 5 com otimização SCVT, utilizando-se o método de $4^{a}$ ordem sem limitador.

A avaliação qualitativa do método de $2^{\mathrm{a}}$ ordem, na Figura 5.5, do método de $3^{\mathrm{a}}$ ordem, na Figura 5.1.2 e para o método de $4^{\mathrm{a}}$ ordem, na Figura 5.7, permite concluir que a reconstrução da solução final foi efetuada com êxito. Nota-se também que a difusão numérica é maior no método de $3^{a}$ ordem. Um comparativo da qualidade dessas soluções com resultados da literatura será abordado na próxima seção.

\begin{tabular}{|c|c|c|}
\hline Método & $L_{\infty}$ & $L_{2}$ \\
\hline $2^{\mathrm{a}}$ ordem & 1,50 & 1,41 \\
\hline $3^{\mathrm{a}}$ ordem & 1,99 & 1,81 \\
\hline $4^{\mathrm{a}}$ ordem & 2,14 & 2,31 \\
\hline
\end{tabular}

Tabela 5.9: Ordem de precisão para o transporte de um sino de cosseno.

Por meio da regressão linear aplicado nas Tabelas 5.6, 5.7 e 5.8 obtemos as ordens efetivas para o transporte de um sino de cosseno, ilustradas na Tabela 5.9. Observa-se que o método de $4^{\mathrm{a}}$ ordem, conseguiu ordem efetiva na norma do quadrático médio de 2,31 . Isso não diz a ordem real do método, conforme foi observado anteriormente, ou seja, a avaliação quantitativa das ordens reais só são obtidas utilizando-se funções suaves, em particular a colina de gaussiana. Mas, pelo fato de muitos pesquisadores utilizarem o sino de cosseno para avaliar as ordens, também foi explorada a função sino de cosseno neste trabalho.

Novamente deve-se ressaltar que a vantagem em se utilizar métodos de alta ordem reside no fato que para uma dada precisão, o tempo de CPU será menor, ou seja, para a mesma precisão, o esforço computacional é menor. Considere-se como exemplo, erro com precisão de $10^{-1}$, conforme ilustrado na Tabela 5.10. Como exposto anteriormente, os métodos de alta ordem permitem obter a mesma precisão em malhas mais grosseiras, com o menor tempo de CPU.

Dada a precisão em estudo, note que a razão do tempo de CPU entre $2^{\mathrm{a}}$ e $3^{\mathrm{a}}$ ordens é 4,5 vezes mais rápido e a razão do tempo de $\mathrm{CPU}$ entre $2^{\mathrm{a}}$ e $4^{\mathrm{a}}$ ordens é 34,6 vezes mais rápido. Mesmo a função sino de cosseno possuindo descontinuidade de derivada, o tempo de CPU é menor, o que 


\begin{tabular}{|c|c|c|c|}
\hline Ordem & Nível & Erro 2 & Tempo (s) \\
\hline 2 & 7 & $3,28 \mathrm{E}-002$ & 8640,3 \\
\hline 3 & 6 & $6,99 \mathrm{E}-002$ & 1931,7 \\
\hline 4 & 4 & $4,25 \mathrm{E}-002$ & 249,5 \\
\hline
\end{tabular}

Tabela 5.10: Comparativo da precisão e tempo de CPU para um sino de cosseno, utilizando-se os métodos de $2^{a}, 3^{a}$ e $4^{a}$ ordens.

justifica o estudo dos métodos de alta ordem.

\subsubsection{Comparação com o método FV-GAS}

Os resultados numéricos obtidos para a função sino de cosseno são comparados com o trabalho de Skamarock e Gassmann (2011), utilizando-se os métodos de $2^{\mathrm{a}}, 3^{\mathrm{a}}$ e $4^{\mathrm{a}}$ ordens sem limitador, para avaliar a equação do transporte sobre a esfera.

$\mathrm{Na}$ literatura, a maioria dos testes aplicados na esfera para verificar a ordem de métodos utilizam o sino de cosseno. Mas como é uma função de classe $C^{0}$, ou seja, possui descontinuidade de derivada, não é uma função adequada para avaliar a ordem real do método proposto na esfera, no entanto podemos comparar a precisão da solução. Como não encontramos na literatura testes sem limitador para uma colina de gaussiana, foi feito aqui um comparativo dos resultados para o sino de cosseno, por ser utilizado por diversos pesquisadores.

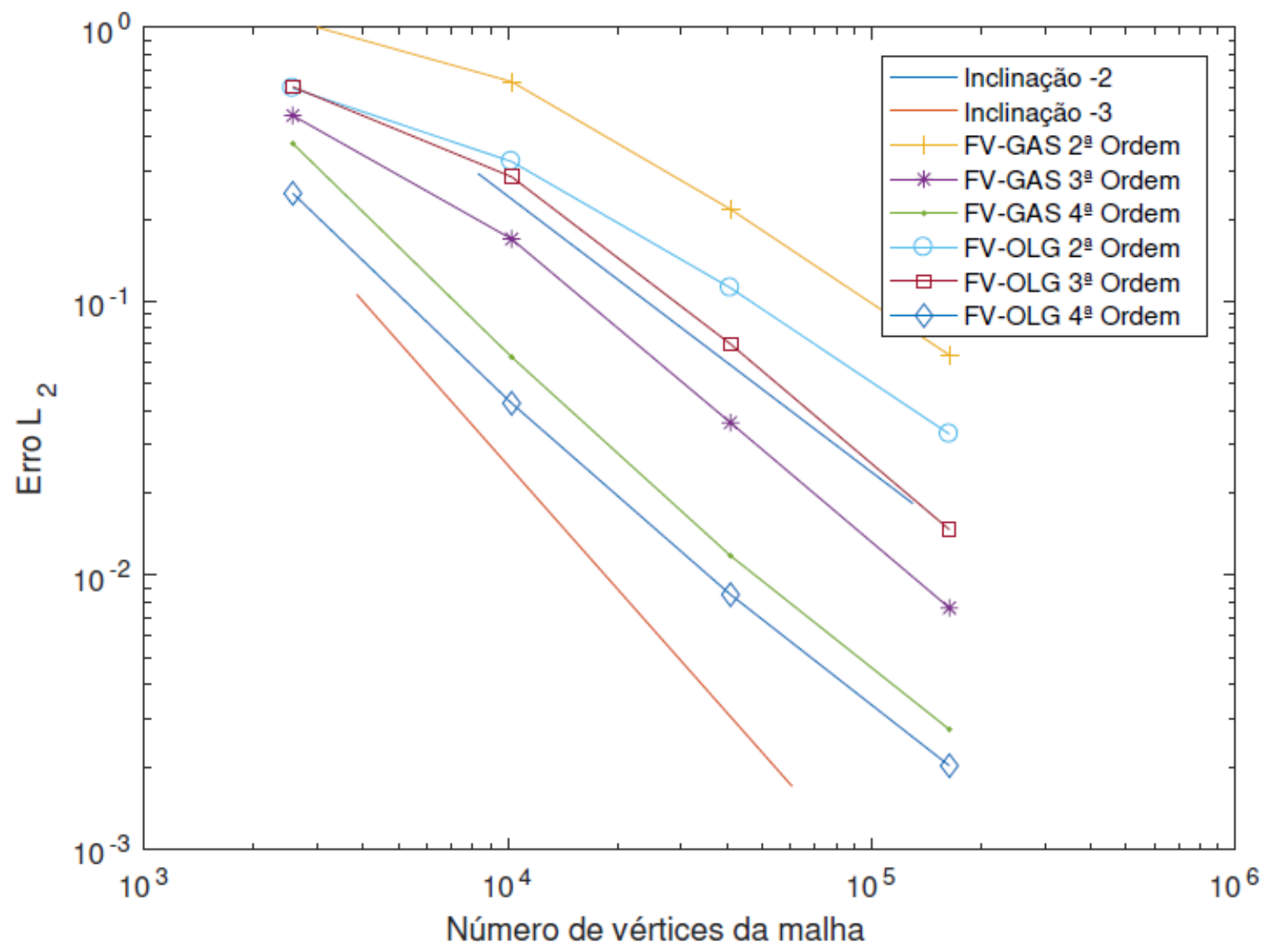

Figura 5.8: Comparatativo do erro quadrático médio para o transporte de um sino de cosseno, utilizando-se o método de $4^{a}$ ordem FV-GAS e FV-OLG sem limitador para as malhas nível 4,5,6 e 7.

Observando os resultados na Figura 5.8, concluímos que os métodos FV-GAS e FV-OLG possuem a mesma taxa de convergência para todas as ordens em estudo. Nos métodos de $2^{\mathrm{a}}$ e $4^{\mathrm{a}}$ ordens, FV-OLG tem uma precisão ligeiramente melhor que FV-GAS, e ocorre uma inversão desse compor- 
tamento para o método de $3^{\mathrm{a}}$ ordem. A seguir, apresentamos os resultados do método FV-GAS e FV-OLG utilizando-se a função um sino de cosseno, que são apresentados na Figura 5.9, para uma malha de nível 6 com otimização SCVT.
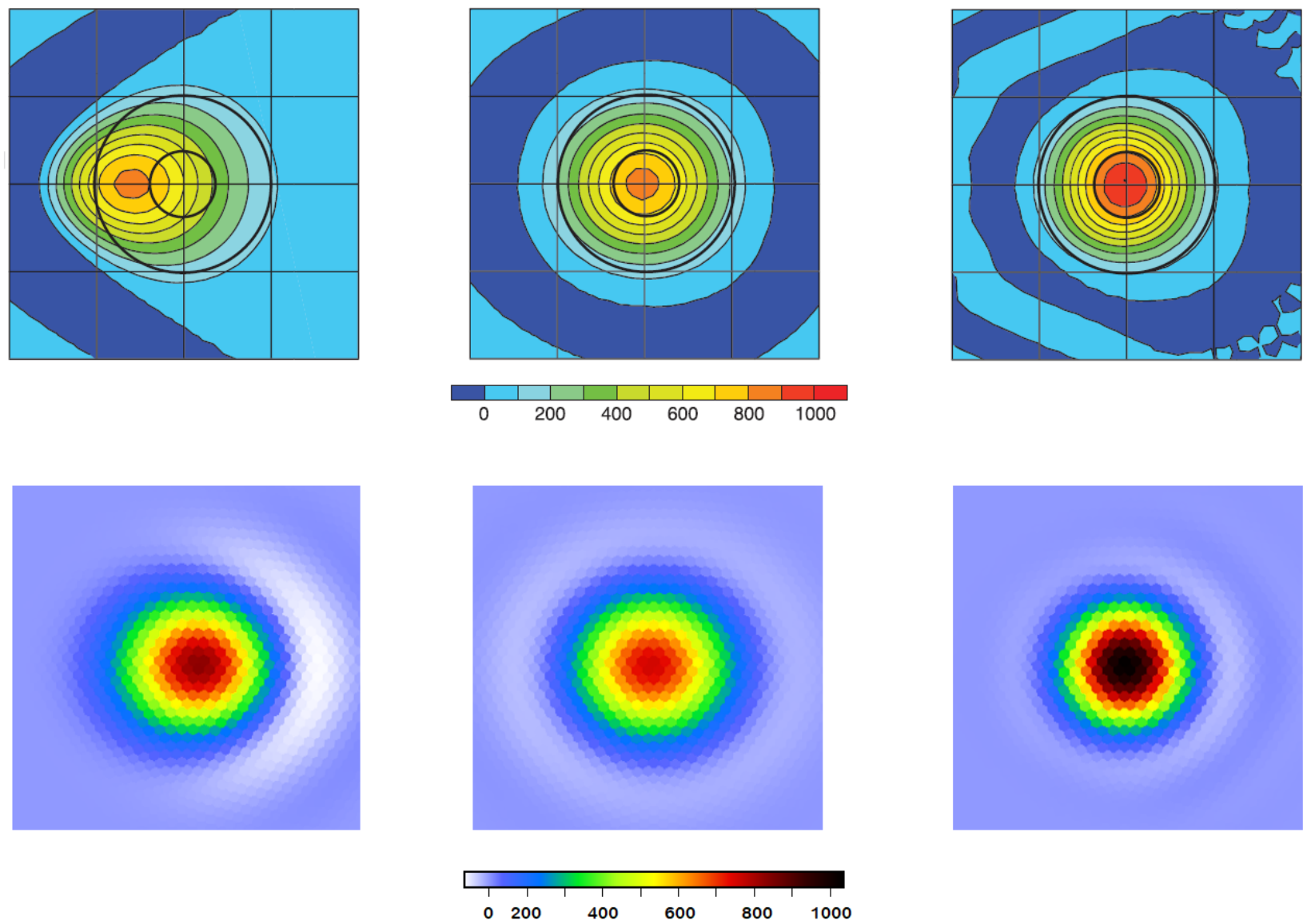

Figura 5.9: Solução final obtida na malha nível 6, sem limitador com os métodos de $2^{a}$, $3^{a}$ e $4^{a}$ ordens de FV-GAS (em cima) e FV-OLG (em baixo), respectivamente.

Ao se avaliar os gráficos da solução final, ou seja, da solução após uma volta completa ao redor da Terra para uma malha de nível 6, observam-se grandes erros de fase no método de $2^{\mathrm{a}}$ ordem, o que não ocorre nos métodos de $3^{\mathrm{a}}$ e $4^{\mathrm{a}}$ ordens. No método de $3^{\mathrm{a}}$ ordem observa-se também um amortecimento da solução, conhecido como difusão numérica. A melhor solução qualitativa foi alcançada utilizando-se o método de $4^{\mathrm{a}}$ ordem, pois, tem-se uma solução praticamente simétrica com pouca difusão numérica. Tanto no método FV-GAS, como no método FV-OLG, ocorre a difusão numérica, porém em nosso método esse fenômeno é menor. Apenas o método de $2^{\mathrm{a}}$ ordem produziu valores abaixo de zero, nos demais métodos o valor mínimo foi de zero, sem a utilização de limitador, o que não ocorre em FV-GAS.

\subsubsection{Um cilindro sólido}

O cilindro sólido, proposto aqui, foi obtido fazendo uma modificação do sino de cosseno de Williamson et al. (1991). O cilindro sólido será advectado sobre a superfície esférica uma vez ao redor da Terra, retornando a sua posição inicial durante o intervalo de tempo de 12 dias. O objetivo dessa função proposta, será avaliar os fenômenos de dispersão e difusão numérica na presença de uma descontinuidade e, posteriormente, verificar a implementação do limitador para controlar as oscilações numéricas nessa classe de problemas. 
A condição inicial escalar do cilindro sólido é dado por

$$
\phi(\lambda, \theta)=\left\{\begin{array}{lll}
1000 & \text { se } \quad r<R \\
0 & \text { se } \quad r \geqslant R .
\end{array}\right.
$$

O campo de velocidade é dado por

$$
\begin{aligned}
& u=\frac{2 \pi a \cdot \cos (\lambda)}{12 \text { dias }}, \\
& v=0,
\end{aligned}
$$

sendo $r$ a distância geodésica entre $(\lambda, \theta)$ e o centro do cilindro sólido, que foi fixado nas coordenadas $\left(\lambda_{c}, \theta_{c}\right)=(3 \pi / 2,0)$ e $R=a / 3$ e $a=6.37122 \times 10^{6} m$ é o raio da Terra.

\section{Resultados numéricos utilizando-se os métodos de $2^{\mathrm{a}}, 3^{\mathrm{a}}$ e $4^{\mathrm{a}}$ ordens}

Foram avaliados o transporte de um cilindro sólido sem limitador para vários níveis de malha. Após uma volta completa ao redor da Terra, a solução final coincide com a solução inicial. Dessa forma, os resultados nas normas do erro do máximo e do quadrático médio foram calculados e serão apresentados a seguir para as ordens em estudo.

\begin{tabular}{|c|c|c|c|c|c|c|}
\hline Nível & Nós & Erro Máx & Razão Máx & Erro 2 & Razão 2 & Tempo (s) \\
\hline 4 & 2562 & $5,53 \mathrm{E}-001$ & 0,00 & $3,51 \mathrm{E}-001$ & 0,00 & 13,7 \\
\hline 5 & 10242 & $5,57 \mathrm{E}-001$ & 0,99 & $2,88 \mathrm{E}-001$ & 1,22 & 120,8 \\
\hline 6 & 40962 & $5,83 \mathrm{E}-001$ & 0,96 & $2,36 \mathrm{E}-001$ & 1,22 & 1066,2 \\
\hline 7 & 163842 & $5,99 \mathrm{E}-001$ & 0,97 & $1,92 \mathrm{E}-001$ & 1,23 & 8877,5 \\
\hline
\end{tabular}

Tabela 5.11: Erros e tempo de CPU associados à reconstrução de um cilindro sólido em uma malha icosaédrica com otimização SCVT, utilizando-se o método de $2^{a}$ ordem sem limitador.
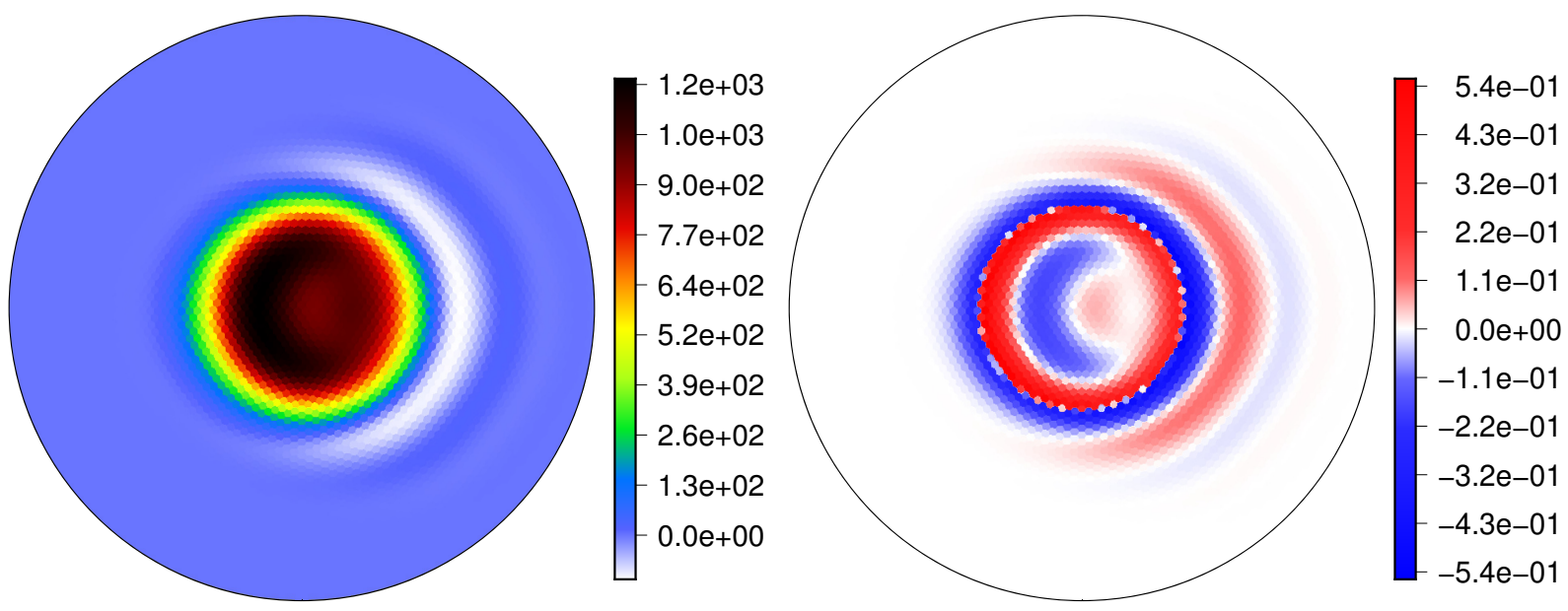

Figura 5.10: Solução final e erro no transporte de um cilindro sólido ao redor da Terra em uma malha icosaédrica de nível 5 com otimização SCVT, utilizando-se o método de $2^{a}$ ordem sem limitador. 


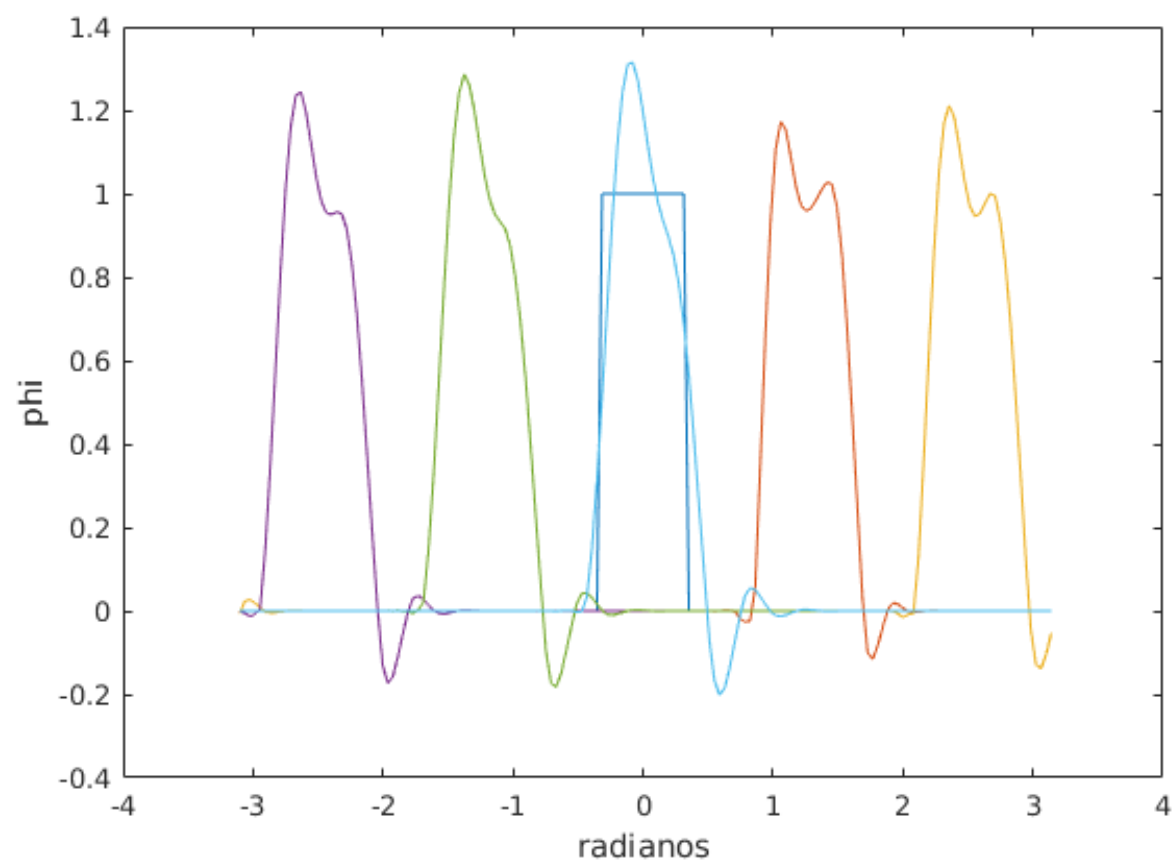

Figura 5.11: Corte transversal da solução de $2^{a}$ ordem cilindro sólido sem limitador, malha nível 5.

Observamos que as soluções intermediárias e a solução final utilizando-se o método de $2^{\mathrm{a}}$ ordem sem o limitador, possuem bastante dispersão e difusão numérica. Na próxima seção será aplicado o limitador para controlar esses fenômenos presentes na solução numérica.

\begin{tabular}{|c|c|c|c|c|c|c|}
\hline Nível & Nós & Erro Máx & Razão Máx & Erro 2 & Razão 2 & Tempo (s) \\
\hline 4 & 2562 & $4,70 \mathrm{E}-001$ & 0,00 & $3,49 \mathrm{E}-001$ & 0,00 & 31,1 \\
\hline 5 & 10242 & $4,74 \mathrm{E}-001$ & 0,99 & $2,77 \mathrm{E}-001$ & 1,26 & 243,3 \\
\hline 6 & 40962 & $4,68 \mathrm{E}-001$ & 1,01 & $2,18 \mathrm{E}-001$ & 1,27 & 1974,2 \\
\hline 7 & 163842 & $4,71 \mathrm{E}-001$ & 0,99 & $1,70 \mathrm{E}-001$ & 1,29 & 16930,9 \\
\hline
\end{tabular}

Tabela 5.12: Erros e tempo de CPU associados à reconstrução de um cilindro sólido em uma malha icosaédrica com otimização SCVT, utilizando-se o método de $3^{a}$ ordem sem limitador.

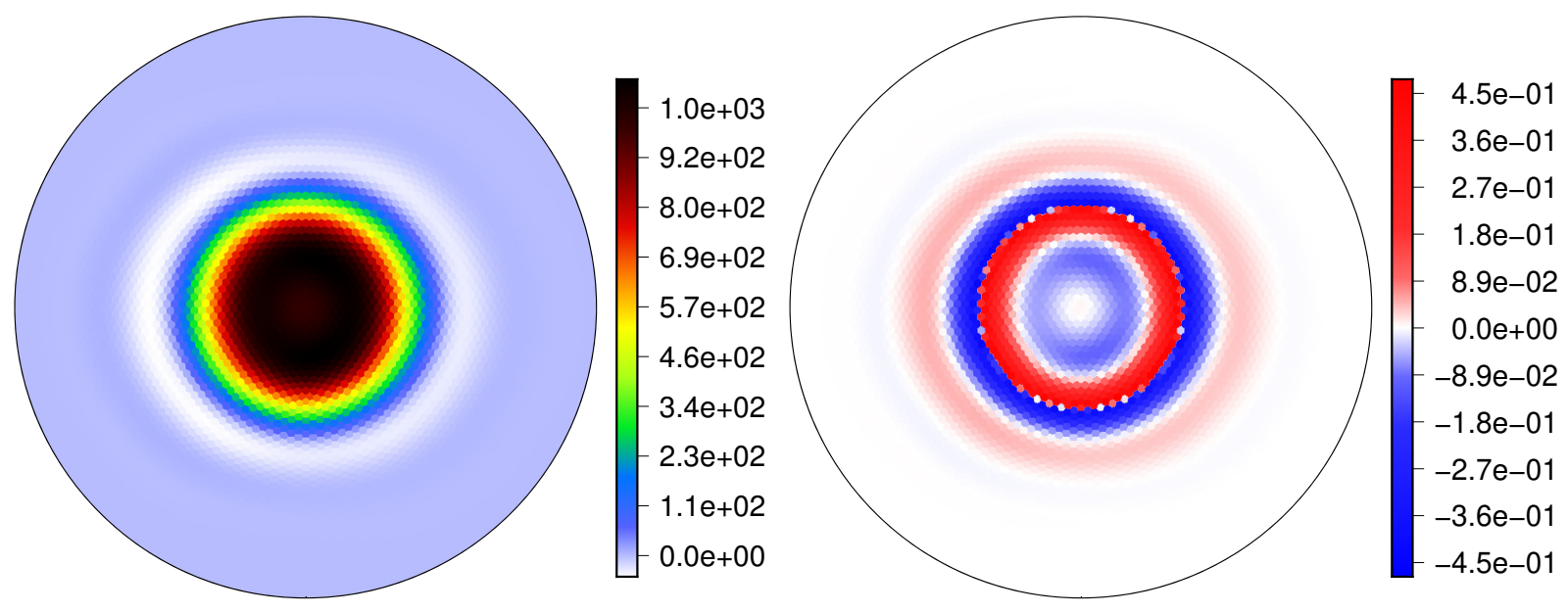

Figura 5.12: Solução final e erro no transporte de um cilindro sólido ao redor da Terra em uma malha icosaédrica de nível 5 com otimização SCVT, utilizando-se o método de $3^{a}$ ordem sem limitador. 


\begin{tabular}{|c|c|c|c|c|c|c|}
\hline Nível & Nós & Erro Máx & Razão Máx & Erro 2 & Razão 2 & Tempo (s) \\
\hline 4 & 2562 & $4,21 \mathrm{E}-001$ & 0,00 & $2,39 \mathrm{E}-001$ & 0,00 & 32,3 \\
\hline 5 & 10242 & $4,37 \mathrm{E}-001$ & 0,96 & $1,89 \mathrm{E}-001$ & 1,26 & 253,3 \\
\hline 6 & 40962 & $4,52 \mathrm{E}-001$ & 0,97 & $1,49 \mathrm{E}-001$ & 1,27 & 2090,3 \\
\hline 7 & 163842 & $4,73 \mathrm{E}-001$ & 0,96 & $1,15 \mathrm{E}-001$ & 1,30 & 18084,8 \\
\hline
\end{tabular}

Tabela 5.13: Erros e tempo de CPU associados à reconstrução de um cilindro sólido em uma malha icosaédrica com otimização SCVT, utilizando-se o método de $4^{a}$ ordem sem limitador.
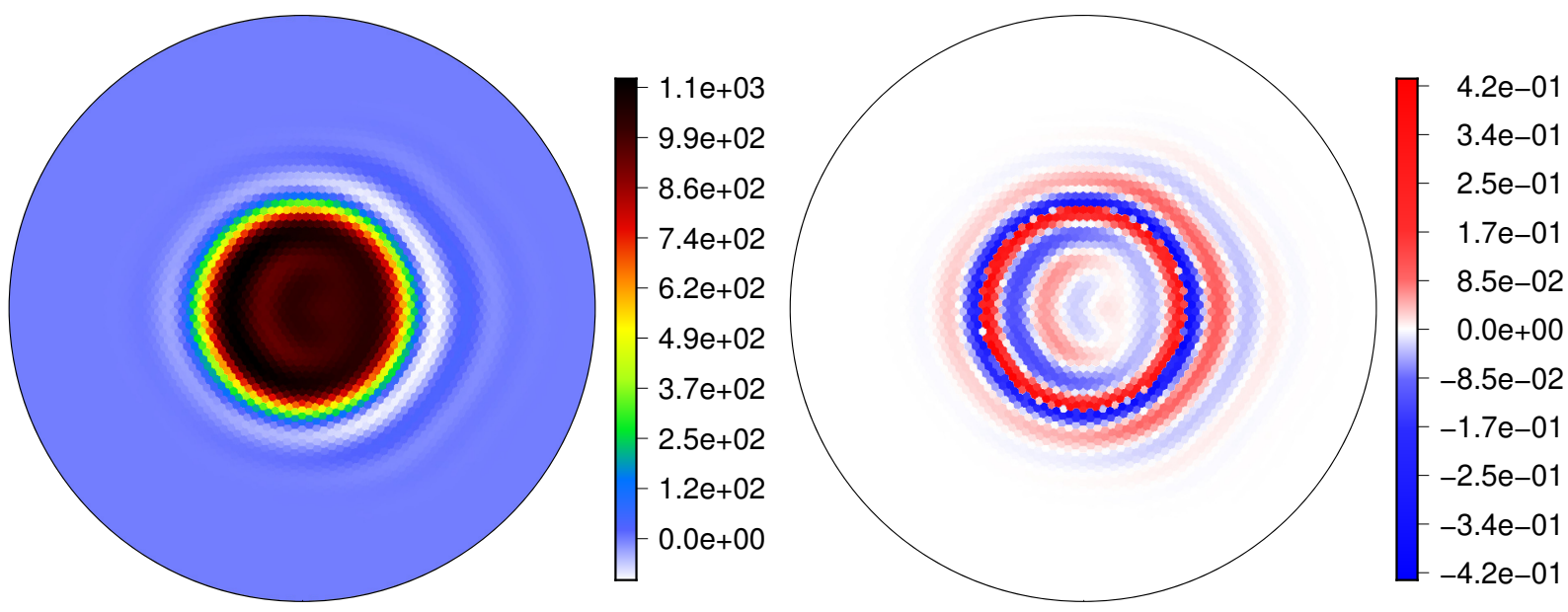

Figura 5.13: Solução final e erro no transporte de um cilindro sólido ao redor da Terra em uma malha icosaédrica de nível 5 com otimização SCVT, utilizando o método de $4^{a}$ ordem sem limitador.

Os resultados da solução final do cilindro sólido são semelhantes do ponto de vista quantitativo, conforme ilustrado nas Tabelas 5.11, 5.12 e 5.13. As diferenças qualitativas podem ser observadas ao analisar o gráfico do erro cometido entre a solução inicial e final ilustrado nas Figuras 5.11, 5.12 e 5.13. Percebe-se que a reconstrução da solução do método de $4^{\mathrm{a}}$ ordem é superior aos demais métodos, pois ao observar a espessura do erro cometido na fronteira do cilindro sólido, onde se localiza o degrau entre 0 e 1000 na interface no cilindro sólido, ocorre de maneira mais "suave" no método de $4^{\mathrm{a}}$ ordem. O método de $2^{\mathrm{a}}$ e $4^{\mathrm{a}}$ ordens apresenta uma maior dispersão numérica e o método de $3^{\mathrm{a}}$ ordem apresenta uma maior difusão numérica e um resultado mais simétrico da solução final.

\subsubsection{Um cilindro cortado}

Neste teste de advecção, vamos utilizar o cilindro cortado, proposto por Williamson (1968), o que se constitui num teste desafiador, devido à descontinuidade nas bordas. Tem-se como objetivo avaliar a qualidade da reconstrução da solução. A condição inicial escalar do cilindro sólido é dada por

$$
\phi(\lambda, \theta)=\left\{\begin{array}{l}
\text { c se } r_{1} \leq r e\left|\lambda_{1}-\lambda\right| \geq \frac{r}{6}, \\
c \text { se } r_{1} \leq r e\left|\lambda_{1}-\lambda\right|<\frac{r}{6} \text { e } \theta-\theta_{1}<-\frac{5 r}{12}, \\
b \text { caso contrário. }
\end{array}\right.
$$

O campo de velocidade é dado por 


$$
\begin{aligned}
& u=\frac{2 \pi a \cdot \cos (\lambda)}{12 \text { dias }}, \\
& v=0,
\end{aligned}
$$

sendo $r=a / 2$ e $a=6.37122 \times 10^{6} m$ é o raio da Terra. Os parâmetros $\mathrm{b}=0$ e $\mathrm{c}=1000$. $\mathrm{O}$ cilindro cortado foi fixado nas coordenadas $\left(\lambda_{c}, \theta_{c}\right)=(0,0)$.

\section{Resultados numéricos utilizando-se os métodos de $2^{\mathrm{a}}, 3^{\mathrm{a}}$ e $4^{\mathrm{a}}$ ordens}

Foram avaliados o transporte de um cilindro cortado sem limitador para vários níveis de malha. Após uma volta completa ao redor da Terra, a solução final coincide com a solução inicial. Dessa forma, os resultados nas normas do erro do máximo e do quadrático médio foram calculados e serão apresentados a seguir para as ordens em estudo.

\begin{tabular}{|c|c|c|c|c|c|c|}
\hline Nível & Nós & Erro Máx & Razão Máx & Erro 2 & Razão 2 & Tempo (s) \\
\hline 4 & 2562 & $9,42 \mathrm{E}-001$ & 0,00 & $5,29 \mathrm{E}-001$ & 0,00 & 13,8 \\
\hline 5 & 10242 & $8,06 \mathrm{E}-001$ & 1,17 & $4,16 \mathrm{E}-001$ & 1,27 & 120,9 \\
\hline 6 & 40962 & $7,95 \mathrm{E}-001$ & 1,01 & $3,36 \mathrm{E}-001$ & 1,24 & 1078,9 \\
\hline 7 & 163842 & $7,66 \mathrm{E}-001$ & 1,04 & $2,55 \mathrm{E}-001$ & 1,32 & 8857,6 \\
\hline
\end{tabular}

Tabela 5.14: Erros e tempo de CPU associados à reconstrução de um cilindro cortado em uma malha icosaédrica com otimização SCVT, utilizando-se o método de $2^{a}$ ordem sem limitador.
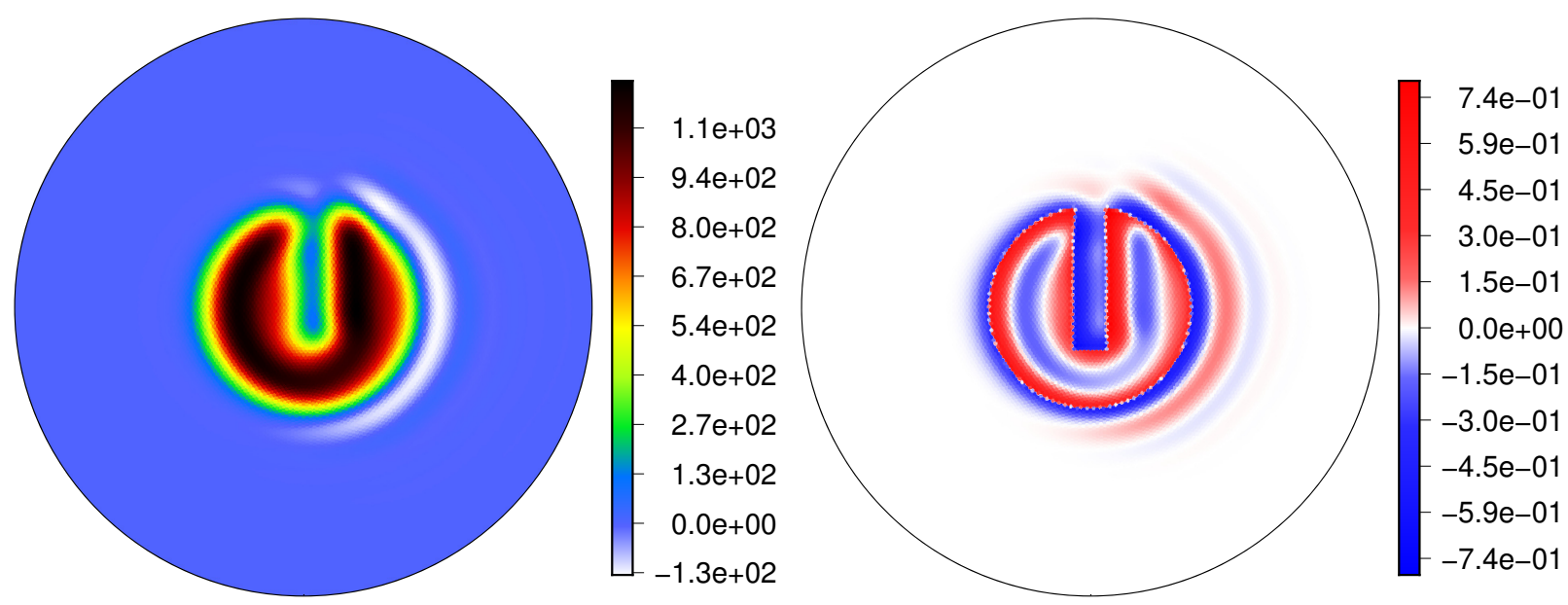

Figura 5.14: Solução final e erro no transporte de um cilindro cortado ao redor da Terra em uma malha icosaédrica de nível 6 com otimização SCVT, utilizando-se o método de $2^{a}$ ordem sem limitador.

\begin{tabular}{|c|c|c|c|c|c|c|}
\hline Nível & Nós & Erro Máx & Razão Máx & Erro 2 & Razão 2 & Tempo (s) \\
\hline 4 & 2562 & $9,24 \mathrm{E}-001$ & 0,00 & $5,25 \mathrm{E}-001$ & 0,00 & 34,6 \\
\hline 5 & 10242 & $7,54 \mathrm{E}-001$ & 1,23 & $3,87 \mathrm{E}-001$ & 1,36 & 239,0 \\
\hline 6 & 40962 & $6,98 \mathrm{E}-001$ & 1,08 & $2,96 \mathrm{E}-001$ & 1,31 & 1966,8 \\
\hline 7 & 163842 & $6,90 \mathrm{E}-001$ & 1,01 & $2,23 \mathrm{E}-001$ & 1,33 & 16540,3 \\
\hline
\end{tabular}

Tabela 5.15: Erros e tempo de CPU associados à reconstrução de um cilindro cortado em uma malha icosaédrica com otimização SCVT, utilizando-se o método de $3^{a}$ ordem sem limitador. 

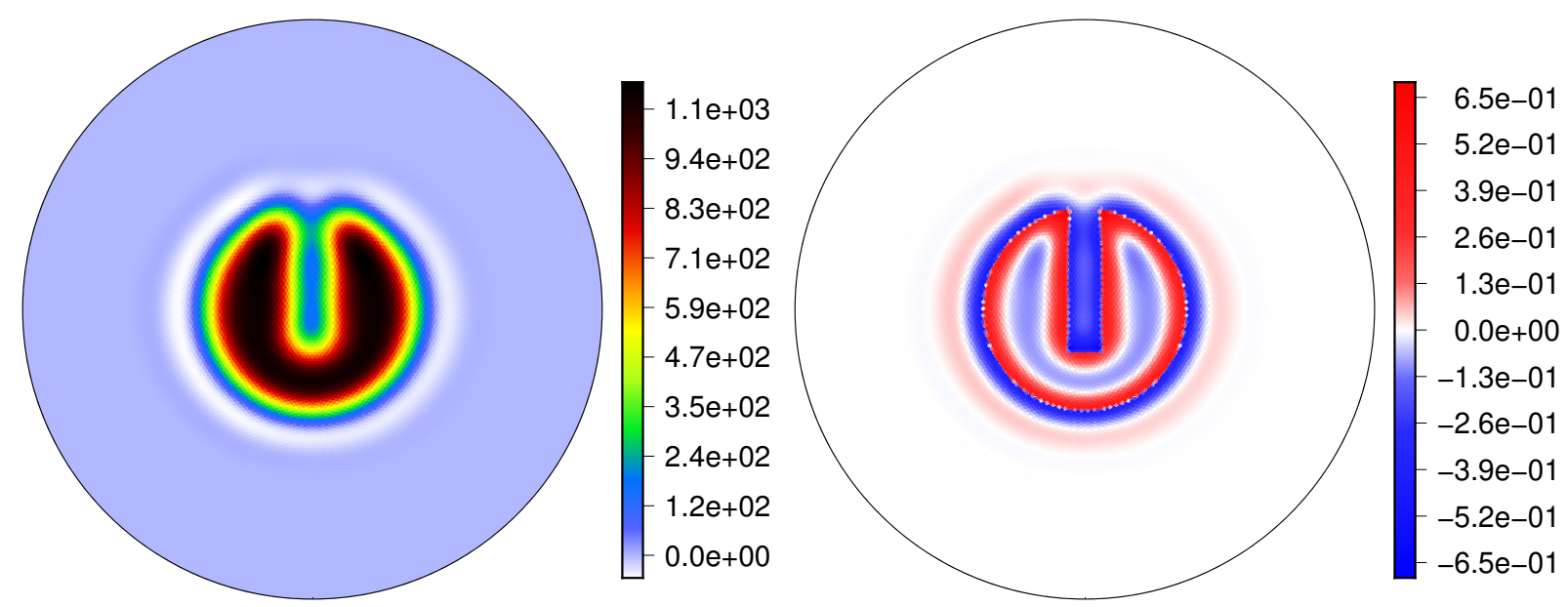

Figura 5.15: Solução final e erro no transporte de um cilindro cortado ao redor da Terra em uma malha icosaédrica de nível 6 com otimização SCVT, utilizando-se o método de $3^{a}$ ordem sem limitador.

\begin{tabular}{|c|c|c|c|c|c|c|}
\hline Nível & Nós & Erro Máx & Razão Máx & Erro 2 & Razão 2 & Tempo (s) \\
\hline 4 & 2562 & $7,45 \mathrm{E}-001$ & 0,00 & $3,42 \mathrm{E}-001$ & 0,00 & 36,2 \\
\hline 5 & 10242 & $5,89 \mathrm{E}-001$ & 1,27 & $2,63 \mathrm{E}-001$ & 1,30 & 251,3 \\
\hline 6 & 40962 & $5,76 \mathrm{E}-001$ & 1,02 & $1,96 \mathrm{E}-001$ & 1,34 & 2040,3 \\
\hline 7 & 163842 & $6,13 \mathrm{E}-001$ & 0,94 & $1,54 \mathrm{E}-001$ & 1,28 & 16693,4 \\
\hline
\end{tabular}

Tabela 5.16: Erros e tempo de CPU associados à reconstrução de um cilindro cortado em uma malha icosaédrica com otimização SCVT, utilizando-se o método de $4^{a}$ ordem sem limitador.
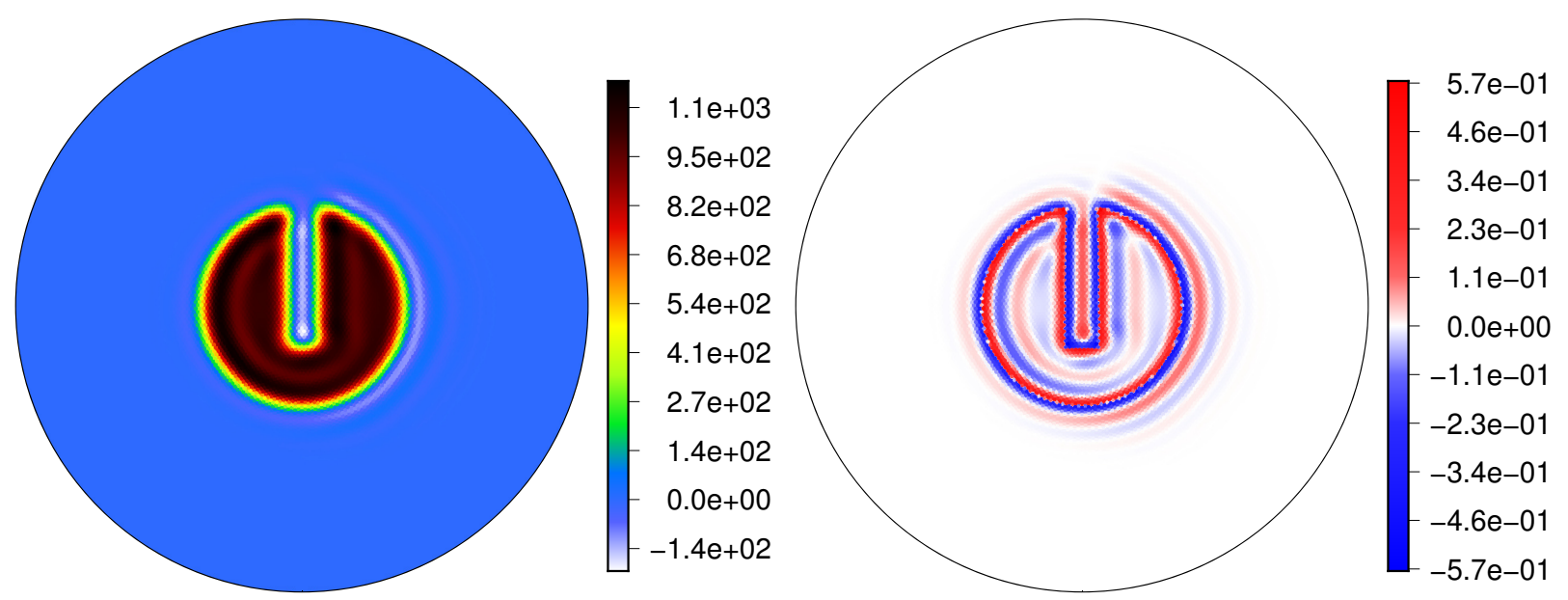

Figura 5.16: Solução final e erro no transporte de um cilindro cortado ao redor da Terra em uma malha icosaédrica de nível 6 com otimização SCVT, utilizando-se o método de $4^{a}$ ordem sem limitador.

Pode-se observar que a solução final do cilindro cortado, utilizando-se o método de $2^{\mathrm{a}}$ ordem sem o limitador, possui maior dispersão devido à descontinuidade nas bordas, como pode ser observado no erro ilustrado na Figura 5.14. O método de $3^{\mathrm{a}}$ ordem apresenta uma simétria da solução final, conforme observada no gráfico do erro ilustrado na Figura 5.15. O método de $4^{\mathrm{a}}$ ordem obteve a melhor reconstrução da solução na região de descontinuidade, como ilustrado na Figura 5.16, quando comparada com os métodos de $2^{\mathrm{a}}$ e $3^{\mathrm{a}}$ ordens.

As taxas de convergência para os métodos de $2^{\mathrm{a}}, 3^{\mathrm{a}}$ e $4^{\mathrm{a}}$ ordens são semelhantes, mas, do ponto de vista qualitativo, o método de $4^{\mathrm{a}}$ ordem obteve a melhor reconstrução da solução para o cilindro cortado, quando comparados com os outros métodos e praticamente com o mesmo tempo de CPU do método de $3^{\text {a }}$ ordem, pois a pseudo-inversa é a mesma para ambos os métodos e já foram calculadas e armazenadas para atualizar os coeficientes dos polinômios de reconstrução. 


\subsection{Resultados numéricos com limitador}

Nesta seção será utilizado o limitador descrito na equação (5.1) em todos os testes descritos anteriormente, por isso não serão abordadas as definições matemáticas das funções e o campo de velocidade utilizado para advectar a solução ao redor da Terra.

\subsubsection{Uma colina de gaussiana}

O primeiro teste com limitador consiste no transporte de uma colina de gaussiana ao redor da Terra. A solução final coincide com a solução inicial, dessa forma, os resultados nas normas do erro do máximo e do quadrático médio foram calculados e serão apresentados a seguir para as ordens em estudo.

O objetivo deste teste é avaliar o efeito do limitador em problemas suaves. No caso de um sistema de equações não-lineares, a priori não se sabe se haverá formação de descontinuidades e como prática, habilita-se o limitador.

Resultados numéricos utilizando-se os métodos de $2^{\mathrm{a}}, 3^{\mathrm{a}}$ e $4^{\mathrm{a}}$ ordens

\begin{tabular}{|c|c|c|c|c|c|c|}
\hline Nível & Nós & Erro Máx & Razão Máx & Erro 2 & Razão 2 & Tempo (s) \\
\hline 4 & 2562 & $1,14 \mathrm{E}-001$ & 0,00 & $1,06 \mathrm{E}-001$ & 0,00 & 18,4 \\
\hline 5 & 10242 & $3,43 \mathrm{E}-002$ & 3,32 & $2,94 \mathrm{E}-002$ & 3,59 & 156,0 \\
\hline 6 & 40962 & $9,18 \mathrm{E}-003$ & 3,74 & $7,57 \mathrm{E}-003$ & 3,89 & 1297,5 \\
\hline 7 & 163842 & $2,28 \mathrm{E}-003$ & 4,03 & $1,90 \mathrm{E}-003$ & 3,98 & 10691,0 \\
\hline
\end{tabular}

Tabela 5.17: Erros e tempo de CPU associados ao transporte de uma colina de gaussiana em uma malha icosaédrica com otimização SCVT, utilizando-se o método de $2^{a}$ ordem com limitador.
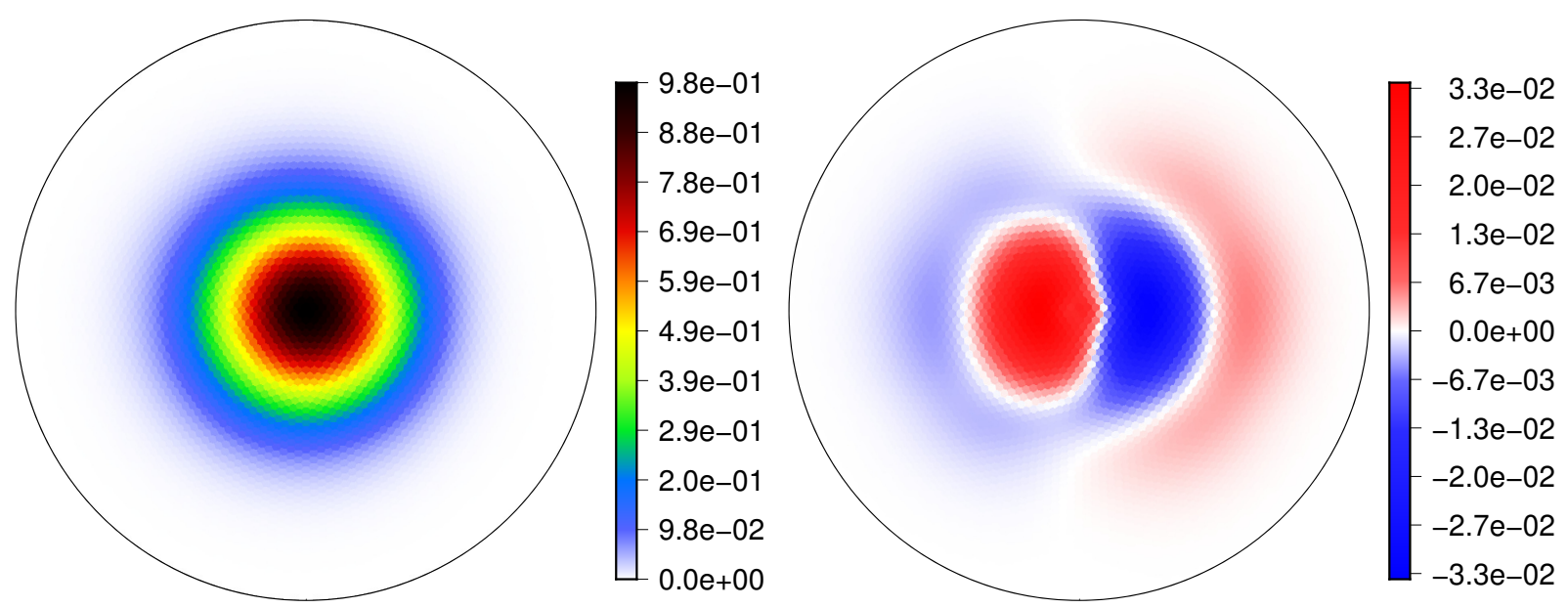

Figura 5.17: Solução final e erro no transporte de uma colina de gaussiana ao redor da Terra em uma malha icosaédrica de nível 5 com otimização SCVT, utilizando-se o método de $2^{a}$ ordem com limitador.

\begin{tabular}{|c|c|c|c|c|c|c|}
\hline Nível & Nós & Erro Máx & Razão Máx & Erro 2 & Razão 2 & Tempo (s) \\
\hline 4 & 2562 & $1,43 \mathrm{E}-001$ & 0,00 & $9,64 \mathrm{E}-002$ & 0,00 & 44,6 \\
\hline 5 & 10242 & $2,86 \mathrm{E}-002$ & 4,99 & $1,66 \mathrm{E}-002$ & 5,80 & 355,0 \\
\hline 6 & 40962 & $4,25 \mathrm{E}-003$ & 6,73 & $2,22 \mathrm{E}-003$ & 7,49 & 3040,4 \\
\hline 7 & 163842 & $6,53 \mathrm{E}-004$ & 6,51 & $2,81 \mathrm{E}-004$ & 7,90 & 31032,5 \\
\hline
\end{tabular}

Tabela 5.18: Erros e tempo de CPU associados ao transporte de uma colina de gaussiana em uma malha icosaédrica com otimização SCVT, utilizando-se o método de $3^{a}$ ordem com limitador. 

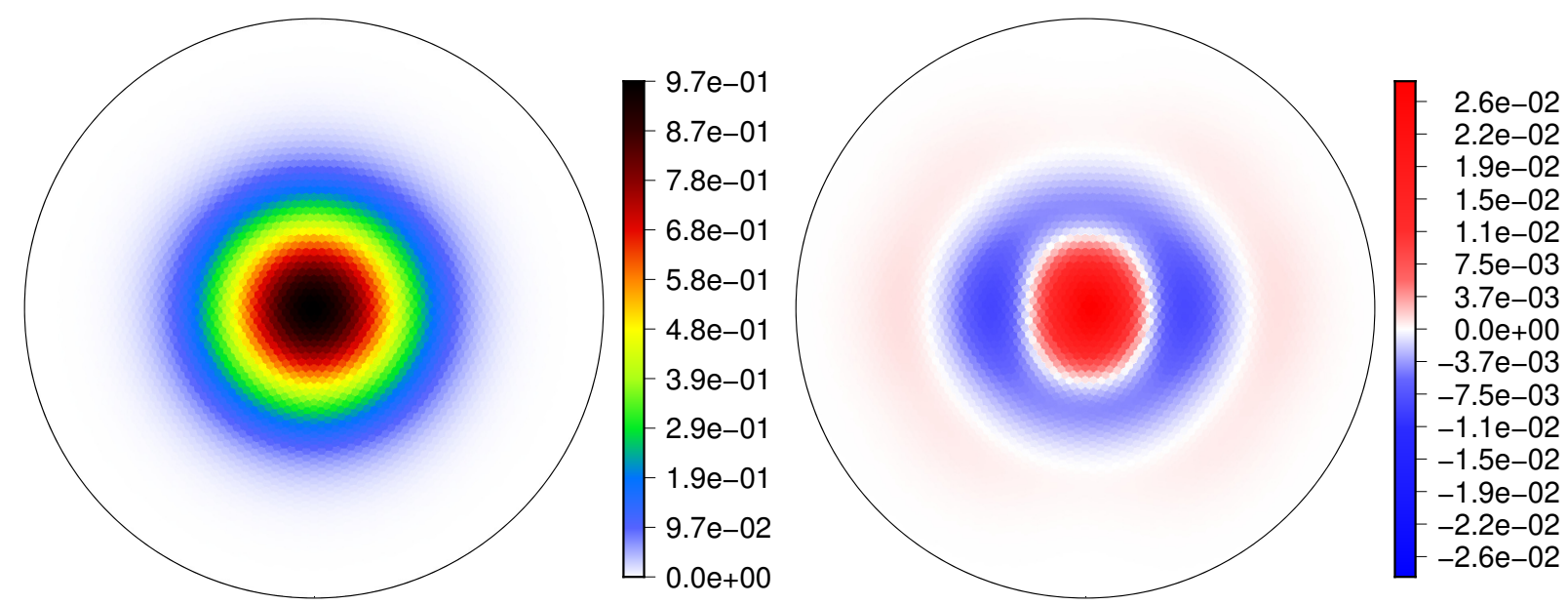

Figura 5.18: Solução final e erro no transporte de uma colina de gaussiana ao redor da Terra em uma malha icosaédrica de nível 5 com otimização SCVT, utilizando-se o método de $3^{a}$ ordem com limitador.

\begin{tabular}{|c|c|c|c|c|c|c|}
\hline Nível & Nós & Erro Máx & Razão Máx & Erro 2 & Razão 2 & Tempo (s) \\
\hline 4 & 2562 & $1,92 \mathrm{E}-002$ & 0,00 & $8,64 \mathrm{E}-003$ & 0,00 & 46,2 \\
\hline 5 & 10242 & $1,10 \mathrm{E}-002$ & 1,74 & $2,40 \mathrm{E}-003$ & 3,60 & 367,0 \\
\hline 6 & 40962 & $3,48 \mathrm{E}-003$ & 3,15 & $4,41 \mathrm{E}-004$ & 5,45 & 2986,1 \\
\hline 7 & 163842 & $1,26 \mathrm{E}-003$ & 2,77 & $9,32 \mathrm{E}-005$ & 4,73 & 23522,5 \\
\hline
\end{tabular}

Tabela 5.19: Erros e tempo de CPU associados ao transporte de uma colina de gaussiana em uma malha icosaédrica com otimização SCVT, utilizando-se o método de $4^{a}$ ordem com limitador.

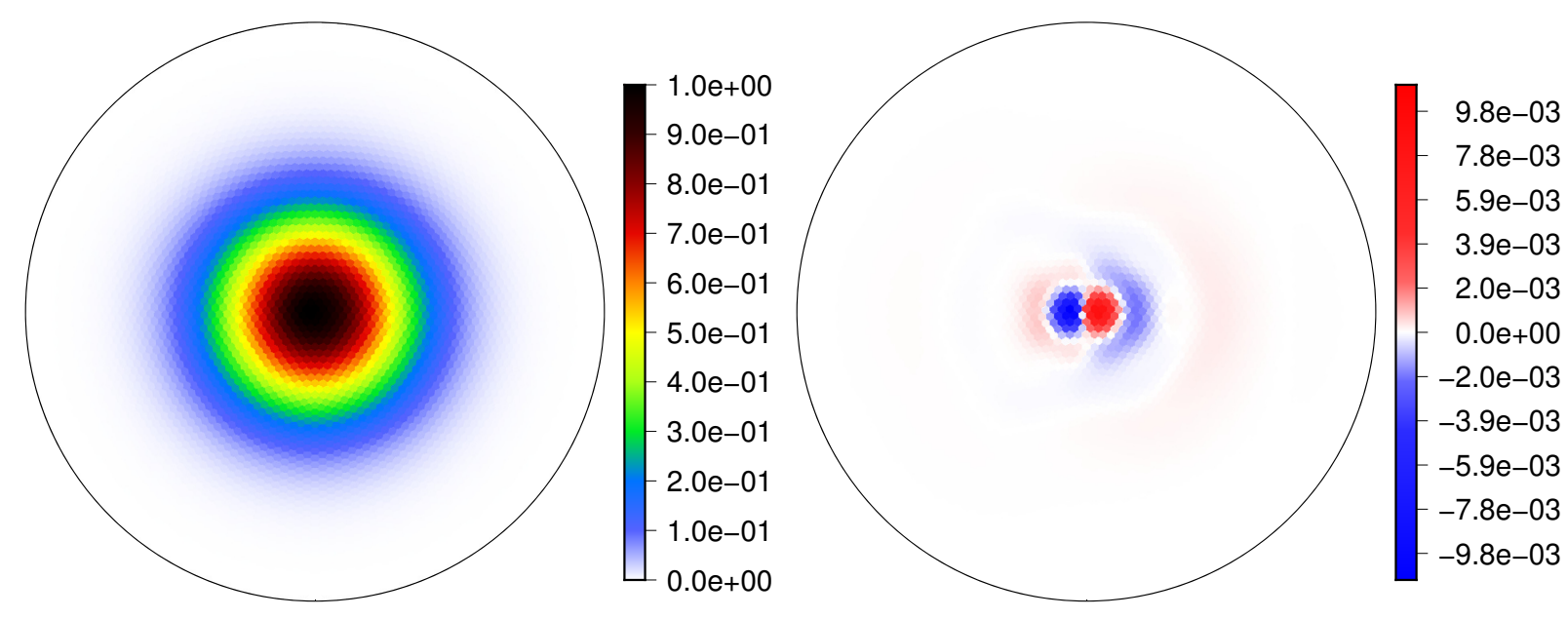

Figura 5.19: Solução final e erro no transporte de uma colina de gaussiana ao redor da Terra em uma malha icosaédrica de nível 5 com otimização SCVT, utilizando-se o método de $4^{a}$ ordem com limitador.

Percebe-se por meio da Figura 5.17 e da Figura 5.18, que no método de $2^{\mathrm{a}}$ e $3^{\mathrm{a}}$ ordens, a solução final de uma colina de gaussiana sem e com o limitador é semelhante, ou seja, o limitador foi pouco utilizado no processo da advecção, uma vez que a gaussiana é uma função suave. A partir das Tabela 5.19, pode-se observar que os efeitos quantitativos da solução sem e com limitador foram significativos, pois percebe-se uma diminuição na taxa de convergência.

Fazendo um ajuste para avaliar a ordem média dos métodos em estudo, por meio do método de regressão linear, conforme Tabela 5.17 o método de $2^{\mathrm{a}}$ ordem, obteve uma ordem de 1,94. Na Tabela 5.18 foi obtido ordem de 2,82, para o método de $3^{\mathrm{a}}$ ordem e na Tabela 5.19 o método de $4^{\mathrm{a}}$ ordem obteve uma ordem de 2,21 . Isso aconteceu, devido ao limitador proposto ter sido acionado mais vezes no método de $4^{\mathrm{a}}$ ordem, quando comparado com o método de $2^{\mathrm{a}}$ e $3^{\mathrm{a}}$ ordens, introduzindo uma maior difusão numérica, consequentemente tem-se uma diminuição da ordem do método ao 


\begin{tabular}{|c|c|c|}
\hline Método & $L_{\infty}$ & $L_{2}$ \\
\hline $2^{\mathrm{a}}$ ordem & 1,88 & 1,94 \\
\hline $3^{\mathrm{a}}$ ordem & 2,61 & 2,82 \\
\hline $4^{\mathrm{a}}$ ordem & 1,34 & 2,20 \\
\hline
\end{tabular}

Tabela 5.20: Ordem de precisão para o transporte de uma colina de gaussina com limitador.

utilizar limitadores. Conclui-se que pela qualidade das soluções sem e com limitador no transporte da colina de gaussiana, por ser uma função suave, não há necessidade de se utilizar limitador para melhorar os resultados numéricos.

\subsubsection{Um sino de cosseno}

O segundo teste com limitador consiste no transporte de um sino de cosseno ao redor da Terra. A solução final coincide com a solução inicial, dessa forma, os resultados nas normas do erro do máximo e do quadrático médio foram calculados e serão apresentados a seguir para as ordens em estudo.

O objetivo deste teste é avaliar o efeito da inclusão do limitador nesse caso, pois existe uma região de descontinuidade de derivada na solução.

Resultados numéricos utilizando-se os métodos de $2^{\mathrm{a}}, 3^{\mathrm{a}}$ e $4^{\mathrm{a}}$ ordens

\begin{tabular}{|c|c|c|c|c|c|c|}
\hline Nível & Nós & Erro Máx & Razão Máx & Erro 2 & Razão 2 & Tempo (s) \\
\hline 4 & 2562 & $5,79 \mathrm{E}-001$ & 0,00 & $5,53 \mathrm{E}-001$ & 0,00 & 18,3 \\
\hline 5 & 10242 & $2,79 \mathrm{E}-001$ & 2,07 & $2,63 \mathrm{E}-001$ & 2,11 & 156,6 \\
\hline 6 & 40962 & $9,91 \mathrm{E}-002$ & 2,82 & $9,24 \mathrm{E}-002$ & 2,84 & 1294,8 \\
\hline 7 & 163842 & $2,63 \mathrm{E}-002$ & 3,76 & $2,94 \mathrm{E}-002$ & 3,15 & 10710,6 \\
\hline
\end{tabular}

Tabela 5.21: Erros e tempo de CPU associados ao transporte de um sino de cosseno em uma malha icosaédrica com otimização SCVT, utilizando-se o método de $2^{a}$ ordem com limitador.

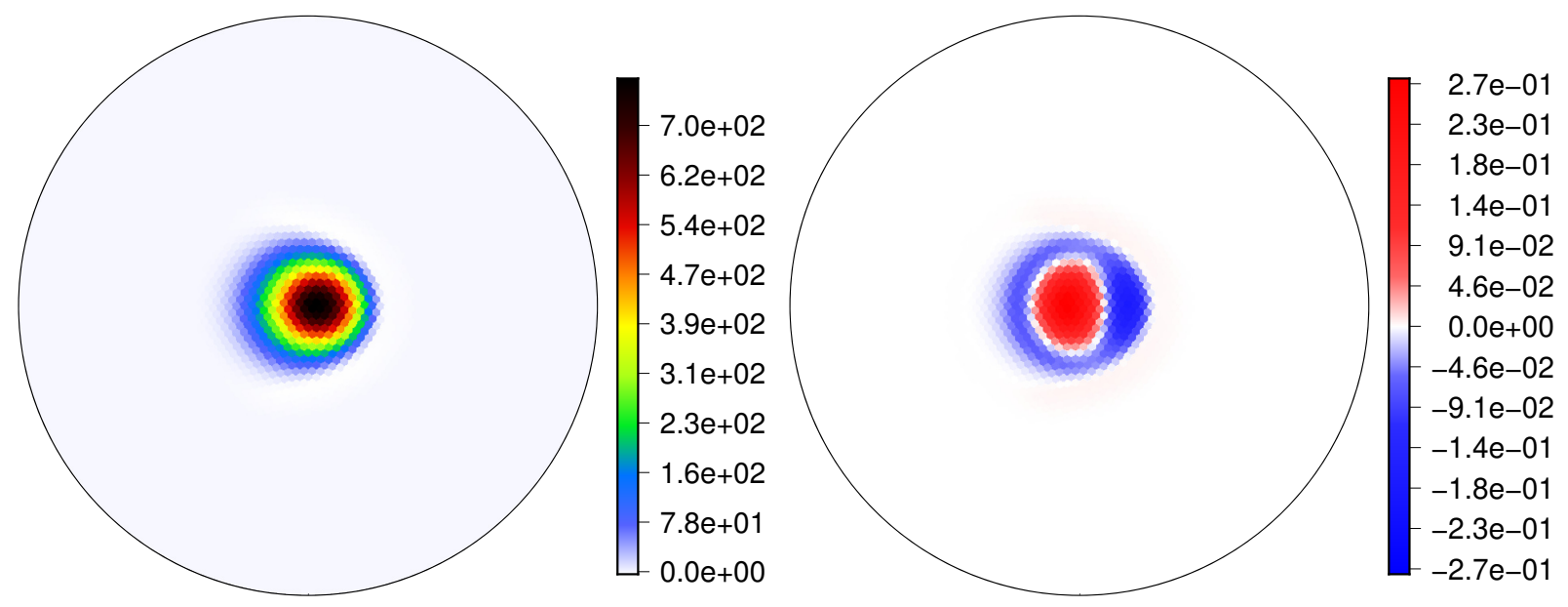

Figura 5.20: Solução final e erro no transporte de um sino de cosseno ao redor da Terra em uma malha icosaédrica de nível 5 com otimização SCVT, utilizando-se o método de $2^{a}$ ordem com limitador. 


\begin{tabular}{|c|c|c|c|c|c|c|}
\hline Nível & Nós & Erro Máx & Razão Máx & Erro 2 & Razão 2 & Tempo (s) \\
\hline 4 & 2562 & $6,39 \mathrm{E}-001$ & 0,00 & $6,13 \mathrm{E}-001$ & 0,00 & 46,3 \\
\hline 5 & 10242 & $2,97 \mathrm{E}-001$ & 2,15 & $2,83 \mathrm{E}-001$ & 2,16 & 368,5 \\
\hline 6 & 40962 & $5,10 \mathrm{E}-002$ & 5,82 & $6,63 \mathrm{E}-002$ & 4,27 & 4498,9 \\
\hline 7 & 163842 & $1,11 \mathrm{E}-002$ & 4,61 & $1,31 \mathrm{E}-002$ & 5,05 & 27256,0 \\
\hline
\end{tabular}

Tabela 5.22: Erros e tempo de CPU associados ao transporte de um sino de cosseno em uma malha icosaédrica com otimização SCVT, utilizando-se o método de $3^{a}$ ordem com limitador.
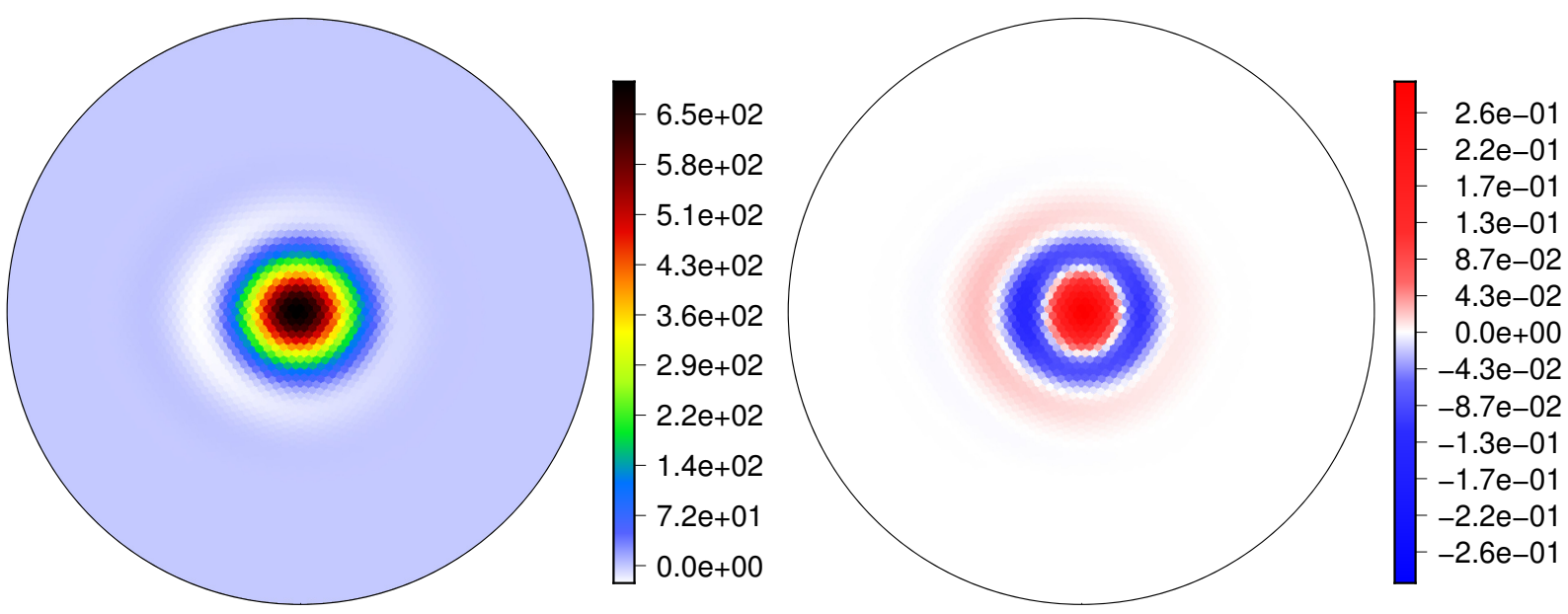

Figura 5.21: Solução final e erro no transporte de um sino de cosseno ao redor da Terra em uma malha icosaédrica de nível 5 com otimização SCVT, utilizando-se o método de $3^{a}$ ordem com limitador.

\begin{tabular}{|c|c|c|c|c|c|c|}
\hline Nível & Nós & Erro Máx & Razão Máx & Erro 2 & Razão 2 & Tempo (s) \\
\hline 4 & 2562 & $2,24 \mathrm{E}-001$ & 0,00 & $1,95 \mathrm{E}-001$ & 0,00 & 47,9 \\
\hline 5 & 10242 & $3,54 \mathrm{E}-002$ & 6,32 & $3,27 \mathrm{E}-002$ & 5,97 & 382,5 \\
\hline 6 & 40962 & $1,46 \mathrm{E}-002$ & 2,43 & $8,19 \mathrm{E}-003$ & 3,99 & 3054,3 \\
\hline 7 & 163842 & $5,56 \mathrm{E}-003$ & 2,62 & $2,43 \mathrm{E}-003$ & 3,37 & 23509,8 \\
\hline
\end{tabular}

Tabela 5.23: Erros e tempo de CPU associados ao transporte de um sino de cosseno em uma malha icosaédrica com otimização SCVT, utilizando-se o método de $4^{a}$ ordem com limitador.
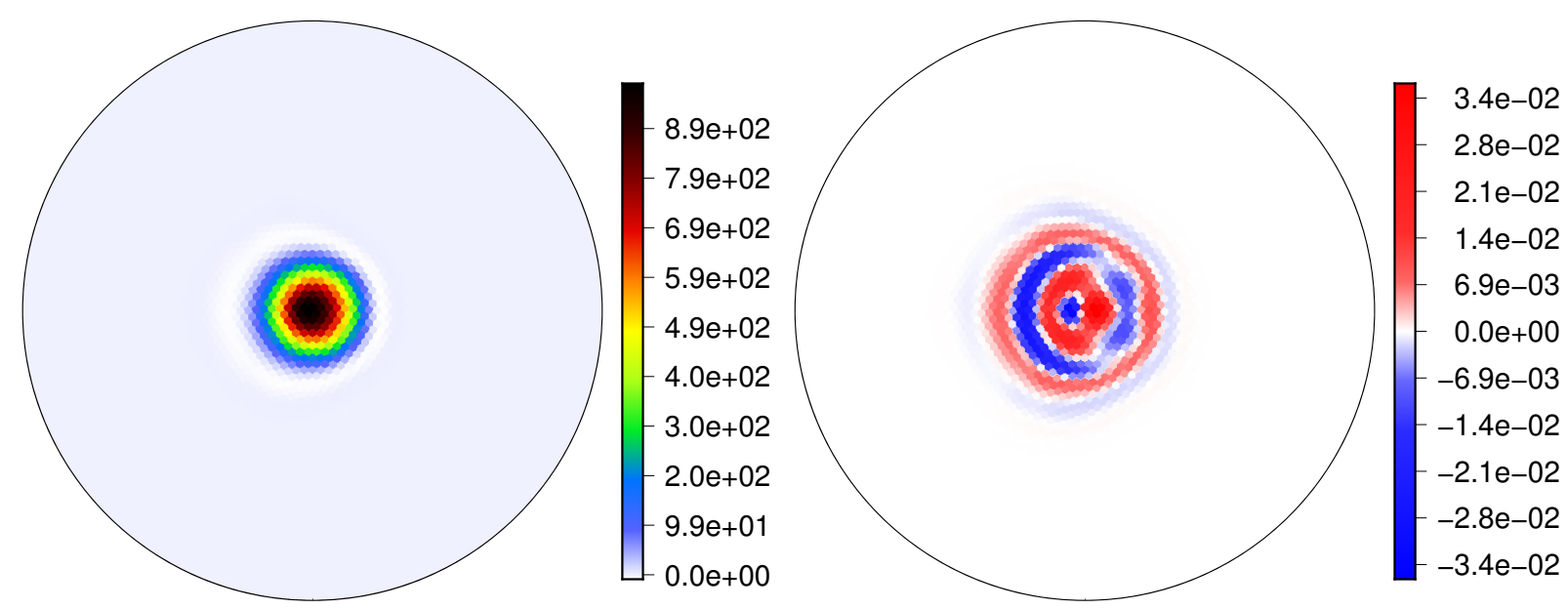

Figura 5.22: Solução final e erro no transporte de um sino de cosseno ao redor da Terra em uma malha icosaédrica de nível 5 com otimização SCVT, utilizando-se o método de $4^{a}$ ordem com limitador. 


\begin{tabular}{|c|c|c|}
\hline Método & $L_{\infty}$ & $L_{2}$ \\
\hline $2^{\mathrm{a}}$ ordem & 1,49 & 1,42 \\
\hline $3^{\mathrm{a}}$ ordem & 2,01 & 1,87 \\
\hline $4^{\mathrm{a}}$ ordem & 1,73 & 2,10 \\
\hline
\end{tabular}

Tabela 5.24: Ordem de precisão para o transporte de um sino de cosseno com limitador.

Foi feito um ajuste, por meio da regressão linear nas Tabelas 5.21, 5.22 e 5.23, obtendo-se a Tabela $5.24 \mathrm{com}$ as ordens efetivas no transporte do sino de cosseno. Pode-se observar que a ordem obtida com o método de $2^{\text {a }}$ ordem é superior à ordem ume os resultados quantitativos sem e com limitador foram semelhantes, porém, o uso do limitador melhora a qualidade da solução numérica, conforme ilustrado na Figura 5.20 do erro cometido entre a solução final e inicial. Os resultados numéricos da solução sem e com limitador do método de $3^{\text {a }}$ ordem também foram semelhantes quantitativamente e qualitativamente.

O método de $4^{\text {a }}$ ordem obteve ordem de 2,10 com limitador e ordem de 2,20 sem limitador. A diminuição da ordem, deve-se ao fato de que essa função possui uma região de descontinuidade, sendo necessário o uso do limitador para controlar as oscilações durante o transporte. De acordo com a Figura 5.22, qualitativamente percebe-se a importância do uso do limitador, pois a reconstrução final com o uso do limitador é mais simétrica, com base no gráfico do erro, em relação aos resultados sem limitador. 


\subsubsection{Comparação com o método FV-MEN}

Neste tópico, compara-se os resultados do método FV-OLG de $2^{\mathrm{a}}$, $3^{\mathrm{a}}$ e $4^{\mathrm{a}}$ ordens para o transporte de um sino de cosseno com o método FV-MEN de $2^{\mathrm{a}}$ e $4^{\mathrm{a}}$ ordens, desenvolvido por Skamarock e Menchaca (2010), e aplicado em malhas icosaédricas com otimização HR95, utilizandose o limitador desenvolvido por Zalesak (1979), para garantir a monotonicidade da solução.

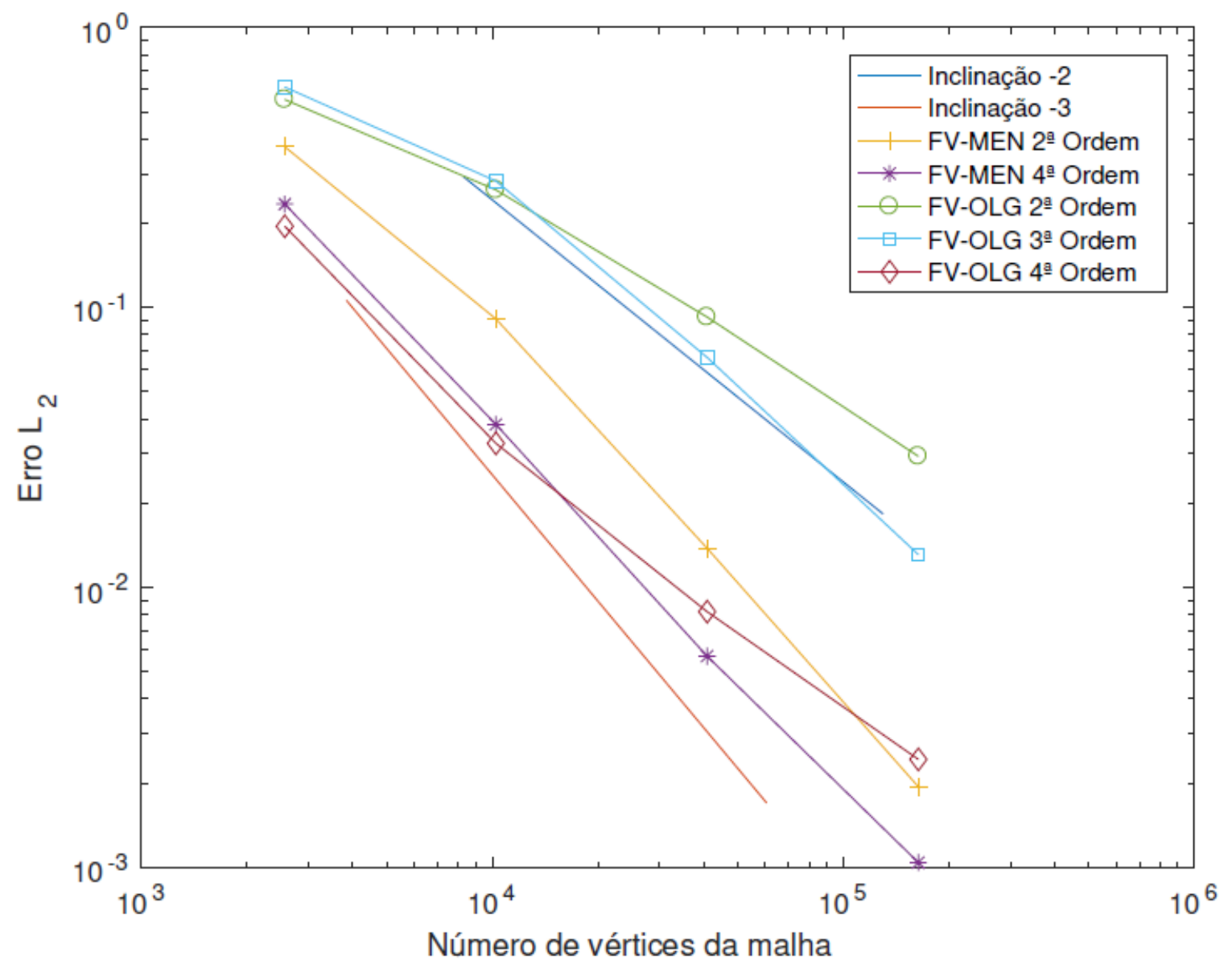

Figura 5.23: Erros associados à reconstrução de um sino de cosseno em uma malha icosaédrica com otimização HR95 e SCVT, utilizando-se o método de $2^{a}$ e $4^{a}$ ordens de FV-MEN e $2^{a}, 3^{a}$ e $4^{a}$ ordens de FV-OLG com limitador, respectivamente.

Por meio da Figura 5.2.3, observa-se que o método de $2^{\mathrm{a}}$ ordem FV-OLG é pior em relação ao método FV-MEN, com ordem inferior a um. O método de $3^{\text {a }}$ ordem de FV-OLG tende a ter a mesma inclinação do método de $2^{\mathrm{a}}$ ordem de FV-MEN, mas com menor precisão. Comparando-se os métodos de $4^{\mathrm{a}}$ ordem, o FV-OLG foi melhor nos primeiros níveis de malhas, porém tende a diminuir a taxa de convergência para malhas mais refinadas. Em suma, o método proposto por FV-MEN para o transporte do sino de cosseno é melhor que o método FV-OLG do ponto de vista quantitativo, porém ambos os métodos entregam a mesma qualidade na reconstrução da solução. 


\subsubsection{Comparação com o método FV-GAS}

Os resultados do método FV-OLG de $2^{\mathrm{a}}, 3^{\mathrm{a}}$ e $4^{\mathrm{a}}$ ordens para o transporte de um sino de cosseno serão comparados com FV-GAS de $2^{\mathrm{a}}$, $3^{\mathrm{a}}$ e $4^{\mathrm{a}}$ ordens, desenvolvidos por Skamarock e Gassmann (2011), e aplicados em malhas icosaédricas com otimização SCVT. O limitador utilizado também foi desenvolvido por Zalesak (1979) para garantir a monotonicidade da solução.

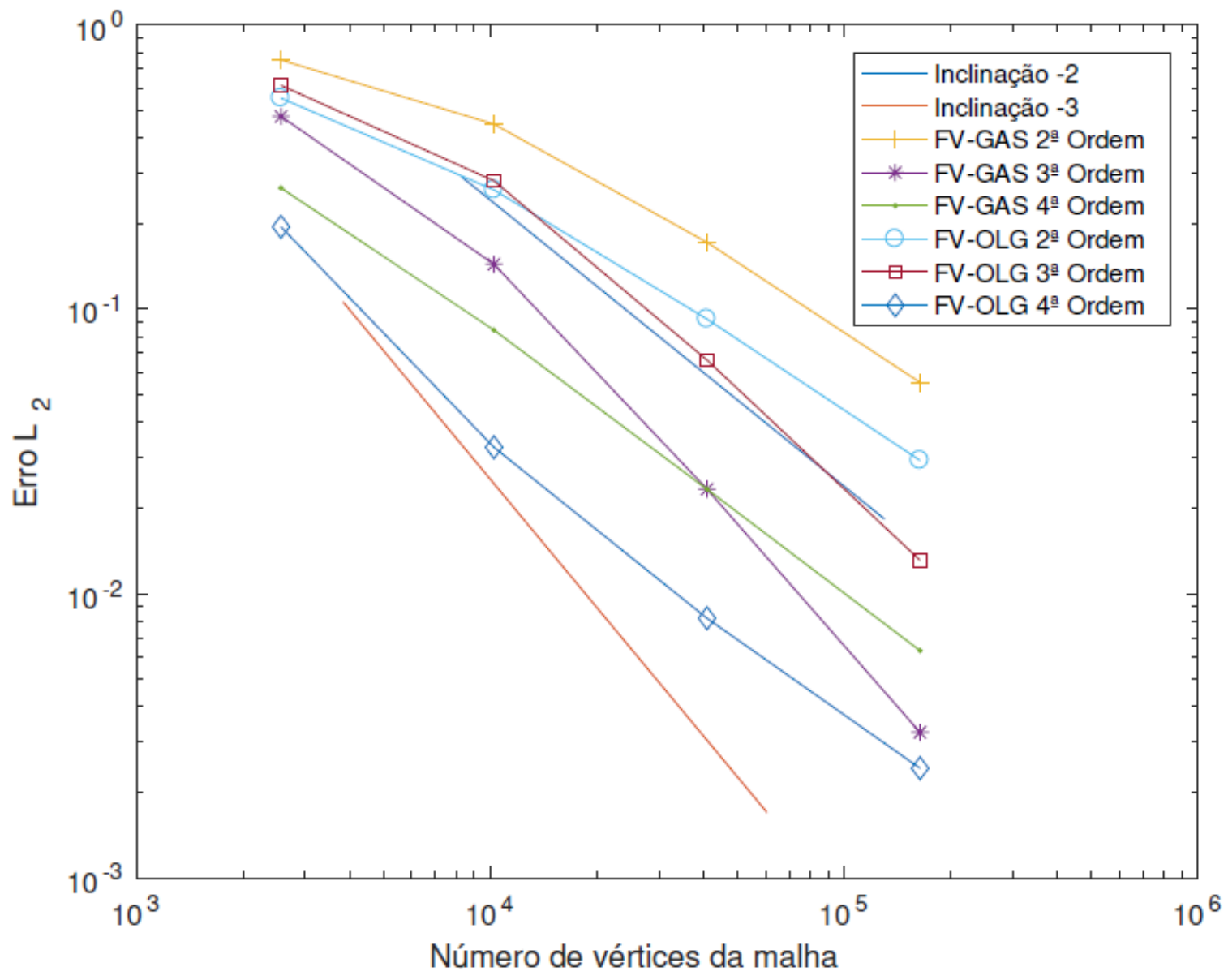

Figura 5.24: Erros associados à reconstrução de um sino de cosseno em uma malha icosaédrica com otimização SCVT, utilizando-se o método de $2^{a}, 3^{a}$ e $4^{a}$ ordens FV-GAS com o método FV-OLG com limitador, respectivamente.

Observando a Figura 5.24, verifica-se que o método de $2^{\mathrm{a}}$ ordem tende a ordem zero, mas a solução qualitativa é semelhante aos resultados obtidos em FV-GAS. O método de $3^{\text {a }}$ ordem tem a mesma inclinação com a utilização do limitador, enquanto o método de $4^{\mathrm{a}}$ ordem tem uma diminuição da ordem de convergência com a utilização do limitador, a medida que aumenta-se o nível de malha.

No geral, os métodos de $2^{\mathrm{a}}, 3^{\mathrm{a}}$ e $4^{\mathrm{a}}$ ordens de FV-GAS têm a mesma taxa de convergência do método FV-OLG. A distância entre as curvas é devido ao volume de controle do método FV-OLG ter o dobro de faces do método FV-GAS, logo FV-OLG terá um erro menor. A inversão no método de $3^{\text {a }}$ ordem FV-OLG com FV-GAS, acreditamos, que seja a razão entre coeficientes e número de vizinhos escolhidos para a construção do polinômio aproximador, pois para $2^{\mathrm{a}}, 3^{\mathrm{a}}$ e $4^{\mathrm{a}}$ ordens temos que determinar 3, 6 e 9 coeficientes e dispomos no mínimo de 5, 15 e 15 vizinhos, respectivamente. 

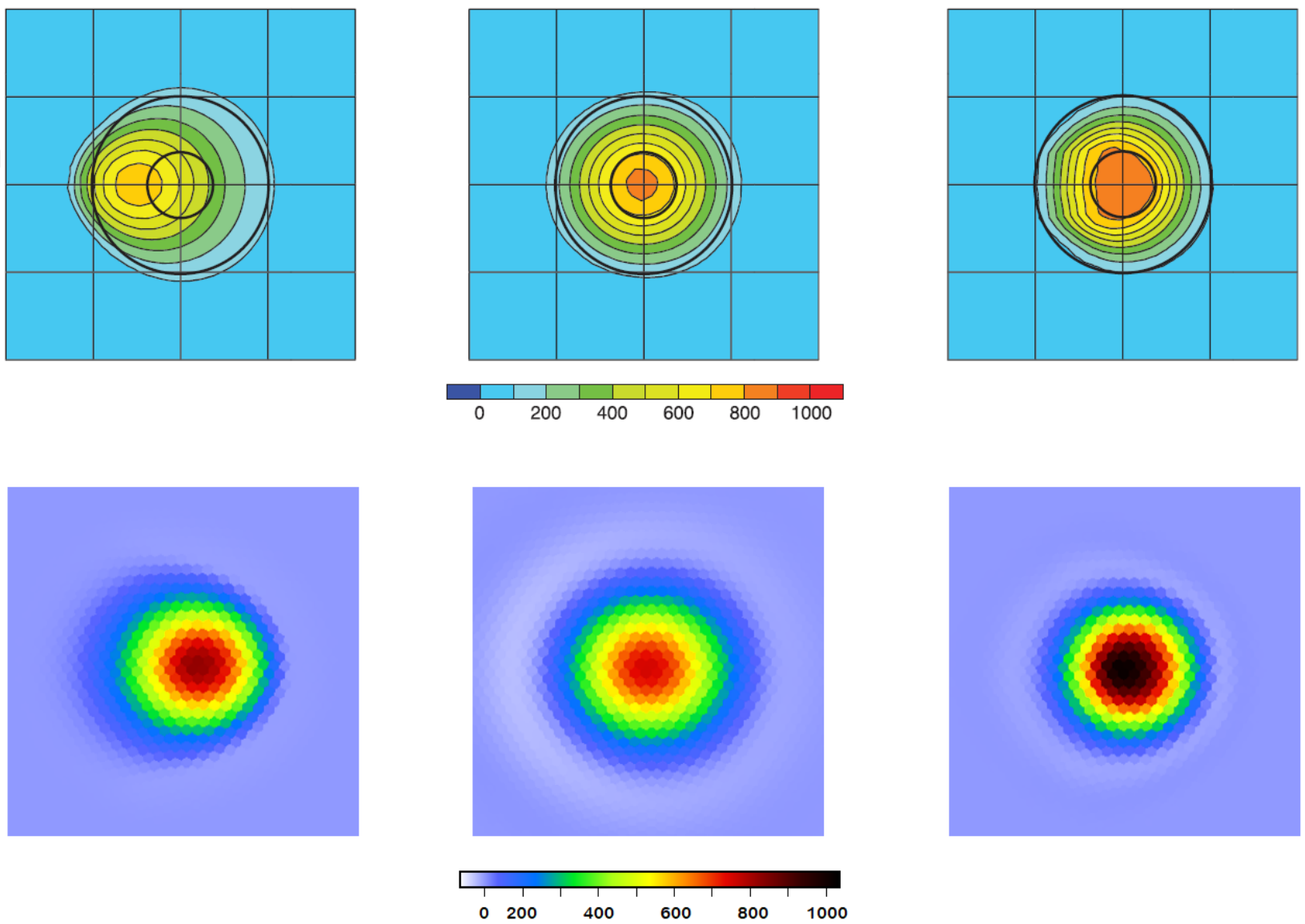

Figura 5.25: Reconstrução da solução final de um sino de cosseno em uma malha icosaédrica nível 6 com otimização SCVT, utilizando-se o método de $2^{a}$, $3^{a}$ e $4^{a}$ ordens de FV-GAS (em cima) e FV-OLG (em baixo), respectivamente.

No contexto, os métodos de $2^{\mathrm{a}}, 3^{\mathrm{a}}$ e $4^{\mathrm{a}}$ ordens de FV-GAS e FV-OLG utilizam limitadores diferentes, porém ambos conseguem fazer a reconstrução da solução final do sino de cosseno, como ilustrado na Figura 5.25. Também observa-se que a utilização do limitador é fundamental para controlar as oscilações numéricas na região com descontinuidade de derivada. 


\subsubsection{Comparação com método FV-ZHA}

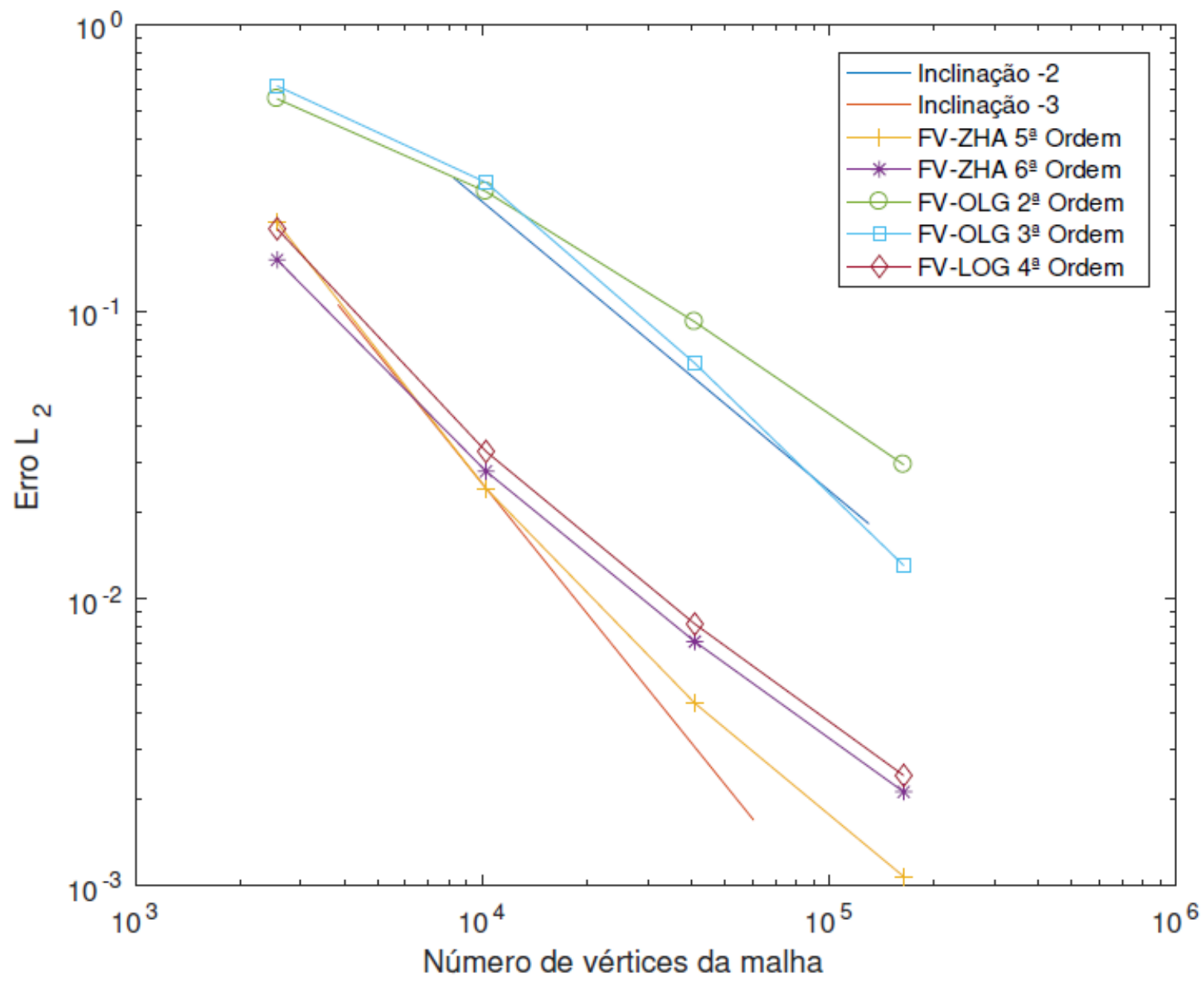

Figura 5.26: Erros associados à reconstrução de um sino de cosseno em uma malha icosaédrica com otimização SCVT, utilizando-se o método de $5^{a}$, $6^{a}$ ordens FV-GAS com o método de $2^{a}$, $3^{a}$ e $4^{a}$ ordens FV-OLG com limitador, respectivamente.

Por meio da Figura 5.26, observa-se que o método de $2^{\mathrm{a}}$ ordem FV-OLG tem a ordem zero. Por sua vez, o método de $3^{\text {a }}$ ordem tem uma inclinação ligeiramente superior à ordem um. O método de $4^{\mathrm{a}}$ ordem de FV-OLG comparado com o método FV-ZHA de $5^{\mathrm{a}}$ e $6^{\mathrm{a}}$ ordens possui a mesma taxa de convergência, sendo o método de $5^{\mathrm{a}}$ ordem mais preciso. Porém, o custo computacional é alto, devido à necessidade do cálculo dos polinômios $\phi_{i}^{2}$ e $\phi_{i}^{4}$ de grau 2 e 4 , respectivamente, por isso os pesquisadores recomendam utilizar o método de $3^{\mathrm{a}}$ ordem de FV-GAS com $\beta=0,25$. 


\subsubsection{Comparação com o método FV-SUB}

No trabalho de Subich (2018) não existe um gráfico da solução final ou do erro associado à reconstrução da solução. Por isso, será avaliado somente o aspecto quantitativo. Dessa forma, serão comparados os resultados do método FV-SUB para o transporte de uma colina de gaussiana e um sino de cosseno com o método FV-OLG. Após uma volta completa ao redor da Terra, a solução final coincide com a solução inicial, dessa forma os resultados nas normas do erro do máximo e do quadrático médio foram calculados e serão apresentados a seguir.

\section{Resultados para o transporte de uma colina de gaussiana}

\begin{tabular}{|c|c|c|c|c|c|}
\hline Nível & Nós & Erro Máx & Razão Máx & Erro 2 & Razão 2 \\
\hline 2 & 162 & $6,04 \mathrm{E}+002$ & 0,00 & $1,80 \mathrm{E}+002$ & 0,00 \\
\hline 3 & 642 & $6,72 \mathrm{E}+002$ & 0,90 & $1,52 \mathrm{E}+002$ & 1,18 \\
\hline 4 & 2562 & $4,72 \mathrm{E}+002$ & 1,42 & $9,45 \mathrm{E}+001$ & 1,61 \\
\hline 5 & 10242 & $1,86 \mathrm{E}+002$ & 2,54 & $3,19 \mathrm{E}+001$ & 2,96 \\
\hline 6 & 40962 & $3,90 \mathrm{E}+001$ & 4,77 & $5,77 \mathrm{E}+000$ & 5,53 \\
\hline 7 & 163842 & $5,49 \mathrm{E}+000$ & 7,10 & $7,78 \mathrm{E}-001$ & 7,42 \\
\hline
\end{tabular}

Tabela 5.25: Erros no transporte de uma colina de gaussiana em malhas icosaédricas com otimização $S C V T$, utilizando-se o método FV-SUB com upwinding.

\begin{tabular}{|c|c|c|c|c|c|}
\hline Nível & Nós & Erro Máx & Razão Máx & Erro 2 & Razão 2 \\
\hline 2 & 162 & $5,89 \mathrm{E}+002$ & 0,00 & $1,76 \mathrm{E}+002$ & 0,00 \\
\hline 3 & 642 & $5,42 \mathrm{E}+002$ & 1,09 & $1,41 \mathrm{E}+002$ & 1,25 \\
\hline 4 & 2562 & $2,58 \mathrm{E}+002$ & 2,10 & $6,29 \mathrm{E}+001$ & 2,24 \\
\hline 5 & 10242 & $5,23 \mathrm{E}+001$ & 4,93 & $9,06 \mathrm{E}+000$ & 6,94 \\
\hline 6 & 40962 & $4,80 \mathrm{E}+000$ & 10,90 & $6,67 \mathrm{E}-001$ & 13,58 \\
\hline 7 & 163842 & $3,98 \mathrm{E}-001$ & 12,06 & $4,76 \mathrm{E}-002$ & 14,01 \\
\hline
\end{tabular}

Tabela 5.26: Erros no transporte de uma colina de gaussiana em malhas icosaédricas com otimização $S C V T$, utilizando-se o método FV-SUB com selective upwinding.

O trabalho de Subich (2018) utiliza um estêncil upwind para avaliar os fluxos nas arestas em toda a malha icosaédrica, mas essa proposta é cara, uma vez que a solução obtida por meio do esquema upwind utiliza todo o estêncil de todas as arestas da malha. Uma forma de aumentar a taxa de convergência, foi utilizar o esquema selective - upwinding em algumas regiões da malha. Essa última proposta consiste em utilizar o esquema centrado e ativar a opção selective - upwinding, caso o peso de interpolação para qualquer volume de controle adjacente e para qualquer ponto de quadratura ao longo dessa aresta for abaixo do valor escolhido empiricamente de 0,235.

Por meio dos resultados da Tabela 5.25 e 5.26, a implementação de selecionar regiões da malha icosaédrica para aplicar o upwinding permite obter reconstruções melhores e consequentemente um erro menor da solução final. O pesquisador chegou às taxas de convergência de 2,68 utilizando o esquema upwinding e obteve para o mesmo teste uma taxa de 3,79 utilizando o esquema selective - upwinding para o erro quadrático médio, como pode ser observado nas taxas dos erros. No método proposto, FV-OLG obteve taxa de convergência de 3,40 para o mesmo teste. 


\section{Resultados para o transporte de um sino de cosseno}

\begin{tabular}{|c|c|c|c|c|c|}
\hline Nível & Nós & Erro Máx & Razão Máx & Erro 2 & Razão 2 \\
\hline 2 & 162 & $6,54 \mathrm{E}+002$ & 0,00 & $1,93 \mathrm{E}+002$ & 0,00 \\
\hline 3 & 642 & $6,91 \mathrm{E}+002$ & 0,95 & $1,69 \mathrm{E}+002$ & 1,14 \\
\hline 4 & 2562 & $4,52 \mathrm{E}+002$ & 1,53 & $1,07 \mathrm{E}+002$ & 1,58 \\
\hline 5 & 10242 & $1,32 \mathrm{E}+002$ & 3,42 & $3,48 \mathrm{E}+001$ & 3,07 \\
\hline 6 & 40962 & $1,92 \mathrm{E}+001$ & 6,88 & $7,30 \mathrm{E}+000$ & 4,77 \\
\hline 7 & 163842 & $5,39 \mathrm{E}+000$ & 3,56 & $1,62 \mathrm{E}+000$ & 4,51 \\
\hline
\end{tabular}

Tabela 5.27: Erros no transporte de um sino de cosseno em malhas icosaédricas com otimização SCVT, utilizando-se o método FV-SUB com upwinding.

\begin{tabular}{|c|c|c|c|c|c|}
\hline Nível & Nós & Erro Máx & Razão Máx & Erro 2 & Razão 2 \\
\hline 2 & 162 & $6,38 \mathrm{E}+002$ & 0,00 & $1,89 \mathrm{E}+002$ & 0,00 \\
\hline 3 & 642 & $5,55 \mathrm{E}+002$ & 1,15 & $1,59 \mathrm{E}+002$ & 1,19 \\
\hline 4 & 2562 & $2,39 \mathrm{E}+002$ & 2,32 & $7,10 \mathrm{E}+001$ & 2,24 \\
\hline 5 & 10242 & $3,41 \mathrm{E}+001$ & 7,01 & $1,22 \mathrm{E}+001$ & 5,82 \\
\hline 6 & 40962 & $8,50 \mathrm{E}+000$ & 4,01 & $2,53 \mathrm{E}+000$ & 4,82 \\
\hline 7 & 163842 & $2,65 \mathrm{E}+000$ & 3,21 & $6,12 \mathrm{E}-001$ & 4,13 \\
\hline
\end{tabular}

Tabela 5.28: Erros no transporte de um sino de cosseno em malhas icosaédricas com otimização SCVT, utilizando-se o método FV-SUB com selective upwinding.

Por meio da Tabela 5.27 e 5.28, os erros obtidos por meio do esquema selective-upwinding são menores quando comparados com o upwinding. A taxa de convergência, utilizando-se o erro quadrático médio, apresentou 2,33 e 2,39, respectivamente. O que demonstra que o método FV-SUB, ao escolher algumas regiões para aplicar o esquema selective-upwinding, permite obter melhores resultados e redução de custo computacional. O método FV-OLG obteve 1,89 de taxa de convergência, demonstrando ser competitivo com as demais propostas da literatura. 


\subsubsection{Um cilindro sólido}

O terceiro teste com limitador consiste no transporte de um cilindro sólido ao redor da Terra. A solução final coincide com a solução inicial, dessa forma, os resultados nas normas do erro do máximo e do quadrático médio foram calculados e serão apresentados a seguir para as ordens em estudo.

O objetivo deste teste é avaliar o efeito da inclusão do limitador, pois o cilindro sólido é uma função desafiadora devido à região de descontinuidade brusca. Serão gerados gráficos com cortes transversais da solução incial e final, para avaliar qualitativamente os resultados do limitador proposto.

\section{Resultados numéricos utilizando-se os métodos de $2^{\mathrm{a}}, 3^{\mathrm{a}}$ e $4^{\mathrm{a}}$ ordens}

\begin{tabular}{|c|c|c|c|c|c|c|}
\hline Nível & Nós & Erro Máx & Razão Máx & Erro 2 & Razão 2 & Tempo (s) \\
\hline 4 & 2562 & $5,05 \mathrm{E}-001$ & 0,00 & $3,15 \mathrm{E}-001$ & 0,00 & 18,6 \\
\hline 5 & 10242 & $5,07 \mathrm{E}-001$ & 1,00 & $2,53 \mathrm{E}-001$ & 1,25 & 157,6 \\
\hline 6 & 40962 & $5,20 \mathrm{E}-001$ & 0,97 & $2,04 \mathrm{E}-001$ & 1,24 & 1322,1 \\
\hline 7 & 163842 & $5,33 \mathrm{E}-001$ & 0,98 & $1,63 \mathrm{E}-001$ & 1,25 & 11043,1 \\
\hline
\end{tabular}

Tabela 5.29: Erros e tempo de CPU associados à reconstrução de um cilindro sólido em uma malha icosaédrica com otimização SCVT, utilizando-se o método de $2^{a}$ ordem com limitador.

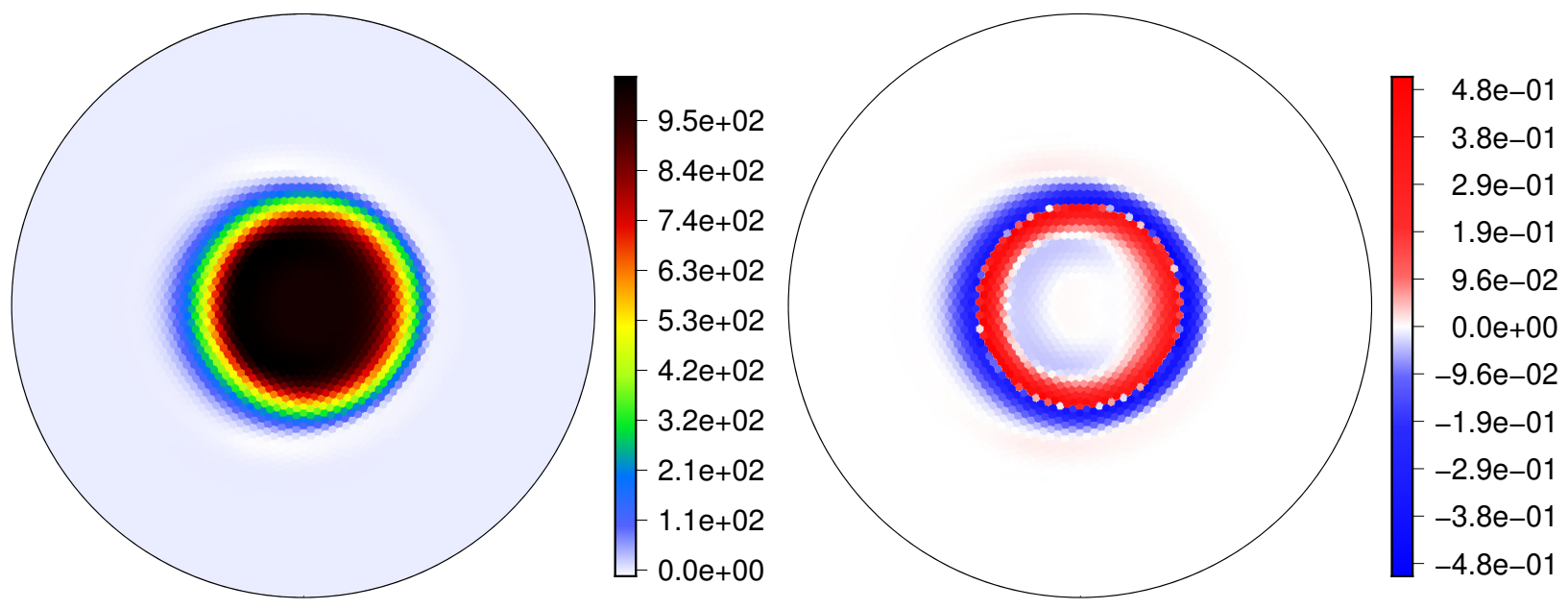

Figura 5.27: Solução final e erro no transporte de um cilindro sólido ao redor da Terra em uma malha icosaédrica de nível 5 com otimização SCVT, utilizando-se o método de $2^{a}$ ordem com limitador.
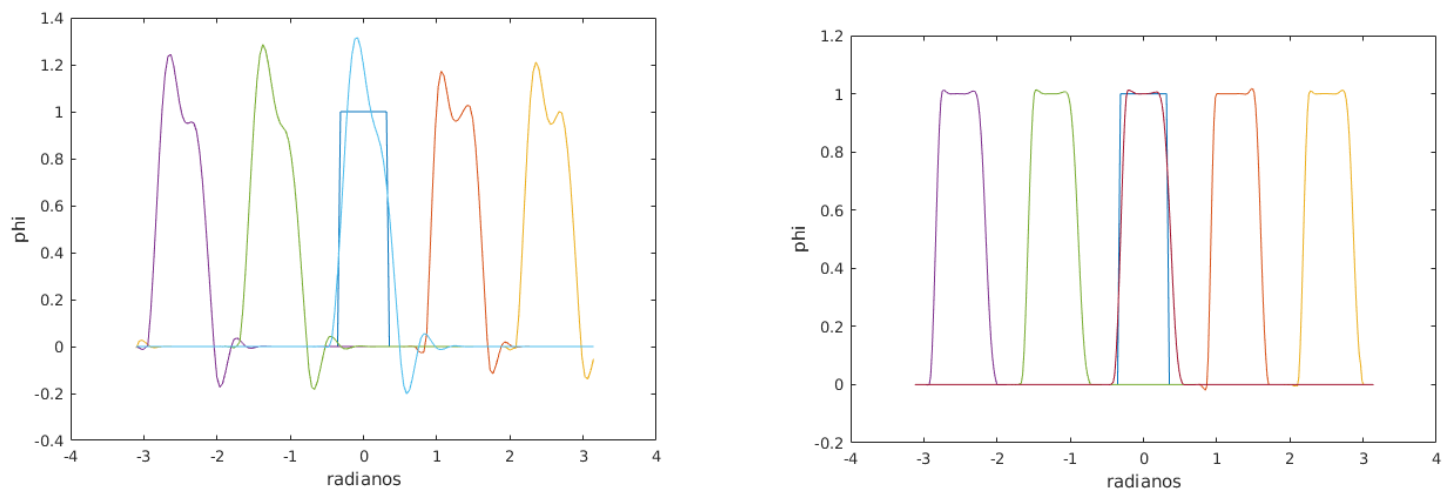

Figura 5.28: Corte transversal da solução de $2^{a}$ ordem cilindro sólido sem e com limitador, malha nível 5. 
Com a utilização do limitador ilustrado na Figura 5.28 para o método FV-OLG de $2^{\mathrm{a}}$ ordem, tem-se uma menor dispersão numérica. Nota-se que o limitador proposto foi capaz de controlar as oscilações numéricas, diminuindo o "overshoot" durante o transporte da solução.

\begin{tabular}{|c|c|c|c|c|c|c|}
\hline Nível & Nós & Erro Máx & Razão Máx & Erro 2 & Razão 2 & Tempo (s) \\
\hline 4 & 2562 & $4,88 \mathrm{E}-001$ & 0,00 & $3,50 \mathrm{E}-001$ & 0,00 & 47,4 \\
\hline 5 & 10242 & $4,85 \mathrm{E}-001$ & 1,01 & $2,78 \mathrm{E}-001$ & 1,26 & 422,1 \\
\hline 6 & 40962 & $4,88 \mathrm{E}-001$ & 0,99 & $2,19 \mathrm{E}-001$ & 1,27 & 2948,7 \\
\hline 7 & 163842 & $4,91 \mathrm{E}-001$ & 0,99 & $1,70 \mathrm{E}-001$ & 1,29 & 25424,0 \\
\hline
\end{tabular}

Tabela 5.30: Erros e tempo de CPU associados à reconstrução de um cilindro sólido em uma malha icosaédrica com otimização SCVT, utilizando-se o método de $3^{a}$ ordem com limitador.

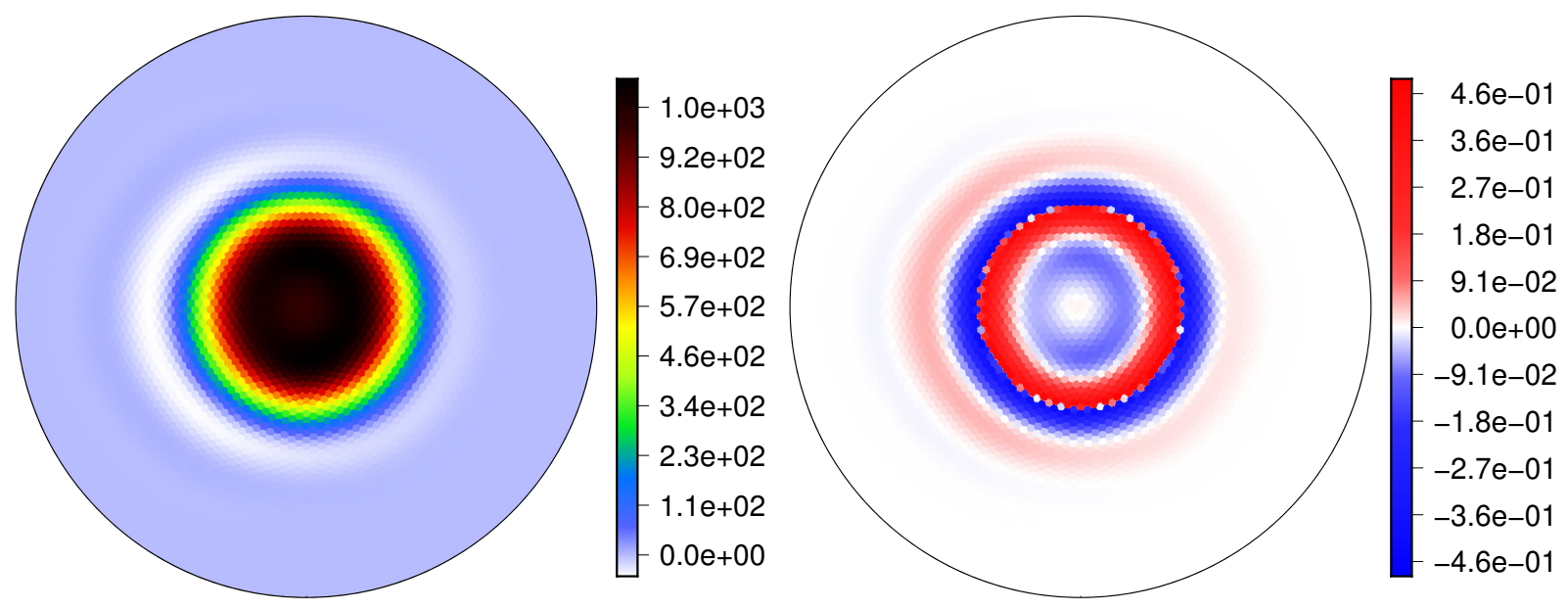

Figura 5.29: Solução final e erro no transporte de um cilindro sólido ao redor da Terra em uma malha icosaédrica de nivel 5 com otimização SCVT, utilizando-se o método de $3^{a}$ ordem com limitador.

No método FV-OLG de $3^{\mathrm{a}}$ ordem percebe-se que a utilização do limitador proporciona melhores resultados qualitativos quando comparados com os resultados sem limitador. O método de $3^{\mathrm{a}}$ ordem possui maior difusão numérica, conforme se observa na Figura 5.29 avaliando-se o erro cometido entre a solução final e inicial, após uma revolução ao redor da Terra.

\begin{tabular}{|c|c|c|c|c|c|c|}
\hline Nível & Nós & Erro Máx & Razão Máx & Erro 2 & Razão 2 & Tempo (s) \\
\hline 4 & 2562 & $3,99 \mathrm{E}-001$ & 0,00 & $2,18 \mathrm{E}-001$ & 0,00 & 49,9 \\
\hline 5 & 10242 & $4,00 \mathrm{E}-001$ & 1,00 & $1,73 \mathrm{E}-001$ & 1,26 & 392,3 \\
\hline 6 & 40962 & $4,67 \mathrm{E}-001$ & 0,86 & $1,36 \mathrm{E}-001$ & 1,27 & 3222,1 \\
\hline 7 & 163842 & $5,30 \mathrm{E}-001$ & 0,88 & $1,05 \mathrm{E}-001$ & 1,30 & 25902,6 \\
\hline
\end{tabular}

Tabela 5.31: Erros e tempo de CPU associados à reconstrução de um cilindro sólido em uma malha icosaédrica com otimização SCVT, utilizando-se o método de $4^{a}$ ordem com limitador. 

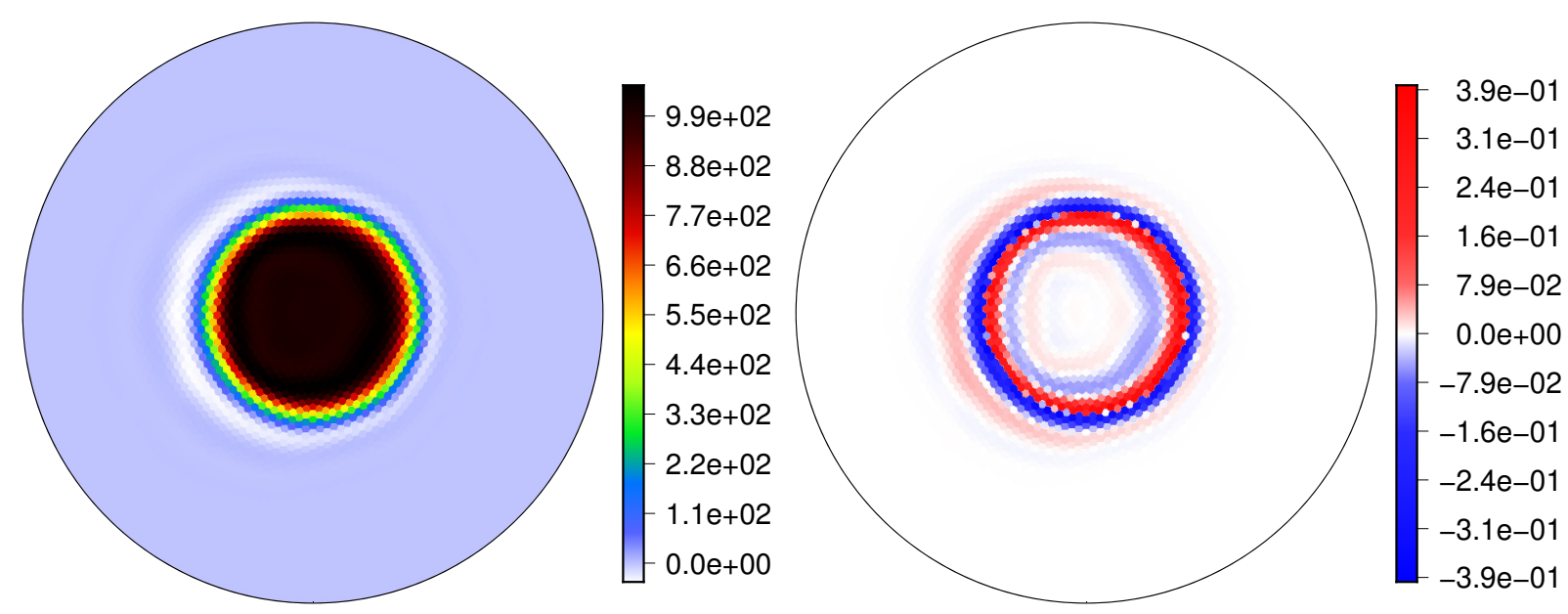

Figura 5.30: Solução final e erro no transporte de um cilindro sólido ao redor da Terra em uma malha icosaédrica de nível 5 com otimização SCVT, utilizando-se o método de $4^{a}$ ordem com limitador.

O método FV-OLG de $4^{\mathrm{a}}$ ordem apresenta melhor qualidade na solução final, apresentando menores oscilações nas bordas do cilindro sólido. Em suma, o método FV-OLG de $2^{\mathrm{a}}, 3^{\mathrm{a}}$ e $4^{\mathrm{a}}$ ordens utilizando-se o limitador, proporcionaram uma solução final mais simétrica, conforme observado na Figura 5.27, 5.29 e 5.30, com menor dispersão numérica quando comparados com os resultados sem limitador.

\subsubsection{Um cilindro cortado}

O quarto teste com o limitador consiste no transporte de uma cilindro cortado ao redor da Terra. A solução final coincide com a solução inicial, dessa forma, os resultados nas normas do erro do máximo e do quadrático médio foram calculados e serão apresentados a seguir para as ordens em estudo. Esse teste é mais desafiador que o cilindro sólido, e tem por objetivo avaliar a capacidade do limitador ao lidar com mais descontinuidades.

\section{Resultados numéricos utilizando-se os métodos de $2^{\mathrm{a}}, 3^{\mathrm{a}}$ e $4^{\mathrm{a}}$ ordens}

\begin{tabular}{|c|c|c|c|c|c|c|}
\hline Nível & Nós & Erro Máx & Razão Máx & Erro 2 & Razão 2 & Tempo (s) \\
\hline 4 & 2562 & $8,20 \mathrm{E}-001$ & 0,00 & $4,91 \mathrm{E}-001$ & 0,00 & 18,6 \\
\hline 5 & 10242 & $7,31 \mathrm{E}-001$ & 1,12 & $3,74 \mathrm{E}-001$ & 1,31 & 157,1 \\
\hline 6 & 40962 & $7,82 \mathrm{E}-001$ & 0,93 & $2,88 \mathrm{E}-001$ & 1,30 & 1326,6 \\
\hline 7 & 163842 & $7,60 \mathrm{E}-001$ & 1,03 & $2,24 \mathrm{E}-001$ & 1,29 & 10948,7 \\
\hline
\end{tabular}

Tabela 5.32: Erros e tempo de CPU associados à reconstrução de um cilindro cortado em uma malha icosaédrica com otimização SCVT, utilizando-se o método de $2^{a}$ ordem com limitador. 

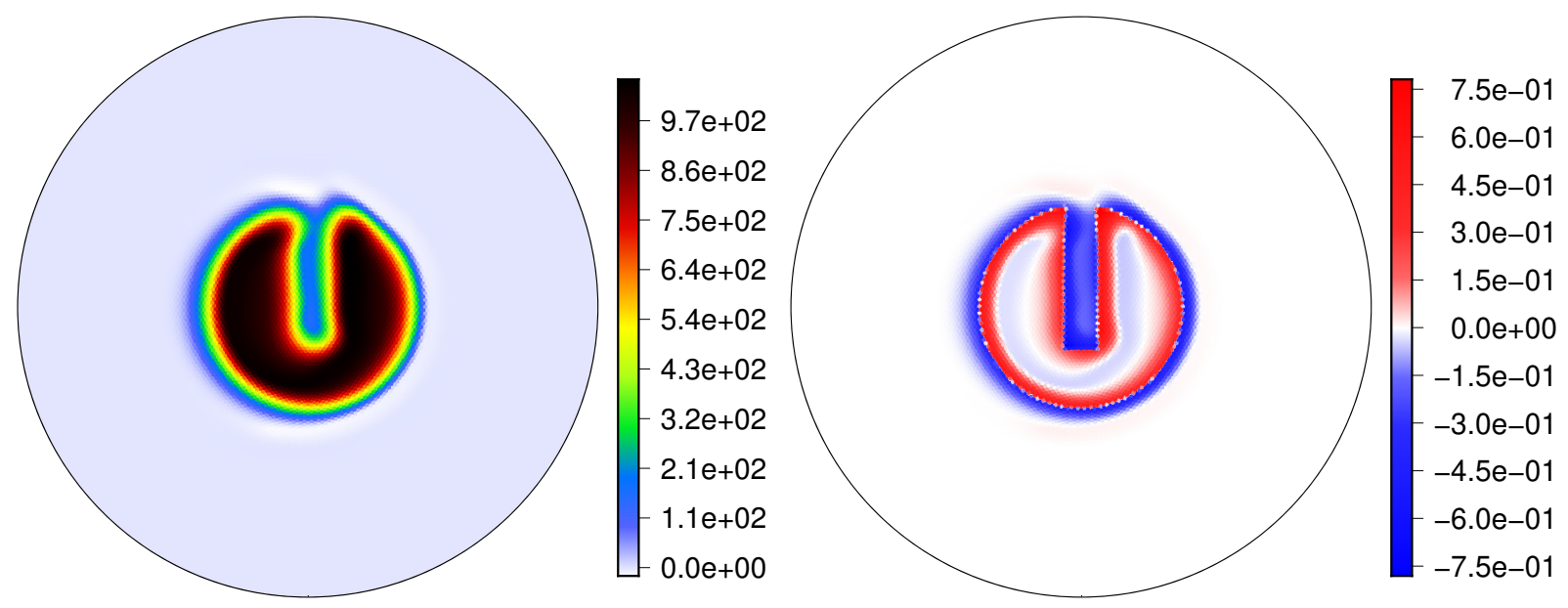

Figura 5.31: Solução final e erro no transporte de um cilindro cortado ao redor da Terra em uma malha icosaédrica de nível 6 com otimização SCVT, utilizando-se o método de $2^{a}$ ordem com limitador.

\begin{tabular}{|c|c|c|c|c|c|c|}
\hline Nível & Nós & Erro Máx & Razão Máx & Erro 2 & Razão 2 & Tempo (s) \\
\hline 4 & 2562 & $9,24 \mathrm{E}-001$ & 0,00 & $5,26 \mathrm{E}-001$ & 0,00 & 47,4 \\
\hline 5 & 10242 & $7,58 \mathrm{E}-001$ & 1,22 & $3,88 \mathrm{E}-001$ & 1,36 & 377,6 \\
\hline 6 & 40962 & $6,99 \mathrm{E}-001$ & 1,08 & $2,97 \mathrm{E}-001$ & 1,31 & 2985,0 \\
\hline 7 & 163842 & $6,92 \mathrm{E}-001$ & 1,01 & $2,23 \mathrm{E}-001$ & 1,33 & 29148,1 \\
\hline
\end{tabular}

Tabela 5.33: Erros e tempo de CPU associados à reconstrução de um cilindro cortado em uma malha icosaédrica com otimização SCVT, utilizando-se o método de $3^{a}$ ordem com limitador.
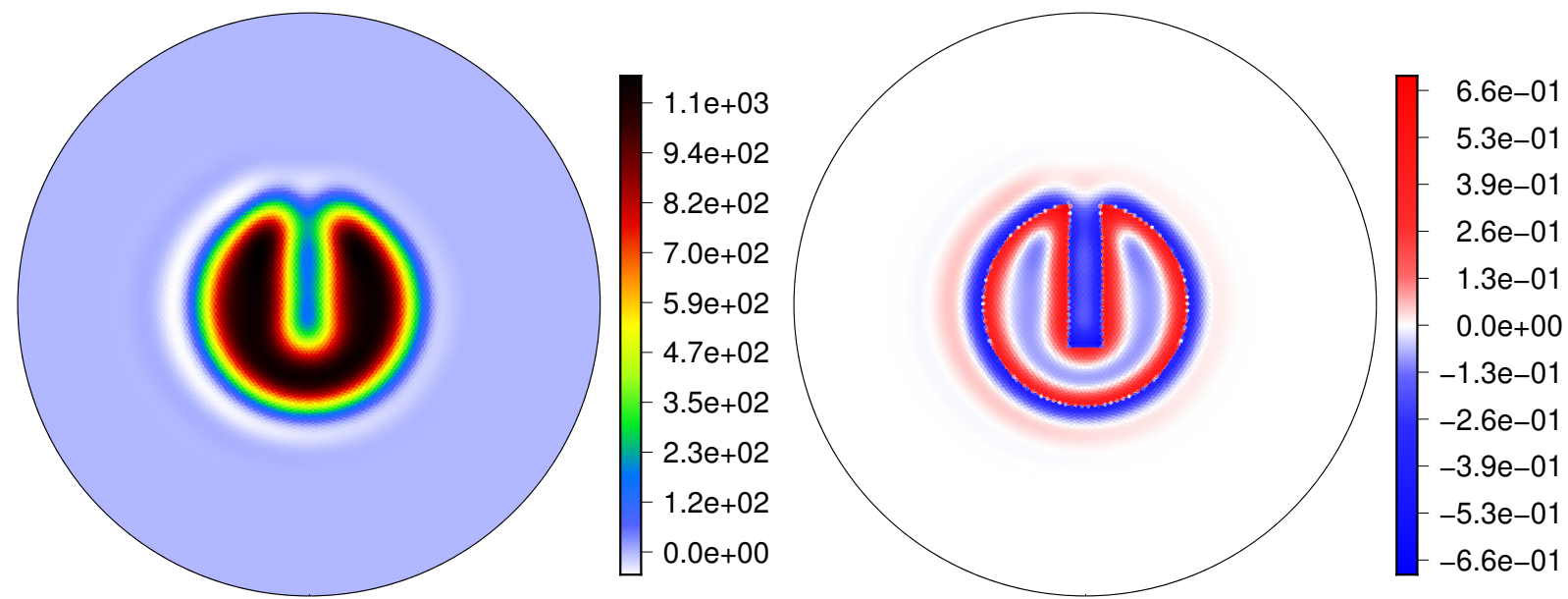

Figura 5.32: Solução final e erro no transporte de um cilindro cortado ao redor da Terra em uma malha icosaédrica de nível 6 com otimização SCVT, utilizando-se o método de $3^{a}$ ordem com limitador. 


\begin{tabular}{|c|c|c|c|c|c|c|}
\hline Nível & Nós & Erro Máx & Razão Máx & Erro 2 & Razão 2 & Tempo (s) \\
\hline 4 & 2562 & $7,12 \mathrm{E}-001$ & 0,00 & $3,25 \mathrm{E}-001$ & 0,00 & 49,4 \\
\hline 5 & 10242 & $5,68 \mathrm{E}-001$ & 1,25 & $2,44 \mathrm{E}-001$ & 1,33 & 610,9 \\
\hline 6 & 40962 & $6,02 \mathrm{E}-001$ & 0,94 & $1,85 \mathrm{E}-001$ & 1,32 & 2980,1 \\
\hline 7 & 163842 & $6,11 \mathrm{E}-001$ & 0,99 & $1,42 \mathrm{E}-001$ & 1,30 & 23980,0 \\
\hline
\end{tabular}

Tabela 5.34: Erros e tempo de CPU associados à reconstrução de um cilindro cortado em uma malha icosaédrica com otimização SCVT, utilizando-se o método de $2^{a}$ ordem com limitador.
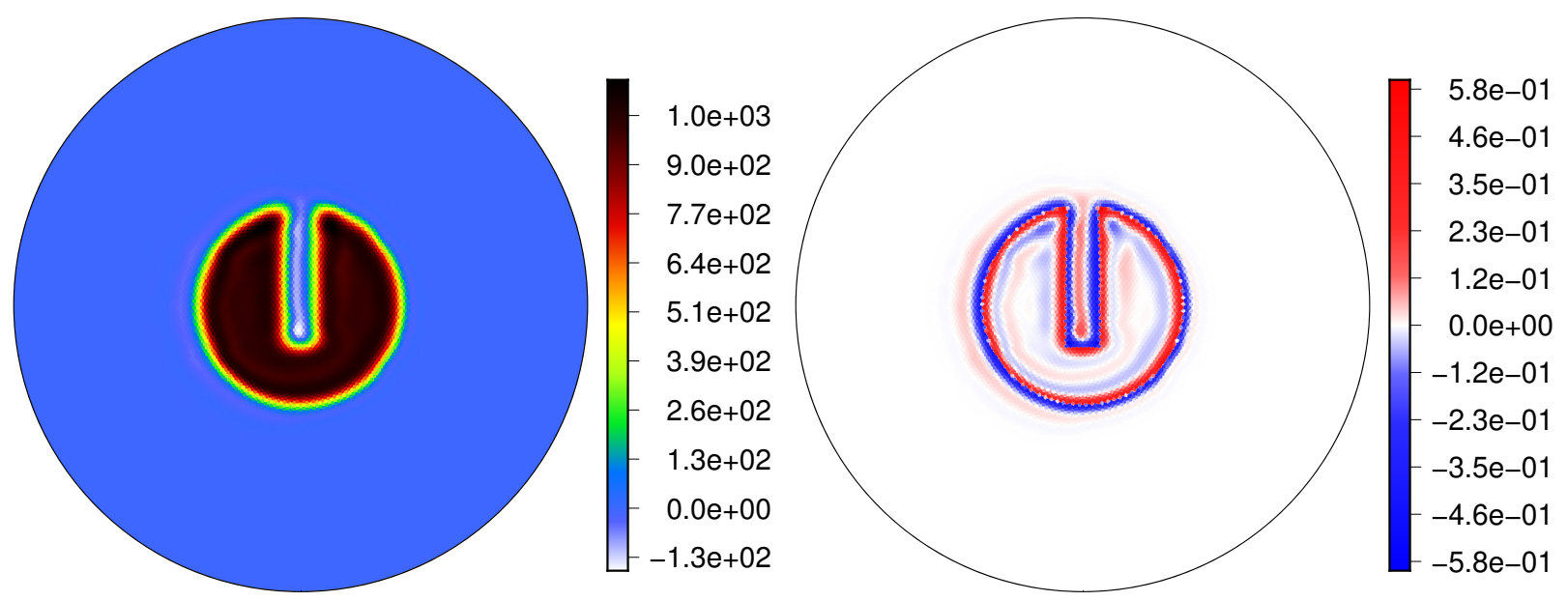

Figura 5.33: Solução final e erro no transporte de um cilindro cortado ao redor da Terra em uma malha icosaédrica de nível 6 com otimização SCVT, utilizando-se o método de $4^{a}$ ordem com limitador.

Pode-se observar que a solução final do cilindro cortado, utilizando-se o método de $2^{\mathrm{a}}$, $3^{\mathrm{a}}$ e $4^{\mathrm{a}}$ ordens com o limitador, possui uma menor dispersão, quando comparada com os resultados sem limitador. Em todos os testes, o método de $3^{\text {a }}$ ordem tende a apresentar uma maior difusão numérica. Como mencionado, para o teste do cilindro sólido, o uso do limitador aplicado nos métodos de $2^{\mathrm{a}}, 3^{\mathrm{a}}$ e $4^{\mathrm{a}}$ ordens proporciona uma solução final mais simétrica também para o cilindro cortado, conforme observado na Figura 5.31, Figura 5.32 e na Figura 5.33, com menor dispersão numérica quando comparados com os resultados sem limitador. 


\subsubsection{Comparação com o método FV-MEN}

Neste tópico, a reconstrução da solução é avaliada qualitativamente utilizando-se o método FVOLG de $2^{\mathrm{a}}$ e $4^{\mathrm{a}}$ ordens com os resultados do método FV-MEN. Ambos os métodos utilizam o mesmo número de Courant, dado no trabalho de Skamarock e Menchaca (2010).
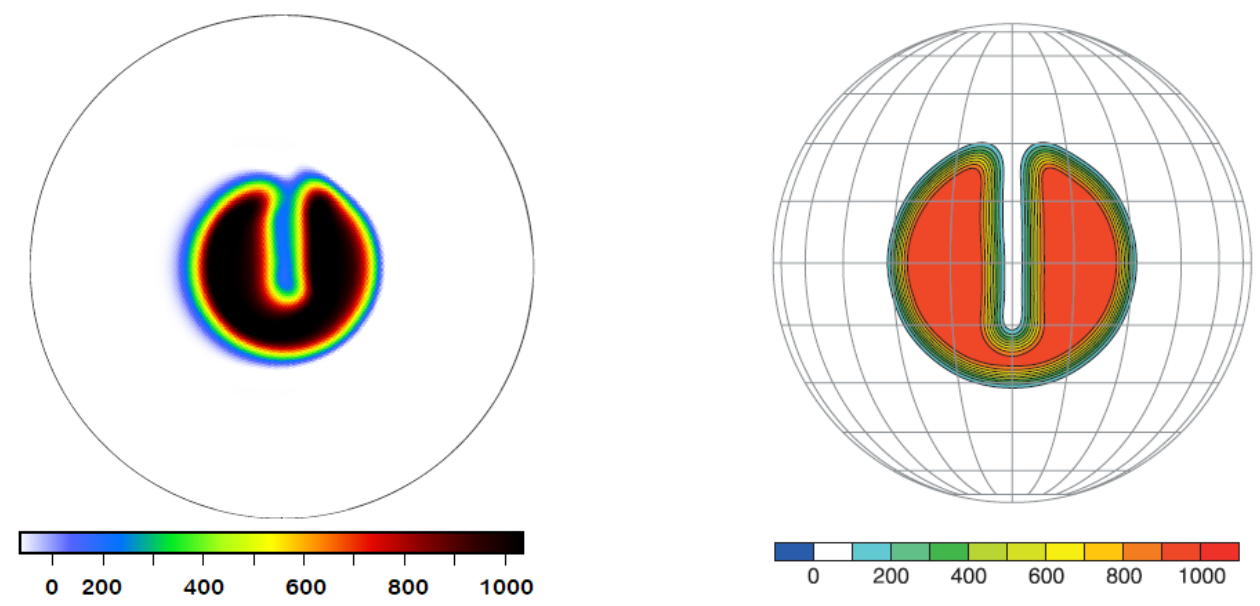

Figura 5.34: Solução final do transporte de um cilindro cortado em uma malha icosaédrica de nível 6 com otimização HR95 e SCVT , utilizando-se o método de $2^{a}$ ordem FV-OLG (esquerda) e FV-MEN (direita) com limitador.

O cilindro cortado foi advectado e, ao final de doze dias retorna a sua posição final que coincide com a posição inicial. Devido à natureza descontínua das bordas do cilindro cortado, a qualidade dos resultados é determinada pelo limitador monotônico e pelo uso de malhas de maior nível, ou seja, mais refinadas.

Conforme observa-se nos gráficos da Figura 5.34, os métodos em estudo apresentam boa qualidade da solução final. No teste do cilindro cortado, utilizando-se FV-MEN, a solução assume valores negativos em algumas regiões. No geral, ambos os métodos foram capazes de produzir uma representação mais nítida nas descontinuidades das bordas. 


\subsubsection{Comparação com o método FV-GAS}

Os resultados qualitativos da reconstrução da solução, utilizando-se o método FV-OLG de $2^{\mathrm{a}}$, $3^{\mathrm{a}}$ e $4^{\mathrm{a}}$ ordens são comparados com os resultados do método FV-GAS. Ambos métodos utilizam o mesmo número de Courant, dado no trabalho de Skamarock e Gassmann (2011).
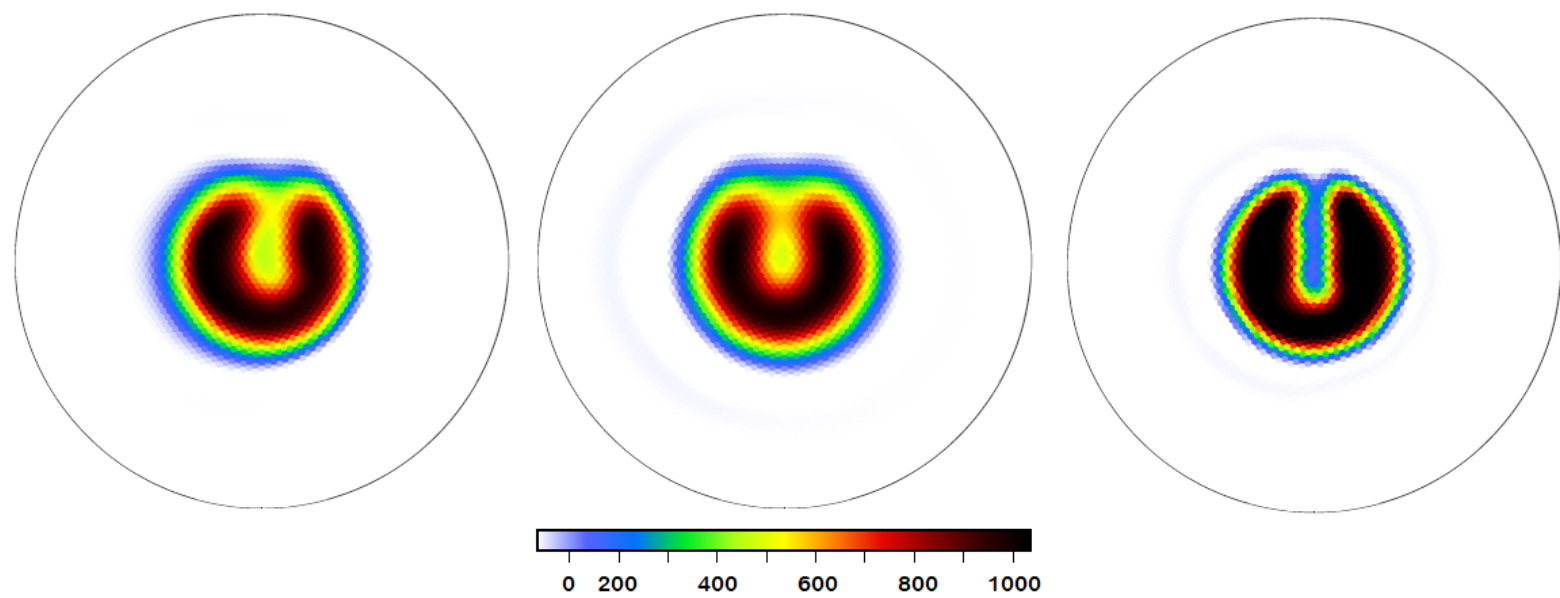

Figura 5.35: Solução final do transporte de um cilindro cortado em uma malha icosaédrica de nível 5 com otimização SCVT, utilizando-se o método FV-OLG de $2^{a}$, $3^{a}$ e $4^{a}$ ordens com limitador.
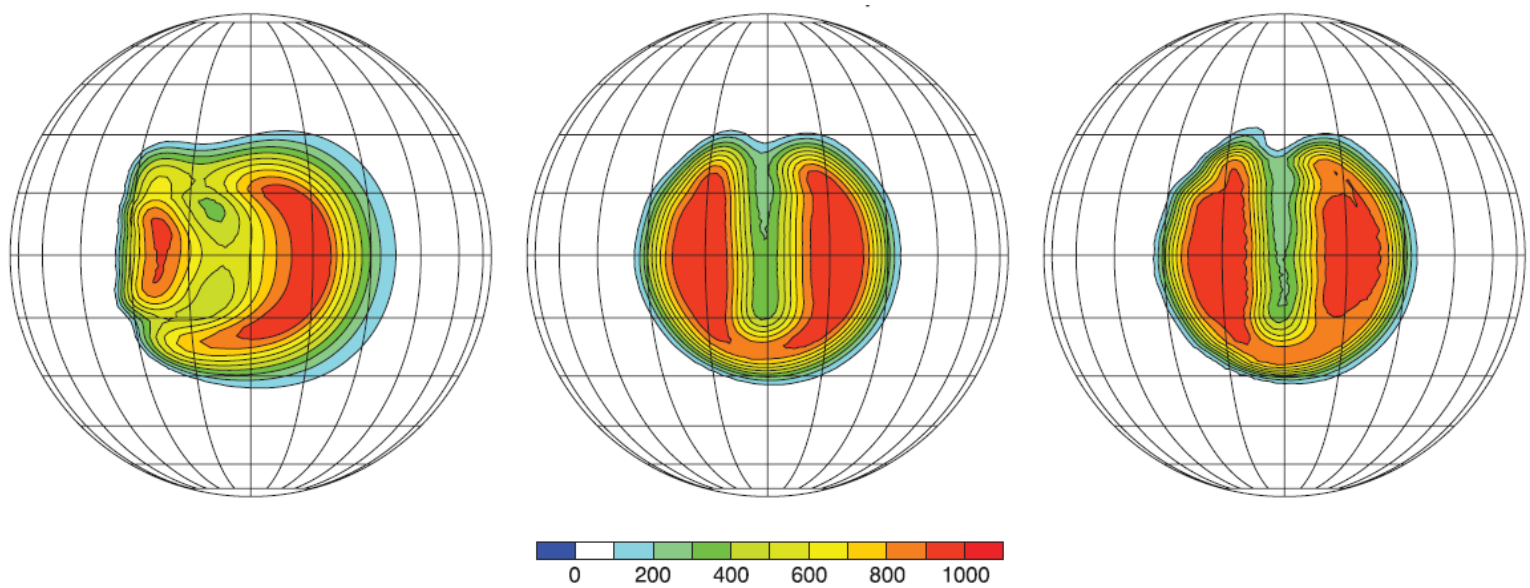

Figura 5.36: Solução final do transporte de um cilindro cortado em uma malha icosaédrica de nível 5 com otimização SCVT, utilizando-se o método $F V$-GAS de $2^{a}, 3^{a}$ e $4^{a}$ ordens com limitador.

Como a função cilindro cortado é descontínua nas bordas, a qualidade dos resultados será determinada pelo uso do limitador. Percebe-se que à medida que aumenta o nível da malha, aumenta também a qualidade da solução final, ou seja, tem-se uma melhor simetria da solução. É possível observar também que a solução do método FV-OLG na Figura 5.35 é melhor que o método FV-GAS na Figura 5.36, após uma volta completa em torno da Terra. 


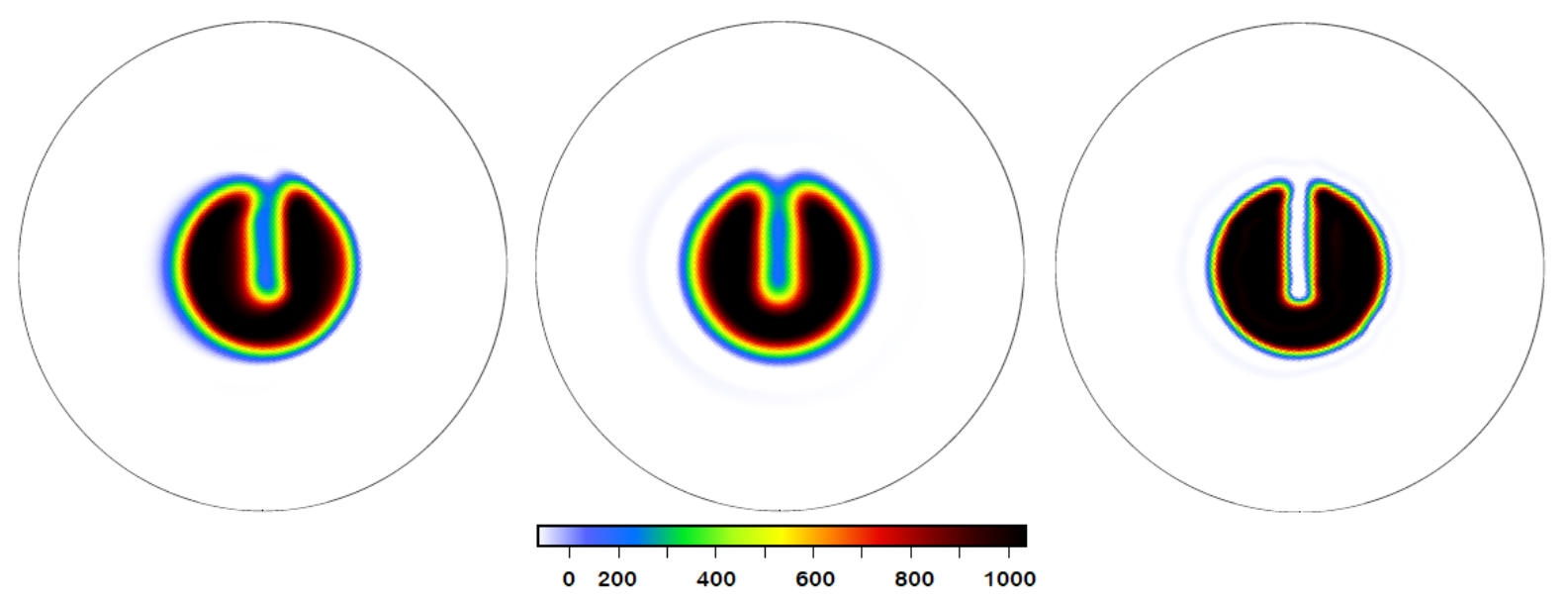

Figura 5.37: Solução final do transporte de um cilindro cortado em uma malha icosaédrica de nível 6 com otimização SCVT, utilizando-se o método FV-OLG de $2^{a}$, $3^{a}$ e $4^{a}$ ordens com limitador.
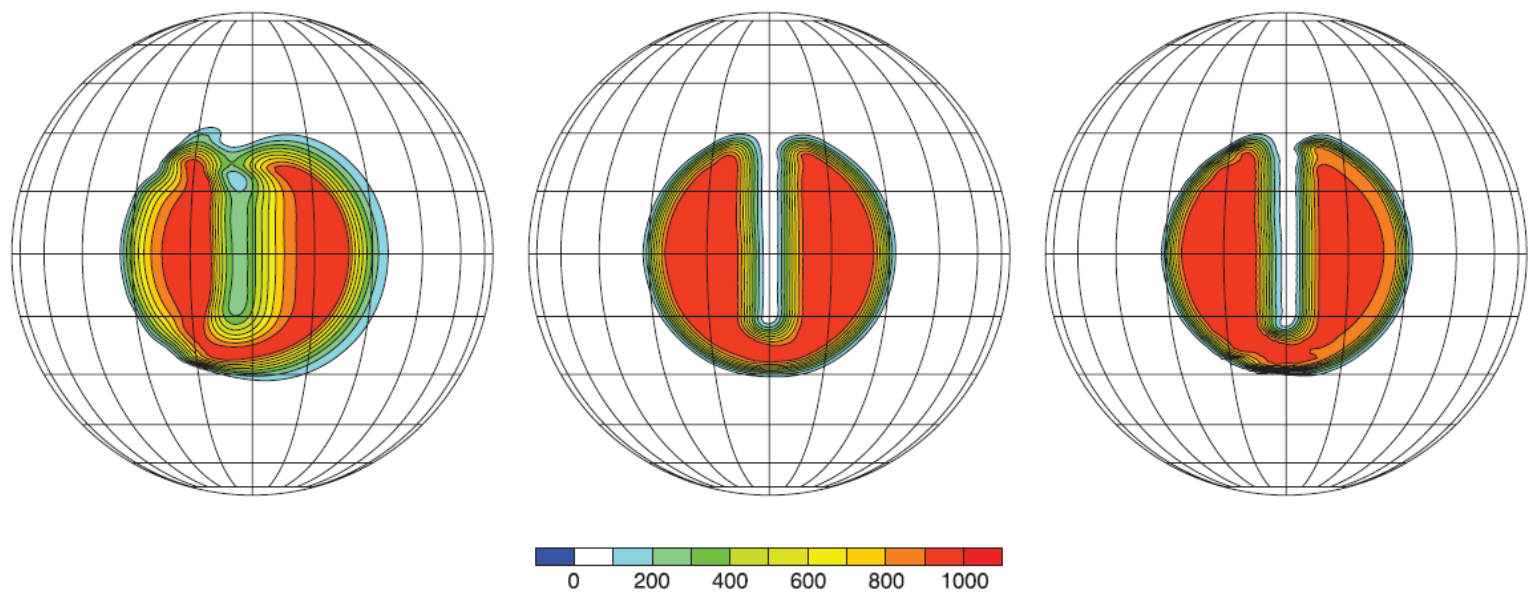

Figura 5.38: Solução final do transporte de um cilindro cortado em uma malha icosaédrica de nível 6 com otimização SCVT, utilizando-se o método FV-GAS de $2^{a}$, $3^{a}$ e $4^{a}$ ordens com limitador.

A função cilindro cortado é um teste desafiador, pois envolve descontinuidades de derivadas, que permitem avaliar a robustez do método e a qualidade da reconstrução da solução final. O método FV-OLG, além de fornecer uma melhor qualidade da solução, tem um limitador proposto com desempenho similar ao método FV-GAS, uma vez que a reconstrução final da solução apresenta valores abaixo de 0 e superiores a 1000. Aumentando o nível da malha, fica evidente que a qualidade da solução da Figura 5.37, produzida pelo método FV-OLG, entrega uma qualidade melhor do contorno do cilindro cortado, quando comparado com a solução da Figura 5.38 do método FVGAS. 


\subsection{Testes de deformação com rotação}

\subsubsection{Duas colinas de gaussianas}

Os resultados numéricos do método FV-GAS, obtidos em Skamarock e Gassmann (2011) e do método FV-ZHA, obtidos em Zhang (2018), serão comparados com o método FV-OLG. Esse teste foi proposto por Nair e Lauritzen (2010) e irá deformar duas colinas de gaussianas até o instante $T / 2$, revertendo então a deformação até reconstruí-las nos seus locais de origem no instante $T$.

Nos testes anteriores, foi utilizado um campo vetorial de rotação para validar as ordens do método FV-OLG e fazer comparações com trabalhos da literatura, mas o campo mencionado não deforma a condição inicial, que é uma importante característica presente em transporte de substâncias na atmosfera. Este teste tem como objetivo avaliar como o método FV-OLG comporta-se ao se utilizar a função teste duas colinas de gaussianas em um campo vetorial não divergente com deformação, acrescido de uma rotação de fundo, o que elimina potenciais cancelamentos de erros.

A condição inicial escalar de duas colinas de gaussianas na esfera unitária é dada por

$$
\phi(\lambda, \theta)=h_{1}(\lambda, \theta)+h_{2}(\lambda, \theta),
$$

onde, cada $h_{i}$ é definido em coordenadas cartesianas como

$$
h_{i}=\exp \left\{-5\left(x-x_{i}\right)+\left(y-y_{i}\right)+\left(z-z_{i}\right)\right\},
$$

sendo fixadas nos pontos $\left(\lambda_{1}, \theta_{1}\right)=(-\pi / 4,0)$ e $\left(\lambda_{2}, \theta_{2}\right)=(\pi / 4,0)$, respectivamente.

O campo de velocidade é dado por

$$
\begin{aligned}
& u(\lambda, \theta, t)=k \sin ^{2}(\lambda+\pi) \sin (2 \theta) \cos (\pi t / T), \\
& v(\lambda, \theta, t)=k \sin (2(\lambda+\pi)) \cos (\theta) \cos (\pi t / T),
\end{aligned}
$$

onde, utiliza-se $k=2$ e período total $T=5$.

Como mencionado, para evitar cancelamentos de erros numéricos foi adicionado uma rotação ao campo vetorial. Isso pode ser feito adicionando o termo $2 \pi \cos (\theta) / T$ na componente zonal do campo de velocidades, resultando em

$$
\begin{aligned}
& u(\lambda, \theta, t)=k \sin ^{2}\left(\lambda^{\prime}+\pi\right) \sin (2 \theta) \cos (\pi t / T)+2 \pi \cos (\theta) / T \\
& v(\lambda, \theta, t)=k \sin \left(2\left(\lambda^{\prime}+\pi\right)\right) \cos (\theta) \cos (\pi t / T)
\end{aligned}
$$

onde, $\lambda^{\prime}=\lambda-2 \pi / T$. 


\section{Resultados numéricos utilizando-se os métodos de $2^{\mathrm{a}}, 3^{\mathrm{a}}$ e $4^{\mathrm{a}}$ ordens}

Foi avaliado o transporte de duas colinas de gaussianas com limitador para vários níveis de malha. Após o tempo $T=5$, a solução final coincide com a solução inicial, dessa forma, os resultados nas normas do erro do máximo e do quadrático médio foram calculados para as ordens em estudo e serão apresentados a seguir.

\begin{tabular}{|c|c|c|c|c|c|c|}
\hline Nível & Nós & Erro Máx & Razão Máx & Erro 2 & Razão 2 & Tempo (s) \\
\hline 5 & 2562 & $3,59 \mathrm{E}-001$ & 0,00 & $2,92 \mathrm{E}-001$ & 0,00 & 480,7 \\
\hline 6 & 10242 & $1,67 \mathrm{E}-001$ & 2,15 & $1,29 \mathrm{E}-001$ & 2,26 & 4016,6 \\
\hline 7 & 40962 & $7,78 \mathrm{E}-002$ & 2,14 & $4,87 \mathrm{E}-002$ & 2,64 & 32576,0 \\
\hline 8 & 163842 & $2,66 \mathrm{E}-002$ & 2,92 & $1,44 \mathrm{E}-002$ & 3,37 & 266011,1 \\
\hline
\end{tabular}

Tabela 5.35: Erros e tempo de CPU associados ao transporte de duas colinas de gaussianas em uma malha icosaédrica com otimização SCVT, utilizando-se o método de $2^{a}$ ordem com limitador.

\begin{tabular}{|c|c|c|c|c|c|c|}
\hline Nível & Nós & Erro Máx & Razão Máx & Erro 2 & Razão 2 & Tempo (s) \\
\hline 5 & 2562 & $3,88 \mathrm{E}-001$ & 0,00 & $3,39 \mathrm{E}-001$ & 0,00 & 1066,0 \\
\hline 6 & 10242 & $1,71 \mathrm{E}-001$ & 2,26 & $1,34 \mathrm{E}-001$ & 2,53 & 8820,9 \\
\hline 7 & 40962 & $4,62 \mathrm{E}-002$ & 3,69 & $3,16 \mathrm{E}-002$ & 4,25 & 72576,3 \\
\hline 8 & 163842 & $8,39 \mathrm{E}-003$ & 5,51 & $4,77 \mathrm{E}-003$ & 6,61 & 598327,6 \\
\hline
\end{tabular}

Tabela 5.36: Erros e tempo de CPU associados ao transporte de duas colinas de gaussianas em uma malha icosaédrica com otimização SCVT, utilizando-se o método de $3^{a}$ ordem com limitador.

\begin{tabular}{|c|c|c|c|c|c|c|}
\hline Nível & Nós & Erro Máx & Razão Máx & Erro 2 & Razão 2 & Tempo (s) \\
\hline 5 & 2562 & $1,57 \mathrm{E}-001$ & 0,00 & $1,08 \mathrm{E}-001$ & 0,00 & 1120,0 \\
\hline 6 & 10242 & $5,76 \mathrm{E}-002$ & 2,73 & $2,08 \mathrm{E}-002$ & 5,18 & 9033,4 \\
\hline 7 & 40962 & $2,38 \mathrm{E}-003$ & 2,41 & $4,50 \mathrm{E}-003$ & 4,62 & 73648,2 \\
\hline 8 & 163842 & $1,03 \mathrm{E}-003$ & 2,31 & $1,43 \mathrm{E}-003$ & 3,13 & 607963,4 \\
\hline
\end{tabular}

Tabela 5.37: Erros e tempo de CPU associados ao transporte de duas colinas de gaussianas em uma malha icosaédrica com otimização SCVT, utilizando-se o método de $4^{a}$ ordem com limitador. 

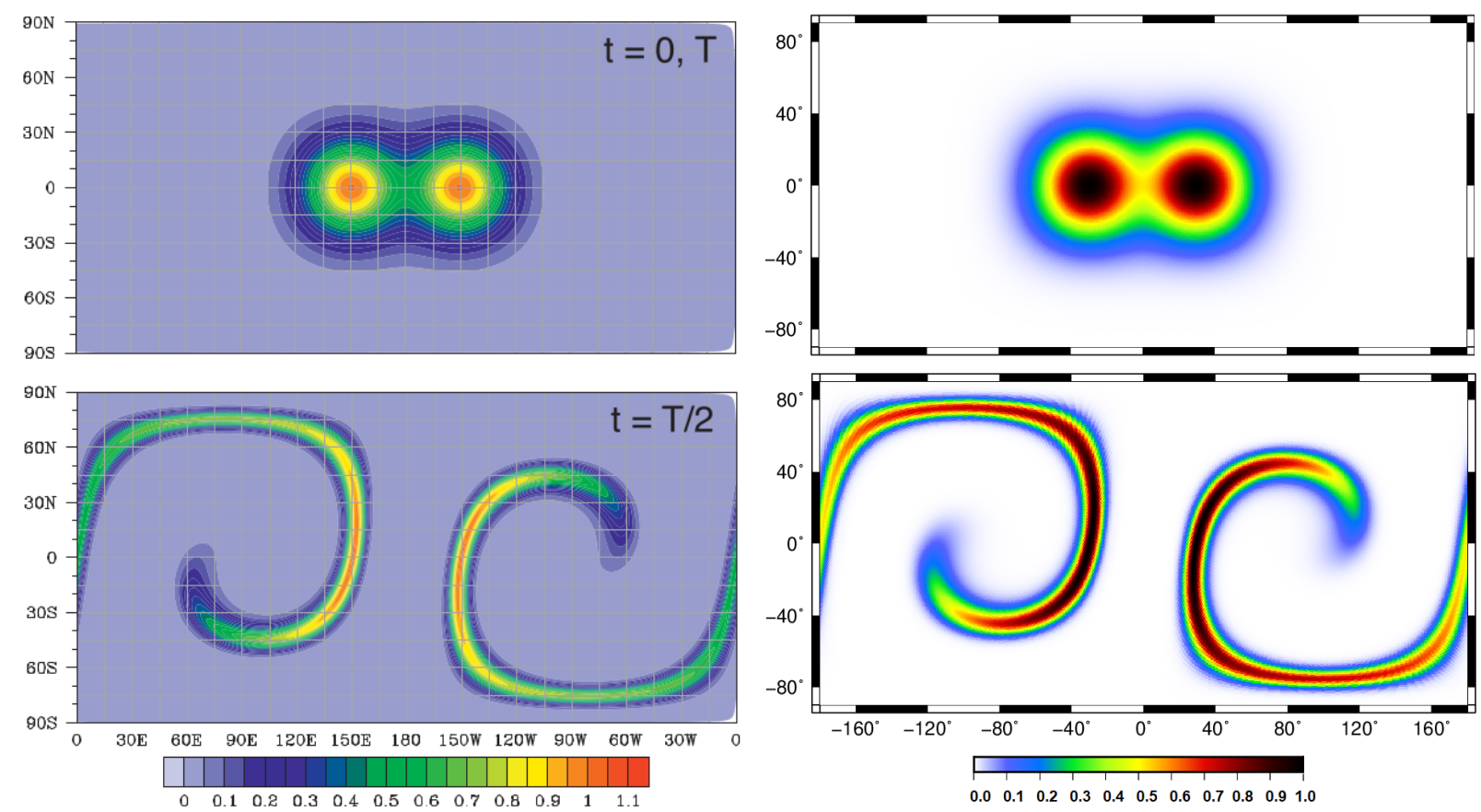

Figura 5.39: Solução inicial e intermediária do teste de deformação com rotação de duas colinas de gaussianas em uma malha icosaédrica de nível 5 com otimização SCVT, utilizando-se o método de $4^{a}$ ordem com limitador (esquerda FV-GAS e direita FV-OLG).
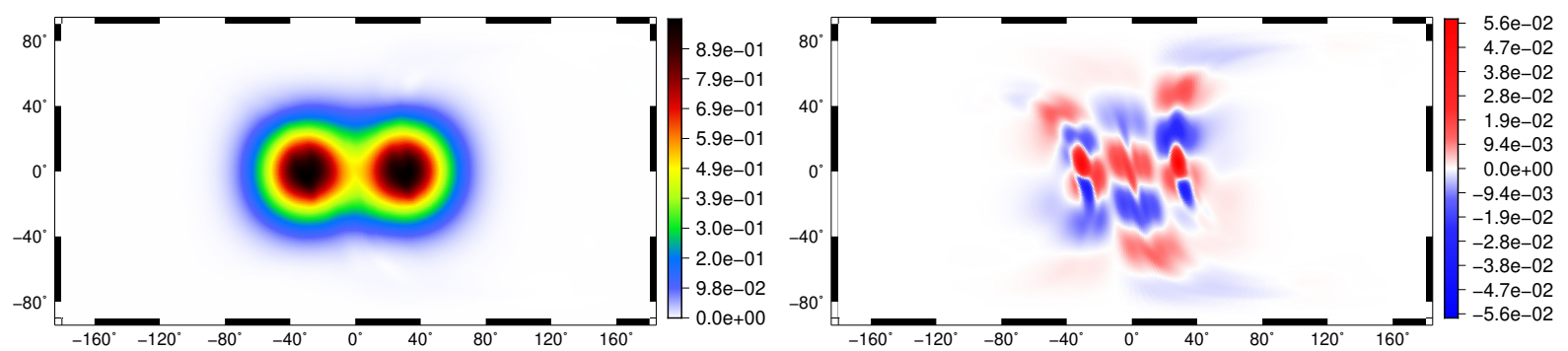

Figura 5.40: Solução final e erro no teste de deformação com rotação de duas colinas de gaussianas em uma malha icosaédrica de nível 5 com otimização SCVT, utilizando-se o método de $4^{a}$ ordem com limitador. 


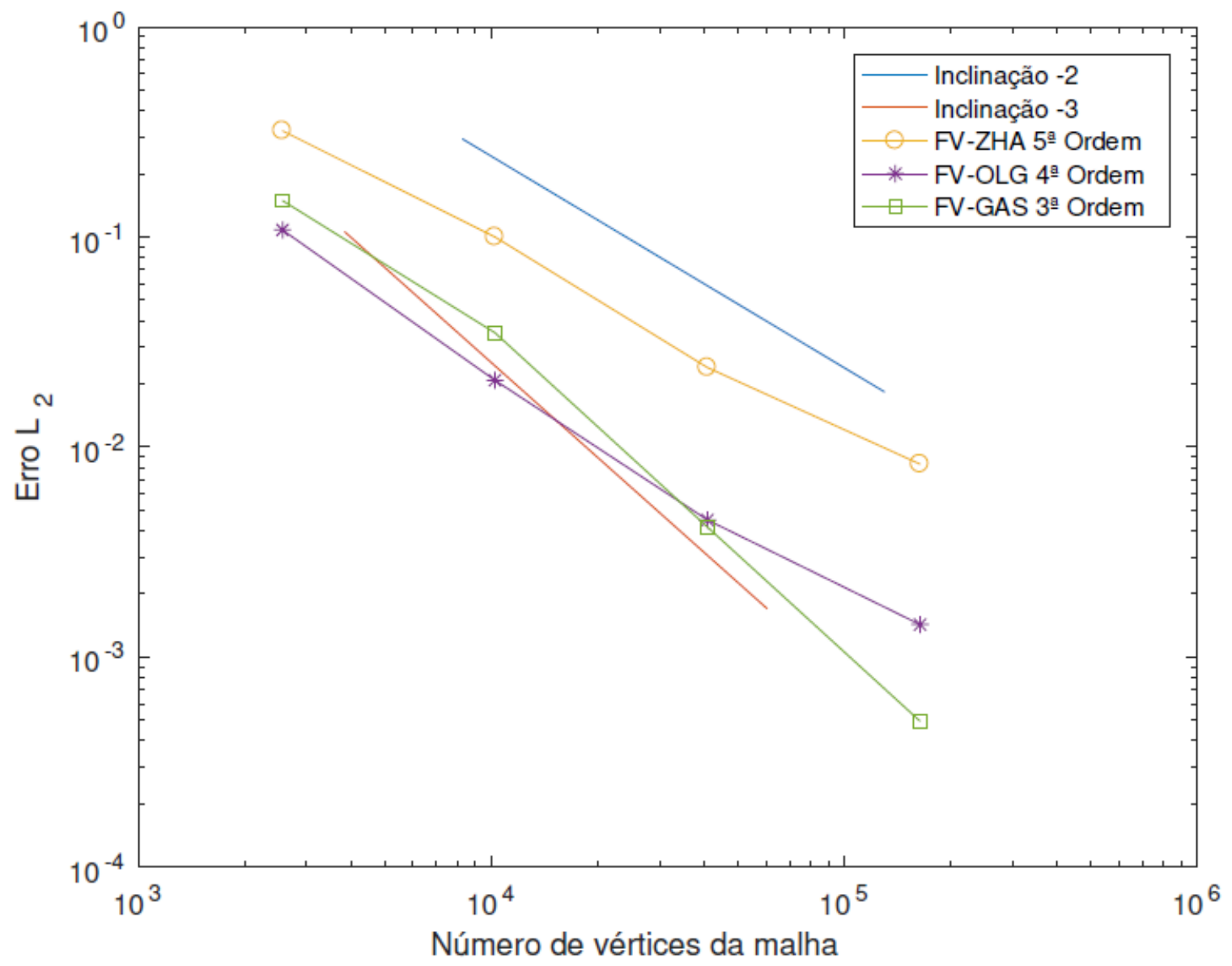

Figura 5.41: Erros associados à reconstrução de duas colinas de gaussinas em uma malha icosaédrica com otimização SCVT, utilizando-se os métodos FV-GAS, FV-OLG, FV-ZHA de $3^{a}$, $4^{a}$ e $5^{a}$ ordens, respectivamente.

Fazendo um ajuste, por meio da regressão linear na Tabela 5.35, o método de $2^{\mathrm{a}}$ ordem atingiu 1,52 de convergência. Na Tabela 5.36, verifica-se que o método de $3^{\text {a }}$ ordem obteve 2,06, e, na Tabela 5.37, tem-se que o método de $4^{\mathrm{a}}$ ordem apresentou uma taxa de convergência de 2,09 e 2,33 com e sem limitador, respectivamente.

O método FV-GAS de $3^{\text {a }}$ ordem apresentou taxa de convergência de 2,39 e 2,79 com e sem limitador, respectivamente. Os resultados qualitativos de ambos os métodos propostos, ilustrados na Figura 5.39 são semelhantes. Porém, observa-se que o método de FV-GAS possui uma maior dispersão numérica. Pode-se observar na Figura 5.40 que o método proposto neste trabalho foi capaz de reconstruir a solução das duas colinas de gaussianas em alta ordem, conforme gráfico do erro cometido entre a solução inicial e final.

Por meio da Figura 5.41, nota-se que os métodos FV-ZHA e FV-OLG possuem a mesma taxa de convergência no teste de deformação de duas colinas de gaussinas. O método FV-GAS de $3^{\text {a }}$ ordem $\operatorname{com} \beta=0,25$ foi superior quantitativamente. 


\subsection{Testes desafiadores}

\subsubsection{Testes com refinamento local}

Dentre os modelos globais de previsão do tempo, alguns são desenvolvidos com resolução variável, o que permite refinamento local. No trabalho de Walsh (1994), foi avaliado o impacto dos Andes na circulação geral do Hemisfério Sul usando um modelo de circulação global e conclui-se que a elevação dos Andes teve uma influência dramática na climatologia próxima à América do Sul e pouco efeito na circulação geral do Hemisfério Sul. Dessa forma, é interessante construir uma malha com maior resolução na região dos Andes, visando estudar o efeito desta cordilheira nas condições climáticas da América do Sul (Seluchi et al., 1998).
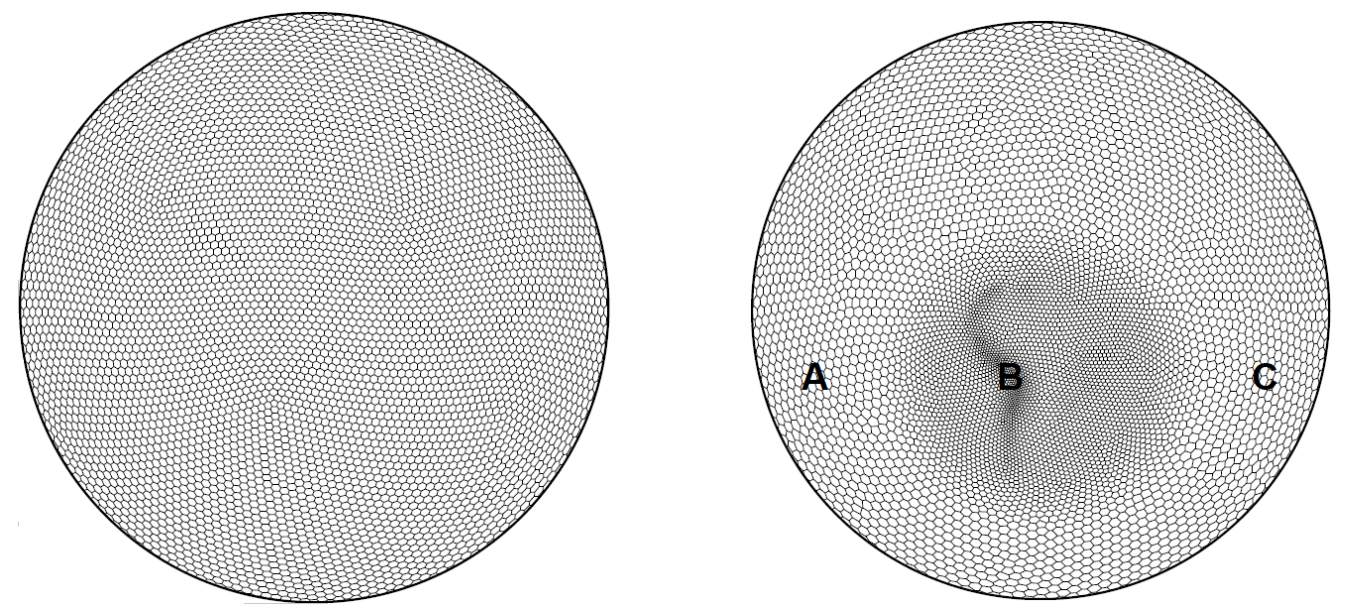

Figura 5.42: Malha icosaédrica nível 5 sem e com refinamento local, respectivamente.

Nesse contexto, o objetivo deste teste será utilizar malhas icosaédricas com refinamento local desenvolvida por Santos (2017), conforme Figura 5.42, para avaliar os resultados do método FVOLG e as suas respectivas taxas de convergência para o transporte de uma colina de gaussiana sem limitador, por ser uma função suave e um cilindro cortado com limitador, por ser uma função com descontinuidades, conforme Figura 5.43. Sabemos que após uma volta completa ao redor da Terra, a solução final coincide com a solução inicial, por esse motivo, os resultados nas normas do erro do máximo e do quadrático médio serão calculados e apresentados a seguir, para as ordens em estudo.
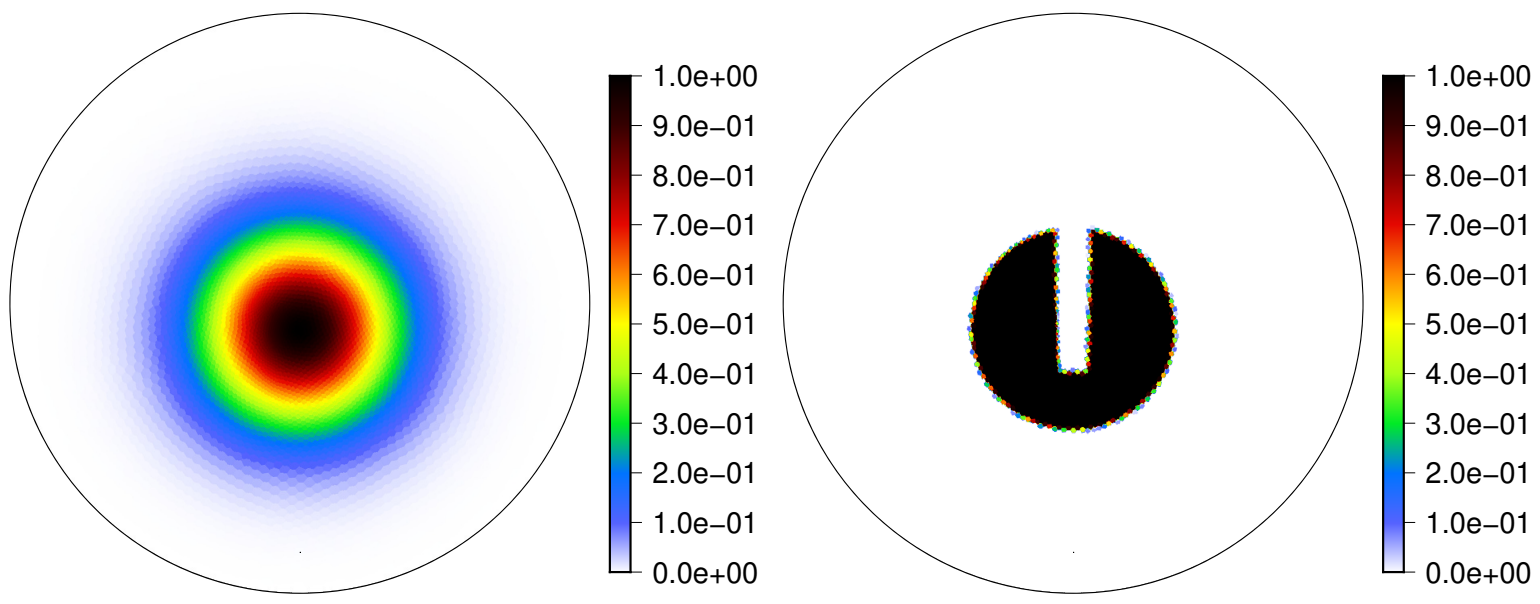

Figura 5.43: Solução final e erro no transporte de uma colina de gaussiana ao redor da Terra em uma malha icosaédrica de nível 5 com refinamento nos Andes, utilizando-se o método de $4^{a}$ ordem sem limitador. 
Avaliamos o transporte em três situações diferentes para a condição inicial: (A) centrada nos Andes, (B) centrada antes dos Andes e (C) centrada depois dos Andes, para avaliar o impacto da solução inicial ao longo do tempo. A condição inicial de uma colina de gaussina vai permitir avaliar as ordens resultantes do método, e o cilindro cortado, permite avaliar a qualidade da solução final, mediante as três situações mencionadas para a equação de adveç̧ão.

Foi avaliado o transporte de uma colina de gaussiana sem limitador para vários níveis de malha. Após uma volta completa ao redor da Terra, a solução final coincide com a solução inicial. Dessa forma, os resultados nas normas do erro do máximo e do quadrático médio foram calculados e serão apresentados a seguir para as ordens em estudo.

\begin{tabular}{|c|c|c|c|c|c|c|}
\hline Nível & Nós & Erro Máx & Razão Máx & Erro 2 & Razão 2 & Tempo (s) \\
\hline 4 & 2562 & $1,42 \mathrm{E}-001$ & 0,00 & $1,17 \mathrm{E}-001$ & 0,00 & 47,5 \\
\hline 5 & 10242 & $3,58 \mathrm{E}-002$ & 3,96 & $2,96 \mathrm{E}-002$ & 3,96 & 399,5 \\
\hline 6 & 40962 & $8,90 \mathrm{E}-003$ & 4,03 & $7,48 \mathrm{E}-003$ & 3,95 & 3269,2 \\
\hline 7 & 163842 & $2,20 \mathrm{E}-003$ & 4,04 & $1,89 \mathrm{E}-003$ & 3,97 & 26031,8 \\
\hline
\end{tabular}

Tabela 5.38: Erros e tempo de CPU associados à reconstrução de uma colina de gaussiana em uma malha icosaédrica SCVT com refinamento local, utilizando-se o método de $2^{a}$ ordem sem limitador.

\begin{tabular}{|c|c|c|c|c|c|c|}
\hline Nível & Nós & Erro Máx & Razão Máx & Erro 2 & Razão 2 & Tempo (s) \\
\hline 4 & 2562 & $1,64 \mathrm{E}-001$ & 0,00 & $1,16 \mathrm{E}-001$ & 0,00 & 106,2 \\
\hline 5 & 10242 & $2,91 \mathrm{E}-002$ & 5,64 & $1,82 \mathrm{E}-002$ & 6,38 & 738,6 \\
\hline 6 & 40962 & $4,08 \mathrm{E}-003$ & 7,13 & $2,55 \mathrm{E}-003$ & 7,13 & 5923,8 \\
\hline 7 & 163842 & $5,56 \mathrm{E}-004$ & 7,33 & $3,75 \mathrm{E}-004$ & 6,81 & 47318,6 \\
\hline
\end{tabular}

Tabela 5.39: Erros e tempo de CPU associados à reconstrução de uma colina de gaussiana em uma malha icosaédrica SCVT com refinamento local, utilizando-se o método de $3^{a}$ ordem sem limitador.

\begin{tabular}{|c|c|c|c|c|c|c|}
\hline Nível & Nós & Erro Máx & Razão Máx & Erro 2 & Razão 2 & Tempo (s) \\
\hline 4 & 2562 & $1,39 \mathrm{E}-002$ & 0,00 & $9,97 \mathrm{E}-003$ & 0,00 & 108,3 \\
\hline 5 & 10242 & $7,34 \mathrm{E}-004$ & 18,94 & $5,38 \mathrm{E}-004$ & 18,53 & 772,2 \\
\hline 6 & 40962 & $6,04 \mathrm{E}-005$ & 12,14 & $3,98 \mathrm{E}-005$ & 13,52 & 6167,7 \\
\hline 7 & 163842 & $6,83 \mathrm{E}-006$ & 8,85 & $4,34 \mathrm{E}-006$ & 9,17 & 49246,7 \\
\hline
\end{tabular}

Tabela 5.40: Erros e tempo de CPU associados à reconstrução de uma colina de gaussiana em uma malha icosaédrica SCVT com refinamento local, utilizando-se o método de $4^{a}$ ordem sem limitador. 


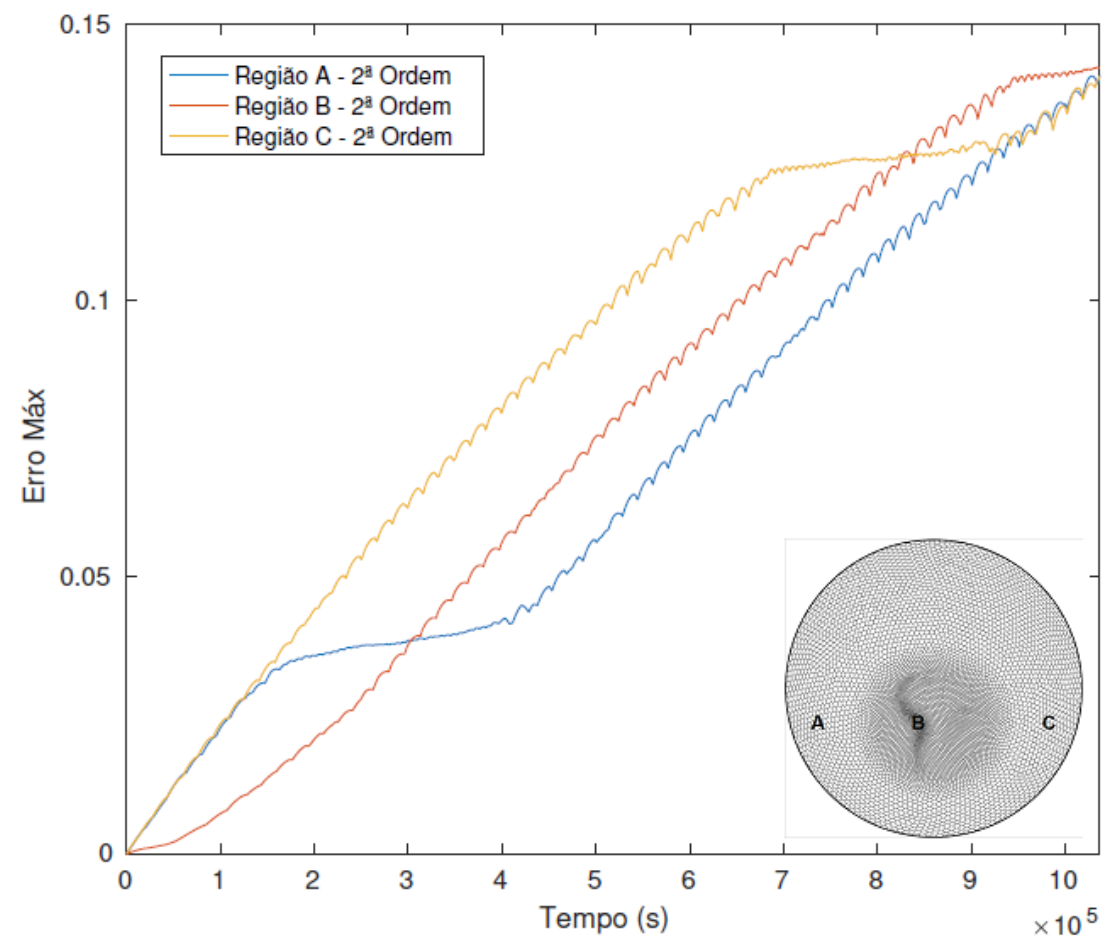

Figura 5.44: Evolução do erro máximo durante uma volta completa ao redor da Terra, utilizando-se o método de $2^{a}$ ordem sem limitador em malhas com refinamento local.

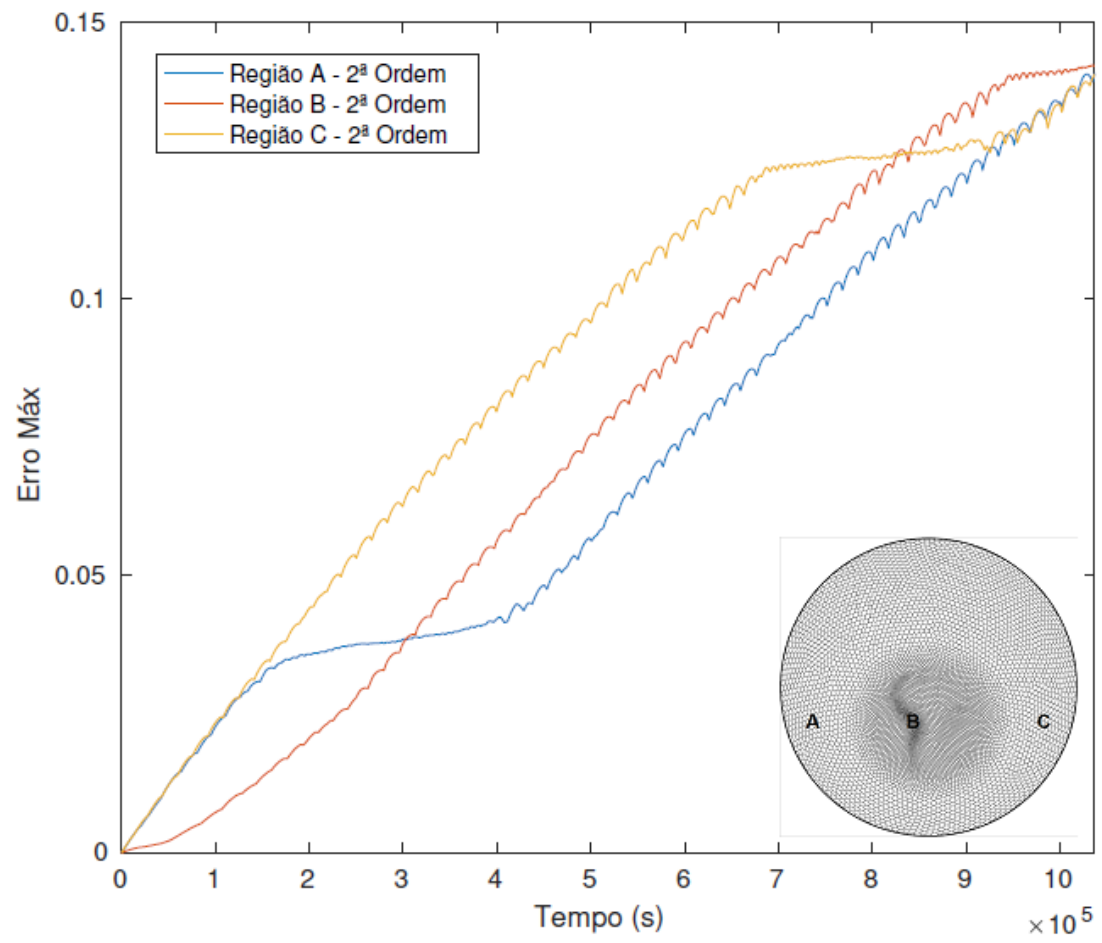

Figura 5.45: Evolução do erro máximo durante uma volta completa ao redor da Terra, utilizando-se o método de $3^{a}$ ordem sem limitador em malhas com refinamento local. 


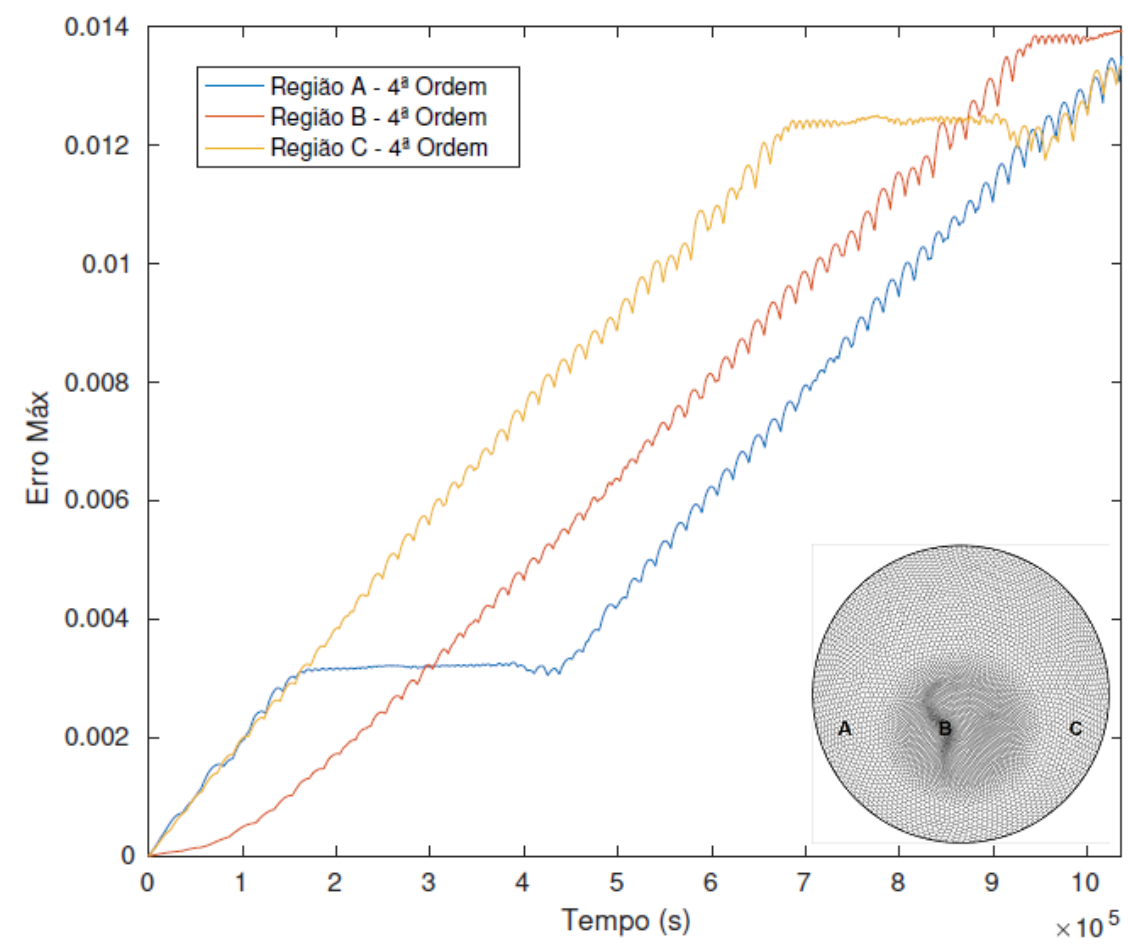

Figura 5.46: Evolução do erro máximo durante uma volta completa ao redor da Terra, utilizando-se o método de $4^{a}$ ordem sem limitador em malhas com refinamento local.

Foi feito um ajuste, por meio da regressão linear, conforme pode ser visto nas Tabelas 5.38, 5.39 e 5.40, para determinar as ordens efetivas dos métodos em estudo que estão ilustrados na Tabela 5.41 .

\begin{tabular}{|c|c|c|}
\hline Método & $L_{\infty}$ & $L_{2}$ \\
\hline $2^{\mathrm{a}}$ ordem & 2,00 & 1,98 \\
\hline $3^{\mathrm{a}}$ ordem & 2,74 & 2,76 \\
\hline $4^{\mathrm{a}}$ ordem & 3,66 & 3,73 \\
\hline
\end{tabular}

Tabela 5.41: Ordem de precisão para o transporte de colina de gaussina em malhas com refinamento local.

Pode-se observar os resultados nas normas do erro máximo e do quadrático médio, que ambos os métodos estão próximos das ordens nominais $2^{\mathrm{a}}, 3^{\mathrm{a}}$ e $4^{\mathrm{a}}$ ordens, respectivamente. Devido aos erros associados de arredondamentos durante o processo de cálculo, não é possível obter a ordem nominal dos métodos. Os resultados qualitativos foram os mesmos obtidos em 5.1.1 para uma colina de gaussiana e em 5.2.10 para um cilindro cortado, por isso não foram apresentados nessa seção.

As Figuras 5.44, 5.45 e 5.46, apresentam a evolução do erro máximo para os métodos de $2^{\mathrm{a}}$, $3^{\mathrm{a}}$ e $4^{\mathrm{a}}$ ordens, partindo de (A) centrada nos Andes, (B) centrada antes dos Andes e (C) centrada depois dos Andes. Observa-se um padrão interessante no comportamento do erro máximo ao longo da evolução temporal, pois em todos os casos, percebe-se que, a colina de gaussiana ao passar na região com refinamento local, o erro praticamente fica inalterado. O erro máximo permanece quase que constante durante a passagem na região com refinamento local e depois volta a aumentar, atingindo praticamente o mesmo valor nas três situações, quando o atinge o tempo final de revolução. 


\subsubsection{Testes em malhas NOPT e HR95}

Foram feitos testes utilizando-se uma colina de gaussiana nas malhas icosaédricas sem otimização NOPT e com otimização HR95 e comparados com as malhas SCVT e SCVT com refinamento local, para avaliar as taxas de convergência e os efeitos da solução numérica nos diversos tipos de malhas icosaédricas.

Sabe-se que após uma volta completa ao redor da Terra, a solução final coincide com a solução inicial, por isso os resultados nas normas do erro do máximo e do quadrático médio serão calculados e apresentados a seguir para as ordens em estudo.

\section{Resultados numéricos utilizando-se os métodos de $2^{\mathrm{a}}, 3^{\mathrm{a}}$ e $4^{\mathrm{a}}$ ordens em malha NOPT}

\begin{tabular}{|c|c|c|c|c|c|c|}
\hline Nível & Nós & Erro Máx & Razão Máx & Erro 2 & Razão 2 & Tempo (s) \\
\hline 4 & 2562 & $1,33 \mathrm{E}-001$ & 0,00 & $1,11 \mathrm{E}-001$ & 0,00 & 13,8 \\
\hline 5 & 10242 & $3,72 \mathrm{E}-002$ & 3,57 & $3,05 \mathrm{E}-002$ & 3,64 & 117,7 \\
\hline 6 & 40962 & $9,29 \mathrm{E}-003$ & 4,00 & $7,69 \mathrm{E}-003$ & 3,97 & 963,8 \\
\hline 7 & 163842 & $2,32 \mathrm{E}-003$ & 4,01 & $1,92 \mathrm{E}-003$ & 4,00 & 7718,2 \\
\hline
\end{tabular}

Tabela 5.42: Erros e tempo de CPU associados à reconstrução de uma colina de gaussiana em uma malha icosaédrica sem otimização NOPT, utilizando-se o método de $2^{a}$ ordem sem limitador.

\begin{tabular}{|c|c|c|c|c|c|c|}
\hline Nível & Nós & Erro Máx & Razão Máx & Erro 2 & Razão 2 & Tempo (s) \\
\hline 4 & 2562 & $1,43 \mathrm{E}-001$ & 0,00 & $9,85 \mathrm{E}-002$ & 0,00 & 28,9 \\
\hline 5 & 10242 & $2,76 \mathrm{E}-002$ & 5,19 & $1,72 \mathrm{E}-002$ & 5,74 & 224,9 \\
\hline 6 & 40962 & $3,83 \mathrm{E}-003$ & 7,22 & $2,34 \mathrm{E}-003$ & 7,33 & 1763,0 \\
\hline 7 & 163842 & $4,90 \mathrm{E}-004$ & 7,81 & $3,18 \mathrm{E}-004$ & 7,35 & 13742,5 \\
\hline
\end{tabular}

Tabela 5.43: Erros e tempo de CPU associados à reconstrução de uma colina de gaussiana em uma malha icosaédrica sem otimização NOPT, utilizando-se o método de $3^{a}$ ordem sem limitador.

\begin{tabular}{|c|c|c|c|c|c|c|}
\hline Nível & Nós & Erro Máx & Razão Máx & Erro 2 & Razão 2 & Tempo (s) \\
\hline 4 & 2562 & $9,21 \mathrm{E}-003$ & 0,00 & $6,96 \mathrm{E}-003$ & 0,00 & 30,2 \\
\hline 5 & 10242 & $7,44 \mathrm{E}-004$ & 12,38 & $4,66 \mathrm{E}-004$ & 14,93 & 236,1 \\
\hline 6 & 40962 & $5,99 \mathrm{E}-005$ & 12,41 & $3,40 \mathrm{E}-005$ & 13,69 & 1835,5 \\
\hline 7 & 163842 & $5,31 \mathrm{E}-006$ & 11,29 & $3,65 \mathrm{E}-006$ & 9,32 & 14699,7 \\
\hline
\end{tabular}

Tabela 5.44: Erros e tempo de CPU associados à reconstrução de uma colina de gaussiana em uma malha icosaédrica sem otimização NOPT, utilizando-se o valor do vértice como média da solução e o método de $4^{a}$ ordem sem limitador. 
Resultados numéricos utilizando-se os métodos de $2^{\mathrm{a}}, 3^{\mathrm{a}}$ e $4^{\mathrm{a}}$ ordens em malha HR95

\begin{tabular}{|c|c|c|c|c|c|c|}
\hline Nível & Nós & Erro Máx & Razão Máx & Erro 2 & Razão 2 & Tempo (s) \\
\hline 4 & 2562 & $1,30 \mathrm{E}-001$ & 0,00 & $1,11 \mathrm{E}-001$ & 0,00 & 15,1 \\
\hline 5 & 10242 & $3,63 \mathrm{E}-002$ & 3,58 & $3,05 \mathrm{E}-002$ & 3,64 & 119,7 \\
\hline 6 & 40962 & $9,11 \mathrm{E}-003$ & 3,98 & $7,68 \mathrm{E}-003$ & 3,97 & 962,9 \\
\hline 7 & 163842 & $2,25 \mathrm{E}-003$ & 4,05 & $1,92 \mathrm{E}-003$ & 4,00 & 7808,8 \\
\hline
\end{tabular}

Tabela 5.45: Erros e tempo de CPU associados à reconstrução de uma colina de gaussiana em uma malha icosaédrica com otimização HR95, utilizando-se o método de $2^{a}$ ordem sem limitador.

\begin{tabular}{|c|c|c|c|c|c|c|}
\hline Nível & Nós & Erro Máx & Razão Máx & Erro 2 & Razão 2 & Tempo (s) \\
\hline 4 & 2562 & $1,42 \mathrm{E}-001$ & 0,00 & $9,87 \mathrm{E}-002$ & 0,00 & 28,5 \\
\hline 5 & 10242 & $2,69 \mathrm{E}-002$ & 5,28 & $1,72 \mathrm{E}-002$ & 5,75 & 221,6 \\
\hline 6 & 40962 & $3,64 \mathrm{E}-003$ & 7,37 & $2,40 \mathrm{E}-003$ & 7,15 & 1750,2 \\
\hline 7 & 163842 & $4,60 \mathrm{E}-004$ & 7,93 & $3,52 \mathrm{E}-004$ & 6,81 & 14047,0 \\
\hline
\end{tabular}

Tabela 5.46: Erros e tempo de CPU associados à reconstrução de uma colina de gaussiana em uma malha icosaédrica com otimização HR95, utilizando-se o método de $2^{a}$ ordem sem limitador.

\begin{tabular}{|c|c|c|c|c|c|c|}
\hline Nível & Nós & Erro Máx & Razão Máx & Erro 2 & Razão 2 & Tempo (s) \\
\hline 4 & 2562 & $9,04 \mathrm{E}-003$ & 0,00 & $6,84 \mathrm{E}-003$ & 0,00 & 30,1 \\
\hline 5 & 10242 & $6,97 \mathrm{E}-004$ & 12,97 & $4,64 \mathrm{E}-004$ & 14,74 & 233,2 \\
\hline 6 & 40962 & $5,27 \mathrm{E}-005$ & 13,25 & $3,58 \mathrm{E}-005$ & 12,96 & 1833,7 \\
\hline 7 & 163842 & $5,42 \mathrm{E}-006$ & 9,72 & $4,26 \mathrm{E}-006$ & 8,40 & 14556,6 \\
\hline
\end{tabular}

Tabela 5.47: Erros e tempo de CPU associados à reconstrução de uma colina de gaussiana em uma malha icosaédrica com otimização HR95, utilizando-se o método de $2^{a}$ ordem sem limitador. 


\subsubsection{Testes aplicando a condição inicial no vértice}

O objetivo deste teste consiste em utilizar a média da solução de cada volume de controle por meio da condição inicial aplicada em cada vértice de $\Omega_{i}$, que terá uma ordem menor que $2^{\mathrm{a}}$ ordem, pois em nossos volumes de controle do método FV-OLG, os vértices não são o centro de massa, como ocorre na malha icosaédrica com otimização SCVT com volumes de controle hexagonais/pentagonais, que impõem que os centros desses volumes de controle sejam o mais próximo do centro de massa, para garantir uma estimativa de $2^{\mathrm{a}}$ ordem.

Sabe-se que após uma volta completa ao redor da Terra a solução final coincide com a solução inicial. Dessa forma, os resultados nas normas do erro do máximo e do quadrático médio serão calculados e apresentados a seguir, para as ordens em estudo.

\begin{tabular}{|c|c|c|c|c|c|c|}
\hline Nível & Nós & Erro Máx & Razão Máx & Erro 2 & Razão 2 & Tempo (s) \\
\hline 4 & 2562 & $1,29 \mathrm{E}-001$ & 0,00 & $1,10 \mathrm{E}-001$ & 0,00 & 14,4 \\
\hline 5 & 10242 & $3,66 \mathrm{E}-002$ & 3,53 & $3,03 \mathrm{E}-002$ & 3,64 & 119,9 \\
\hline 6 & 40962 & $9,21 \mathrm{E}-003$ & 3,97 & $7,63 \mathrm{E}-003$ & 3,97 & 993,3 \\
\hline 7 & 163842 & $2,28 \mathrm{E}-003$ & 4,05 & $1,90 \mathrm{E}-003$ & 4,00 & 8083,5 \\
\hline
\end{tabular}

Tabela 5.48: Erros e tempo de CPU associados à reconstrução de uma colina de gaussiana em uma malha icosaédrica com otimização SCVT, utilizando-se o vértice como média da solução e o método de $2^{a}$ ordem sem limitador.

\begin{tabular}{|c|c|c|c|c|c|c|}
\hline Nível & Nós & Erro Máx & Razão Máx & Erro 2 & Razão 2 & Tempo (s) \\
\hline 4 & 2562 & $1,39 \mathrm{E}-001$ & 0,00 & $9,60 \mathrm{E}-002$ & 0,00 & 27,8 \\
\hline 5 & 10242 & $2,68 \mathrm{E}-002$ & 5,21 & $1,66 \mathrm{E}-002$ & 5,79 & 225,2 \\
\hline 6 & 40962 & $3,70 \mathrm{E}-003$ & 7,23 & $2,21 \mathrm{E}-003$ & 7,48 & 1825,4 \\
\hline 7 & 163842 & $4,70 \mathrm{E}-004$ & 7,88 & $2,80 \mathrm{E}-004$ & 7,91 & 14949,0 \\
\hline
\end{tabular}

Tabela 5.49: Erros e tempo de CPU associados à reconstrução de uma colina de gaussiana em uma malha icosaédrica com otimização SCVT, utilizando-se o vértice como média da solução e o método de $3^{a}$ ordem sem limitador.

\begin{tabular}{|c|c|c|c|c|c|c|}
\hline Nível & Nós & Erro Máx & Razão Máx & Erro 2 & Razão 2 & Tempo (s) \\
\hline 4 & 2562 & $9,67 \mathrm{E}-003$ & 0,00 & $6,97 \mathrm{E}-003$ & 0,00 & 29,4 \\
\hline 5 & 10242 & $8,84 \mathrm{E}-004$ & 10,94 & $5,41 \mathrm{E}-004$ & 12,88 & 231,5 \\
\hline 6 & 40962 & $8,23 \mathrm{E}-005$ & 10,75 & $5,16 \mathrm{E}-005$ & 10,48 & 1897,9 \\
\hline 7 & 163842 & $8,88 \mathrm{E}-006$ & 9,26 & $5,91 \mathrm{E}-006$ & 8,73 & 15528,2 \\
\hline
\end{tabular}

Tabela 5.50: Erros e tempo de CPU associados à reconstrução de uma colina de gaussiana em uma malha icosaédrica com otimização SCVT, utilizando-se o vértice como média da solução e o método de $4^{a}$ ordem sem limitador. 


\subsection{Comentários}

O método FV-OLG de alta ordem proposto para a superfície esférica foi avaliado para diversos testes padrão na esfera, sem e com limitador. A partir dos novos testes, em que utilizou a função suave uma colina de gaussiana, para avaliar a ordem do método FV-OLG em diversos tipos de malhas icosaédricas, foi feito um ajuste de regressão linear e os resultados foram semelhantes em todas as malhas descritas, conforme Tabela 5.51, comprovando que a taxa de convergência sofre pouca influência de distorção de malha. Em todos os testes em que utilizou uma colina de gaussiana, o método FV-OLG atingiu $2^{\mathrm{a}}, 3^{\mathrm{a}}$ e $4^{\mathrm{a}}$ ordens. Denota-se por VÉRTICE a malha SCVT, aplicandose a condição inicial no vértice do volume de controle, e por ANDES a mesma malha SCVT com refinamento local.

\begin{tabular}{|l|c|c|c|c|c|}
\hline & NOPT & HR95 & SCVT & VÉRTICE & ANDES \\
\hline $2^{\text {a } \text { ordem }}$ & 1,95 & 1,95 & 1,96 & 1,95 & 1,98 \\
\hline $3^{\text {a }}$ ordem & 2,72 & 2,77 & 2,82 & 2,72 & 2,76 \\
\hline $4^{\text {a }}$ ordem & 3,56 & 3,65 & 3,78 & 3,56 & 3,73 \\
\hline
\end{tabular}

Tabela 5.51: Ajuste por meio de regressão linear para avaliar a ordem efetiva do método FV-OLG em diferentes tipos de malhas icosaédricas.

O teste com sino de cosseno foi utilizado para verificar o comportamento do limitador diante da descontinuidade de derivada. Em geral, os resultados qualitativos foram semelhantes aos trabalhos da literatura. Os testes com descontinuidades bruscas, como o cilindro sólido, foram utilizados para verificar a qualidade do limitador implementado. Foram feitos cortes para avaliar seu desempenho em controlar a dispersão numérica, diminuindo os "overshoot". O teste com cilindro cortado possui uma maior quantidade de descontinuidades e foi possível comparar com a literatura, concluindo que os resultados numéricos do método FV-OLG foram superiores.

O teste de duas gaussianas em um campo vetorial com deformação foi importante para avaliar possíveis fontes de erros, que poderiam estar "mascarando" a verdadeira ordem do método. O teste do transporte da colina de gaussiana na malha com refinamento nos Andes veio confirmar que o método FV-OLG é robusto no sentido de adaptabilidade em qualquer tipo de otimização de malha, mantendo as mesmas taxas de convergência e que todas as etapas de validação foram executadas corretamente. 


\section{Capítulo 6}

\section{Conclusões}

Diversos pesquisadores, nos últimos anos, têm-se interessado em desenvolver métodos de alta ordem para modelagem de fenômenos atmosféricos na esfera, otimizando os recursos computacionais por meio do processamento paralelo e memória distribuida, utilizando malhas geodésicas, principalmente as geradas a partir do icosaedro, por serem mais uniformes quando comparadas com malhas lat/lon. Essas malhas, denominadas icosaédricas, permitem várias possibilidades de otimização para melhorar a qualidade da solução numérica e têm sido utilizadas por diversos modelos atmosféricos operacionais, pois têm permitido processamento paralelo com menos gargalos de comunicação.

Nesse contexto, a proposta deste trabalho foi desenvolver um método de alta ordem para a superfície esférica, utilizando malhas icosaédricas. O método, denominado de FV-OLG, é parte dos trabalhos de Ollivier-Gooch e colaboradores, possuindo diversas aplicações no plano. No capítulo 2, foram abordados na revisão bibliográfica os diversos métodos de volumes finitos de alta ordem na esfera, destacando a diferença em avaliar o fluxo nas arestas dos volumes de controle com a formulação básica de fluxo na esfera. O capítulo 3 abordou a teoria e as etapas necessárias para se obter o método de alta ordem FV-OLG na esfera. O capítulo 4 consistiu em validar as implementações discutidas no capítulo anterior, por meio de testes numéricos de interpolação e integração. Os resultados demonstraram que o método proposto obteve $2^{\mathrm{a}}, 3^{\mathrm{a}}$ e $4^{\mathrm{a}}$ ordens de precisão, como o desejado. Por fim, conseguiu-se obter alta ordem de precisão na discretização do operador divergente.

Para avaliar a viabilidade do método FV-OLG na esfera foi utilizada a equação de advecção, que consiste no transporte de um escalar, com testes de complexidade variada, os comparando com os resultados disponíveis da literatura. Nos resultados verificados no transporte do sino de cosseno sem limitador, observa-se que o método FV-OLG de $2^{\mathrm{a}}$ e $4^{\mathrm{a}}$ ordem foi mais preciso que o FV-GAS. Em ambos os métodos, o esquema de $2^{\mathrm{a}}$ ordem apresentou erros de fase, o esquema de $3^{\mathrm{a}}$ ordem uma maior difusão da solução final e o esquema de $4^{\mathrm{a}}$ ordem uma melhor qualidade da solução. Para o mesmo teste com limitador, os métodos de $2^{\mathrm{a}}$ ordem de FV-MEN e $3^{\mathrm{a}}$ ordem de FV-GAS foram ligeiramente mais precisos que o método de $4^{\mathrm{a}}$ ordem de FV-OLG. Em geral, ambos entregaram soluções similares do ponto de vista qualitativo.

Por meio dos cortes no cilindro sólido, percebe-se que o limitador implementado diminuiu as oscilações numéricas e "overshoots" diante das descontinuidades. O teste com cilindro cortado possui regiões com descontinuidade e os resultados qualitativos de FV-MEN e FV-OLG são semelhantes. Ao se comparar esse mesmo teste com os esquemas de $2^{\mathrm{a}}, 3^{\mathrm{a}}$ e $4^{\mathrm{a}}$ ordens de FV-GAS, nota-se que FVOLG entrega uma melhor qualidade da solução final para as respectivas ordens, sem deformação da solução, o que não ocorreu no esquema de $2^{\text {a }}$ ordem de FV-GAS. O método de alta ordem FV-OLG apresentou uma boa qualidade da solução final quando comparado com os resultados disponíveis da literatura, presentes neste trabalho, para qualquer tipo de malha, conforme resultados do capítulo 5.

Além dos resultados da solução numérica, é importante considerar também o custo computacional dos esquemas estudados e sua precisão em função dos níveis da malha. Nesse sentido, ressalta-se que todos os testes para avaliar o método FV-OLG, utilizado na equação do transporte, foram realizados de modo serial, utilizando-se um único processador e registrou-se o tempo de CPU em cada nível de malha e para cada ordem em estudo. O tempo de CPU de $3^{\mathrm{a}}$ e $4^{\mathrm{a}}$ ordens são equivalentes, 
pois, durante o avanço temporal, todas as pseudo-inversas já foram calculadas e armazenadas para serem utilizadas durante o processo. Observa-se que os métodos de $3^{\mathrm{a}}$ e $4^{\mathrm{a}}$ ordens, utilizando-se a malha sem e com otimizações para os testes de uma colina de gaussiana, um sino de cosseno, um cilindro sólido, um cilindro cortado, os métodos de $3^{\mathrm{a}}$ e $4^{\mathrm{a}}$ ordens gastam em torno de 2,2 vezes o tempo de CPU em relação ao método de $2^{\mathrm{a}}$ ordem. Ao utilizar o esquema com limitador, houve um aumento médio de 1,5 vezes em relação ao tempo de CPU sem utilizar limitador.

Percebeu-se também que para os testes realizados com descontinuidades de derivadas nas regiões de contorno do domínio, o erro obtido é muito similar. No entanto, é possível observar que solução qualitativa de $4^{\mathrm{a}}$ ordem foi superior aos esquemas de $2^{\mathrm{a}}$ ou $3^{\mathrm{a}}$ ordens. Dessa forma, sugere-se utilizar o método de $4^{\mathrm{a}}$ ordem em todos os problemas de transporte, uma vez que o tempo de CPU é equivalente ao esquema de $3^{\text {a }}$ ordem e a solução qualitativa será sempre superior, como observado pela simetria das soluções à medida que a ordem é aumentada.

Em todos os testes abordados no capítulo 5, foi utilizada quadratura de $6^{\mathrm{a}}$ ordem de Dunavant (1985) para estimar a média da solução, com o objetivo de isolar o erro na verificação da ordem final do método FV-OLG. No entanto, foi feito um teste adicional advectando uma colina de gaussiana ao redor da Terra em malha SCVT utilizando-se o valor da função no vértice do volume de controle como sendo a média da solução para avaliar a qualidade desses resultados. Nesse caso, a média da solução não chega a ser de $2^{\text {a }}$ ordem, pois os vértices dos volumes de controle no método FV-OLG não coincidem com os respectivos centros de massa, como foi descrito utilizando-se o diagrama de Voronoi com pentágonos/hexágonos. Mesmo assim o método FV-OLG conseguiu obter alta ordem de precisão, demonstrando em que a ordem que foi armazenada a condição inicial não afeta a ordem efetiva do nosso método.

Em relação aos testes abordados neste trabalho, recomendamos que a advecção de uma colina de gaussiana é a uma boa opção para avaliar a taxa de convergência de um método numérico, por ser suave. O método de alta ordem aplicado na equação do transporte obteve $2^{\mathrm{a}}$, $3^{\mathrm{a}}$ e $4^{\mathrm{a}}$ ordens de convergência para malhas não otimizadas e para qualquer tipo de otimização, tendo resultados semelhantes com o método de FV-SUB. O mesmo ocorreu nas malhas com refinamento local, demonstrando adaptabilidade do método em malhas com resolução variável, importante aspecto a ser considerado no desenvolvimento de modelos de previsão do tempo.

No teste de deformação, o método FV-GAS possui uma maior dispersão numérica, porém é mais preciso que FV-OLG. No entanto, o método FV-OLG não apresentou oscilações numéricas nesse teste, mantendo as mesmas taxas de convergência do método FV-ZHA. Esse é um bom teste para avaliar o potencial do método FV-OLG, pois na maioria dos modelos de previsão global as substâncias transportadas sofrem algum tipo de deformação.

Por fim, o método FV-OLG foi submetido a diversos testes padrões requeridos para uma possível aplicação em modelos globais, proporcionando bons resultados independente da malha icosaédrica utilizada, conforme os testes e comentários feitos no capítulo 5. Ou seja, não há dependência da taxa de convergência em função da distorção de malha, demonstrando que todas as etapas foram implementadas com êxito. Conclui-se que o objetivo de desenvolver um método de alta ordem para a superfície esférica foi alcançado, sendo uma proposta original a ser explorada em modelos globais de previsão do tempo. 


\section{Apêndice A}

\section{Geometria esférica}

\section{Coordenadas geodésicas}

As coordenadas esféricas ou geográficas (longitude-latitude) são denotadas por $(\lambda, \theta)$. Neste trabalho utilizamos a convenção de que no meridiano de Greenwich a longitude é nula, a leste positiva e a esquerda negativa, portanto, temos $-\pi \leq \lambda \leq \pi$. A latitude será nula no equador, positiva no hemisfério norte, e negativa no hémisfério sul, assim sendo, $-\pi / 2 \leq \theta \leq \pi / 2$.

A superfície da esfera também pode ser reprentada em coordenadas cartesianas $(x, y, z)$. Vamos supor a esfera de raio unitário e que o $\mathbb{R}^{3}$ decomposto nas suas coordendas canônicas $\vec{x}, \vec{y}, \vec{z}$, o zero do sistema cartesiano fique no centro da esfera. O eixo $\vec{z}$ é orientado do polo sul para o norte, sendo o polo sul dado por $(0,0,-1)$, e o polo norte $(0,0,1)$. O ponto de longitude e latitude zero será o ponto $(1,0,0)$, o que define a orientação do eixo $\vec{x}$. Dessa forma, o eixo $\vec{y}$ fica definido e, de tal forma, que o ponto de longitude $\pi / 2$ e latitude zero será dado pelo ponto $(0,1,0)$.

Assim, dado um sistema de coordenadas geográficas, $(\lambda, \theta)$, o respectivo ponto em coordenadas cartesianas será dado por $(x, y, z)$ com

$$
\begin{aligned}
& x=\cos (\theta) \cos (\lambda), \\
& y=\cos (\theta) \sin (\lambda), \\
& z=\sin (\theta),
\end{aligned}
$$

Dado um ponto em coordenadas cartesianas $(x, y, z)$, suas coordenadas geográficas $(\lambda, \theta)$, será dado por:

$$
\begin{aligned}
& r=\sqrt{x^{2}+y^{2}+z^{2}}, \\
& \lambda= \begin{cases}\tan ^{-1}\left(\frac{y}{x}\right), & \text { se } x \neq 0 \\
0, & \text { se } x=0\end{cases} \\
& \theta=\sin ^{-1}\left(\frac{z}{r}\right) .
\end{aligned}
$$

\section{Distâncias geodésicas}

Para dois pontos em coordenadas geográficas $\left(\lambda_{1}, \theta_{1}\right)$ e $\left(\lambda_{2}, \theta_{2}\right)$, utiliza-se a Fórmula de Vicenty para calculas as distâncias geodésicas, dadas por:

$$
d=\arctan \left(\frac{\sqrt{\left(\cos \left(\theta_{2}\right) \sin (d \lambda)\right)^{2}+\left(\cos \left(\theta_{1}\right) \sin \left(\theta_{2}\right)\right)-\sin \left(\theta_{1}\right)\left(\cos \left(\theta_{2}\right) \cos (d \lambda)\right)^{2}}}{\sin \left(\theta_{1}\right) \sin \left(\theta_{2}\right)+\cos \left(\theta_{1}\right) \cos \left(\theta_{2}\right) \cos (d \lambda)}\right)
$$

onde $d \lambda=\lambda_{1}-\lambda_{2}$. 


\section{Áreas geodésicas}

As áreas geodésicas dos volumes de controle $\left|\Omega_{i}\right|$, serão obtidas pelo somatório das áreas dos triângulos esféricos que faz parte de $\Omega_{i}$. As áreas são obtidas utilizando o teorema de L'Huilier, com base no excesso esférico $(e)$, dado por:

$$
e=4 \arctan \left(\sqrt{\tan \left(\frac{s}{2}\right) \tan \left(\frac{s-a}{2}\right) \tan \left(\frac{s-b}{2}\right) \tan \left(\frac{s-c}{2}\right)}\right)
$$

onde $s=\frac{(a+b+c)}{2}$ é o semi-perímetro e os termos $a, b$ e $c$ representam os comprimentos dos arcos do triângulo esférico. 


\section{Apêndice B}

\section{Considerações técnicas}

Os testes numéricos desse trabalho foram realizados em um servidor numérico do laboratório de computação científica em matemática aplicada (LabMap) do IME-USP com as seguintes configurações:

- Processador: Intel(R) Core(TM) i7-2600 CPU @ $3.40 \mathrm{~Hz}$

- Memória: $16 \mathrm{~Gb}$

- Sistema Operacional: Debian Version 9

- Compilador: GNU Fortran Compiler Version 6.3.0 
APÊNDICE B 


\title{
Referências Bibliográficas
}

\begin{abstract}
Abgrall(1994) Rémi Abgrall. An essentially non-oscillatory reconstruction procedure on finiteelement type meshes: Application to compressible flows. Computer methods in applied mechanics and engineering, 116(1-4):95-101. Citado na pág. 3
\end{abstract}

Ascher e Greif(2011) Uri M Ascher e Chen Greif. A first course on numerical methods, volume 7. Siam. Citado na pág. 25, 43, 45

Barth(1993) Timothy Barth. Recent developments in high order k-exact reconstruction on unstructured meshes. Em 31st Aerospace Sciences Meeting, página 668. Citado na pág. 23, 30

Barth e Frederickson(1990) Timothy Barth e Paul Frederickson. Higher order solution of the euler equations on unstructured grids using quadratic reconstruction. Em 28th aerospace sciences meeting, página 13. Citado na pág. 3, 4, 23, 28

Buchmüller et al.(2018) Pawel Buchmüller, Jürgen Dreher e Christiane Helzel. Improved accuracy of high-order weno finite volume methods on cartesian grids with adaptive mesh. Theory, Numerics and Applications of Hyperbolic Problems I: Aachen, Germany, August 2016, 236:263. Citado na pág. 3

Budgell et al.(2007) William Paul Budgell, Anabela Oliveira e Morten D Skogen. Scalar advection schemes for ocean modelling on unstructured triangular grids. Ocean Dynamics, 57(4-5):339-361. Citado na pág. 1

Casavilca(2016) Juan Eduardo Silva Casavilca. p-Multigrid explícito para um método de volumes finitos de alta-ordem não estruturado. Tese de Doutorado, Universidade de São Paulo. Citado na pág. 4, 23

Chassaing et al.(2013) Jean-Camille Chassaing, Sofiane Khelladi e Xesús Nogueira. Accuracy assessment of a high-order moving least squares finite volume method for compressible flows. Computers \& Fluids, 71:41-53. Citado na pág. 3

Chen e Xiao(2008) Chungang Chen e Feng Xiao. Shallow water model on cubed-sphere by multimoment finite volume method. Journal of Computational Physics, 227(10):5019-5044. Citado na pág. 2

Dubey et al.(2014) Sarvesh Dubey, Rashmi Mittal e Peter H Lauritzen. A flux-form conservative semi-lagrangian multitracer transport scheme (ff-cslam) for icosahedral-hexagonal grids. Journal of Advances in Modeling Earth Systems, 6(2):332-356. Citado na pág. 14

Dumbser e Boscheri(2013) Michael Dumbser e Walter Boscheri. High-order unstructured lagrangian one-step weno finite volume schemes for non-conservative hyperbolic systems: applications to compressible multi-phase flows. Computers \& Fluids, 86:405-432. Citado na pág. 3

Dunavant(1985) DA Dunavant. High degree efficient symmetrical gaussian quadrature rules for the triangle. International journal for numerical methods in engineering, 21(6):1129-1148. Citado na pág. $25,27,36,40,102$ 
Durran(2010) Dale R Durran. Numerical methods for fluid dynamics: With applications to geophysics, volume 32. Springer Science \& Business Media. Citado na pág. 1, 14

Fu et al.(2018) Lin Fu, Xiangyu Y Hu e Nikolaus A Adams. A new class of adaptive high-order targeted eno schemes for hyperbolic conservation laws. Journal of Computational Physics, 374: 724-751. Citado na pág. 3

Giorgetta et al.(2018) Marco A Giorgetta, Renate Brokopf, Traute Crueger, Monika Esch, Stephanie Fiedler, J Helmert, Cathy Hohenegger, Luis Kornblueh, M Köhler, Elisa Manzini et al. Icon-a, the atmosphere component of the icon earth system model: I. model description. Journal of Advances in Modeling Earth Systems, 10(7):1613-1637. Citado na pág. 3

Giraldo e Rosmond(2004) Francis X Giraldo e Thomas E Rosmond. A scalable spectral element eulerian atmospheric model (see-am) for nwp: Dynamical core tests. Monthly Weather Review, 132(1):133-153. Citado na pág. 1

Golub e Van Loan(2012) Gene H Golub e Charles F Van Loan. Matrix computations, volume 3. JHU Press. Citado na pág. 26, 31

Gregory et al.(2008) Matthew J Gregory, A Jon Kimerling, Denis White e Kevin Sahr. A comparison of intercell metrics on discrete global grid systems. Computers, Environment and Urban Systems, 32(3):188-203. Citado na pág. 2

Ha et al.(2017) Soyoung Ha, Chris Snyder, William C Skamarock, Jeffrey Anderson e Nancy Collins. Ensemble kalman filter data assimilation for the model for prediction across scales (mpas). Monthly Weather Review, 145(11):4673-4692. Citado na pág. 3

Heikes e Randall(1995) Ross Heikes e David A Randall. Numerical integration of the shallowwater equations on a twisted icosahedral grid. part i: Basic design and results of tests. Monthly Weather Review, 123(6):1862-1880. Citado na pág. 12

Hoshyari e Ollivier Gooch(2018) Shayan Hoshyari e Carl F Ollivier Gooch. A higher-order unstructured finite volume solver for three-dimensional compressible flows. Em 2018 AIAA Aerospace Sciences Meeting, página 1306. Citado na pág. 4, 23

Hu e Shu(1999) Changqing Hu e Chi-Wang Shu. Weighted essentially non-oscillatory schemes on triangular meshes. Journal of Computational Physics, 150(1):97-127. Citado na pág. 3

Hundsdorfer et al.(1995) W Hundsdorfer, Barry Koren, M Van Loon e Jan G Verwer. A positive finite-difference advection scheme applied on locally refined grids. Citado na pág. 17

Ivan et al.(2015) Lucian Ivan, Hans De Sterck, A Susanto e Clinton PT Groth. High-order central eno finite-volume scheme for hyperbolic conservation laws on three-dimensional cubed-sphere grids. Journal of Computational Physics, 282:157-182. Citado na pág. 3

Jablonowski e Williamson(2011) Christiane Jablonowski e David L Williamson. The pros and cons of diffusion, filters and fixers in atmospheric general circulation models. Em Numerical Techniques for Global Atmospheric Models, páginas 381-493. Springer. Citado na pág. 1

Jalali et al.(2014) Alireza Jalali, Mahkame Sharbatdar e Carl Ollivier-Gooch. Accuracy analysis of unstructured finite volume discretization schemes for diffusive fluxes. Computers \& Fluids, 101:220-232. Citado na pág. 4, 23

Lashley(2002) Raymond K Lashley. Automatic generation of accurate advection schemes on unstructured grids and their application to meteorological problems. Tese de Doutorado, University of Reading. Citado na pág. 12, 13, 25, 36, 39, 59 
Lauritzen et al.(2018) Peter Hjort Lauritzen, Ram D Nair, AR Herrington, P Callaghan, S Goldhaber, JM Dennis, JT Bacmeister, BE Eaton, CM Zarzycki, Mark A Taylor et al. Ncar release of cam-se in cesm2. 0: A reformulation of the spectral element dynamical core in drymass vertical coordinates with comprehensive treatment of condensates and energy. Journal of Advances in Modeling Earth Systems, 10(7):1537-1570. Citado na pág. 2

Lee et al.(2018) Euntaek Lee, Hyung Taek Ahn e Hong Luo. Cell-centered high-order hyperbolic finite volume method for diffusion equation on unstructured grids. Journal of Computational Physics, 355:464-491. Citado na pág. 3

Li e Xiao(2010) Satoshi Li e Feng Xiao. A global shallow water model using high order multimoment constrained finite volume method and icosahedral grid. Journal of Computational physics, 229(5):1774-1796. Citado na pág. 3, 10

Li et al.(2013) Xingliang Li, Xueshun Shen, Xindong Peng, Feng Xiao, Zhaorong Zhuang e Chungang Chen. An accurate multimoment constrained finite volume transport model on yin-yang grids. Advances in Atmospheric Sciences, 30(5):1320-1330. Citado na pág. 2, 3

Lin et al.(2017) Shian-Jiann Lin, Lucas Harris, Xi Chen, Weiye Yao e Junyi Chai. Colliding modons: A nonlinear test for the evaluation of global dynamical cores. Journal of Advances in Modeling Earth Systems, 9(7):2483-2492. Citado na pág. 2

MacDonald et al.(1968) Carolyn T MacDonald, Julian H Gibbs e Allen C Pipkin. Kinetics of biopolymerization on nucleic acid templates. Biopolymers: Original Research on Biomolecules, 6 (1):1-25. Citado na pág. 11, 27

Majewski et al.(2002) Detlev Majewski, Dörte Liermann, Peter Prohl, Bodo Ritter, Michael Buchhold, Thomas Hanisch, Gerhard Paul, Werner Wergen e John Baumgardner. The operational global icosahedral-hexagonal gridpoint model gme: description and high-resolution tests. Monthly Weather Review, 130(2):319-338. Citado na pág. 3, 55

Michalak(2009) Christopher Michalak. Efficient high-order accurate unstructured finite-volume algorithms for viscous and inviscid compressible flows. Tese de Doutorado, University of British Columbia. Citado na pág. 3, 7

Miura(2007) Hiroaki Miura. An upwind-biased conservative advection scheme for spherical hexagonal-pentagonal grids. Monthly Weather Review, 135(12):4038-4044. Citado na pág. 15

Miura e Kimoto(2005) Hiroaki Miura e Masahide Kimoto. A comparison of grid quality of optimized spherical hexagonal-pentagonal geodesic grids. Monthly weather review, 133(10):28172833. Citado na pág. 10, 12

Miura e Skamarock(2013) Hiroaki Miura e William C Skamarock. An upwind-biased transport scheme using a quadratic reconstruction on spherical icosahedral grids. Monthly Weather Review, 141(2):832-847. Citado na pág. 16

Nair e Lauritzen(2010) Ramachandran D Nair e Peter H Lauritzen. A class of deformational flow test cases for linear transport problems on the sphere. Journal of Computational Physics, 229(23):8868-8887. Citado na pág. 36, 39, 55, 88

Nair et al.(2005) Ramachandran D Nair, Stephen J Thomas e Richard D Loft. A discontinuous galerkin global shallow water model. Monthly weather review, 133(4):876-888. Citado na pág. 2

Nejat e Ollivier-Gooch(2008) Amir Nejat e Carl Ollivier-Gooch. A high-order accurate unstructured finite volume newton-krylov algorithm for inviscid compressible flows. Journal of Computational Physics, 227(4):2582-2609. Citado na pág. 4, 23 
Ollivier-Gooch(1997) Carl Ollivier-Gooch. High-order eno schemes for unstructured meshes based on least-squares reconstruction. Em 35th Aerospace Sciences Meeting and Exhibit, página 540. Citado na pág. 4, 7, 23

Ollivier-Gooch e Van Altena(2002) Carl Ollivier-Gooch e Michael Van Altena. A high-orderaccurate unstructured mesh finite-volume scheme for the advection-diffusion equation. Journal of Computational Physics, 181(2):729-752. Citado na pág. 4, 23, 29, 31

Ollivier-Gooch et al.(2009) Carl Ollivier-Gooch, Amir Nejat e Krzysztof Michalak. Obtaining and verifying high-order unstructured finite volume solutions to the euler equations. AIAA journal, 47(9):2105. Citado na pág. 4, 23, 24, 25, 27

Peixoto(2013) Pedro da Silva Peixoto. Análise de discretizações e interpolações em malhas icosaédricas e aplicações em modelos de transporte semi-lagrangianos. Tese de Doutorado, Universidade de São Paulo. Citado na pág. 11, 12, 23, 26, 27, 48, 49, 50

Peixoto e Barros(2013) Pedro S Peixoto e Saulo RM Barros. Analysis of grid imprinting on geodesic spherical icosahedral grids. Journal of Computational Physics, 237:61-78. Citado na pág. $47,50,51$

Ringler et al.(2013) Todd Ringler, Mark Petersen, Robert L Higdon, Doug Jacobsen, Philip W Jones e Mathew Maltrud. A multi-resolution approach to global ocean modeling. Ocean Modelling, 69:211-232. Citado na pág. 1

Ringler et al.(2000) Todd D Ringler, Ross P Heikes e David A Randall. Modeling the atmospheric general circulation using a spherical geodesic grid: A new class of dynamical cores. Monthly Weather Review, 128(7):2471-2490. Citado na pág. 3

Ronchi et al.(1996) C Ronchi, R Iacono e Pier S Paolucci. The cubed sphere: a new method for the solution of partial differential equations in spherical geometry. Journal of Computational Physics, 124(1):93-114. Citado na pág. 2

Sadourny(1972) Robert Sadourny. Conservative finite-difference approximations of the primitive equations on quasi-uniform spherical grids. Monthly Weather Review, 100(2):136-144. Citado na pág. 2

Saito(2008) Olga Harumi Saito. Esquema numérico com reconstrução mínimos quadrados de alta ordem em malhas não-estruturadas para a formulação euleriana do transporte de partículas. Tese de Doutorado, Universidade de São Paulo. Citado na pág. 4, 23, 32

Santana(2007) Alessandro Alves Santana. Identificação de parâmetros em problemas de advecçãodifusão combinando a técnica do operador adjunto e métodos de volumes finitos de alta ordem. Tese de Doutorado, Universidade de São Paulo. Citado na pág. 4, 23

Santos(2017) Luan da Fonseca Santos. Local refinement and interpolation in spherical icosahedral grids., 2017. Monografia, USP (Universidade de São Paulo), São Paulo, Brazil. Citado na pág. 92

Seluchi et al.(1998) Michael Seluchi, YV Serafini e H Le Treut. The impact of the andes on transient atmospheric systems: A comparison between observations and $\mathrm{gcm}$ results. Monthly weather review, 126(4):895-912. Citado na pág. 92

Skamarock(2006) William C Skamarock. Positive-definite and monotonic limiters for unrestricted-time-step transport schemes. Monthly weather review, 134(8):2241-2250. Citado na pág. 14

Skamarock e Gassmann(2011) William C Skamarock e Almut Gassmann. Conservative transport schemes for spherical geodesic grids: High-order flux operators for ode-based time integration. Monthly Weather Review, 139(9):2962-2975. Citado na pág. 3, 17, 18, 19, 62, 75, 86, 88 
Skamarock e Menchaca(2010) William C Skamarock e Maximo Menchaca. Conservative transport schemes for spherical geodesic grids: High-order reconstructions for forward-in-time schemes. Monthly Weather Review, 138(12):4497-4508. Citado na pág. 3, 15, 16, 74, 85

Staniforth e Thuburn(2012) Andrew Staniforth e John Thuburn. Horizontal grids for global weather and climate prediction models: a review. Quarterly Journal of the Royal Meteorological Society, 138(662):1-26. Citado na pág.

Strang(1980) G. Strang. Linear algebra and its applications: Second edition, 1980. Citado na pág.

Stuhne e Peltier(1996) GR Stuhne e WR Peltier. Vortex erosion and amalgamation in a new model of large scale flow on the sphere. Journal of Computational Physics, 128(1):58-81. Citado na pág. 15

Su et al.(2018) Shuai Su, Qiannan Dong e Jiming Wu. A decoupled and positivity-preserving discrete duality finite volume scheme for anisotropic diffusion problems on general polygonal meshes. Journal of Computational Physics, 372:773-798. Citado na pág. 11, 27

Subich(2018) Christopher J Subich. Higher-order finite volume differential operators with selective upwinding on the icosahedral spherical grid. Journal of Computational Physics, 368:21-46. Citado na pág. $3,20,21,56,78$

Thuburn(1996) John Thuburn. Multidimensional flux-limited advection schemes. Journal of Computational Physics, 123(1):74-83. Citado na pág. 14

Tomita et al.(2002) Hirofumi Tomita, Masaki Satoh e Koji Goto. An optimization of the icosahedral grid modified by spring dynamics. Journal of Computational Physics, 183(1):307-331. Citado na pág. 3,12

Ullrich e Jablonowski(2012) Paul A Ullrich e Christiane Jablonowski. Mcore: A non-hydrostatic atmospheric dynamical core utilizing high-order finite-volume methods. Journal of Computational Physics, 231(15):5078-5108. Citado na pág. 2

Walsh(1994) Kevin Walsh. On the influence of the andes on the general circulation of the southern hemisphere. Journal of Climate, 7(6):1019-1025. Citado na pág. 92

Wicker e Skamarock(2002) Louis J Wicker e William C Skamarock. Time-splitting methods for elastic models using forward time schemes. Monthly weather review, 130(8):2088-2097. Citado na pág. 17

Williamson(1968) David L Williamson. Integration of the barotropic vorticity equation on a spherical geodesic grid. Tellus, 20(4):642-653. Citado na pág. 66

Williamson(2007) David L Williamson. The evolution of dynamical cores for global atmospheric models. Journal of the Meteorological Society of Japan. Ser. II, 85:241-269. Citado na pág. 3, 7, 10

Williamson et al.(1991) David L Williamson, JJ Hack, R Jakob, Paul N Swarztrauber e JB Drake. A standard test set for numerical approximations to the shallow water equations in spherical geometry. Relatório técnico, Oak Ridge National Lab., TN (United States). Citado na pág. 59, 63

Zalesak(1979) Steven T Zalesak. Fully multidimensional flux-corrected transport algorithms for fluids. Journal of computational physics, 31(3):335-362. Citado na pág. 14, 19, 74, 75

Zhang(2018) Yi Zhang. Extending high-order flux operators on spherical icosahedral grids and their applications in the framework of a shallow water model. Journal of Advances in Modeling Earth Systems, 10(1):145-164. Citado na pág. 3, 18, 19, 20, 88

Zhang et al.(2017) Yi Zhang, Rucong Yu e Jian Li. Implementation of a conservative two-step shape-preserving advection scheme on a spherical icosahedral hexagonal geodesic grid. Advances in Atmospheric Sciences, 34(3):411-427. Citado na pág. 14 